Igor Baria

\title{
PERCEPÇÃO DA SOCIEDADE E DOS ESPECIALISTAS SOBRE OS BENEFÍCIOS DOS SISTEMAS DE TRANSPORTE PÚBLICO URBANO SOBRE TRILHOS
}

\begin{abstract}
Dissertação apresentada à Escola de Engenharia de São Carlos da Universidade de São Paulo, como parte dos requisitos para obtenção do Título de Mestre em Engenharia dos Transportes.
\end{abstract}

Orientador: Prof. Titular Antônio Clóvis Pinto Ferraz

São Carlos

2009 
AUTORIZO A REPRODUÇÃO E DIVULGAÇÃO TOTAL OU PARCIAL DESTE TRABALHO, POR QUALQUER MEIO CONVENCIONAL OU ELETRÔNICO, PARA FINS DE ESTUDO E PESQUISA, DESDE QUE CITADA A FONTE.

Ficha catalográfica preparada pela Seção de Tratamento da Informação do Serviço de Biblioteca - EESC/USP

\begin{tabular}{|c|c|}
\hline \multirow[t]{3}{*}{ B252p } & $\begin{array}{l}\text { Bária, Igor } \\
\quad \text { Percepção da sociedade e dos especialistas sobre os } \\
\text { benefícios dos sistemas de transporte público urbano } \\
\text { sobre trilhos / Igor Bária ; orientador Antônio Clóvis } \\
\text { Pinto Ferraz. -- São Carlos, } 2009 \text {. }\end{array}$ \\
\hline & $\begin{array}{l}\text { Dissertação (Mestrado-Programa de Pós-Graduação em } \\
\text { Engenharia de Transportes e Área de Concentração em } \\
\text { Planejamento e Operação de Sistema de Transporte) -- } \\
\text { Escola de Engenharia de São Carlos da Universidade de São } \\
\text { Paulo, 2009. }\end{array}$ \\
\hline & $\begin{array}{l}\text { 1. Transporte público. 2. Transporte sobre trilhos. } \\
\text { 3. Planejamento de transporte. 4. Sistema de transporte } \\
\text { urbano. I. Título. }\end{array}$ \\
\hline
\end{tabular}




\section{FOLHA DF ,IIT.GAMTYTO}

Cancidato: Engenheiro IGOR BARIA.

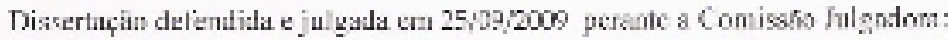

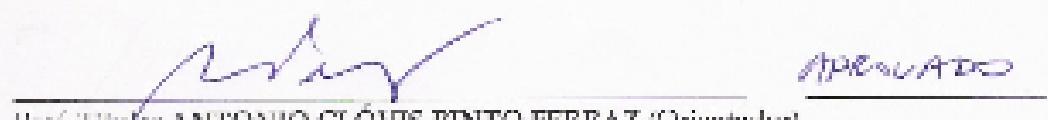

Pro. I I I W AN IOVIO CLOVTS PINTO FERRAZ Orientadur!

(tesola de Engentarin de San Carks: (ISP)

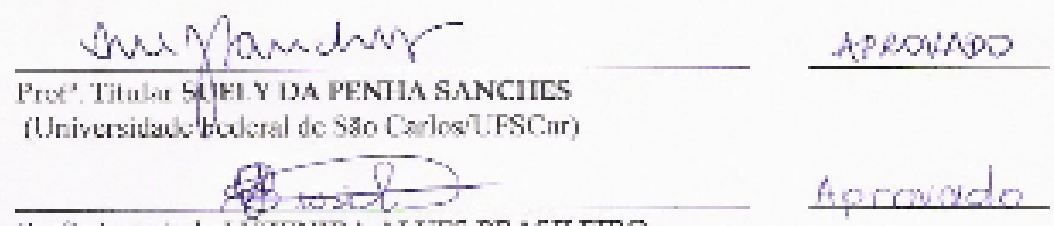

Puol", Aserciada I ITKF.NIRA ALVLS BRASILEIRO

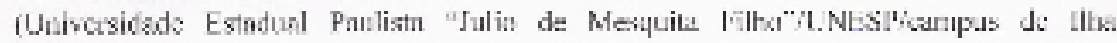
St:leiral

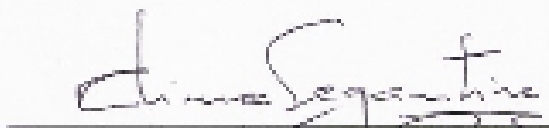

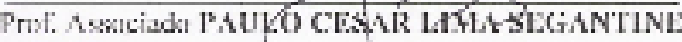

Courdensdar da lopyranalde Piss-Graduapajo su

Lingeaharia de Jiansporles

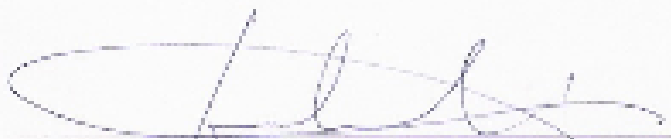

Prof, Titular GF.RAIIDO RORF.RTO MARTINSDA COSTA Precidenre dn Comissto da Pŕs-Girnduscito da T.T.SC. 


\section{DEDICATÓRIA}

A minha esposa, Rita, minha alma gêmea, companheira fiel de todos os momentos da minha vida, maior apoiadora de meus estudos e maior responsável pelos meus sucessos.

A meu avô Vincas Dzetulionis, figura marcante de minha infância, que sempre dizia: "ao final de um dia de trabalho deveríamos descansar a cabeça em uma pedra e os pés no travesseiro, afinal os pés só ficam cansados por que a cabeça não pensou o suficiente para que o trabalho fosse mais leve".

A meus pais, Izabel e Ari, por ensinarem-me o caminho do conhecimento e me apoiarem neste caminho. As minhas filhas, Natália e Giovana, razão de meus esforços. 


\section{AGRADECIMENTOS}

A Deus, por permitir que tudo seja realizado.

A minha esposa Rita, por compreender a necessidade da minha ausência para a conclusão deste trabalho, mas, mais que compreender a ausência, incentivar-me a cada vez buscar mais qualificação e conhecimento, "Vi" agradece.

As minhas filhas Natália e Giovana, pelo seu apoio em todos os momentos. Labai ačiu mergaitès.

A Universidade de São Paulo, pela minha aceitação no programa de Pósgraduação.

Meus sinceros e prestimosos agradecimentos ao Prof. Antonio Clóvis "Coca" Pinto Ferraz da Universidade de São Paulo, que me aceitou como seu orientado, e conduziu sua orientação com espírito educador, dinâmico e incentivador.

Meus agradecimentos aos Professores Antônio Nélson Rodrigues da Silva e Jaime Waisman da Universidade de São Paulo pelo apoio, conselhos e ensinamentos.

Agradeço a Prof ${ }^{a}$. Suely Sanches da Universidade Federal de São Carlos e ao Prof. José Felex da Universidade de São Paulo pelas sugestões ao trabalho no exame de qualificação.

Agradeço a Prof ${ }^{a}$. Suely Sanches da Universidade Federal de São Carlos e a Prof ${ }^{a}$. Luzenira Alves Brasileiro da Universidade Estadual de São Paulo - UNESP, pela participação na banca de aprovação e pelas sugestões para revisão do trabalho.

Meus mais sinceros agradecimentos aos professores da Universidade de São Paulo José Leomar Ferandes, José Reynaldo A. Setti, Manoel Alba Sória, Eiji Kawamoto, Jaime Waisman, Antonio Nelson Rodrigues Silva, Antonio Clovis "Coca" Pinto Ferraz, José Felex e Fernando Pinto pelos ensinamentos transmitidos em sala de aula. 
Externo os meus agradecimentos às secretárias do Departamento de Transportes (STT), Heloísa, Beth e D. Magaly que sempre atenderam com muito profissionalismo, atenção e dedicação as solicitações que encaminhei.

Meus agradecimentos aos funcionários do STT: Gigante, Paulo, Toco, Vicente, Alexandre, João e Walter por estarem sempre prestativos.

Ao amigo Paulo Dalmazzo, parceiro presente em todos estes anos e incentivador de minha senda acadêmica.

A minha amiga Adriane Fontana e ao amigo Célio Daroncho, meus "tutores", pelos ensinamentos e conselhos dados.

Aos amigos, André Cunha, Adson, Eymard, Mateus Araújo Silva, Jesner, Tauyl Selyngard. Marcelo, Weslley e as amigas, Ana Larocca, Andréa Júlia e Camilla Carrara, pela amizade durante o período em que freqüentei o STT.

Aos amigos Marcello Lemos e Dória, durante o período em que freqüentei o departamento de engenharia naval da escola Politécnica.

Ao amigo Fernando Cardoso de Sá, pela companhia nas viagens entre São Paulo e São Carlos e pela amizade durante a permanência no STT.

Aos colegas do Metrô SP, que cito nominalmente mesmo sabendo que incorrerei na gafe de omitir colegas que foram inestimáveis no apoio a este trabalho, André Calçada, Neimar, Walter Castro, Jair Candido, Manoel Ferreira, Thomaz Winter, Nelson Scaglione, Décio Tambelli, Lazarini, Pedro Machado, Emília e Cecília.

A jornalista Cleri Ane, pela correção do texto e sugestões para melhorar a compreensão dos parágrafos.

Aos profissionais do Metrô SP, CPTM, AEAMESP e USP que responderam a pesquisa dos especialistas em transporte.

Aos demais amigos que sempre me acompanham meus sinceros agradecimentos! 


\title{
Lietuviškai patarlè
}

\section{Kas skaito ir rašo duonos neprašo}

\author{
Ditado Lituano
}

Quem lê e escreve pão não pede. 


\section{RESUMO}

BARIA, I. Percepção da Sociedade e dos Especialistas Sobre os Benefícios dos Sistemas de Transporte Público Urbano Sobre Trilhos. 2009. 147 f. Dissertação (mestrado) - Escola de Engenharia de São Carlos, Universidade de São Paulo, São Carlos, 2009.

Os objetivos deste trabalho são dois: avaliar a percepção da sociedade e dos especialistas em transporte sobre os benefícios alcançados com a implantação de sistemas de transporte público urbano sobre trilhos e verificar se a percepção dos especialistas é alinhada com a percepção da sociedade. O trabalho foi desenvolvido a partir de uma pesquisa bibliográfica para identificação dos benefícios do transporte público sobre trilhos. Após definidos os benefícios foi aplicada uma pesquisa, de caráter exploratório, utilizando a escala de Likert, à sociedade, mais especificamente a alunos de graduação de cursos universitários na região metropolitana de São Paulo num total de 433 respondentes, distribuídos em 7 locais distintos. Em seguida foi realizada uma pesquisa junto a especialistas em Transporte, com utilização de uma planilha para avaliação dos benefícios com base no Método de Análise Hierárquica - MAH. Na pesquisa com especialistas obteve-se 34 planilhas distribuídas em 4 grupos distintos. Os resultados mostram que a sociedade e os especialistas possuem uma percepção bastante positiva dos benefícios gerados pela implantação de sistemas de transporte público urbano sobre trilhos, havendo, no entanto, diferenças sensíveis nas avaliações, que refletem na ordem de importância dos benefícios.

Palavras-Chave: Transporte Sobre Trilhos. Transporte Público. Planejamento de Transportes. Sistemas de Transporte Urbano. 


\begin{abstract}
BARIA, I. Society and Specialists Perception About the Generated Profits with Urban Public Rail Transportation Systems. 2009. 147 p. Dissertation (Master's Thesis) Engineering School of São Carlos, University of São Paulo, São Carlos, 2009.

The objectives of this work are, over all, two: evaluate the society's and transportation specialists the perception on the benefits, reached with the implantation of urban public transport on tracks systems and to verify if the perception of the specialists is aligned up with the perception of the society. The work was developed from a bibliographical research that had the goal to identify the benefits of the public transport on tracks. After defined the benefits the research was applied to the society using the Likert's scale, in exploratory way, more specifically the graduation's pupils of university courses in the metropolitan region of São Paulo in a total of 433 respondents, distributed in seven distinct places. After that was carried through a research next to Transportation's specialists, with the resource of a spread sheet for evaluation of the benefits on the basis of the Analytic Hierarchical Process - AHP. About the research with specialists, one got 34 spread sheets distributed in four distinct groups. The results show that the society and the specialists possess a sufficiently positive perception about the benefits generated for the implantation of urban public transport on tracks systems, having, however, sensible differences in the evaluations, that they reflect in the order of the benefits importance.
\end{abstract}

Keywords: Heavy Mass Transit. Public Transportation. Transportation Planning. Urban Transportation Systems. 


\section{LISTA DE FIGURAS}

Figura 1.1 Visão geral da qualidade no Transporte Público. 3

$\begin{array}{lll}\text { Figura } 1.2 \text { Influência dos indicadores de qualidade da comunidade } & 4\end{array}$ nos demais indicadores.

Figura 2.1 Modelo de Desenvolvimento. 14

Figura 2.2 Espaço necessário, em $\mathrm{m}^{2}$, de ruas por pessoa em 19 função do modo de transporte.

Figura 3.1 Intervalo de Confiança das médias. 31

Figura 4.1 Distribuição das Pesquisas na RMSP. 58

Figura 4.2 Detalhe dos locais de Pesquisa e proximidade com os 59 meios de transporte sobre trilhos.

$\begin{array}{lll}\text { Figura 4.3 Distribuição da amostra pesquisada por sexo. } & 59\end{array}$

Figura 4.4 Distribuição da amostra por local de pesquisa. 60

Figura 4.5 Distribuição da freqüência de utilização do sistema de 60 transporte sobre trilhos da amostra pesquisada.

$\begin{array}{lll}\text { Figura 4.4 Distribuição da idade na amostra pesquisada. } & 61\end{array}$

Figura 4.7 Distribuição da amostra pesquisada por ocupação. 61

Figura 4.8 Distribuição do rendimento na amostra pesquisada. 62

Figura 4.9 Ranking Médio Geral. 66

$\begin{array}{lll}\text { Figura 4.10 } & \text { Ranking Médio estratificado por sexo. } & 67\end{array}$

Figura 4.11 Ranking Médio estratificado por local de pesquisa. 68

$\begin{array}{lll}\text { Figura 4.12 Ranking Médio por tipo de utilização. } & 69\end{array}$

Figura 4.13 Ranking Médio estratificado por Idade. 70

$\begin{array}{lll}\text { Figura 4.14 } & \text { Ranking Médio estratificado por Ocupação. } & 71\end{array}$

$\begin{array}{lll}\text { Figura 4.15 Ranking Médio estratificado por Rendimento. } & 72\end{array}$

$\begin{array}{lll}\text { Figura 4.16 Distribuição das Avaliações entre os especialistas. } & 73\end{array}$

Figura 4.17 Matriz de Comparação Par a Par com Consistência 75 Adequada. 
Figura 4.18 Matriz de Comparação Par a Par com Consistência Inadequada.

Figura 4.19 Gráfico de Comparação das Médias. 82

$\begin{array}{lllllll}\text { Figura } 5.1 \text { Comparação dos Escores entre Especialistas e } & 87\end{array}$ População 


\section{LISTA DE TABELAS}

Tabela 2.1 Fatalidades por modo de Transporte nos EUA em 2001. 16

Tabela 2.2 Perda de Horas e Valores no Trânsito. 17

Tabela 3.1 Análise de Variância 33

Tabela 3.2 Tabela de exemplo para cálculo do ranking médio. 37

Tabela 3.3 Escala de Comparação Contínua. 45

Tabela 3.4 Escala de comparação de critérios. 45

Tabela 3.5 Matriz de Comparação par a par. 46

Tabela 3.6 Índice de Aleatoriedade. 49

Tabela 4.1 Ranking Médio Obtido nas Notas dos Entrevistados. 63

Tabela 4.2 Fatores da Avaliação Par a Par dos Especialistas. 77

$\begin{array}{lll}\text { Tabela 4.3 Opinião dos Especialistas - Acadêmicos. } & 78\end{array}$

$\begin{array}{lllllll}\text { Tabela } 4.4 & \text { Opinião dos Especialistas } & \text { - } & \text { Associação dos } & 79\end{array}$ Engenheiros e Arquitetos.

Tabela 4.5 Opinião dos Especialistas - CPTM. 79

Tabela 4.6 Opinião dos Especialistas - Metrô. 80

Tabela 4.7 Comparação das Médias dos fatores. 80

Tabela 4.8 Classificação das Assertivas com base na média. 81

Tabela 5.1 Resumo da Opinião da Sociedade - Likert. 84

Tabela 5.2 Ranking Médio das Opiniões Emitidas Pela Sociedade. 85

Tabela 5.3 Ranqueamento e Comparação da Opinião da População 88 e Especialistas. 


\section{SUMÁRIO}

\begin{tabular}{rlr}
\hline Capítulo 1 & \multicolumn{1}{c}{ Introdução } & 1 \\
\hline 1.1 & Fundamentação da Pesquisa & 1 \\
1.2 & Colocação do Problema & 3 \\
1.3 & Objetivos do trabalho & 6 \\
1.4 & Metodologia da Pesquisa & 7 \\
1.5 & Organização do Trabalho & 7 \\
\hline Capítulo 2 & Benefícios Percebidos & 9 \\
\hline 2.1 & Apresentação dos Benefícios & 9 \\
2.2 & Revisão Bibliográfica & 10 \\
\hline Capítulo 3 & Métodos de Análise dos Dados Coletados & 23
\end{tabular}

3.1 Conceitos Gerais 23

3.2 Correlação entre Variáveis 25

3.3 Distribuição de Probabilidade 28

3.3.1 Inferência Estatística 28

3.4 Comparação de Médias 30

3.4.1 Teste t para Diferenças entre Duas Médias 30 Aritméticas

3.4.2 Análise de Variância - ANOVA 31

3.5 Escala para Medidas de Juízo Emitidas Através de 33 Indivíduos

3.5.1 A escala de Likert 36

3.6 Um Processo de Avaliação Multicritério para 38 Mensurar a Opinião de Indivíduos Utilizando a Comparação.

3.6.1 Justificativas do Método 39

3.6.2 Método de Análise Hierárquica - MAH 41 


\section{Capítulo 4 Estudo de Caso}

4.1 Estudo com a População

4.1.1 O Levantamento de Dados

4.1.2 Sobre a Pesquisa Exploratória 56

4.1.3 Resultados do Questionário 58

4.2 Tratamento de Dados Especialistas 73

$\begin{array}{lll}4.2 .1 & \text { Introdução } & 73\end{array}$

$\begin{array}{lll}\text { 4.2.2 Resultados da Pesquisa } & 76\end{array}$

$\begin{array}{llr}\text { Capítulo } 5 \text { Conclusões } & 83\end{array}$

$\begin{array}{lll}5.1 & \text { Da Proposta do Trabalho } & 83\end{array}$

5.2 Percepção da Sociedade 84

5.3 Percepção dos Especialistas 86

5.4 Comparação das Percepções 87

5.5 Sugestões para Trabalhos Futuros 89

\begin{tabular}{llr}
\hline & Referências & 91 \\
\hline Apêndice A & Modelo da Pesquisa Aplicada a Sociedade & 97 \\
Apêndice B & Modelo da Planilha Enviada aos Especialistas & 98 \\
Apêndice C & Resultados da Pesquisa junto a Sociedade & 99 \\
Apêndice D & Resultados da Pesquisa Junto aos Especialistas & 115
\end{tabular}




\section{Capítulo 1 - Introdução}

\subsection{Fundamentação da Pesquisa}

O objetivo subjacente à toda pesquisa é adquirir conhecimento. As pesquisas para obtenção deste conhecimento podem ser voltadas para resolver problemas, para formular teorias ou para testar teorias.

A pesquisa voltada para a solução de problemas tem um cunho eminentemente prático. A formulação de teorias procura a relação entre causa e efeito para então estabelecer uma regra genérica a este fenômeno, em geral utilizando a indução como metodologia. O teste de teorias segue basicamente a mesma metodologia da formulação de teorias, porém, a aplicação do teste procura, por meio de avaliação das teorias, encontrar constantes matemáticas nas fórmulas apresentadas pela teoria.

No estudo aqui dirigido, a obtenção do conhecimento é impulsionada pela aplicação da solução de problemas, direcionada para um problema prático na engenharia de transportes.

Nesse contexto surge a seguinte questão: a opinião pública (a sociedade) tem percepção dos benefícios que um sistema de transporte sobre trilhos pode trazer às comunidades urbanas?

Pergunta-se, ainda: a percepção da sociedade com relação a estes 
benefícios é alinhada com a percepção que os especialistas do setor têm sobre estes benefícios?

Eco (1977) sugere três pré-requisitos para justificar o estudo de um problema e torná-lo parte central de um estudo científico, a saber:

- O estudo deve valer-se de um objeto reconhecível e definido de tal forma que seja reconhecível pelos outros;

- O estudo deve dizer algo sobre o objeto que ainda não foi dito ou explorar um assunto já debatido sob uma ótica diferente, de maneira a agregar valor científico ao objeto, e;

- O estudo deve ser útil aos demais.

Richardson (2007) identifica os princípios básicos da pesquisa científica. Estes princípios baseiam-se na existência de uma estrutura subjacente comum a todas as pesquisas, integrada por cinco elementos:

- Meta: objetivo do estudo;

- Modelo: qualquer abstração do que está sendo trabalhado ou estudado;

- Dados: as observações realizadas para representar a natureza do fenômeno;

- Avaliação: processo de decisão sobre a validade do modelo;

- Revisão: mudanças necessárias do modelo.

O ponto de partida da pesquisa é a meta, ou objetivo. Depois de estabelecido o objetivo do estudo, desenvolve-se um modelo do processo que será estudado, seguido da coleta de informações sobre o modelo estabelecido. Com base nas informações coletadas comparam-se os dados com o modelo estabelecido, com o intuito de verificar se os dados e o modelo dão sentido ao estudo. Caso a comparação leve a conclusão de que não há sentido entre o modelo e os dados apresentados, procede-se a revisão do modelo inicialmente estabelecido. 
A pesquisa científica, que se utiliza do método científico como base para a sua elaboração, repousa no pressuposto da indução como fonte de informação. A indução permite que se tenha conhecimento de muitas coisas observando-se algumas poucas. Obviamente, o conhecimento indutivo é incompleto, porém básico, para a maioria dos estudos em que é aplicado.

O método científico pressupõe que para estudar um fenômeno deve ser possível a sua mensuração. O pesquisador deve procurar maneiras para mensurar os conceitos que estuda, operacionalizando este conceito por meio de instrumentos, medições ou códigos e, assim, possibilitar que o seu estudo seja uma ferramenta de convicção, em função da objetividade e eficiência proporcionadas pela utilização do método científico.

\subsection{Colocação do Problema}

De acordo com Ferraz e Torres (2004), a qualidade dos sistemas de transporte público urbano deve ser contemplada com uma visão geral, isto é, deve considerar o nível de satisfação de todos os atores direta ou indiretamente envolvidos com o sistema: usuários, comunidade, governo, trabalhadores do setor e empresários do ramo (operadores). A Figura 1.1 ilustra essas relações.

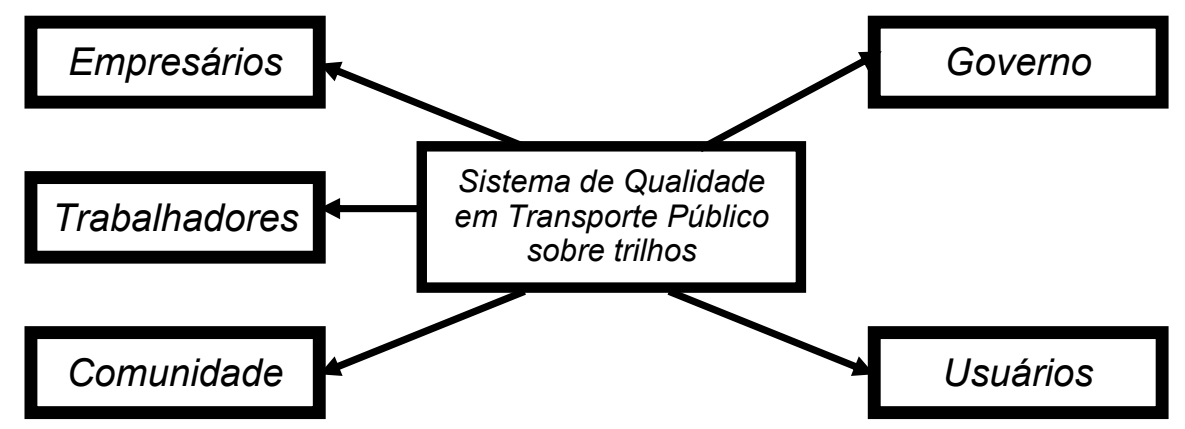

Figura 1.1 - Visão geral da qualidade no Transporte Público. 
Os trabalhos desenvolvidos na área de qualidade em transporte público abordam, na sua maioria, os indicadores de qualidade para a satisfação do usuário. É justo afirmar que a investigação destes indicadores, direcionada aos usuários, acaba, pela sua essência, trazendo informações para todos os outros indicadores do sistema. O usuário é também membro da comunidade e, em algum momento, a qualidade que ele recebe neste serviço de transporte reflete na sua comunidade. Por outro lado a empresa operadora tem uma referência sobre o que deve medir para que o usuário esteja satisfeito com o serviço, oferecendo aquilo que o usuário deseja e, desta forma, otimizando os seus processos e recursos financeiros. O governo, tendo conhecimento das expectativas do usuário do transporte público pode elaborar políticas públicas adequadas para atendê-lo, cumprindo o seu papel de gestor e fiscalizador do serviço prestado.

Por outro lado, pouco tem sido estudado sobre os indicadores de qualidade para a comunidade e como estes indicadores influenciam os demais indicadores, conforme ilustrado na Figura 1.2. 


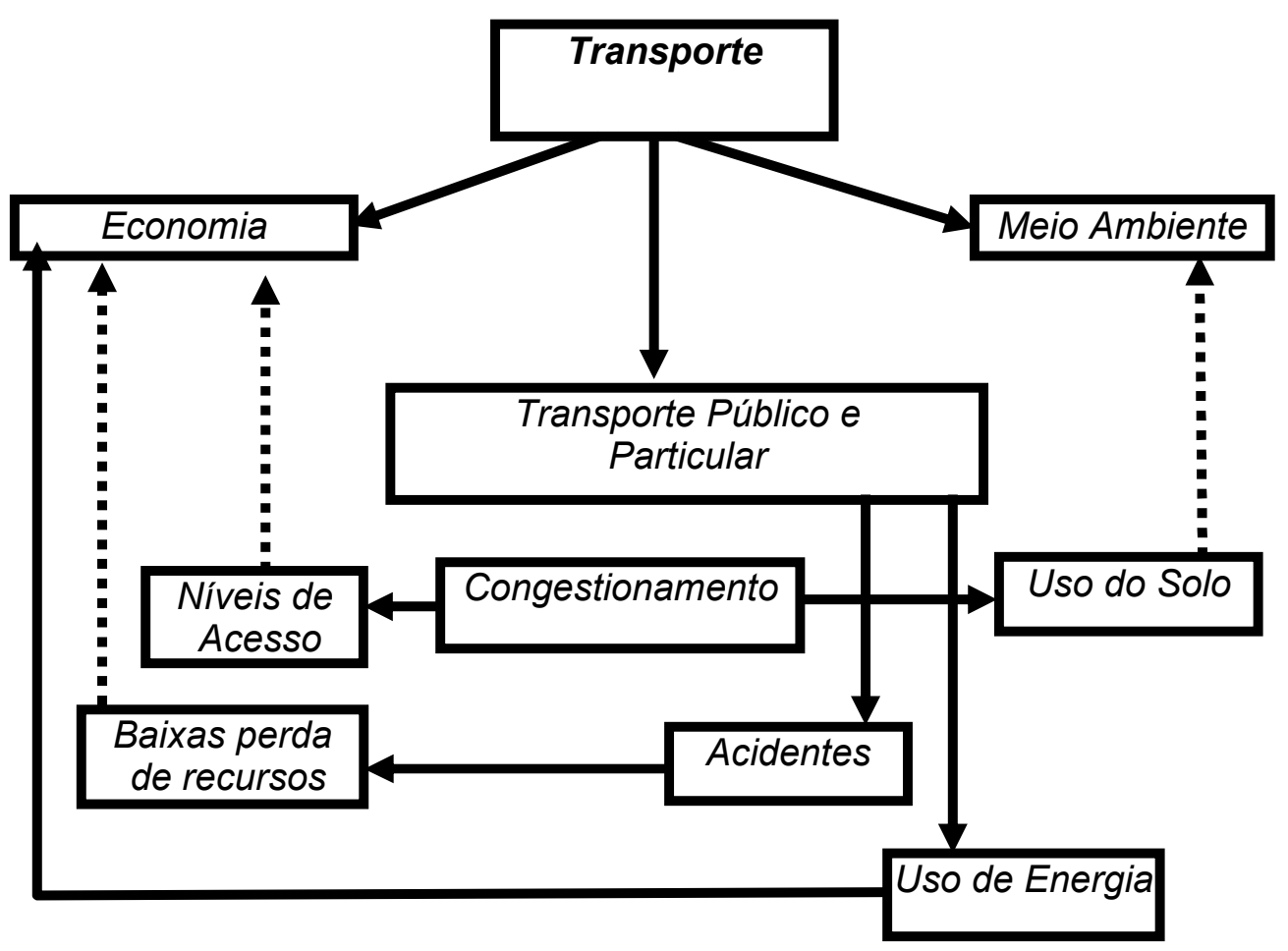
indicadores.

Figura 1.2 - Influência dos indicadores de qualidade para a comunidade nos demais

Os investimentos em transporte público sobre trilhos podem chegar à bilhões de reais, e um embasamento acadêmico deve ser encarado como uma ferramenta de apoio na tomada de decisões, auxiliando os gestores a encontrarem a solução mais adequada ao problema do retorno do investimento.

Segundo Tyson (1991), haverá sérios problemas se o nível de investimento em transporte público for diminuído, e, ainda, o transporte público é mais eficiente para atender as diversas demandas do que o carro particular quando o impacto aos não usuários é levado em conta.

Um estudo de Litman (2005) mostra que a implantação de sistemas de transporte sobre trilhos diminui o tempo de viagem por automóvel, justamente pela troca de viagens de automóvel por transporte público.

O sistema metroviário da cidade de São Paulo, de acordo com Metrô 
(2004), apresentou os seguintes números em 2002 na contabilização do seu balanço social: a emissão de poluentes teve uma redução de 58.809 ton, $315.270 \mathrm{~m}^{3}$ de combustível deixaram de ser consumidos, economizaram-se 317.612 horas de viagem e deixaram de ocorrer 3.160 acidentes. Esses benefícios, associados a outros, corresponderam a uma economia de $\mathrm{R} \$$ 2.9941.937.000,00. A metodologia utilizada para medir esses benefícios sociais é reconhecida pelo BIRD, Banco Mundial e BNDES.

Litman (2005) mostra que o número de viagens realizadas em uma cidade com uma grande infra-estrutura de transporte sobre trilhos é três vezes maior que nas cidades com pequena infra-estrutura de transporte sobre trilhos, ou nas cidades com somente transporte público baseado em ônibus.

Ridley e Fawkner (1987) consideram que as pressões sofridas pelo governo, que ainda é o maior investidor na implantação de sistemas de transporte público sobre trilhos, conduzirão a uma redução no suporte aos transportes. No entanto, esta aparente economia financeira não suplantará as perdas sociais e econômicas advindas da redução de investimentos.

Nota-se que existem receios quanto à continuidade de investimentos em transporte público sobre trilhos, que, a bem da verdade, são ainda esparsos e pequenos. Por outro lado é notória a importância dos sistemas de transporte público sobre trilhos para continuidade do crescimento ordenado das cidades. Embora haja suspeita de uma diminuição de investimentos, um componente de fundamental importância na alocação de recursos financeiros neste sistema de transporte público é a opinião pública.

\subsection{Objetivos do Trabalho}

O primeiro objetivo da pesquisa é realizar um estudo de caso mediante 
pesquisa exploratória junto à sociedade para avaliar a percepção desta sobre os benefícios gerados pelos sistemas de transporte público sobre trilhos.

O segundo objetivo é apresentar a relação dos benefícios para um grupo de especialistas em Transporte, para que façam uma análise dos mesmos, visando obter uma avaliação dos especialistas sobre os benefícios do transporte público urbano sobre trilhos.

O terceiro objetivo é comparar as respostas das duas pesquisas para verificar o nível de concordância das opiniões dos dois grupos pesquisados.

\subsection{Metodologia da Pesquisa}

A pesquisa exploratória conduzida junto à sociedade é mostrada no apêndice I e utiliza a escala de Likert.

A pesquisa junto aos especialistas em transporte público encontra-se no apêndice II e utiliza o método de análise hierárquica - MAH (SAATY, 1980), o que permite estabelecer uma média das resposta para determinar 0 ranqueamento dos benefícios.

\subsection{Organização do Trabalho}

Este trabalho está organizado em cinco capítulos. Este primeiro capítulo contém a introdução do trabalho, apresentando a fundamentação, os objetivos e a metodologia.

O segundo capítulo apresenta o estado da prática dos benefícios e revisão bibliográfica sobre o assunto, elencando os benefícios que são hoje 
aceitos e estudados.

O terceiro capítulo apresenta as técnicas que são utilizadas para analisar os dados coletados junto a população e especialistas.

O quarto capítulo apresenta o estudo de caso, mostrando como foram realizadas as pesquisas junto a população e especialistas, quais os dados coletados, a compilação dos dados e a análise deste dados com as técnicas apresentadas no terceiro capítulo.

O quinto capítulo apresenta as conclusões sobre os resultados, responde as questões abordadas nos objetivos do trabalho e sugere algumas alternativas para trabalhos futuros. 


\section{Capítulo 2 - Benefícios Percebidos}

\subsection{Apresentação dos Benefícios}

Tyson (1991) apresentou no $49^{\circ}$ Congresso Internacional da UITP interessante trabalho sobre os benefícios do transporte público para a sociedade. Esse tema já havia sido abordado por Flieger (1985), Ridley e Fawkner (1987) e Felz (1989), que discutiram as questões de financiamento do transporte público, a revitalização dos centros das cidades e as externalidades do transporte público.

De acordo com Tyson (1991), os sete benefícios para a comunidade, quando da implantação de sistemas de transporte público, são:

- Diminuição do trânsito de automóveis devido ao uso do transporte público;

- Aumento da qualidade de vida devido à diminuição de dano ecológico e diminuição da poluição sonora, do ar e visual;

- Economia do dinheiro público devido à redução da necessidade de investimentos em construção e manutenção de vias públicas;

- Acesso aos serviços públicos com maior eficiência (hospitais, repartições públicas, etc.);

- Melhora a economia da cidade e dos centros regionais.

- Uso das fontes de petróleo com eficiência devido ao menor consumo em função do uso do transporte público, e;

- Redução no custo dos acidentes de trânsito e danos provocados por eles. 
Esses benefícios referem-se à implantação de sistemas de transporte público em geral. Segundo Tyson (1991), quando o transporte público é sobre trilhos os benefícios são multiplicados.

\subsection{Revisão Bibliográfica}

Os benefícios advindos da implantação de sistemas de transporte público, e mais notadamente dos sistemas sob trilho, sob a ótica da sociedade, podem ser chamados de benefícios sociais. Diversos autores exploram esta questão (DORN, 2003; FTA, 2006; UITP, 2003; O'MAHONY et al., 2004; WEYRICH e LIND, 2003; BANCO MUNDIAL, 2003; LITMAN, 2005a; SHAPIRO, HASSET e ARNOLD, 2002; ECMT, 2000; GLEAVE, 2005).

Kawamoto (2002) explica, pela ótica da economia, que os benefícios sociais são o excedente do equilíbrio entre receita e despesa.

Os números aqui apresentados são sempre resultado dos estudos dos autores e, em grande parte, obtidos a partir de dados publicados por instituições que estudam e analisam o transporte. O detalhamento das fontes e dos métodos para obtenção destes resultados devem ser procurados junto aos autores listados na bibliografia.

Investimentos em serviços públicos propiciam, em geral, significativos benefícios para terceiras partes. O transporte público, em particular, é um grande gerador destes benefícios, considerando que já no primeiro plano é um redutor do trânsito na cidade, beneficiando os motoristas e aumentando a sua mobilidade, devido à transferência do usuário do transporte particular para o transporte público.

Além da transferência de usuários, parece existir uma tendência de diminuição no consumo de energia e diminuição da poluição atmosférica e sonora, notadamente se o transporte público oferecido for sobre trilhos. Outra 
tendência é de valorização do solo nas áreas próximas ao sistema de transporte público (RIDLEY e FAWKNER, 1987).

Goodwil (2004) argumenta que as estratégias de transporte público têm se tornado uma ferramenta essencial no planejamento das cidades. Para as cidades que adotam esta medida observou-se o crescimento de viagens. De uma maneira geral os benefícios para a sociedade, como um todo, têm acompanhado este crescimento.

$\mathrm{Na}$ busca de indicadores que mostrem as vantagens e benefícios do transporte público, Vivier (1999) publicou uma avaliação dos custos externos do transporte particular e do transporte público, utilizando como indicadores alguns dos benefícios sociais apresentados por Tyson (1991). Entenda-se, neste estudo de Vivier, como transporte particular o carro. O método para obtenção dos números aqui apresentados foi aplicado na região de Paris. Contudo o método seria aplicável em qualquer outra cidade com uma rede de transporte público eficiente. Os resultados são: i) o transporte público consome três vezes menos energia por passageiro x quilômetro, em relação ao transporte particular; ii) o transporte sobre trilhos emite 20 vezes menos dióxido de carbono $\left(\mathrm{CO}_{2}\right)$ por passageiro x quilômetro, do que o transporte particular; iii) o transporte particular contribui doze vezes mais para o efeito estufa, em relação ao transporte público; iv) o transporte particular promove 53 pessoas com ferimentos graves e 10,1 pessoas mortas por bilhões de passageiros transportados $x$ quilômetro, contra 2,7 e 1,1 pessoas, respectivamente, no sistema de transporte público sobre trilhos; v) o transporte particular utiliza 10 vezes mais espaço para estacionamento em relação ao transporte público para viagens de trabalho de $10 \mathrm{~km}$; vi) o transporte particular utiliza 3 a 10 vezes mais espaço de estacionamento do que o transporte público, para as viagens destinadas a compras em um raio de $10 \mathrm{~km}$.

Um estudo de comparação dos custos de transporte na Irlanda em relação a outros países da Europa, com particular atenção aos custos sociais, apresenta resultados referentes aos dados de 1996, com projeções para 2005. 
Nesse estudo, O'Mahony et al (2004) mostram que os custos com acidentes na Áustria, Dinamarca, França, Irlanda, Países Baixos, Espanha e Inglaterra variam de $€ 20,00$ (França) a $€ 160,00$ (Áustria), per capita. Os custos com poluição sonora e do ar variam de $€ 120,00$ (Áustria) a $€ 440,00$ (França), per capita, incluídos os custos com aquecimento global. Não foram observados, por O'Mahony et al. (2004), custos devido à poluição sonora na Dinamarca.

Dorn (2003) ressalta que o benefício com investimento do transporte público pode ser percebido por cidadãos e governo. Para o transporte de 15.000 pessoas em uma direção, são necessárias 34 faixas de circulação de ruas urbanas, ou 14 faixas de pistas expressas. O mesmo número de pessoas pode ser transportado com apenas duas linhas de ônibus com tráfego priorizado ou, ainda, com apenas uma linha de transporte sobre trilhos. Isto significa economia de tempo de viagem, não somente para os usuários, mas também para todo o sistema, o que permite um fluxo de mercadorias, bens e serviços mais rápido, influindo diretamente no custo destes. $O$ investimento no transporte público talvez seja a maneira mais efetiva e com resultados mais visíveis para a diminuição da emissão de poluentes. Ainda segundo Dorn (2003), a cada US\$1,00 investido em transporte público consegue-se até US\$ 3,00 em crescimento econômico.

A valorização do solo foi estudada por Weyrich e Lind (2003). A valorização de propriedades que estão localizadas em um raio de até 500 metros de uma estação do MAX (Metropolitan Área Express), em Portland, são $10,2 \%$ mais valorizadas do que aquelas localizadas fora deste raio. Outro estudo conduzido em Massachusetts, na área de influência do MBTA, indica uma valorização de $171 \%$, no período de 1995 a 2002, das propriedades nas cercanias servidas por esse serviço.

Litman (2005a) apresenta informações mostrando que apesar dos custos de congestionamento mostrarem-se mais altos nas cidades em que existe uma infra-estrutura grande de transporte sobre trilhos, os valores não gastos devido à existência deste modo de transporte também são significativos. 
Em Nova lorque, por exemplo, o custo do congestionamento, per capita, é de US\$ 500,00, enquanto o valor não gasto é de US\$450,00. Ou seja, para o caso de Nova lorque, se não existisse o transporte sobre trilho o custo do congestionamento, per capita, seria na ordem de US\$ 950,00.

No relatório apresentado por Gleave (2005), sobre os benefícios de implantação de sistemas VLT (Light Rail), na Inglaterra, observa-se que 4 dos 5 benefícios listados são sociais. Os benefícios são: i) maneira eficiente de transportar grande número de pessoas; ii) diminui o número de carros nas ruas e auxilia na diminuição dos congestionamentos mais que os outros sistemas; iii) melhora a imagem da cidade e promove o crescimento econômico; iv) promove a inclusão social; v) melhora o meio ambiente urbano e auxilia na diminuição dos acidentes de trânsito.

Cervero, Sandoval e Landis (2002) concluem que as pessoas que podem acessar o sistema de transportes público por meio de caminhada estão mais habilitadas a conseguir uma oportunidade de trabalho. Isto significa que a iniciativa de criar uma rede de transporte que possibilite as pessoas acessarem a pé tem influência marginal nas taxas de emprego.

A busca por soluções que indiquem a utilização do transporte público como uma alternativa economicamente viável levou a UITP (União Internacional de Transportes Públicos, 2003) a apresentar um modelo de desenvolvimento que privilegia este modo de transporte e se iguala ao modelo apresentado por Tyson (1991), em que existe um ganho expressivo para a comunidade como um todo, considerando os benefícios gerados. Este modelo de desenvolvimento é apresentado na figura 2.1 . 


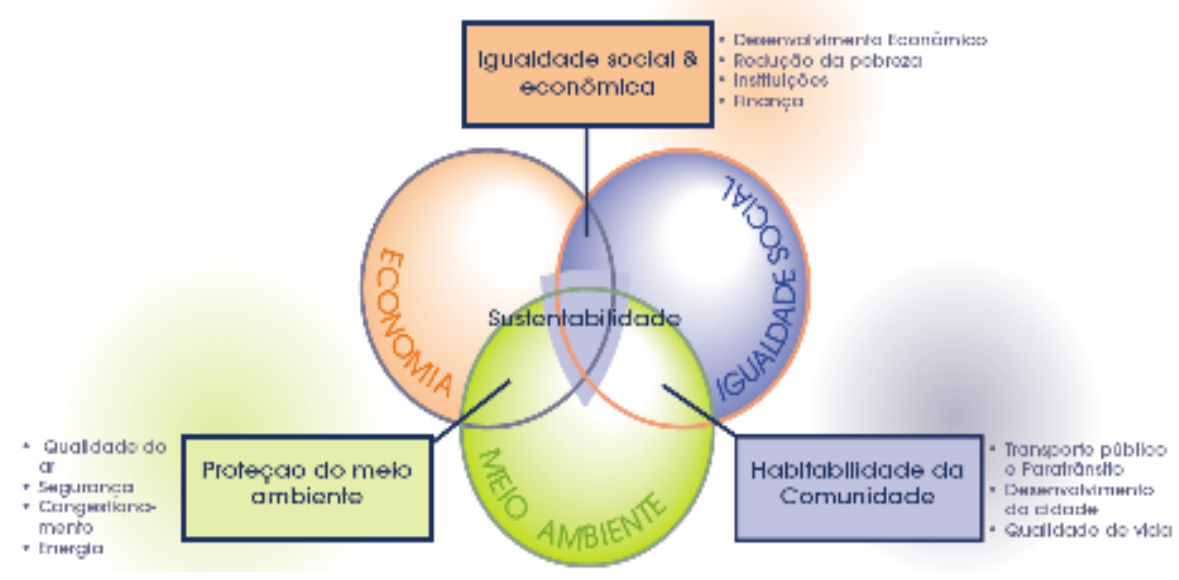

Figura 2.1 - Modelo de Desenvolvimento. Fonte UITP (2003).

No campo nacional, o Programa de Engenharia de Transportes da COPPE (2006) desenvolveu um estudo das externalidades que os sistemas metroferroviários podem gerar para a sociedade como um todo. As externalidades são basicamente as mesmas apresentadas por Tyson (1991). No entanto, existe uma preocupação pronunciada com a questão energética. Estes benefícios são apresentados a seguir:

- O sistema metroferroviário emite $75 \%$ menos óxido de nitrogênio que os automóveis com um ocupante e quase nenhum hidrocarboneto e monóxido de carbono;

- A extensão dos congestionamentos, no sistema metroferroviário, é de zero quilômetro e independe dos horários de pico. O gasto com o tempo de viagem é da ordem de metade do tempo viajando de trem ou metrô se comparado ao ônibus ou automóvel;

- Um trem cheio possui uma eficiência energética 15 vezes superior à do automóvel;

- Baixo índice de acidentes gerando menos danos às famílias e a sociedade, em função da não ocorrência de acidentes e fatalidades observadas no transporte privado;

- O sistema metroferroviário oferece a mais alta capacidade de evacuação da população, entre os sistemas de transportes urbanos, em situações de emergência, como catástrofes naturais ou atentados terroristas; 
- A infraestrutura do sistema metroferroviário gera efeitos nocivos mínimos de drenagem urbana se comparados ao sistema rodoviário;

- Os imóveis residenciais e de negócios lindeiros às estações dos sistemas metroferroviários são valorizados, aumentando as arrecadações tributárias;

- Os carros, estações e leitos ferroviários podem ser explorados para a veiculação de propaganda de diversos modos, gerando receitas extras ou promovendo o interesse público;

- Aproximadamente 1250 passageiros são transportados em uma composição de $65 \mathrm{~m}$, o que corresponderia a uma fila de 25 ônibus $(300 \mathrm{~m})$ ou 830 automóveis $(4000 \mathrm{~m})$.

O último tópico apresenta alguns valores extremados. Uma composição típica de seis carros mede, em média, 120m. A lotação dos ônibus e automóveis para a consecução do cálculo da quantidade necessária de veículos parece utilizar um valor médio da taxa de lotação, com 50 passageiros por ônibus e 1,5 ocupantes por automóvel. Uma aproximação mais razoável seria utilizar a taxa de lotação máxima dos automóveis e ônibus, para que o cálculo fosse compatível com a taxa de ocupação utilizada no sistema metroferroviário. Mesmo assim, os valores apresentados são significativos para visualizar a capacidade do sistema metroferroviário frente às alternativas de transporte.

A existência de um sistema de transporte público contribui para a diminuição dos acidentes e, conseqüentemente, o custo envolvido nestas fatalidades. A Tabela 2.1 apresenta as fatalidades ocorridas no ano de 2001 nos EUA e mostra que os acidentes ocorridos nos sistemas públicos, inclusive bicicletas e pedestres, representa $11 \%$ do total de acidentes. O transporte público, além de gerar um custo menor no tratamento das fatalidades, também contribui para que a sociedade tenha uma diminuição nos transtornos causados pelo transporte particular. 

(2004)

Tabela 2.1 - Fatalidades por modo de Transporte nos EUA em 2001. Fonte: Litman

\begin{tabular}{lrrr}
\hline \hline & Fatalidades por Modo em 2001 & & \\
& Quantidade & Totais & $\%$ \\
\hline \hline Automóveis & 23.599 & & \\
Motocicletas & 3.216 & & \\
Caminhões Leves & 15.091 & & \\
Caminhões Pesados & 4.897 & 46.803 & 89,0 \\
\hline Ônibus Intermunicipal & 45 & & \\
Ônibus Urbano & 96 & & \\
Metrô & 31 & & \\
Trem Suburbano & 78 & & \\
VLT & 22 & 272 & 0,5 \\
\hline Pedestres & 4.901 & & \\
Ciclistas & 732 & 5.633 & 10,5 \\
\hline Totais & & 52.708 & 100 \\
\hline \hline
\end{tabular}

No grau em que o sistema de transportes provê um uso do solo mais acessível, isto tende a tornar o sistema viário mais seguro. As comunidades que possuem uma política de valorização do transporte público, com uma taxa de viagens alta, possuem uma taxa per capita de acidentes muito menor que as comunidades que possuem uma densidade habitacional baixa e são orientadas para o uso do automóvel (LITMAN, 2004).

A utilização de sistemas de transporte voltados para a população menos favorecida mostra-se como uma ferramenta eficaz para diminuição das dificuldades sociais. A possibilidade de deslocar-se para os locais de trabalho de forma rápida, segura e financeiramente adequada trás benefícios para a sociedade como um todo e muito mais para os usuários do sistema. $O$ Transmilênio, implantado na cidade de Bogotá, no ano de 2000 , tem $37 \%$ de sua demanda utilizada por uma população de renda abaixo de US\$ 5,73 diários. A implantação do Transmilênio trouxe uma economia diária de US\$ 0,60 por viagem, além de proporcionar um ganho de 16 minutos por viagem, para a população que vive na periferia e desloca-se diariamente para os centros de trabalho da cidade (HIDALGO e YEPES, 2005).

Verifica-se que a disponibilidade de transporte público é de fundamental 
importância para que as pessoas e bens de consumo desloquem-se nas cidades de maneira adequada. A inexistência de um sistema público de transportes aumentaria em 1,1 bilhão o saldo, já negativo, de horas perdidas no trânsito, em uma análise para os valores de 2003, conduzida por Schrank e Lomax (2005), mostrado na Tabela 2.2. Este número de horas corresponde a mais de 18 milhões de dólares que foram poupados em função da existência de um sistema de transporte público.

Tabela 2.2 - Perda de Horas e Valores no Trânsito

\begin{tabular}{ccccc}
\hline \hline Grupo & Média Anual de & \multicolumn{2}{c}{ Redução da Perda em Função do Transporte Público } \\
\cline { 3 - 5 } Populacional e & $\begin{array}{c}\text { Usuário-Milha } \\
\text { Número de }\end{array}$ & $\begin{array}{c}\text { Horas } \\
\text { viajado (milhões) }\end{array}$ & $\begin{array}{c}\text { Base Percentual } \\
\text { Perdidas }\end{array}$ & $\begin{array}{c}\text { Valores Não Gastos } \\
\text { das Perdas }\end{array}$ \\
\hline Muito Grandes & 2.718 & 919 & 33 & 15.289 \\
Grandes & 233 & 148 & 16 & 2.485 \\
Médias & 58 & 27 & 9 & 444 \\
Pequenas & 17 & 2 & 4 & 25 \\
\hline 85 Areas & 43.403 & 1.096 & 27 & 18.243 \\
\hline \hline
\end{tabular}

Fonte: APTA Operating Statistics and TTI Review

Notadamente, o acréscimo de mais de um bilhão de horas perdidas no trânsito das pessoas e bens de consumo afetaria diretamente o custo dos serviços e bens de consumo. Não é leviano afirmar que a implantação de um sistema de transporte adequado é fundamental para que uma região seja economicamente atraente e, assim, contribua para o desenvolvimento da mesma, em função do incremento de negócios e moeda circulante. A utilização deste tipo de política gera uma espiral positiva, um círculo virtuoso, trazendo e aumentando os benefícios percebidos pela implantação de um eficiente sistema de transportes público.

Diversos estudos (SCHRANCK e LOMAX, 1999, 2005; NEFF, 1996; LEWIS e WILLIANS, 1999) mostram que a eficiência de uma linha de transporte público sobre trilhos é muito maior que a eficiência de uma autopista. Esses estudos mostram que uma milha de transporte público sobre trilhos substitui de 5,4 a 7,5 milhas de autopista. Indicam, também, que a elasticidade do crescimento do trânsito é da ordem de $0,9 \%$ para cada $1 \%$ de 
incremento de autopistas. Outro fator demonstrado é de que para transportar 11.000 pessoas/hora/sentido uma autopista precisa de uma faixa de 90 metros, enquanto que uma linha de transporte público sobre trilhos necessita de uma faixa de 30 metros.

Vários estudos foram realizados sobre o impacto do uso do solo na região de influência do BART, em São Francisco. Estes estudos, em sua maioria, chegaram a conclusão que um sistema de transporte sobre trilhos urbano produz uma significativa ocupação do solo e, conseqüentemente, propicia facilidades para a locação dos imóveis; isto se a região contar com uma economia crescente e programas complementares ao sistema de transporte sobre trilhos, como uma política de zoneamento que permita uma densidade ocupacional alta e a provisão de infra-estrutura adequada, como praças para pedestres e melhorias nas ruas adjacentes. Todas as áreas estudadas com relação ao impacto no uso do solo estão localizadas em um raio de 400 metros de uma estação referenciada.

No caso dos imóveis localizados próximos a estação de um sistema de transporte público sobre trilhos pode oferecer um acesso privilegiado, levando a uma valorização do imóvel (STRAND e VÅGNES, 2001).

Segundo Litman (1995), a quantidade de solo necessária por passageiro varia significativamente, dependendo do tipo de transporte escolhido, mostrado na Figura 2.2. Cidades que tem o sistema de transporte orientado para $\circ$ deslocamento a pé perdem menos de $10 \%$ do solo disponível em seu sistema de transporte, enquanto as cidades com um sistema de transporte direcionado ao uso do veículo particular gastam de 30 a $50 \%$ do solo disponível em ruas e locais para estacionamento. Além deste custo, que é facilmente observado, existem os impactos indiretos provenientes do espalhamento urbano. 


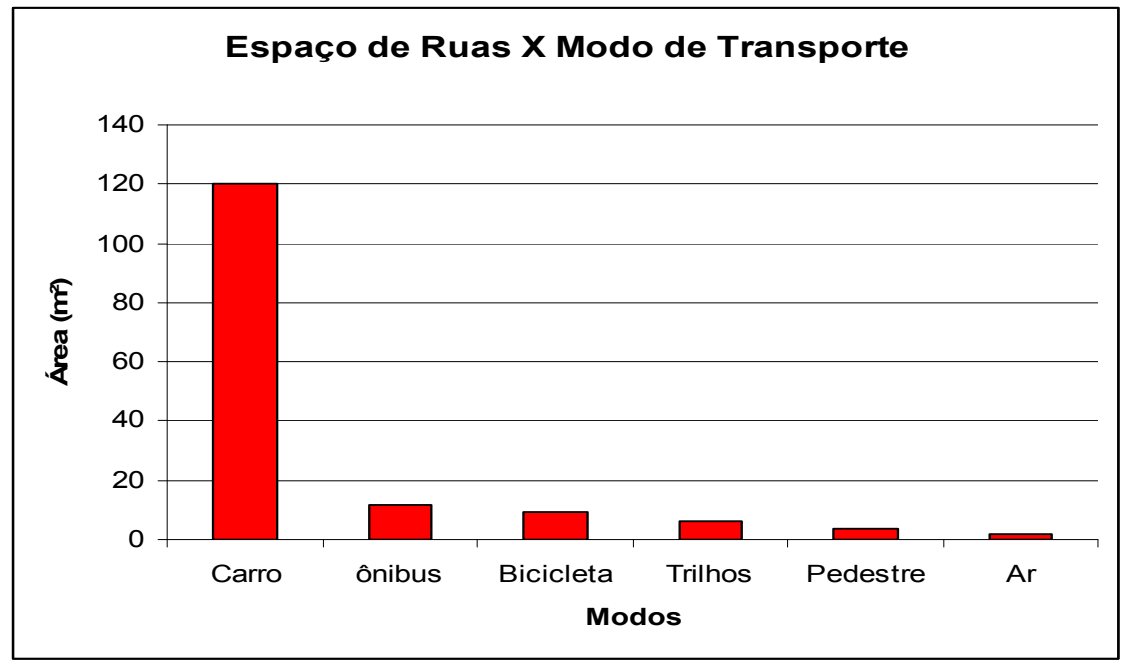

Figura 2.2 - Espaço necessário, em $\mathrm{m}^{2}$, de ruas por pessoa em função do modo de transporte. Adaptado de Litman (1995).

Para demonstrar a valorização dos imóveis comerciais que estão localizados próximos às estações dos sistemas WMATA, em Washington e MARTA, em Atlanta, nos EUA, Cervero (1992) utiliza a técnica de regressão múltipla, com dados de 1978 a 1989. O artigo mostra que existem vantagens tanto para os construtores como para o estado, que através de joint development constroem prédios de escritórios para então terem uma grande facilidade de locação destes imóveis, devido a acessibilidade do local. Assim ganham as duas partes, o construtor na velocidade de locação do imóvel e o estado com o recebimento de uma taxa de utilização do uso do solo próximo às estações do sistema de transporte público sobre trilhos.

O joint development é baseado na premissa de que os investimentos em sistemas de transporte aportam significativa acessibilidade regional, que leva a altos índices de uso do solo no entorno das estações do sistema de transporte. Altos índices de uso do solo, por sua vez, podem indicar valores elevados para locação de imóveis, o que, por sua vez, provoca o aumento da densidade ocupacional do solo e uma rápida ocupação do espaço construído.

A WMATA recebe anualmente rendimentos na casa dos US\$200.000 
por cessão de uso do solo na região da estação de Ballston, de propriedade da agência, para investidores que exploram o aluguel de imóveis construídos nestes locais.

O Betheseda Metro Center, em Washington, localizado acima da estação de metrô de Betheseda, é um grande empreendimento de uso misto (escritórios, hotel e comércio) que representa um rendimento anual de US\$ 1.600.000 em locação.

$\mathrm{Na}$ estação Arts Center, a IBM Tower tem gerado rendimentos, em função de locação de imóveis, acima de US\$1.500.000 para o MARTA. Proprietários de escritórios no Resurges Plaza, um luxuoso condomínio de escritórios, construído nas adjacências da estação Lenox, pagam anualmente ao MARTA mais de US\$ 100.00 em rendimentos de locações.

Cervero (1992) verifica que o valor da locação sobe em US\$ 4,00 para cada pé quadrado de imóvel para o acréscimo de 100.000 usuários no sistema de transporte.

Os custos que são gerados em função da implantação de um sistema de transporte devem ser incorporados na matriz de composição dos custos, conforme Litman (1995) sugere, para que eles sejam avaliados e a tomada de decisões tenha uma visão mais abrangente do problema.

A mudança de preços dos imóveis é um indicador que aponta para a mudança do uso do solo e também indica o potencial de mudança que o sistema de transporte sobre trilhos exerce sob a forma urbana (Gatzlaff e Smith, 1993).

Ferguson, Goldberg e Mark, apud Gatzlaff e Smith(1993), concluem que 
mudanças em acessibilidade e transporte podem ter influência no arranjo urbano e no mercado de imóveis, incluindo o efeito nos preços e no uso do solo.

Gatzlaff e Smith (1993), no entanto, afirmam que existem outros estudos que interpretam que o sistema de transporte sob sobre trilhos tem pouca influência na estrutura urbana devido à ausência de outros fatores favoráveis.

Gatzlaff e Smith (1993) concluem que encontraram fracas evidencias de que haja um efeito valorizador dos imóveis após o anunciamento da implantação de um sistema de transporte sobre trilhos, mais especificamente o Miami Metrorail. Ao mesmo tempo também não visualizaram mudanças significativas na forma urbana devido à implantação do Miami Metrorail.

Mastaglio (2006) aponta que os trens suburbanos são uma ferramenta para o desenvolvimento dos ajuntamentos urbanos que estejam localizados ao longo das linhas destes sistemas de transporte. Cita o caso do DART, em Dallas, que propiciou o desenvolvimento de diversas indústrias de tecnologia eletrônica na ponta norte do sistema.

Em teoria, a proximidade de imóveis residenciais a uma linha de transporte sobre trilhos pode ter dois efeitos diferentes. Por um lado a acessibilidade pode incrementar o valor de propriedade dos imóveis. Por outro lado os efeitos indesejáveis da proximidade a uma linha podem fazer com que o preço dos imóveis tenha uma queda (CHEN, RUFOLO e DUECKER, 1997).

As conclusões de Strand e Vågnes (2001) apontam que existe um forte relacionamento entre a valorização das unidades de moradia e a proximidade da linha quando o raio de influência está na casa dos $100 \mathrm{~m}$. No estudo conduzido observaram que a elasticidade do preço destes imóveis está na 
faixa de 0,1 a 0,3. Este valor de elasticidade parece mostrar que existe uma procura maior que a oferta e, desta forma, os imóveis, nesta faixa de influência, são valorizados.

Os benefícios observados são relevantes para a sociedade como um todo. Foram apresentados estudos que demonstram que a inexistência de um sistema de transporte público em cidades desenvolvidas acaba por inviabilizar estas cidades, tornando o deslocamento dos bens e serviços muito caro, onerando a própria sociedade, que arca com estes custos. Por outro lado, a concepção de um sistema de transportes adequado promove 0 desenvolvimento das cidades, diminui os gastos públicos com a manutenção do sistema viário, em função da diminuição da carga, aproxima as pessoas dos aparelhos públicos, contribui sensivelmente para a diminuição da poluição do ar e aumento da qualidade de vida, contribui de maneira significativa para a diminuição do trânsito e também contribui para que os gastos com acidentes de trânsito sejam minimizados, bem como diminui o sofrimento das famílias que poderiam ser envolvidas nestes acidentes. 


\section{Capítulo 3 - Métodos de Análise dos}

\section{Dados Coletados}

\subsection{Conceitos Gerais}

Este capítulo trata dos métodos de análise utilizados nas análises dos dados coletados junto à população e especialistas.

Por estatística entende-se:

- Estatística é a ciência da coleta, simplificação e descrição de dados, e também das inferências obtidas através da análise de dados e suas características;

- O conjunto de todos os elementos (ou dados, ou valores atribuídos aos dados) a que pertencem os sujeitos de estudo é chamado de população, ou universo. Um subconjunto do universo, constituído de alguns elementos pertencentes à população é chamado amostragem sobre a população, ou amostra.

A estatística descritiva é o conjunto de ações para coletar, simplificar e fornecer as principais propriedades dos dados. A inferência estatística é o conjunto de técnicas que pode ser utilizado para julgamentos sobre a população, a partir de propriedades observadas em amostras obtidas entre a população.

Chama-se parâmetro estatístico, ou parâmetro, a uma propriedade 
numérica de população. Um número que representa uma propriedade estatística que caracterize elementos de uma amostra é chamado de estatística, ou teste estatístico.

O conjunto a que pertencem sujeitos cujas características sejam observadas em experimentos é chamado população, ou universo.

Fixado um padrão, ou seja, uma grandeza unitária para servir de referência a uma característica de elemento de uma população, diz-se que medir sobre características de dado sujeito é a atividade para verificar quantas vezes ocorre o padrão em cada sujeito observado. Assim define-se:

- Medida (sobre o sujeito observado) é o resultado dessa ação para medir a característica analisada;

- Amostra sobre uma população é um subconjunto de elementos desse universo;

- Amostragem é o processo para obter amostras;

- O produto de uso de uma regra, ou método matemático, para associar uma medida à dada característica de cada elemento pertencente a uma amostra sobre uma população é chamado variável aleatória sobre aquele espaço;

- Um número particular, associado a uma medida sobre elemento específico de uma amostra, pode ser chamado dado ou valor medido para uma característica de variável aleatória em um espaço de amostragem. Em experimentos, dado é sinônimo de dado observado, e;

- Uma amostra sobre uma população é dita aleatória quando os exemplares obtidos têm o mesmo tamanho e igual probabilidade de ocorrer.

Ao analisar conjuntos de dados que expressem medidas sobre uma característica variável de elementos de população: 
- Diz-se que estão sendo estudados valores numéricos de medidas sobre características de elementos da população;

- E, em parcela das decisões sobre características de população, usam-se conceitos da estatística e parâmetros que descrevam o comportamento de propriedades de elementos de amostras;

- O conjunto de medidas sobre uma variável aleatória é chamado contínuo se seus elementos pertencem a um conjunto dos números reais de intervalo definido - a variável aleatória observada é então classificada como variável aleatória contínua;

- O conjunto de medidas sobre uma variável aleatória é chamado discreto se os seus elementos pertencem a uma seqüência de números isolados - a variável aleatória observada é então chamada variável aleatória discreta, e;

- O valor, ou medida, que pertence a uma variável aleatória contínua usualmente é usado para medir algo. Se pertencer a uma variável discreta é usualmente utilizado para contar algo.

\subsection{Correlação entre Variáveis}

Por vezes interessa estudar possíveis relações entre variáveis. Quantas vezes não nos perguntamos se duas variáveis são independentes ou pelo contrário dependentes? E se forem dependentes, qual o tipo e grau de dependência? A resposta a estas questões pode levar a diferentes métodos de análise estatística, por exemplo, na comparação da localização entre dois grupos de observações (amostras emparelhadas versus amostras independentes).

Infelizmente não é fácil responder a estas questões porque não existe nenhuma forma completa de medir a dependência entre variáveis. Duas variáveis podem depender de tantas formas diferentes que se torna impossível 
encontrar uma forma única de avaliar a dependência. Medir o grau de dependência está em um grau mais elevado do que simplesmente testar a existência de alguma associação entre variáveis. É obviamente de interesse poder medir o grau de associação entre dois conjuntos de observações obtidos a partir de um dado conjunto de unidades experimentais.

Dadas duas amostras de observações medidas numa escala de intervalos ou razões, podemos medir o grau de associação linear entre elas através do coeficiente de correlação de Pearson ou simplesmente coeficiente de correlação amostral (Pearson product-moment correlation coe \pm cient)

Se estivermos perante duas varíaveis medidas apenas em uma escala ordinal, ou que apresentam uma relação não linear mas monótona (se uma aumenta a outra tem sempre tendência a aumentar, ou a diminuir), o coeficiente de Pearson não pode ser aplicado. Mais ainda, mesmo quando estamos em condições de aplicar o coeficiente de Pearson mas não podemos garantir os pressupostos da realização do teste de hipóteses a esse coeficiente, temos como alternativa o coeficiente de correlação de Spearman (Spearman rank-order coeficient). A idéia de construção deste coeficiente é baseada na ordenação. Dadas duas amostras de observação ordenáveis, substitui-se cada um dos seus valores pela sua ordem de ordenação, em inglês rank. Este coeficiente é um caso particular do coeficiente de Pearson, que é aplicado aos ranks.

$$
\begin{aligned}
& \rho=1-\frac{6 \sum d_{i}^{2}}{n\left(n^{2}-1\right)}, \text { onde } \\
& \mathrm{d}_{\mathrm{i}}=\mathrm{x}_{\mathrm{i}}-\mathrm{y}_{\mathrm{i}}-\text { diferença entre as posições do rank; } \\
& \mathrm{n}=\text { número de posições em cada conjunto de dados }(\mathrm{x} \text { e } \mathrm{y}) .
\end{aligned}
$$


Uma alternativa ao coeficiente de Spearman é o coeficiente $\tau$ de Kendall (Kendall's tau coeficient) que se aplica nas mesmas condições.

Existem duas vantagens deste coeficiente sobre o anterior: se as amostras tiverem dimensão muito reduzida e valores repetidos, os resultados do teste ao coeficiente são mais precisos no caso presente; por outro lado, o coeficiente $\tau$ de Kendall pode ser generalizado para correlações parciais que são correlações medidas entre duas variáveis após remoção do efeito de uma possível terceira variável sobre ambas. Por exemplo se estudarmos a relação entre o domínio da linguagem ea altura de crianças em idade escolar iremos certamente encontrar uma associação. Mas essa associação não refleete uma relação direta mas sim resulta do fato de ambas as variáveis estarem diretamente relacionadas com a idade.

Uma diferença muito importante entre os dois coeficientes (Kendall e Spearman) reside na sua interpretação e na impossibilidade de comparar diretamente valores provenientes de ambos. Embora o objetivo comum seja o de medir associação, a forma de o fazer é distinta.

O coeficiente de Kendall é muitas vezes descrito como uma medida de concordância entre dois conjuntos de classificações relativas a um conjunto de objetos ou experiências. Por exemplo, se pedirmos a dois professores para classificarem (por ordem crescente de qualidade) um conjunto de exames podemos tentar medir o grau de concordância entre os dois avaliadores através do coeficiente de Kendall. Basicamente este coeficiente mede a diferença entre a probabilidade de as classificações estarem na mesma ordem e a probabilidade de estarem em ordens diferentes.

O coeficiente de Kendall é calculado com base na seguinte fórmula:

$$
\tau=\frac{n_{c}-n_{d}}{\frac{1}{2} n(n-1)}, \text { onde }
$$


$\mathrm{n}_{\mathrm{c}}-$ Total de pares concordantes;

$\mathrm{n}_{\mathrm{d}}$ - Total de pares discordantes;

n - Número total de pares.

\subsection{Distribuição de Freqüência}

Medidas brutas, sobre uma população, são identificadas como aquelas que não foram organizadas por meio de uma seqüência numérica. Por exemplo: opiniões de pessoas classificando a importância de um benefício.

Um grande número de medidas é de difícil manuseio e processamento. Por isso, é usual organizar esses dados por intervalos de valores. Por exemplo, notas de um a cinco, cujas médias podem variar dentro dos números reais que pertençam aos intervalos de classe "1" a "2", "2" a "3", "3" a "4", e "4" a "5".

\subsubsection{Inferência estatística}

A inferência estatística é o processo de explicação das relações associada aos parâmetros estatísticos de uma população, a partir de medidas de características estimadas sobre amostras. Há dois tipos de inferência estatística:

- A estimativa de parâmetros, ou seja, a aproximação de parâmetros estatísticos descritivos de população (média, desvio padrão, etc.), e;

- A tomada de decisões, mais conhecida como teste de hipóteses, que consiste em escolher entre duas afirmativas opostas sobre parâmetros de população. As afirmativas são chamadas hipóteses. 


\subsubsection{Estimativa das médias para grandes amostras}

A média $\bar{x}$, de dados obtidos em uma amostragem sobre dada população, é uma estimativa por pontos da média de população, $\mu$.

O processo para estimativa da média de população leva a um intervalo numérico onde pode estar contida essa média de população, o intervalo de estimativa da média, ou simplesmente intervalo das médias, e, de ocorrência daquele parâmetro, a característica do processo de estimativa usado. Essa probabilidade é chamada de nível de confiança $1-\alpha$, e o intervalo resultante de intervalo de confiança.

Se $x$ é um conjunto de dados estimados sobre uma população caracterizada por uma média $\mu$ e desvio padrão $\sigma$, e $\bar{x}$ representa a média em uma amostragem definida por amostras aleatórias de tamanho $\mathrm{n}$; nas estimativas de parâmetros sobre as populações o uso do teorema do limite central facilita à obtenção das distribuições de probabilidades de ocorrência associáveis porque demonstra que:

- A média das médias sobre as amostras tenderá à média de população, $\mu_{\overline{-}}=\mu$;

- O desvio padrão poderá ser estimado a partir dos desvios das amostras, $\sigma_{\bar{x}}=\sigma / \sqrt{n}, \mathrm{e}$

- A média $\bar{x}$ terá distribuição aproximadamente normal quando $n$ for maior que 30 .

O desvio padrão sobre a amostragem $S$ é usado para estimativa do desvio padrão de população $\sigma$, quando o número de elementos das amostras é $n \geq 30$. Para aplicar o conceito de intervalo de confiança, exposto a amostras com menos que 30 elementos, é indispensável conhecer o desvio padrão, $\sigma$, de população. 


\subsection{Comparação de Médias}

A comparação de médias é um procedimento estatístico que verifica, dado um conjunto de dados, se as médias destes conjuntos são iguais ou diferentes. Este procedimento é útil para situações em que se deseja verificar, por exempo, se a média das notas atribuidas a um conjunto de benefícios por dois grupos (masculino e feminino, por exemplo), ou mais de dois grupos (uma amostra entre diferentes idades) são iguais ou diferentes.

Para o caso de dois grupos utiliza-se o Teste t para diferenças entre duas médias aritméticas. Para a situação de mais de duas médias o procedimento utilizado é a análise de variâncias (ANOVA). Estes dois procedimentos são apresentados a seguir

\subsubsection{Teste t para Diferenças entre Duas Médias Aritméticas}

Dadas duas amostras extraídas de uma população temos as respectivas médias destas amostras, $\bar{X}_{1}$ e $\bar{X}_{2}$, e o desvio padrão, $S_{1} \quad e \quad S_{2}$. A estatística do teste determina a diferença entre as médias $\left(X_{1}-X_{2}\right)$. Por utilizar o teorema do limite central como referência o teste assume que a distribuição é normal, com $n \geq 30$. Se as amostras forem retiradas de forma aleatória da população e considerando que as variâncias das populações são iguais $\left(\sigma_{1}^{2}=\sigma_{2}^{2}\right)$, o teste $\mathrm{t}$ de variância agrupada pode ser aplicado para verificar se existem diferenças entre as médias das populações. O teste t é expresso da seguinte forma: 


$$
t=\frac{\left(\bar{X}_{1}-\bar{X}_{2}\right)-\left(\mu_{1}-\mu_{2}\right)}{\left(S_{p}^{2}\left(\frac{1}{n_{1}}+\frac{1}{n_{2}}\right)\right)^{\frac{1}{2}}}
$$

$$
S_{p}^{2}=\frac{\left(n_{1}-1\right) S_{1}^{2}+\left(n_{2}-1\right) S_{2}^{2}}{\left(n_{1}-1\right)+\left(n_{2}-1\right)},
$$

onde

$S_{p}^{2}$ - Variância Agrupada;

$\bar{X}_{1} \quad e \quad \bar{X}_{2}$ - Média aritmética das amostras extraídas das populações 1 e 2;

$S_{1}^{2} \quad$ e $S_{2}^{2}$ - Variância das amostras extraídas das populações 1 e 2;

$n_{1} \quad e \quad n_{2}$ - Tamanho das amostras extraídas das populações 1 e 2.

A estatística do Teste t para variância agrupada segue uma distribuição t com $n_{1}+n_{2}-2$ graus de liberdade. Para um determinado nível de significância $\alpha$, em um teste bicaudal, a hipótese nula $\left(H_{0}: \mu_{1}-\mu_{2}=0\right.$, ou $\left.\mu_{1}=\mu_{2}\right)$ é rejeitada caso o t calculado seja maior que o valor crítico da cauda superior e menor que o valor crítico na cauda inferior, conforme mostrado na figura 3.1

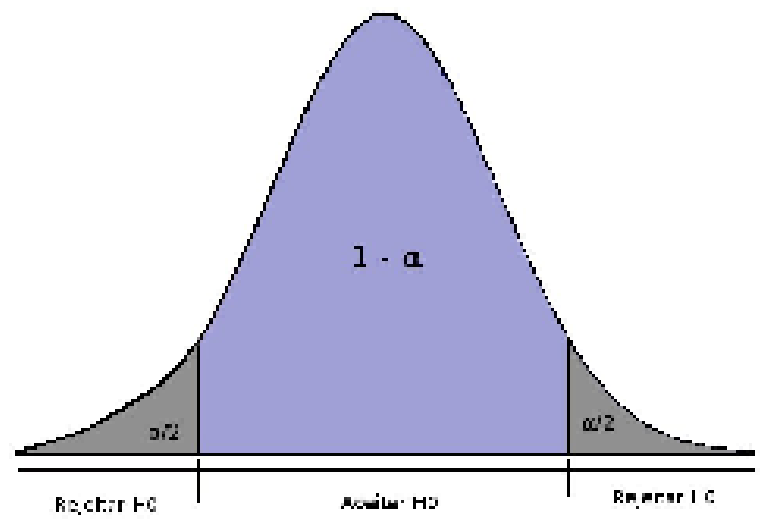

Figura 3.1 - Regiões de aceitação e rejeição da hipótese nula.

\subsubsection{Análise de Variância - ANOVA}

A análise de variância é um teste estatístico para comparar mais do que dois grupos experimentais com relação a uma variável quantitativa. O teste verifica se existe uma diferença significativa entre as médias e se os fatores 
exercem influência em alguma variável dependente. Isto é, caso sejam comparados quatro grupos em um mesmo experimento, a hipótese nula a ser testada $H_{0}: \mu_{1}=\mu_{2}=\mu_{3}=\mu_{4}$, em relação a hipótese alternativa $H_{1}:$ Nem todas as $\mu_{j}$ são iguais.

Em certo sentido o termo análise de variância não parece adequado, pois o objetivo é o de verificar a variação das médias aritméticas dos grupos. No entanto, analisando a variação dos dados dos grupos, seja entre eles ou internamente a eles, as conclusões podem ser tiradas sobre as possíveis diferenças nas médias aritméticas.

A análise de variância baseia-se na decomposição da variação total da variável resposta em partes que podem ser atribuıdas a variância entre grupos (SQE) e a variância dentro de cada grupo (SQD), considerando "c" o número de grupos e "C" a variação total. Essa variação pode ser medida por meio das somas de quadrados definidas para cada um dos seguintes componentes:

$$
\begin{array}{ll}
S Q T=\sum_{i=1}^{i} \sum_{j=1}^{j} y_{i j}^{2}-C & S Q E=\sum_{i=1}^{i} \frac{y_{i}^{2}}{j}-C \\
S Q D=S Q T-S Q E & C=\left(\sum_{i=1}^{i} \sum_{j=1}^{j} y_{i j}\right)^{2} \div i j \\
M Q E=\frac{S Q E}{c-1} & M Q D=\frac{S Q D}{n-c}
\end{array}
$$

Essas somas de quadrados podem ser organizadas em uma tabela, denominada tabela da análise de variância, apresentada na tabela 3.1. Para testar a hipótese nula, utiliza-se o teste $\mathrm{F}$ apresentado na tabela da Análise de Variância. Convém lembrar que esse teste é válido se os pressupostos assumidos para os erros do modelo estiverem satisfeitos. 
Tabela 3.1 - Análise de Variância

\begin{tabular}{lllll}
\hline \hline Causas da & Graus de & Soma dos & Quadrados & F Calculado \\
Variação & Liberdade & Quadrados & Médios & \\
\hline Entre Grupos & $\mathrm{i}-1$ & SQE & MQE & MQE/MQD \\
Dentro do Grupo & $\mathrm{i}(\mathrm{j}-1)$ & SQD & MQD & \\
Total & $\mathrm{ij}-1$ & SQT & & \\
\hline \hline
\end{tabular}

Pode-se mostrar que o quociente MQE/MQD tem distribuição F com (i-1) e i(j-1) graus de liberdade, supondo que yij sejam variáveis aleatórias independentes, todos os tratamentos tem variâncias iguais a $\sigma^{2} \quad e \quad y_{i j} \sim N\left(\mu_{i}, \sigma^{2}\right)$. Por esses motivos, os pressupostos da ANOVA devem ser testados ou avaliados em qualquer análise.

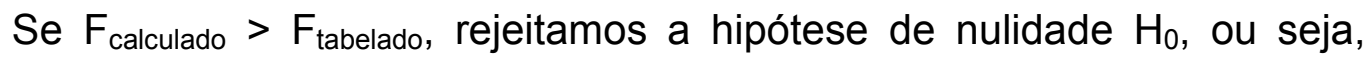
existem evidências de diferenças significativa entre pelo menos um par de médias de tratamentos, ao nível a de significância escolhido. Caso contrário, não rejeita-se a hipótese nula, ou seja, não há evidências de diferença significativa entre tratamentos, ao nível a de significância escolhido.

Outra maneira de avaliar a significância da estatística $\mathrm{F}$ é utilizando o $p$ valor. Se o $p$-valor $<\alpha$, rejeitamos a hipótese nula. Caso contrário, não rejeitamos a hipótese nula, ou seja, não há evidências de diferenças significativas entre os tratamentos, ao nível a de significância escolhido.

\subsection{Escala para Medidas de Juízo Emitidas Através de Indivíduos}

Juízo é uma faculdade intelectual do homem, que compara e julga. Os valores sobre coisas podem ser formados a partir de juízos emitidos por indivíduos. Exemplo de aplicação de juízos emitidos por homens pode ser: "atribuir notas na escala de um a cinco sobre cumprimento do prazo na entrega de um produto". 
A distribuição estatística de classificações obtidas por juízos pode se transformar em conjunto de medidas. Servem, por exemplo, para classificar resultados de experimentos da psicologia, observações sobre estética, verificação de características de pessoas ou resultados de ações de indivíduos ou "nível para qualidade de produto ou serviço", etc.

Os juízos podem ser comparativos ou absolutos - inclusive a inexistência de juízo que pode ser absoluta ou produto de comparação. Os exemplos ilustram esta definição:

"Esta entrega é mais rápida que aquela outra" é uma comparação;

"Não é possível utilizar este serviço de entrega" é um juízo absoluto que contém uma comparação (existiria outro serviço de entrega).

Um juízo único reflete uma única posição de classificação, e não fornece suficiente informação para obter uma medida. Mas, um conjunto de juízos pode contribuir para classificar um sujeito observado. Por isso, opiniões emitidas por indivíduos podem ser úteis para medir dificuldade, qualidade, estética ou percepção, etc.

Medidas podem ser descrições de posições em uma escala. Ou seja, exprimir classificações ou ordenações de características de variáveis.

O juízo sobre características de pessoas ou coisas é muitas vezes emitido através de classificação em um pequeno número de classes definidas e ordenadas. Apesar de os limites da escala de classificação conter intervalos de classe iguais, ou seja, eqüidistante, a sua transformação em medidas pode ser mais bem efetuada assumindo-os como simples intervalos de classes sucessivas de uma escala. Isso porque no uso de intervalos sucessivos é latente a ordem de classificação. Juízos contêm a relação de ordem de classificação e a expressão de escalas internas de quem classifica uma característica de coisas.

Define-se escala para classificação a partir de opiniões de indivíduos (ou simplesmente escala) a um valor de medida associada à distribuição de 
ocorrências de classificações obtidas ao acionar a escolha ou percepção sobre a ocorrência de características numéricas ou contagens sobre variáveis. A escala é um conceito de origem lógica para a medida.

As escalas podem ser usadas para associar medidas a valor de característica abstrata de sujeitos observados - o termo "característica abstrata" é aqui entendido como qualquer aspecto que identifique a diferença entre fatos ou objetos. Por exemplo, comprimento, peso, percepção visual de formas, dureza, dificuldade para escrever, simpatia política, qualidade de tráfego de veículos, qualidade de viagens, etc. Esta medida também pode ser realizada através da classificação das notas em conceitos que sejam mais aderentes ao objeto de estudo. Um exemplo disto é a utilização de uma escala assumida em "Discordo Totalmente", "Discordo", "Indiferente", "Concordo" e "Concordo Totalmente", para que após a avaliação do juízo esta escala seja transformada em uma escala numérica variando de "1" a "5". Neste caso assume-se "Discordo Totalmente" com nota equivalente a "1" e assim, sucessivamente, até que "Concordo Totalmente" tenha atribuída a nota " 5 ".

A definição de escala é processo de aplicação comum em estudos da Psicologia e da Educação - porque, nessas ciências "medem-se" expressões e julgamentos emitidos por indivíduos. Exemplos de aplicações podem ser classificações de: aprendizagem, memorização, captação ou assemelhados.

Segundo Vargas (2005), dos métodos para medir a atitude, a escala de atitudes é o utilizado com mais freqüência e também o mais planejado e comprovado. Uma escala de atitudes consiste em um conjunto de sentenças, entre seis e vinte e quatro, em que o respondente concorda ou não com o afirmado. A maneira como a escala discrimina entre indivíduos depende da forma construtiva da escala e da forma de verificação dos resultados. Diversas escalas são conhecidas, a saber: de intervalos aparentemente iguais de Thurstone, as cumulativas e as somatórias.

As atitudes apresentam-se em grupos variados e são sujeitas a considerável flutuação. As atitudes em relação a determinadas coisas nem 
sempre são estáveis, podendo mudar com a passagem do tempo ou mesmo com o grau de conhecimento ou compreensão dos fenômenos que estão envolvidos. Uma resposta a uma determinada questão relacionada a atitudes pode variar, dependendo de como o respondente entenda a questão. A compreensão das perguntas apresentadas pela escala desejada é influenciada pela forma como é escrita a pergunta.

\subsubsection{A escala de Likert}

A escala de Likert é um exemplo clássico de uma escala somatória, em que são usados apenas itens que parecem ser favoráveis ou desfavoráveis. Neste tipo de escala a pessoa não indica apenas o item que concorda, mas indica o seu grau de acordo ou desacordo para cada item. Cada resposta tem um valor numérico que indica o fato de ser favorável ou desfavorável, sendo as respostas favoráveis mais significativas que as desfavoráveis. A soma algébrica dos resultados individuais dá o resultado total que é interpretado como a representação de sua posição em uma escala favorável-desfavorável com relação ao objeto.

A utilização destes valores parece seguir a lógica de que a probabilidade de concordar com um item favorável em uma série de itens favoráveis, ou discordar, em uma série de itens desfavoráveis, varia diretamente com o grau de aceitabilidade do respondente. Pode-se esperar que um respondente com uma atitude favorável responda de maneira favorável a muitos itens, da mesma forma que um respondente com atitude desfavorável responda de maneira desfavorável a muitos itens e, seguindo o mesmo raciocínio, um respondente neutro responderá de maneira indiferente a um grande número de itens.

A escala de Likert é também chamada de escala de pontuações somadas ou escala somativa, porque, supostamente, é uma escala unidimensional e mede apenas uma propriedade. A escala de Likert permite a expressão da intensidade de sentimento, pelo menos dentro dos limites das opções de resposta oferecidos. 
Diversos trabalhos (FARIA, 1985; COSTA, 2001; DARONCHO, 2001; RODRIGUES, 2006; etc.) têm utilizado a escala de Likert para medir a percepção do usuário com relação às características do nível de serviço de transporte coletivo por ônibus com resultados amplamente satisfatórios.

Por ser a escala mais adotada em trabalhos de medidas psicométricas, por apresentar um grau de precisão mais acurado, pois a precisão da escala está diretamente ligada à quantidade de respostas alternativas que podem ser dadas, serem de fácil construção, e devido a sua utilização em diversos trabalhos da área de transportes, optou-se por utilizar-se a escala de Likert neste trabalho.

O exposto levou à definição de processos para tratamento de dados que levam à definição de escalas partindo de juízos sobre coisas ou pessoas cujas características sejam enquadradas em um número definido de classes.

\subsubsection{O Ranking Médio da Escala de Likert}

O ranking médio (OLIVEIRA, 2005) é uma maneira de avaliar a resposta, de acordo com as notas obtidas, para situar em que porção do universo de respostas está àquela específica assertiva. O processo para obtenção do ranking médio, demonstrado na Tabela 4.3, consiste em multiplicar o número de respostas de cada assertiva pelo valor da nota e dividir este resultado pelo número de respostas.

Exemplificando este processo:

Tabela 3.2 - Tabela de exemplo para cálculo do ranking médio.

\begin{tabular}{llllll}
\hline Conceito sobre a assertiva & CT & C & I & D & DT \\
Intervalo de notas & 5 & 4 & 3 & 2 & 1 \\
\hline Freqüência de ocorrência & 220 & 167 & 27 & 13 & 6
\end{tabular}




$$
\begin{aligned}
& R M=\left[\frac{\left(n_{C T} * 5\right)+\left(n_{C} * 4\right)+\left(n_{I} * 3\right)+\left(n_{D} * 2\right)+\left(n_{D T} * 1\right)}{\left(n_{C T}+n_{C}+n_{I}+n_{D}+n_{D T}\right)}\right] \Rightarrow \\
& R M=\frac{[(220 * 5)+(167 * 4)+(27 * 3)+(13 * 2)+(6 * 1)]}{(220+167+27+13+6)} \Rightarrow \\
& \therefore R M=4,344
\end{aligned}
$$

\subsection{Um Processo de Avaliação Multicritério para Mensurar a Opinião de Indivíduos Utilizando a Comparação.}

Conforme Silva e Wayt (2004), os processos de decisão buscam um ou múltiplos objetivos e, assim, a avaliação é baseada em um ou múltiplos critérios. Desta maneira é comum que diversos critérios tenham que ser avaliados e combinados, em um processo decisório. O método que se utiliza nesta busca é chamado de Avaliação Multicritério.

Malczewski (1999) apud Costa (2001) identifica uma série de elementos que estruturam um processo de decisão, dentre eles:

- Objetivo ou conjunto de objetivos que devem ser atingidos;

- Decisor ou grupo de decisores envolvidos no processo e suas preferências no que diz respeito aos critérios de avaliação;

- Conjunto de critérios de avaliação (elementos e/ou atributos)om base nos quais os decisores irão avaliar as alternativas de ação;

- Conjunto de alternativas de decisão ou variáveis de ação;

- Conjunto de variáveis externas ou fora do controle dos decisores (estados da natureza);

- Conjunto de conseqüências ou resultados associados a cada uma das alternativas (KEENEY e RAIFFA 1976; PITZ e MCKILLIP, 1984 apud COSTA, 2001). 
Segundo Pomeranz (1992) apud Lisboa (2002), o método de multicritérios é definido conforme as seguintes etapas:

- Formulação de alternativas;

- Escolha de critérios e indicadores;

- Avaliação das alternativas segundo os critérios e indicadores escolhidos (avaliação parcial);

- Agregação das avaliações parciais.

- Através da avaliação parcial aprecia-se o grau de alcance dos objetivos do projeto expressos pelos critérios.

O cerne da questão em problemas com múltiplos critérios é a adequada atribuição de pesos às variáveis estudadas, de maneira que os decisores tenham a garantia de que a sua opinião concreta sobre cada uma das questões avaliadas seja mantida.

\subsubsection{Justificativas do Método}

A utilização de um método de análise multicritério justifica-se, pois, segundo Vincke (1992) apud Lisboa (2002), ela fornece ao tomador de decisão algumas ferramentas de forma a capacitá-lo a avançar na solução de problemas de decisão onde diversos, geralmente contraditórios, pontos de vista e critérios devem ser considerados.

As externalidades, que se expressam principalmente através de custos sociais provocados pela atividade econômica e não ressarcidos como, por exemplo, a poluição, não são captadas pelo mercado, porque não estão sujeitas a preços ou compensações financeiras (LISBOA, 2002).

Segundo Saaty (1980), apesar do dinheiro servir como base de medida para todos os bens e serviços, e apesar da evolução desta unidade de medida (o dinheiro) ter contribuído para a estruturação da teoria econômica, a própria teoria enfrenta problemas ao tratar de algumas questões políticas e sociais de 
difícil, ou mesmo impossível, transformação em valores monetários. Valores sociais nas sociedades modernas requerem métodos de medição que permitam avaliar, cotidianamente, relações entre dinheiro, meio ambiente, saúde, felicidade e outras questões similares. $\mathrm{O}$ autor conclui afirmando que a teoria dos Métodos de Decisão Multicritério de Auxílio à Tomada de Decisão tem o propósito de modelar tais problemas.

Ozernoy (1994) apud Lisboa (2002) reconhece que a seleção da metodologia mais apropriada dentre os diversos Métodos Multicritério é por si própria um problema multicriterial de decisão, que não possui uma solução óbvia. Muitos métodos podem ser úteis para um determinado problema de decisão, entretanto, diferentes métodos geralmente representam diferentes formas de aproximação para a tomada de decisão. A seleção depende do problema particular considerado, das preferências pessoais do tomador de decisão e de muitos outros fatores. Estes métodos são difíceis de classificar, avaliar e comparar, porque são baseados numa variedade de suposições sobre as preferências do tomador de decisão e utilizam deferentes tipos de informações de preferência.

Ramanathan (2001) apud Lisboa (2002) afirma que é sabido que outros métodos "multicritério" também podem ser aplicados, conforme se verifica em Saaty (1980), porém aponta as seguintes vantagens do MAH sobre os outros métodos:

- É geralmente mais flexível;

- Permite uma ação intuitiva dos tomadores de decisão; e permite uma fácil verificação da consistência dos julgamentos.

Assim, o autor conclui que o MAH pode ser uma ferramenta útil em uma análise sistemática de opiniões de diversos grupos de especialistas pertencentes a diversos campos dos estudos de avaliação ambiental.

Estas aplicações mostram que o $\mathrm{MAH}$, na teoria e na prática, fornece uma estrutura flexível, aproximando da realidade as tomadas de decisão em sistemas complexos. 
A grande vantagem do MAH é que ele permite aos seus usuários atribuir pesos relativos para múltiplos critérios (ou múltiplas alternativas para um dado critério) de forma intuitiva, ao mesmo tempo em que realiza uma comparação par a par entre os mesmos. Isso permite que, mesmo quando duas variáveis sejam incomparáveis, a mente humana poderá ainda assim reconhecer qual dos critérios é mais importante do que o outro (SAATY, 1980).

Muitos métodos para a definição de pesos podem ser encontrados na literatura (SAATY, 1980). Entre os métodos mais utilizados estão os baseados no ordenamento dos critérios; os baseados em escalas de pontos; os baseados na distribuição de pontos e os baseados em comparações de critérios par a par.

Com base na revisão bibliográfica, êste estudo foi adotada a comparação par a par como método para a definição dos pesos dos benefícios para a sociedade na implantação de um sistema de transporte público sobre trilhos.

\subsubsection{Método de Análise Hierárquica - MAH}

A metodologia de comparação par a par constitui uma ferramenta promissora para a obtenção de pesos para vários critérios. A técnica denominada de Processo Analítico Hierárquico (Analytic Hierarchy Process,) foi desenvolvida na Wharton School of Business pelo matemático Thomas Saaty (SAATY 1980), com o objetivo de facilitar a solução de problemas complexos relacionados à tomada de decisão. A teoria foi desenvolvida para um problema específico de planejamento de contingência, em 1972, e depois, numa aplicação maior, para projetos futuros alternativos do Sudão, em 1977. Por meio desta, pesos e prioridades são derivados a partir de um conjunto de julgamentos subjetivos realizados por avaliadores ou participantes envolvidos no processo. 
Esta técnica baseia-se em uma matriz quadrada $\mathrm{n} \times \mathrm{n}$ de comparação de n critérios, onde estes são dispostos na mesma ordem ao longo das linhas e das colunas.

A difusão e a aplicabilidade do MAH se devem principalmente à reunião de características como a simplicidade na aplicação, à naturalidade no trato de aspectos subjetivos e a flexibilidade de uso.

Para Saaty (1980), os princípios básicos do pensamento analítico são: a estruturação hierárquica, a obtenção de prioridades e a consistência lógica. Todas essas três qualidades então presentes neste método, uma vez que o método procura reproduzir o raciocínio humano na avaliação comparativa dos elementos de um conjunto, com base na percepção de analistas. A aplicação do método produz como resultado a atribuição de pesos numéricos a metas e alternativas, através da comparação dos elementos, par a par. Os objetivos e as alternativas que contribuem para alcançá-los são estruturados hierarquicamente. No nível mais alto da hierarquia deve ser colocado o objetivo geral, logo abaixo objetivos intermediários, e sucessivamente até chegar ao nível das atividades através das quais se pretende alcançar o objetivo. A partir dessa estrutura, ou árvore hierárquica, são montadas matrizes para comparação dos elementos de cada nível.

$\mathrm{O} \mathrm{MAH}$ incorpora conceitos importantes largamente aceitos no contexto da decisão multicritério. São eles:

\section{a) Estruturação de sistemas complexos em hierarquias}

Através da psicologia, provou-se que o cérebro humano tem um limite de sete itens quer na sua capacidade de memória de curto período quer na capacidade de discriminação. Para lidar com situações mais complexas e ultrapassar esta limitação, estrutura as entidades em hierarquias ou agrupamentos lógicos. Como exemplo: quando nos é pedido a memorização de uma seqüência de números, como um número de telefone, a atitude mais freqüente é fazer agrupamentos de dois ou três algarismos; 
Quanto à estruturação hierárquica, segundo SAATY (1980), os seres humanos têm uma grande habilidade de perceber fatos e idéias, identificá-los e comunicar o que observam. Usualmente, é possível avaliar entre seis e nove alternativas ao mesmo tempo. Além disto, na aplicação do método não se utiliza mais do que nove critérios de avaliação conjuntamente.

A aplicação do MAH requer a estruturação do problema em hierarquia, assim, o sistema a ser analisado deverá ser dividido em subsistemas (grupos de critérios e indicadores), onde o tomador de decisão deve definir um objetivo global único e selecionar os critérios e indicadores para atingir este objetivo. Todos os elementos deverão estar estruturados hierarquicamente ou em formato de árvore invertida.

Estruturar a hierarquia de um sistema ou problema traz diversas vantagens para o seu entendimento, diagnóstico e decisão, dado que a representação hierárquica pode ser usada para descrever como mudanças em prioridades nos níveis mais altos afetam a prioridade dos níveis mais baixos e também permite uma visão geral de atores e de seus propósitos nos níveis mais altos.

b) Comparações relativas de pares de critérios

As comparações relativas são muito mais fáceis de fazer que julgamentos absolutos. Por exemplo, é difícil decidir qual dos 14 critérios é aquele com mais peso na decisão, e depois fazer o mesmo para os restantes. É muito mais fácil fazer comparações dois a dois entre todos os critérios.

No MAH estabelece-se uma relação entre cada nível da hierarquia pela comparação dos critérios/indicadores aos pares. Essa relação representa o impacto relativo dos critérios/indicadores de um dado nível com cada critério/indicador do nível acima mais próximo. Essa comparação par a par é então repetida para todos os critérios/indicadores em cada nível. O resultado desse processo discriminatório é um vetor das prioridades relativas dos pesos 
dos critério/indicadores de decisão, em cada nível ou grupo. O último estágio consiste em consolidar as prioridades relativas até o nível das alternativas, ou seja, relacionar todos os pesos, propagando o efeito dos pesos na estrutura até o nível das alternativas. A tomada da decisão é dada pela classificação das alternativas em análise, ordenadas relativamente ao objetivo global.

Entretanto, para se calcular as prioridades é preciso haver um método prático que gere uma escala de mensuração. Com isso a metodologia utiliza números para representar a variação de julgamentos. As avaliações são organizadas em matrizes de comparação paritária.

O preenchimento dos dados na matriz de comparação paritária requer o entendimento de alguns conceitos:

Um elemento é igualmente importante quando comparado com ele mesmo. Portanto ao compararmos o elemento A com o elemento $A$ o fator comparativo é igual a 1. Desta forma, a diagonal da matriz sempre será preenchida por 1.

Ao compararmos um elemento com outro e depois o segundo com o primeiro os fatores comparativos são inversos entre si, isto é, ao compararmos o elemento A com o elemento $B$, poderemos obter o fator comparativo de 2 , por exemplo, e ao compararmos o elemento B com o elemento A teremos, consequentemente, o fator comparativo $1 / 2$.

Em uma Matriz de Comparação Paritária, cada par de critérios é julgado apenas uma única vez. Desta forma, tem-se $[n(n-1) / 2]$ julgamentos para cada grupo de $n$ elementos.

Para a determinação dos pesos, elabora-se uma matriz quadrada em que os seus elementos refletem comparações entre pares de critérios. Por exemplo, o elemento aij reflete a comparação entre o critério $i$ e o critério $j$. Estas comparações apresentam-se na forma de médias que quantificam a importância que um critério tem sobre outro na tomada de decisão. Saaty elaborou uma escala de comparações contínua, com nove pontos (SAATY, 1980), analisando estudos desenvolvidos por Ernest Heinrich Weber (1795- 
1878), Gustav Theodor Fechner (1801-1887) e Stanley Smith Steven (19061973), importantes autores do assunto "Estímulo e Respostas", associando-os aos estudos de Yoram Wind com os de A. Miller, e estabeleceu a tabela de fatores apresentados nas Tabelas 3.3 e 3.4:

Tabela 3.3 - Escala de Comparação Contínua. Adaptado de SAATY (1980).

\begin{tabular}{|c|c|c|}
\hline $\begin{array}{l}\text { Intensidade de } \\
\text { Importância }\end{array}$ & Definição & Explicação \\
\hline 1 & Importância igual. & $\begin{array}{l}\text { Duas ações potenciais Contribuem } \\
\text { igualmente para o objetivo. }\end{array}$ \\
\hline 3 & $\begin{array}{l}\text { Importância fraca de uma } \\
\text { sobre a outra. }\end{array}$ & $\begin{array}{l}\text { A experiência e o julgamento favorecem } \\
\text { levemente uma atividade em relação à } \\
\text { outra. }\end{array}$ \\
\hline 5 & Importância forte. & $\begin{array}{l}\text { A experiência e o julgamento favorecem } \\
\text { fortemente uma atividade em relação à } \\
\text { outra. }\end{array}$ \\
\hline 7 & Importância muito forte. & $\begin{array}{l}\text { Uma atividade é fortemente favorecida em } \\
\text { relação à outra e sua dominância é } \\
\text { demonstrada na prática. }\end{array}$ \\
\hline 9 & Importância absoluta. & $\begin{array}{l}\text { A evidência favorecendo uma atividade em } \\
\text { relação à outra é do mais alto grau de } \\
\text { certeza. }\end{array}$ \\
\hline $2,4,6,8$ & $\begin{array}{l}\text { Valores intermediários } \\
\text { Entre dois julgamentos } \\
\text { Adjacentes. }\end{array}$ & $\begin{array}{l}\text { Quando é necessária uma } \\
\text { condição de compromisso. }\end{array}$ \\
\hline $\begin{array}{l}\text { Valores } \\
\text { recíprocos aos } \\
\text { anteriores }\end{array}$ & $\begin{array}{l}\text { Se um critério } i \text { possui ur } \\
\text { critério } j \text {, então o critério } \\
\text { o critério } i \text {. }\end{array}$ & $\begin{array}{l}\text { valores inferiores quando comparado com c } \\
\text { ui o valor recíproco quando comparado com }\end{array}$ \\
\hline
\end{tabular}

Tabela 3.4 - Escala de comparação de critérios, adaptado de COSTA (2003).

\begin{tabular}{lllllllll}
\hline MENOS IMPORTANTE & \multicolumn{6}{c}{ MAIS IMPORTANTE } \\
\hline Extremamente & Bastante & Muito & Pouco & Igual & Pouco & Muito & Bastante & Extremamente \\
$1 / 9$ & $1 / 7$ & $1 / 5$ & $1 / 3$ & 1 & 3 & 5 & 7 & 9 \\
\hline
\end{tabular}

Assim, se o critério $i$ for ligeiramente mais importante que o critério $j$, ao elemento aij será atribuído o valor 3 na escala. Como é evidente, o elemento aji terá o valor $1 / 3$, isto é, o critério j é ligeiramente menos importante que o critério $i$.

c) Construção da matriz de comparação par a par. 
Para efeito de exemplo prático utilizaremos uma tabela montada para este fim específico, conforme a tabela 5.3.

Tabela 3.5 - Matriz de Comparação par a par, adaptado de COSTA (2003).

\begin{tabular}{l|l|l|l|l|l|l}
\hline & Critério 1 & Critério 2 & Critério 3 & Critério 4 & Critério 5 & Critério 6 \\
\hline Critério 1 & $\mathbf{1}$ & $1 / 2$ & 2 & 2 & 3 & 1 \\
Critério 2 & 2 & $\mathbf{1}$ & 4 & 4 & 6 & 2 \\
Critério 3 & $1 / 2$ & $1 / 4$ & $\mathbf{1}$ & 1 & 2 & $1 / 2$ \\
Critério 4 & $1 / 2$ & $1 / 4$ & 1 & $\mathbf{1}$ & 2 & $1 / 2$ \\
Critério 5 & $1 / 3$ & $1 / 6$ & $1 / 2$ & $1 / 2$ & $\mathbf{1}$ & $1 / 3$ \\
Critério 6 & 1 & $1 / 2$ & 2 & 2 & 3 & $\mathbf{1}$ \\
\hline
\end{tabular}

Uma vez preenchidas todas as matrizes de comparações paritárias, o próximo passo é determinar as prioridades relativas de pesos dos elementos de cada matriz em relação ao elemento correspondente de seu nível hierárquico superior. A prioridade relativa calculada para cada elemento deve ter um valor entre 0 e 1. Para cada grupo de critérios / indicadores de decisão, a soma total dos pesos deve resultar no valor unitário.

O MAH utiliza o método do autovetor para determinar os pesos dos elementos de um grupo. Este método consta em:

- Somar o total de cada coluna da matriz de comparações; normalizar a matriz, dividindo cada elemento pelo total da sua respectiva coluna;

- Calcular a média aritmética de cada linha da matriz normalizada.

A média de cada linha é a estimativa de prioridades dos critérios de decisão de cada linha. O conjunto destas médias é o autovetor dos critérios/indicadores de decisão de cada grupo. O mesmo processo deve ser aplicado para cada matriz de comparações, abrangendo toda a estrutura hierárquica do problema em questão.

Para qualquer matriz $\mathrm{A}$ pode-se calcular o vetor $w_{i}$ pela resolução do sistema da equação abaixo:

$$
A_{w}=\lambda_{\max }{ }^{*} w \text {, onde: }
$$

$A_{w}$ é a matriz de comparação par a par; 
$w$ é o vetor de pesos pretendidos, e

$\lambda_{\text {Max }}$ é o máximo autovetor da matriz $\mathrm{A}$.

O autovetor resultante do máximo autovalor da matriz $A$, segundo Saaty (1980), traduz a prioridade dos fatores e preserva a preferência ordinal entre duas alternativas. Os valores do vetor $w$ podem, então, ser obtidos pela equação a seguir:

$W_{i}=\left(\prod_{j=1}^{n} a_{i j}\right)^{1 / n} \div \sum_{j=1}^{n}\left[\left(\prod_{j=1}^{n} a_{i j}\right)^{1 / n}\right]$

O máximo autovalor é dado por:

$\lambda_{\text {max }}=\frac{1}{n}\left(\frac{w_{1}^{\prime}}{w_{1}}+\frac{w_{2}^{\prime}}{w_{2}}+\frac{w_{3}^{\prime}}{w_{3}}+\Lambda+\frac{w_{n}^{\prime}}{w_{n}}\right)$

O vetor $w$ 'é obtido com a seguinte fórmula:

$W^{\prime}=A^{*} W$, onde:

A é a matriz de comparação par a par, e

$w$ é o vetor de pesos encontrado na etapa anterior

Utilizando-se das fórmulas apresentadas obtém-se $\lambda_{\max }=6,01703$

\subsubsection{Consistência Lógica das Comparações de Critérios}

O terceiro princípio do pensamento analítico é a consistência lógica. Nesse sentido, o ser humano tem a habilidade de estabelecer relações entre objetos ou idéias, de tal forma a buscar uma coerência entre eles, ou seja, de relacioná-los entre si e avaliar sua consistência.

No MAH usa-se a redundância entre comparações de critérios para reduzir os erros provenientes de uma comparação menos acertada e para 
produzir um índice de consistência dessas comparações que, em última análise, pode validar ou não essas comparações.

O método MAH permite trabalhar com a subjetividade das preferências. Entretanto, a qualidade da decisão final depende da consistência dos julgamentos entre os pares de elementos. Os elementos são fatores de decisão que compõem uma matriz de comparações paritárias e podem ser subobjetivos, critérios ou alternativas utilizadas na árvore hierárquica do $\mathrm{MAH}$. Uma matriz de comparações paritárias é consistente, se os seus elementos respeitarem a relação de transitividade aik. akj = aij.

A recomendação do MAH para reduzir o alto nível de inconsistência é a revisão dos julgamentos da matriz de comparações paritária correspondente. Caso a inconsistência persista, duas hipóteses devem ser consideradas: o conhecimento dos fatores de decisão é insuficiente ou estes fatores não são regidos pela relação de transitividade.

\subsubsection{Cálculo do grau de consistência RC}

O Índice de Consistência (IC) de uma matriz de comparações paritárias (A) $\mathrm{n} \times \mathrm{n}$ é usado para mostrar quanto o valor $\lambda_{\max }$ desta matriz está afastado de seu valor esperado. O valor teórico esperado de $\lambda_{\max }$ é $n$, portanto o desvio é dado por: $\lambda_{\max }-3$.

Esta diferença é medida relativamente ao número dos graus de liberdade desta matriz (n-1). Como a matriz é um conjunto de julgamentos relativos entre os próprios $n$ elementos, resultam que a matriz tem $n-1$ graus de liberdade. Assim, pode-se definir o índice de consistência de uma matriz de comparações paritárias como um valor não negativo, conforme a fórmula abaixo:

$$
I C=\frac{\left(\lambda_{\max }\right)-1}{n-1}
$$


O valor de RC deveria ser chamado de Índice de Inconsistência, pois quanto maior o número, maior a inconsistência. Saaty (1994) apud Lisboa (2002), afirma que o RC deve ser pequeno para que as matrizes de comparações paritárias tenham o mínimo de consistência. $E$ que esta inconsistência deve ser de uma ordem de grandeza de, no máximo, 10 vezes, o que implica estar na faixa dos $10 \%$. Se fosse maior, a matriz não toleraria as inconsistências dos julgamentos, o que reduziria a naturalidade do processo.

Portanto, a medida da consistência de uma matriz de comparações paritárias é dada pela Razão de Consistência (RC). Este indicador fornece ao decisor a necessidade, ou não, de revisão dos julgamentos para cada matriz de comparações do problema. Esta razão é expressa da seguinte forma:

$$
R C=\frac{I C}{R I}
$$

Saaty (1980) propôs valores para $R /$ através do cálculo dos valores médios de $\mathrm{Cl}$ obtidos para matrizes recíprocas geradas aleatoriamente. $\mathrm{A}$ tabela 5.4 apresenta os valores obtidos:

Tabela 3.6 - Índice de Aleatoriedade, adaptado de Saaty (1980).

\begin{tabular}{llllll}
\hline $\mathbf{N}$ & $\mathbf{R I}$ & $\mathbf{n}$ & $\mathbf{R I}$ & $\mathbf{n}$ & $\mathbf{R I}$ \\
\hline 1 & 0,00 & 6 & 1,24 & 11 & 1,51 \\
2 & 0,00 & 7 & 1,32 & 12 & 1,48 \\
3 & 0,58 & 8 & 1,41 & 13 & 1,56 \\
4 & 0,90 & 9 & 1,45 & 14 & 1,57 \\
5 & 1,12 & 10 & 1,49 & 15 & 1,59 \\
\hline
\end{tabular}

Desta forma, com todos os elementos apresentados, obtém-se $C R=$ $0,003405 / 1,24=0,00275$. Este valor de CR, para a tabela de exemplo 5.3, é um execelente resultado, muito abaixo de 0,1 , ou seja, $10 \%$ máximo de inconsitência.

Todas as matrizes devem ser verificadas de forma análoga. Com este procedimento, assegura-se um nível tolerável de inconsistência dentro da estrutura hierárquica. 
Cabe destacar que a tabela possui valores nulos de IR para $n=1$ e $n=2$, pois para haver comparações é necessário mais de um elemento, portanto para $\mathrm{n}=1$ esta tarefa é impossível. Com 2 elementos já é possível comparar, porém, para detectar inconsistências internas é necessário um terceiro elemento, de redundância, para fornecer a referência da inconsistência. Com isto, a tabela inicia-se com $n=3$.

$\mathrm{Na}$ ocorrência de $\mathrm{RC}$ maior que 0,1 uma reavaliação da matriz de comparação par a par é necessária. 


\section{Capítulo 4 - Estudo de Caso}

\subsection{Estudo com a População}

O tratamento das variáveis características, do ponto de vista de usuários, é relativamente difícil porque em cada caso (FELEX, 1983):

- Há que se decidir sobre quais as variáveis interferem no sujeito analisado;

- Levantar dados sobre estas variáveis que na maioria das vezes, são qualitativas e dependem da caracterização do usuário, e;

- Tratar de estudar as inter-relações entre os conjuntos de variáveis envolvidos.

Para estudos que incluem variáveis que possam se alterar com as variações de comportamentos humanos dever-se-á ter em conta que as dificuldades se devem às interferências em resultados atribuídas ao pesquisador e ao processo de levantamento de dados, que poderão modificar e condicionar as respostas às questões sob análise. Por exemplo: no levantamento de dados por entrevistas a usuários a simples escolha das palavras que constam nos questionários alteram as distribuições de respostas obtidas (FELEX, 1983).

Uma caracterização deste exemplo é quando uma pesquisa que avalia o transporte sobre trilhos enfoca unicamente o Metrô de São Paulo ou o sistema 
de transporte sobre trilhos como um todo. Para as pesquisas que enfocam unicamente o Metrô de São Paulo o grau de exigência dos usuários é mais alto e, conseqüentemente, as respostas são mais críticas ao sistema do que quando a pesquisa enfoca o sistema sobre trilhos de uma forma genérica (metrô e subúrbio).

Os tipos de pesquisas de opinião mais utilizados em transportes são (ANTP, 1997):

- Avaliação de serviços: levantamento das opiniões e avaliação do usuário sobre serviços ou aspectos específicos de serviço;

- Avaliação de imagem: levantamento "do como" a população e os usuários "vêem" ou "percebem" os serviços de transporte coletivo, levando em conta não somente sua opinião sobre o desempenho operacional destes serviços, mas também sobre as próprias empresas operadoras em nível institucional;

- Pesquisa sobre expectativas: levantamento expectativas sobre o transporte pelos usuários, uma função de serviços ou equipamentos a serem implantados, como novas linhas, trechos, estações ou terminais.

- Pesquisas sobre impactos: levantamento de efeitos causados por implantação ou alterações em serviços de transporte, através de opiniões e avaliação de aceitação pela população e grupos afetados, verificação do como as intervenções são percebidas e absorvidas.

As pesquisas de opinião e entrevistas têm limitações, pois:

- A interação entre entrevistados pode gerar distorções ou omissão de respostas devido à inibição, desconfiança ou intimidação;

- A opinião do usuário depende do acesso que ele tem a informação e do interesse que ele tem pelo problema em questão, o que varia conforme a posição do indivíduo na sociedade, entre outros fatores. 
Segundo ANTP (1996), os resultados de pesquisas sobre transportes fornecem aos órgãos gestores e às empresas operadoras embasamento para tomada de decisão e intervenções concretas no sistema, como, por exemplo: diagnóstico de operação do serviço; elaboração de programas e planos, com determinação de diretrizes e metas a serem desenvolvidas; definição de políticas de relacionamento com o usuário; subsídios para treinamento de empregados; ajuste de indicadores e padrões de desempenho; e outros. Em médio prazo, é importante ressaltar que os resultados de pesquisas contribuem para formação de uma massa crítica com embasamento teórico, entre técnicos do segmento, modificando o bom senso e a visão empírica de cada um.

\subsubsection{O Levantamento de Dados}

A abrangência da pesquisa realizada neste trabalho é de toda a Região Metropolitana de São Paulo - RMSP, haja vista a influência do transporte sobre trilhos.

Para a RMSP, com uma população aproximada de 20 milhões de habitantes, uma pesquisa para avaliação dos benefícios para a sociedade deveria, seguindo os preceitos científicos da estatística, ser aplicada a uma população de aproximadamente 2300 pessoas, utilizando-se de procedimentos adequados para a validação da pesquisa como instrumento efetivo na determinação da percepção da sociedade com relação aos objetivos do trabalho. No entanto, dada as dificuldades de condução de uma pesquisa deste porte, principalmente devido ao alto custo, optou-se pela realização de uma pesquisa exploratória, aplicada a população de alunos de graduação em campi universitários na RMSP. Esta forma de aplicação pôde, então, diminuir o custo da pesquisa, mas, por outro lado, os resultados devem ser olhados apenas como "sinalizadores". 
Existem, contudo premissas que devem ser seguidas. A literatura sobre o assunto, mais especificamente Hair et al. (1985), determina que o tamanho mínimo de amostras, utilizando a escala de Likert, deve ser de, pelo menos, quatro a cinco vezes o número de assertivas.

A pesquisa exploratória foi conduzida nos meses de maio a junho de 2008, nos seguintes locais:

- Campus da FATEC SCS, na cidade de São Caetano do Sul;

- Campus da UniABC, na cidade de Santo André;

- Campus da Uninove, na cidade de Osasco;

- Campus da Uninove, no bairro de Santana, São Paulo;

- Campus da Uninove, no bairro da Vila Mariana, São Paulo;

- Campus da FATEC ZL, no bairro de Artur Alvim, São Paulo;

- Campus da Anhembi Morumbi, no bairro da Vila Olímpia, São Paulo.

O questionário de pesquisa (Apêndice I), preenchido pelo próprio respondente, tem algumas questões sobre a situação sócio-demográfica do respondente e, em seguida, a avaliação propriamente dita das assertivas com relação ao objeto de estudo, os benefícios do transporte público sobre trilhos na cidade de São Paulo.

Os valores obtidos a partir da aplicação dos questionários encontram-se no Apêndice II. De maneira a facilitar o processamento dos dados algumas abreviações, ou siglas, foram utilizadas no questionário, a saber:

Dados sócio-econômicos:

- $\mathrm{S} 1$ - Sexo, sendo

$\checkmark$ f-feminino;

$\checkmark \mathrm{m}-$ masculino.

- $\quad$ S2 - Freqüência semanal de uso do transporte sobre trilhos, sendo:

$\checkmark \quad 0$ - Não utiliza; 
$\checkmark \quad 1$ a 7 - Número de dias na semana que utiliza;

$\checkmark$ F - Utiliza somente aos finais de semana.

- S3 - Idade, sendo

$\checkmark 1-17$ a 19 anos;

$\checkmark 2-20$ a 24 anos;

$\checkmark 3-25$ a 29 anos;

$\checkmark \quad 4-30$ a 39 anos;

$\checkmark 5-40$ a 49 anos;

$\checkmark 6-50$ a 59 anos;

$\checkmark 7$ - Acima de 60 anos.

- S4 - Rendimento, sendo:

$\checkmark 0$-Sem rendimento;

$\checkmark 1$ - até $\mathrm{R} \$ 415,00$;

$\checkmark 2$ - de $\mathrm{R} \$ 415,00$ a $\mathrm{R} \$ 830,00$;

$\checkmark 3$ - de $\mathrm{R} \$ 830,00$ a $\mathrm{R} \$ 1245,00$;

$\checkmark 4$-de $\mathrm{R} \$ 1245,00$ a $\mathrm{R} \$ 2075,00$;

$\checkmark 5$ - de $\mathrm{R} \$ 2075,00$ a $\mathrm{R} \$ 4150,00$;

$\checkmark 6$ - de $\mathrm{R} \$ 4150,00$ a $\mathrm{R} \$ 8300,00$;

$\checkmark 7$ - acima de $\mathrm{R} \$ 8300,00$.

- S5 - Ocupação, sendo:

$\checkmark 1$ - Membros das forças armadas, policiais e bombeiros militares;

$\checkmark 2$ - Membros superiores do poder público, dirigentes de organizações de interesse público, de empresas e gerentes;

$\checkmark 3$-Ocupações mal especificadas;

$\checkmark 4$ - Profissionais das ciências e das artes;

$\checkmark 5$ - Trabalhadores dos serviços, vendedores do comércio em lojas e mercados;

$\checkmark 6$ - Trabalhadores de serviços administrativos;

$\checkmark 7$ - Trabalhadores em serviços de reparação e manutenção;

$\checkmark 8$ - Trabalhadores da produção de bens e serviços industriais; 
$\checkmark 9$ - Técnicos de nível médio.

Assertivas sobre os benefícios do transporte público sobre trilhos:

- V1 - Diminuição do trânsito devido ao uso do Transporte sobre Trilhos;

- V2 - Aumento da qualidade de vida devido a diminuição da poluição do ar, sonora, visual e dano ecológico;

- V3 - Economia do dinheiro público devido a baixos investimentos em construção e manutenção de vias públicas;

- V4 - Acesso aos serviços públicos com maior eficiência (hospitais, repartições públicas, etc);

- V5 - Melhora a economia da cidade e dos centros regionais;

- V6 - Uso das fontes de petróleo com eficiência devido ao menor consumo em função do uso do transporte público;

- V7 - Redução no custo dos acidentes de trânsito e danos provocados por eles.

A caracterização de usuário ou não do sistema é feita em função do número de vezes de utilização na semana. Os utilizadores com freqüência maior ou igual a três vezes na semana é considerado usuário.

\subsubsection{Sobre a Pesquisa Exploratória}

O termo pesquisa exploratória é utilizado nas mais diversas áreas, desde a saúde até o marketing. Ela tem por objetivo proporcionar familiaridade com o objeto de estudo e permitir a construção de hipóteses. A pesquisa exploratória também é utilizada para a aquisição de dados de maneira que o problema a ser estudado tenha a sua condição de contorno adequadamente estabelecida. 
A pesquisa exploratória procura conhecer as características de um fenômeno para encontrar explicações das causas e conseqüências do mesmo. Por exemplo, estudar as reações de um grupo de consumidores ao lançamento de um novo produto, ou então descobrir quais as variáveis que são avaliadas pelo consumidor na escolha ou na preferência de determinada marca. Ela visa prover o pesquisador de um conhecimento mais profundo sobre o tema ou problema de pesquisa em perspectiva, por isso é apropriada para os primeiros estágios da investigação, quando a familiaridade, o conhecimento e a compreensão do fenômeno por parte do pesquisador são, geralmente, insuficientes.

Resumindo, a pesquisa exploratória pode ser usada para os seguintes objetivos (REVILLION, 2003):

- Familiarizar e elevar a compreensão de um problema de pesquisa em perspectiva;

- Ajudar no desenvolvimento ou criação de hipóteses explicativas de fatos a serem verificados numa pesquisa causal;

- Auxiliar na determinação de variáveis a serem consideradas num problema de pesquisa;

- Verificar se pesquisas semelhantes já foram realizadas, quais os métodos utilizados e quais os resultados obtidos, determinar tendências, identificar relações potenciais entre variáveis e estabelecer rumos para investigações posteriores mais rigorosas;

- Investigar problemas do comportamento humano, identificar conceitos ou variáveis e sugerir hipóteses verificáveis.

Considerando o ineditismo da pesquisa conduzida neste trabalho, de medir a percepção da sociedade com relação aos benefícios do transporte público sobre trilhos, a adoção de um modelo de pesquisa exploratória parece ser adequado, dado que desta maneira as hipóteses sobre o problema podem ser apresentadas. 


\subsubsection{Resultados do Questionário}

A pesquisa exploratória sobre a opinião da sociedade com relação aos benefícios obtidos pelos não usuários do transporte público sobre trilhos, com a implantação de sistemas deste tipo, utilizando-se as premissas apresentadas por Tyson (1991), foi realizada de maio a junho de 2008, nos laocais mostrados nas Figuras 4.1 e 4.2. Os dados obtidos com a pesquisa exploratória estão disponíveis no Apêndice C.

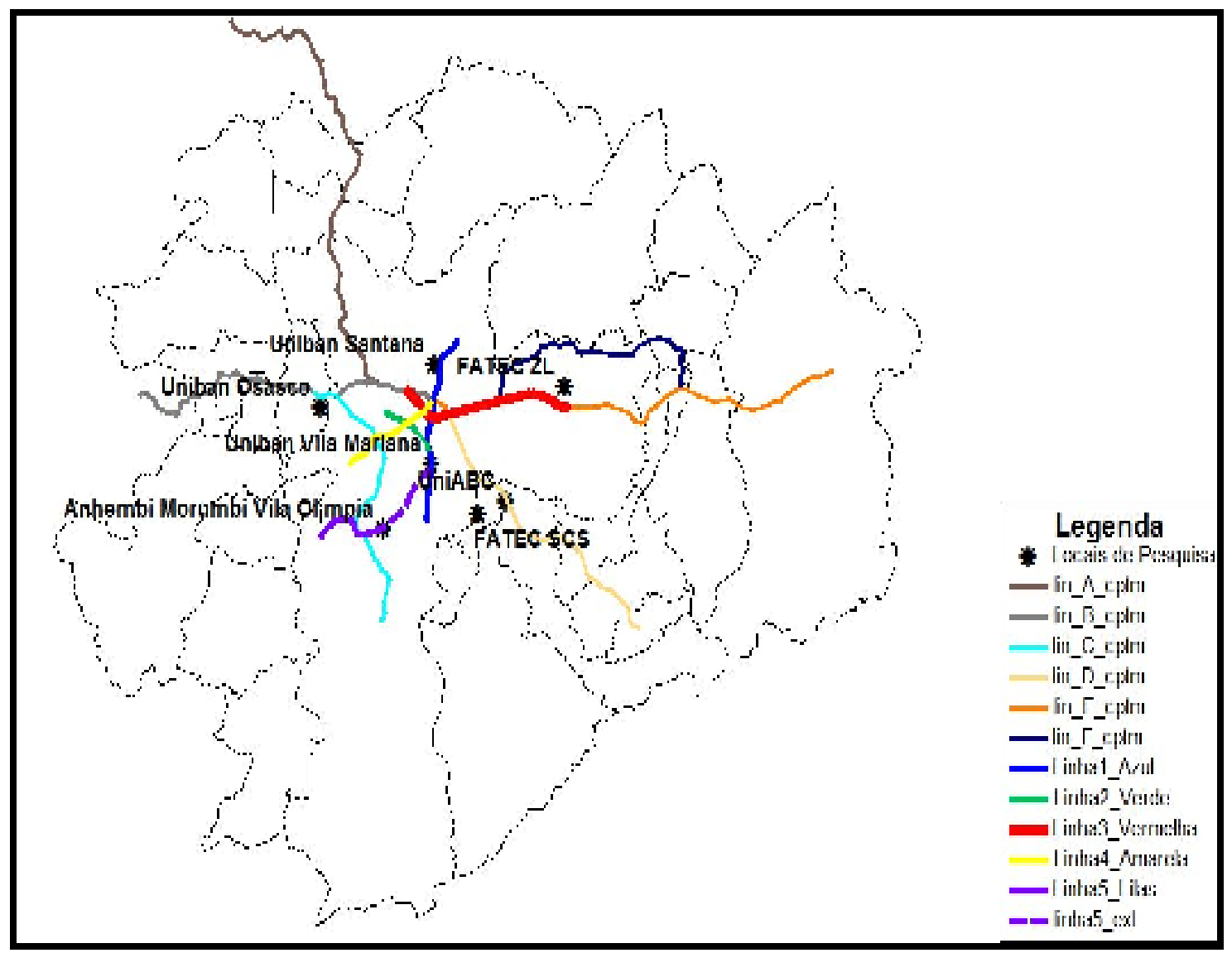

Figura 4.1 - Distribuição das Pesquisas na RMSP. 


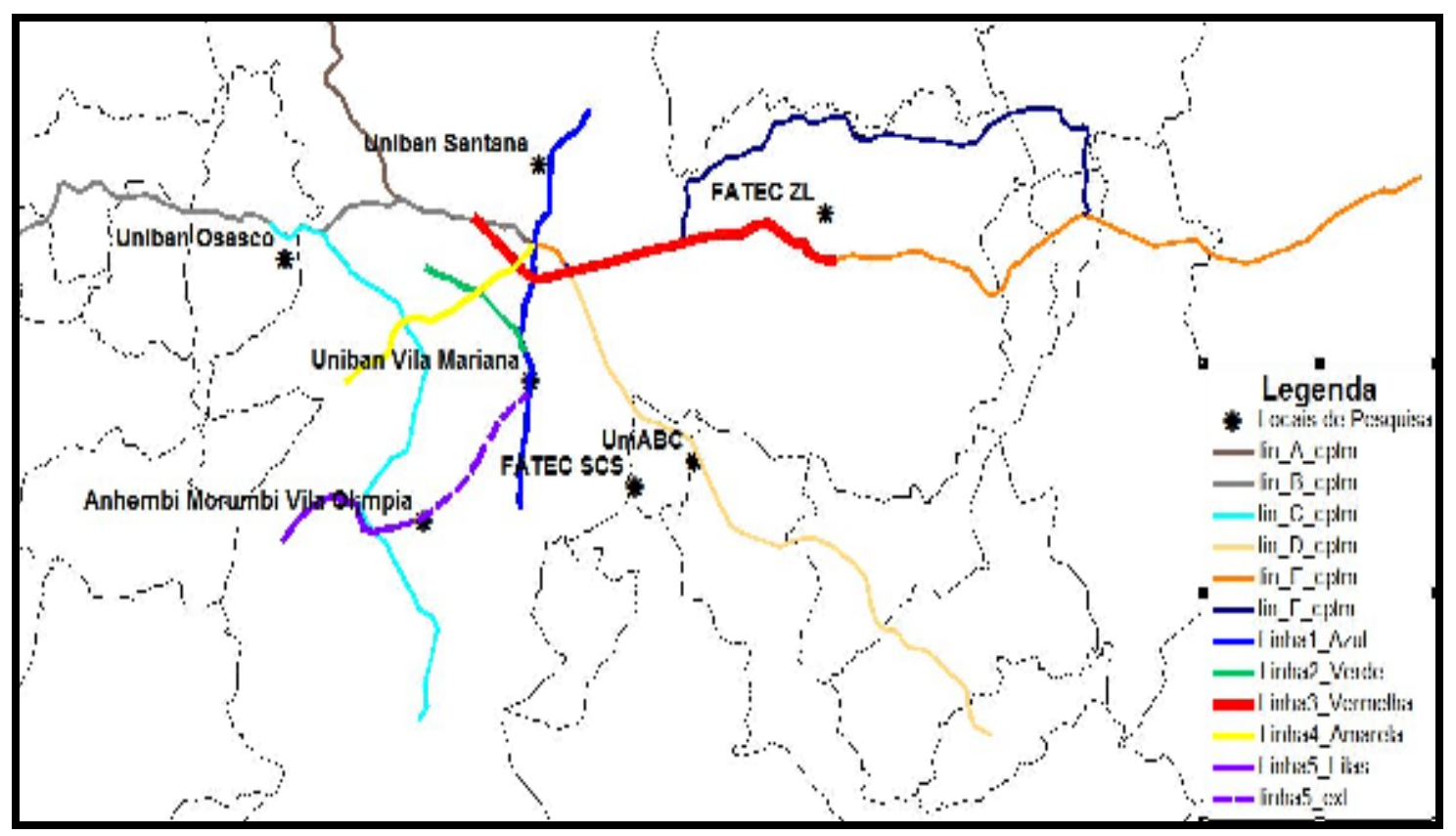

Figura 4.2 - Detalhe dos locais de Pesquisa e proximidade com os meios de transporte sobre trilhos.

\subsubsection{Dados Sócio-Econômicos dos Entrevistados}

Os dados sócio econômicos obtidos na pesquisa exploratória são apresentados nas figuras 4.3 a 4.8 .

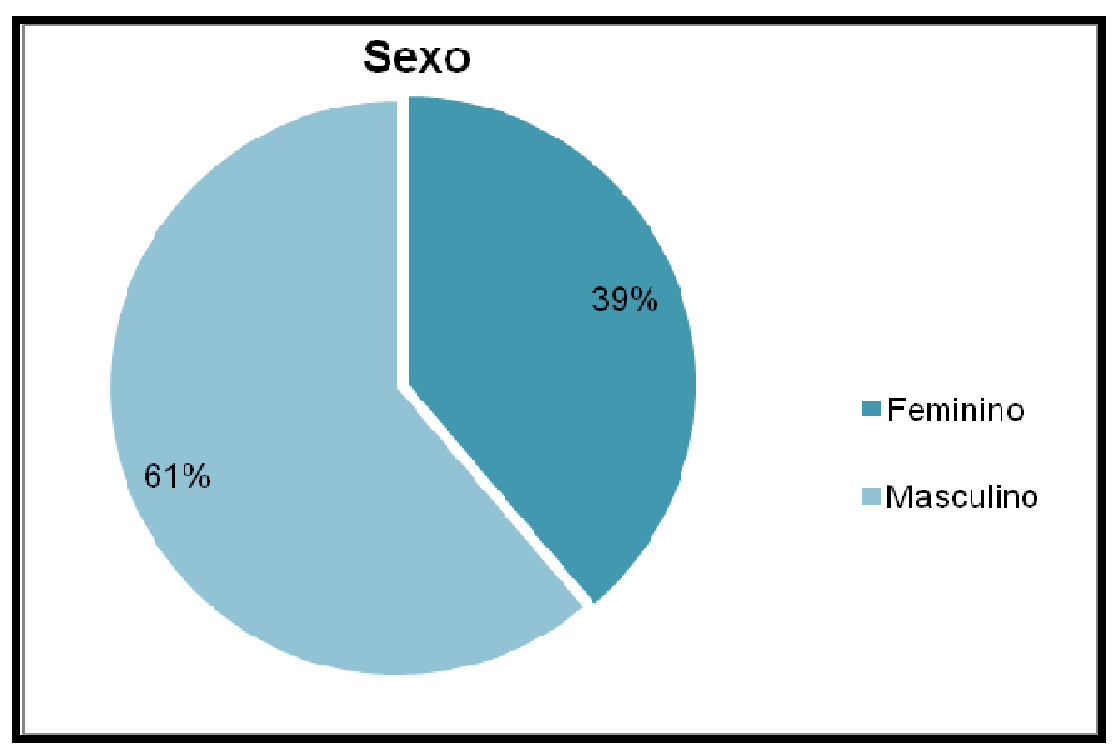

Figura 4.3 - Distribuição da amostra pesquisada por sexo. 


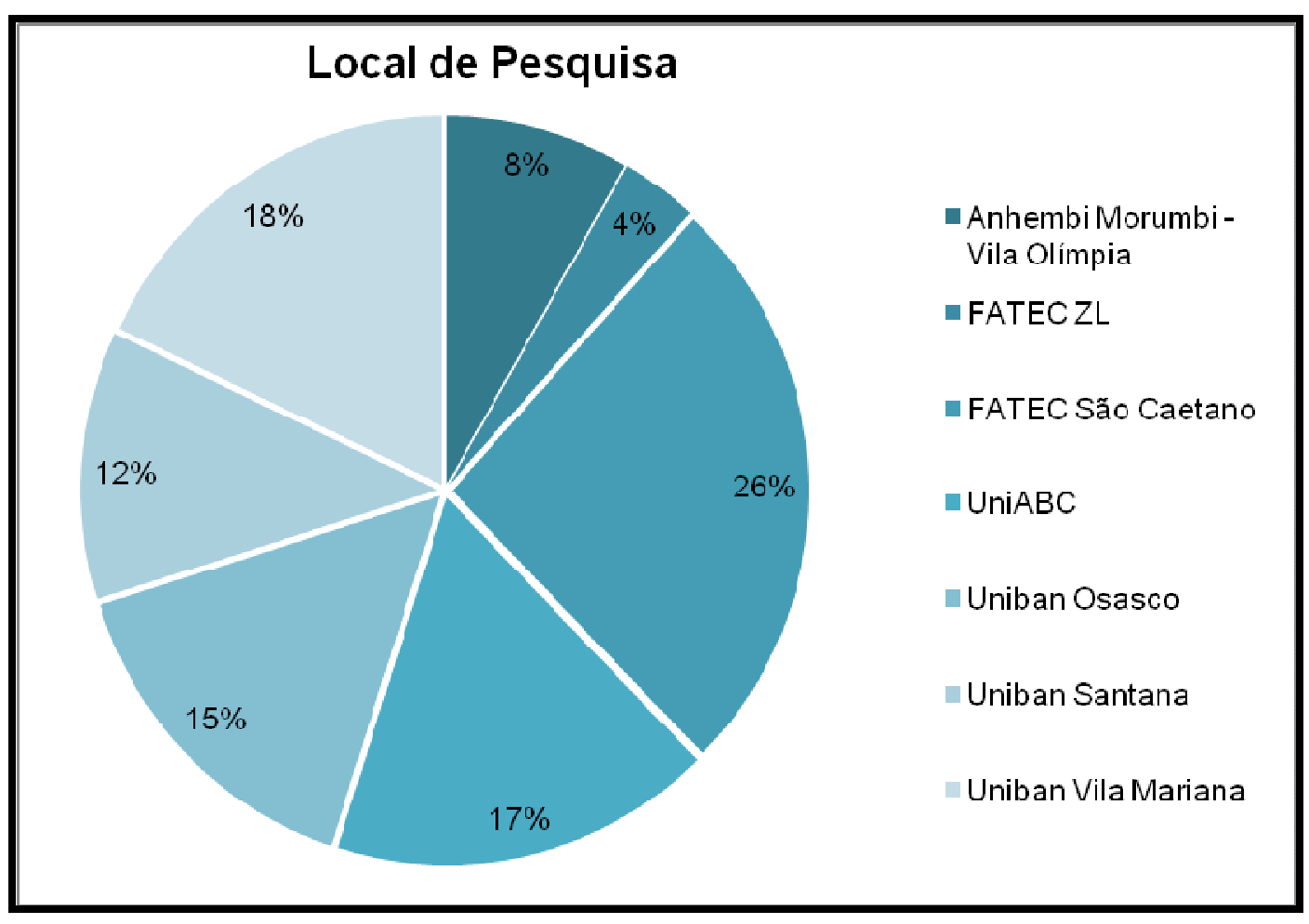

Figura 4.4 - Distribuição da amostra por local de pesquisa.

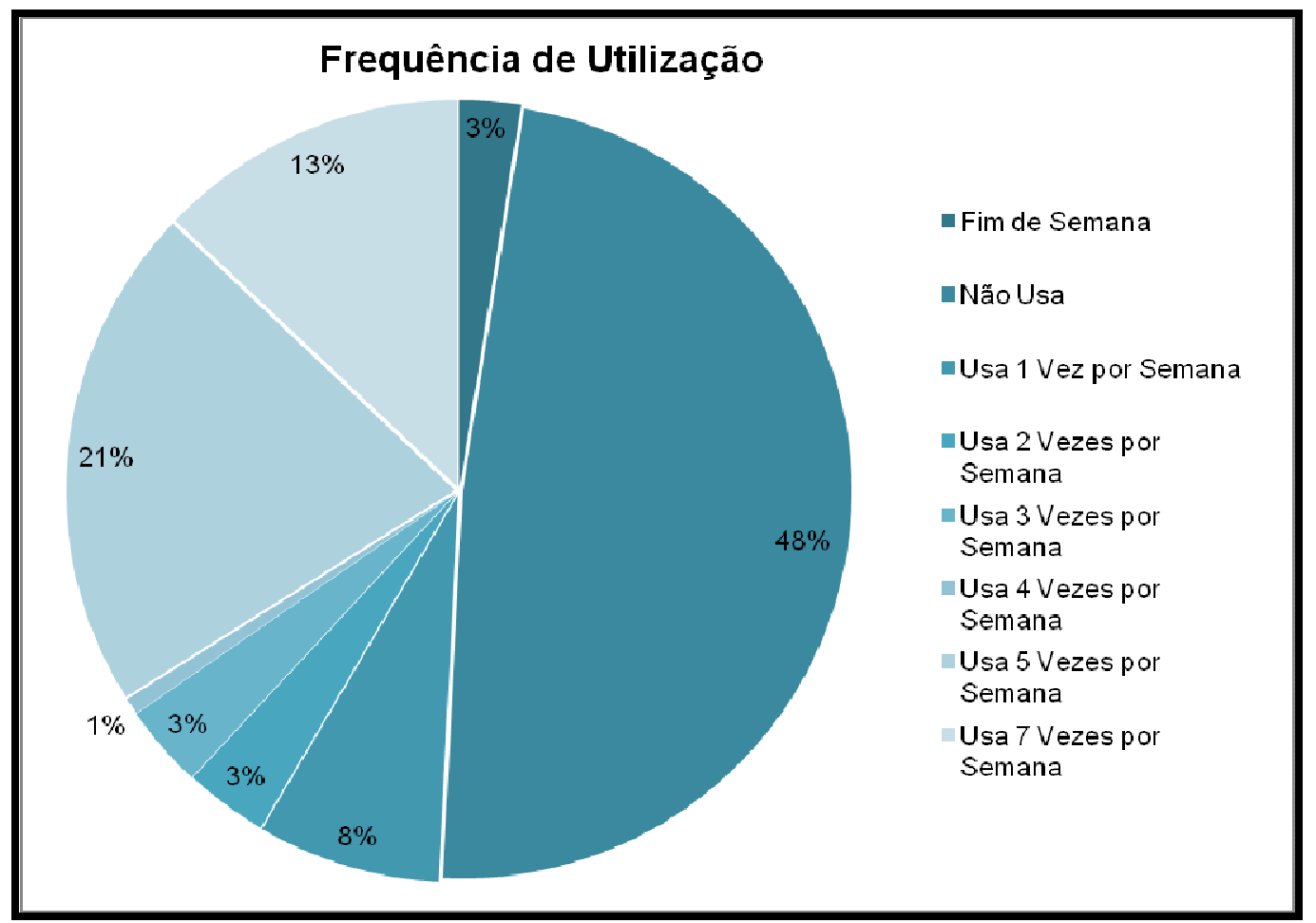

Figura 4.5 - Distribuição da freqüência de utilização do sistema de transporte sobre trilhos da amostra pesquisada. 


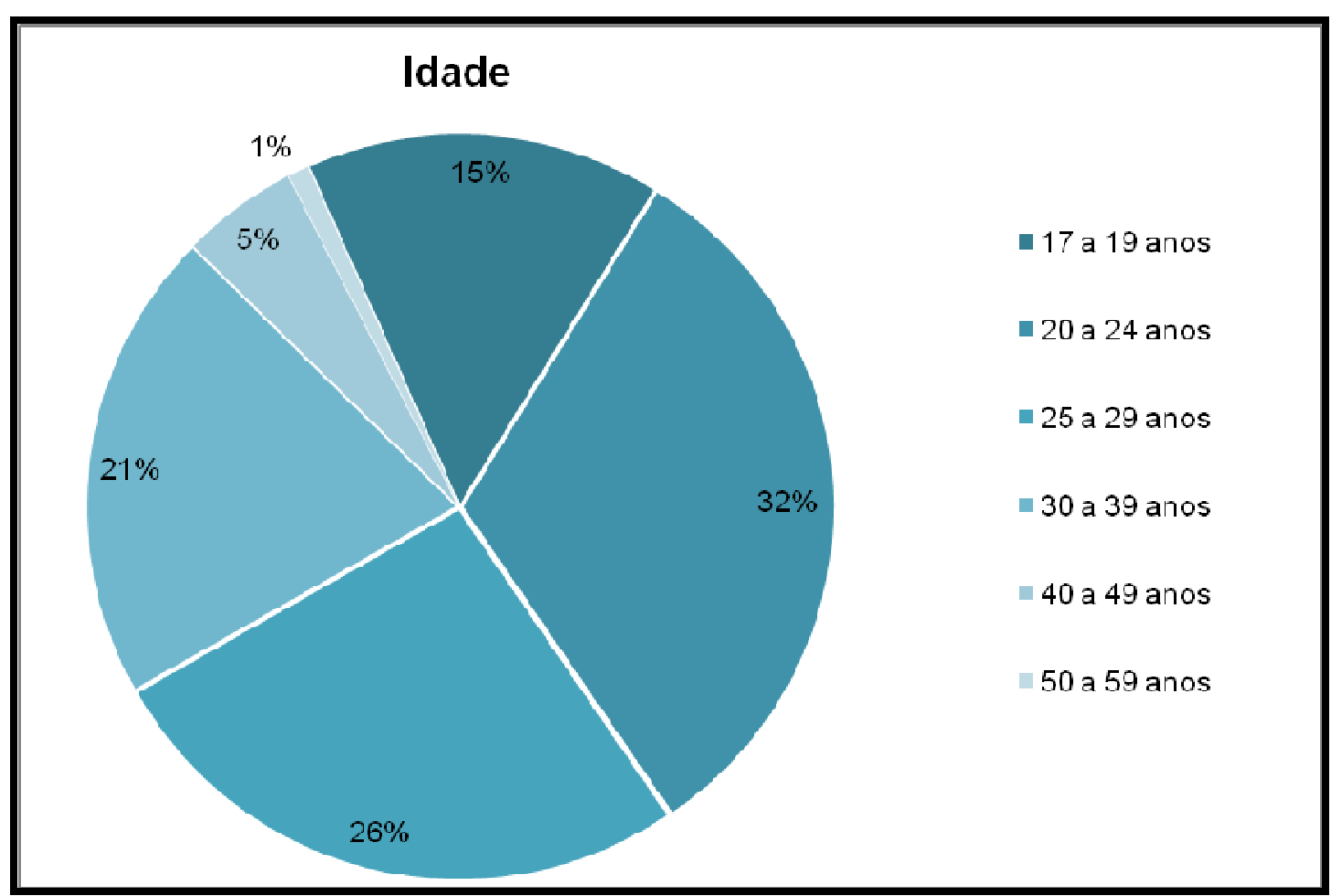

Figura 4.6 - Distribuição da idade na amostra pesquisada.

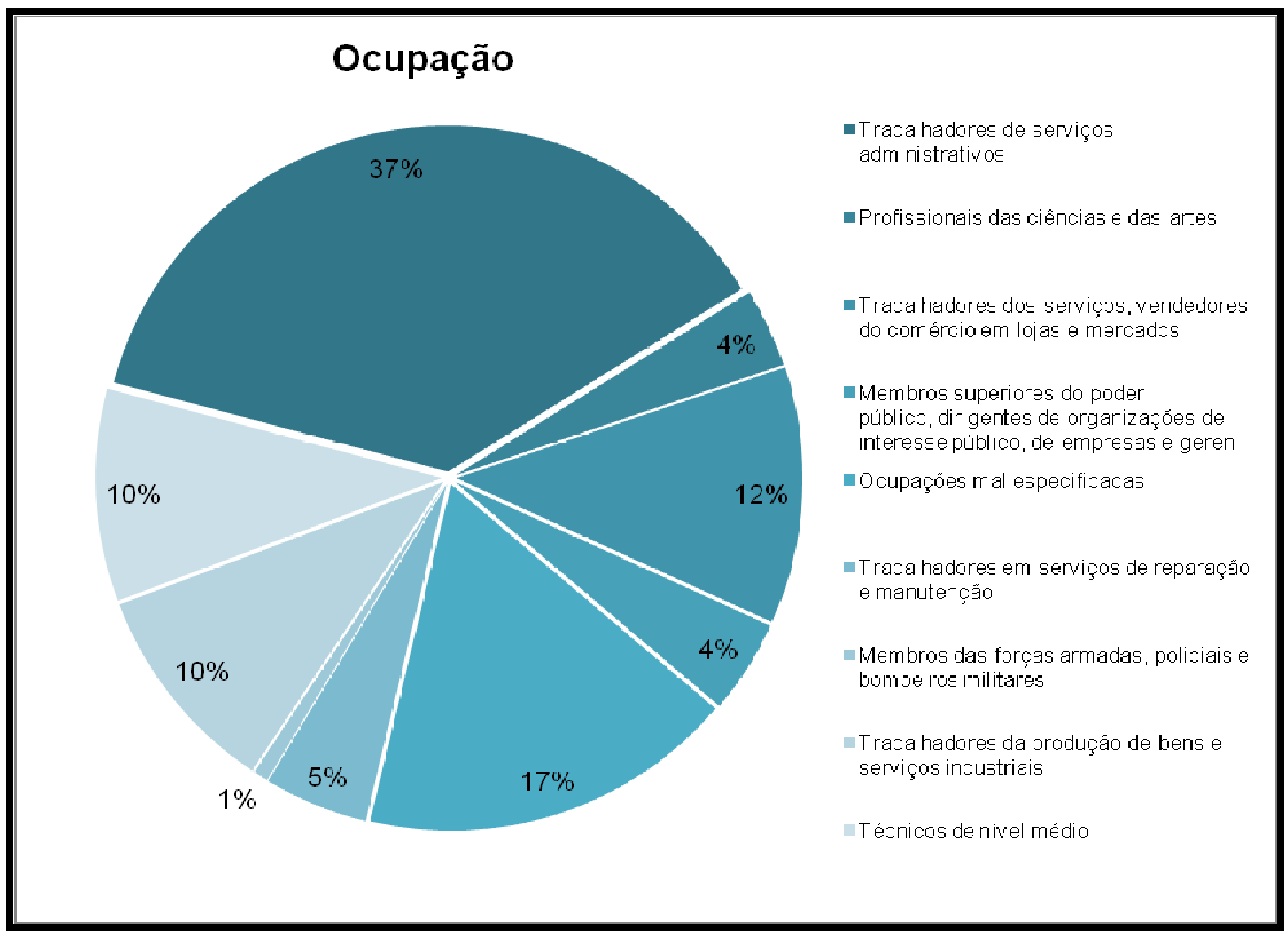

Figura 4.7 - Distribuição da amostra pesquisada por ocupação. 


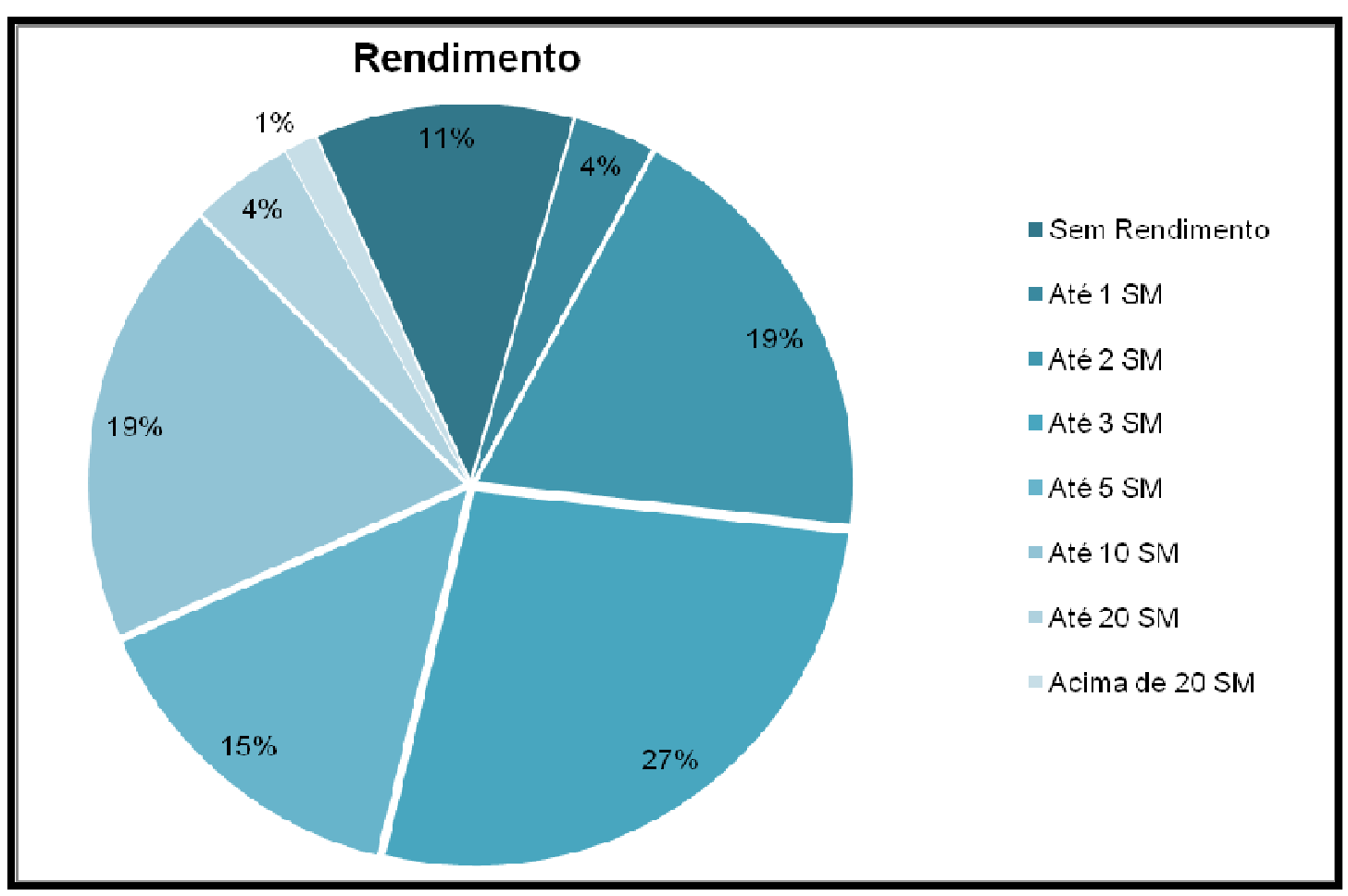

Figura 4.8 - Distribuição do rendimento na amostra pesquisada.

\subsection{3..2 Ranking Médio}

O ranking médio (OLIVEIRA, 2005), é apresentado no capítulo referente a estatística envolvida na avaliação dos dados coletados junto a população. $\mathrm{O}$ ranking médio serve, então, para situar em que porção do universo de respostas está aquela específica assertiva. O processo para obtenção do ranking médio consiste em multiplicar o número de respostas de cada assertiva pelo valor da nota e dividir este resultado pelo número de respostas.

As variáveis analisadas, $\mathrm{V} 1$ a V7, são:

- V1 - Diminuição do trânsito devido ao uso do Transporte sobre Trilhos;

- V2 - Aumento da qualidade de vida devido a diminuição da poluição do ar, sonora, visual e dano ecológico;

- V3 - Economia do dinheiro público devido a baixos investimentos em construção e manutenção de vias públicas; 
- V4 - Acesso aos serviços públicos com maior eficiência (hospitais, repartições públicas, etc);

- V5 - Melhora a economia da cidade e dos centros regionais;

- V6 - Uso das fontes de petróleo com eficiência devido ao menor consumo em função do uso do transporte público;

- V7 - Redução no custo dos acidentes de trânsito e danos provocados por eles.

Os resultados do ranking médio foram calculados para os estratos da população pesquisada e apresentados na Tabela 4.1, conforme as informações sócio demográficas da pesquisa. Estes estratos são:

- Sexo;

- Local da Pesquisa;

- Idade;

- Freqüência semanal de uso do transporte sobre trilhos;

- Rendimento, e

- Ocupação.

Tabela 4.1 - Ranking Médio Obtido nas Notas dos Entrevistados.

\begin{tabular}{|c|c|c|c|c|c|c|c|}
\hline Variáveis & V1 & V2 & V3 & V4 & V5 & V6 & v7 \\
\hline Geral & 4,344 & 4,319 & 3,446 & 3,552 & 3,732 & 3,864 & 4,122 \\
\hline Masculino & 4,392 & 4,374 & 3,487 & 3,596 & 3,823 & 3,879 & 4,181 \\
\hline Feminino & 4,268 & 4,232 & 3,381 & 3,482 & 3,589 & 3,839 & 4,030 \\
\hline $\begin{array}{l}\text { Anhembi Morumbi Campus Vila } \\
\text { Olímpia - São Paulo }\end{array}$ & 4,583 & 4,389 & 3,472 & 3,611 & 4,111 & 4,083 & 4,306 \\
\hline $\begin{array}{c}\text { FATEC - Campus Zona Leste - } \\
\text { São Paulo }\end{array}$ & 4,667 & 4,600 & 3,467 & 3,533 & 4,000 & 4,333 & 4,267 \\
\hline $\begin{array}{c}\text { FATEC - Campus São Caetano } \\
\text { - São Caetano do Sul }\end{array}$ & 4,286 & 4,223 & 3,527 & 3,446 & 3,616 & 3,866 & 4,080 \\
\hline UniABC - Campus Santo André & 4,467 & 4,453 & 3,640 & 3,667 & 3,840 & 3,840 & 4,320 \\
\hline
\end{tabular}




\begin{tabular}{|c|c|c|c|c|c|c|c|}
\hline UNIBAN - Campus Osasco & 4,303 & 4,227 & 3,333 & 3,227 & 3,636 & 3,788 & 4,015 \\
\hline $\begin{array}{c}\text { UNIBAN - Campus Santana - } \\
\text { São Paulo }\end{array}$ & 4,098 & 4,235 & 3,020 & 3,529 & 3,647 & 3,843 & 3,843 \\
\hline $\begin{array}{l}\text { UNIBAN - Campus Vila } \\
\text { Mariana - São Paulo }\end{array}$ & 4,333 & 4,372 & 3,500 & 3,859 & 3,705 & 3,769 & 4,154 \\
\hline Idade -17 a 19 anos & 4,328 & 4,254 & 3,478 & 3,582 & 3,552 & 3,731 & 4,075 \\
\hline Idade - 20 a 24 anos & 4,314 & 4,255 & 3,307 & 3,423 & 3,759 & 3,832 & 4,044 \\
\hline Idade -25 a 29 anos & 4,307 & 4,316 & 3,316 & 3,596 & 3,614 & 3,868 & 4,123 \\
\hline Idade - 30 a 39 anos & 4,348 & 4,360 & 3,618 & 3,551 & 3,831 & 3,899 & 4,180 \\
\hline Idade -40 a 49 anos & 4,727 & 4,773 & 4,091 & 4,000 & 4,227 & 4,182 & 4,500 \\
\hline Idade - 50 a 59 anos & 4,500 & 4,250 & 4,000 & 3,750 & 4,250 & 4,500 & 4,250 \\
\hline $\begin{array}{l}\text { Usuário - Região Metropolitana } \\
\text { SP - Exceto Capital }\end{array}$ & 4,295 & 4,269 & 3,526 & 3,513 & 3,679 & 3,910 & 4,154 \\
\hline $\begin{array}{c}\text { Não Usuário - Região } \\
\text { Metropolitana SP - Exceto } \\
\text { Capital }\end{array}$ & 4,366 & 4,303 & 3,503 & 3,429 & 3,691 & 3,806 & 4,126 \\
\hline Usuário - São Paulo Capital & 4,299 & 4,391 & 3,333 & 3,770 & 3,851 & 3,897 & 4,126 \\
\hline $\begin{array}{c}\text { Não Usuário - São Paulo } \\
\text { Capital }\end{array}$ & 4,387 & 4,323 & 3,376 & 3,613 & 3,742 & 3,903 & 4,086 \\
\hline Sem Rendimento & 4,250 & 4,208 & 3,417 & 3,396 & 3,646 & 3,646 & 3,833 \\
\hline $\begin{array}{c}\text { Rendimento - Até } 1 \text { Salário } \\
\text { Mínimo }\end{array}$ & 4,267 & 4,333 & 3,600 & 3,667 & 4,133 & 3,867 & 4,400 \\
\hline $\begin{array}{c}\text { Rendimento - Até } 2 \text { Salários } \\
\text { Mínimos }\end{array}$ & 4,098 & 4,146 & 3,427 & 3,488 & 3,561 & 3,768 & 4,000 \\
\hline $\begin{array}{c}\text { Rendimento - Até } 3 \text { Salários } \\
\text { Mínimos }\end{array}$ & 4,427 & 4,393 & 3,316 & 3,556 & 3,692 & 3,846 & 4,239 \\
\hline $\begin{array}{c}\text { Rendimento - Até } 5 \text { Salários } \\
\text { Mínimos }\end{array}$ & 4,397 & 4,381 & 3,444 & 3,444 & 3,683 & 3,952 & 4,111 \\
\hline $\begin{array}{c}\text { Rendimento - Até } 10 \text { Salários } \\
\text { Mínimos }\end{array}$ & 4,422 & 4,325 & 3,590 & 3,723 & 3,916 & 3,940 & 4,241 \\
\hline $\begin{array}{c}\text { Rendimento - Até } 20 \text { Salários } \\
\text { Mínimos }\end{array}$ & 4,737 & 4,632 & 3,632 & 3,632 & 3,895 & 4,158 & 4,105 \\
\hline $\begin{array}{l}\text { Rendimento - Acima de } 20 \\
\text { Salários Mínimos }\end{array}$ & 4,167 & 4,333 & 3,500 & 3,833 & 4,000 & 4,333 & 3,667 \\
\hline
\end{tabular}




\begin{tabular}{|c|c|c|c|c|c|c|c|}
\hline $\begin{array}{l}\text { Ocupação - Trabalhadores de } \\
\text { serviços administrativos }\end{array}$ & 4,450 & 4,313 & 3,381 & 3,506 & 3,669 & 3,900 & 4,094 \\
\hline $\begin{array}{l}\text { Ocupação - Profissionais das } \\
\text { ciências e das artes }\end{array}$ & 4,375 & 4,438 & 3,875 & 3,688 & 3,875 & 3,750 & 4,000 \\
\hline $\begin{array}{l}\text { Ocupação - Trabalhadores dos } \\
\text { serviços, vendedores do } \\
\text { comércio em lojas e mercados }\end{array}$ & 4,192 & 4,385 & 3,404 & 3,500 & 3,692 & 3,712 & 4,115 \\
\hline $\begin{array}{c}\text { Ocupação - Membros } \\
\text { superiores do poder público, } \\
\text { dirigentes de organizações de } \\
\text { interesse público, de empresas } \\
\text { e gerentes }\end{array}$ & 4,318 & 4,409 & 3,818 & 3,909 & 3,864 & 3,955 & 4,045 \\
\hline Ocupações mal especificadas & 4,289 & 4,197 & 3,408 & 3,500 & 3,763 & 3,711 & 4,066 \\
\hline $\begin{array}{l}\text { Ocupação - Trabalhadores em } \\
\text { serviços de reparação e } \\
\text { manutenção }\end{array}$ & 4,190 & 4,333 & 2,952 & 3,143 & 3,619 & 3,714 & 4,095 \\
\hline $\begin{array}{l}\text { Ocupação - Trabalhadores da } \\
\text { produção de bens e serviços } \\
\text { industriais }\end{array}$ & 4,209 & 4,256 & 3,442 & 3,488 & 3,605 & 3,953 & 4,349 \\
\hline $\begin{array}{c}\text { Ocupação - Técnicos de nível } \\
\text { médio }\end{array}$ & 4,442 & 4,442 & 3,698 & 3,907 & 4,023 & 4,163 & 4,209 \\
\hline
\end{tabular}

O ranking médio também é apresentado de maneira gráfica, indicando qual a opinião dos entrevistados sobre cada uma das assertivas e em qual patamar de avaliação encontra-se a assertiva, nas Figuras 4.9 a 4.15. As figuras apresentam o ranking médio estratificado pela situação sócio demográfica (sexo, local de pesquisa, freqüência de utilização, idade, rendimento e ocupação). Em cada um dos gráficos estão apontados os valores máximo e mínimo do estrato estudado, com exceção do ranking médio geral, que tem todos os valores apresentados. 


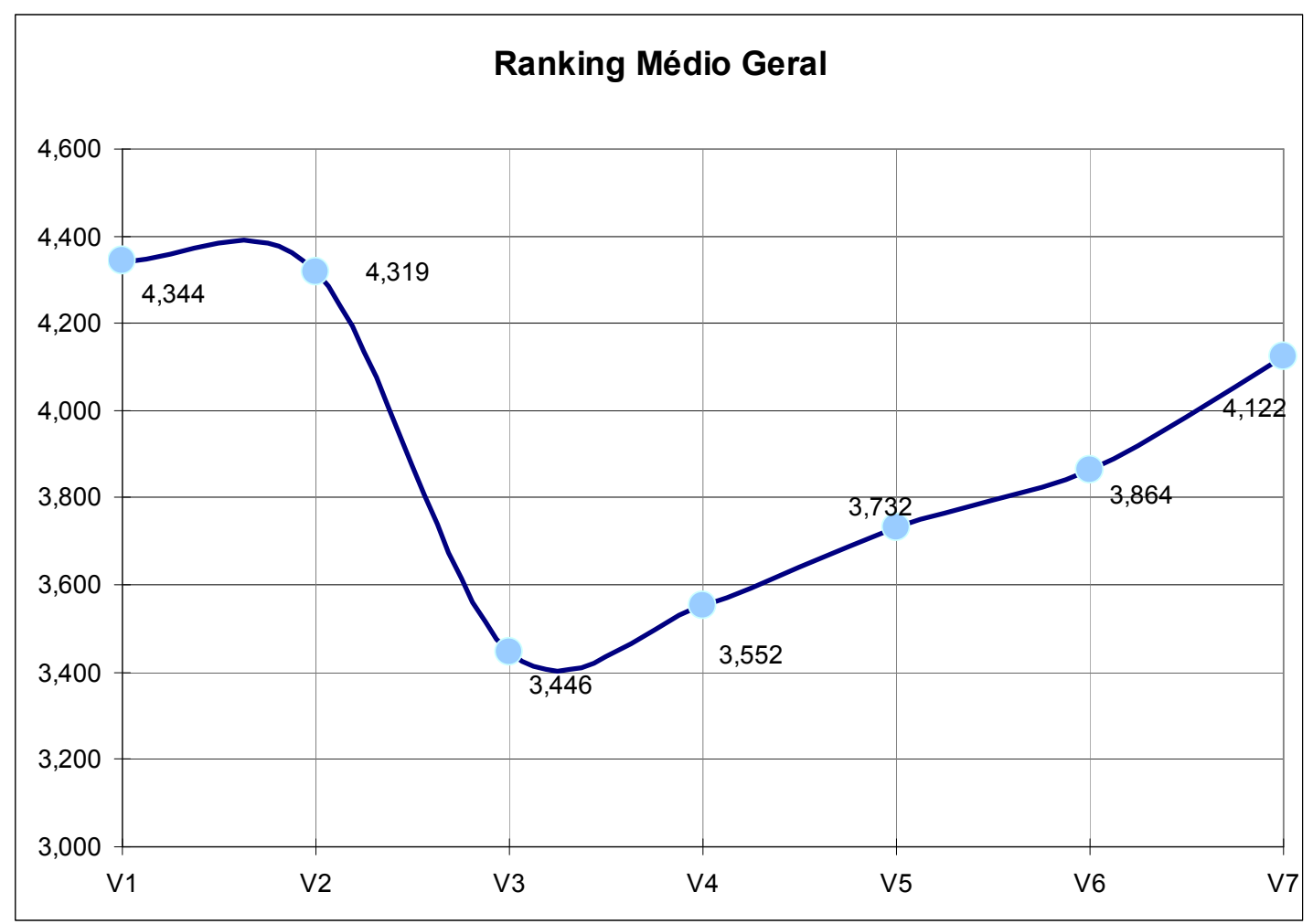

Figura 4.9 - Ranking Médio Geral.

A figura 4.9 mostra o ranking médio geral, resultado do cálculo utilizando todas as pesquisas. Esta avaliação mostra que em nenhuma das variáveis ocorreram valores abaixo de três (3), ou seja, o limiar da avaliação que indica "Indiferente" na concordância com a assertiva foi superado. A média alcançada em V1 - Diminuição do Trânsito é a mais alta, chegando a 4,344 e a média em V3 - Economia Dinheiro Público é a assertiva com pontuação mais baixa, igual a 3,446. Esta pontuação parece ter conexão com um descrédito da população com a adequada utilização do dinheiro público por parte dos administradores públicos. 


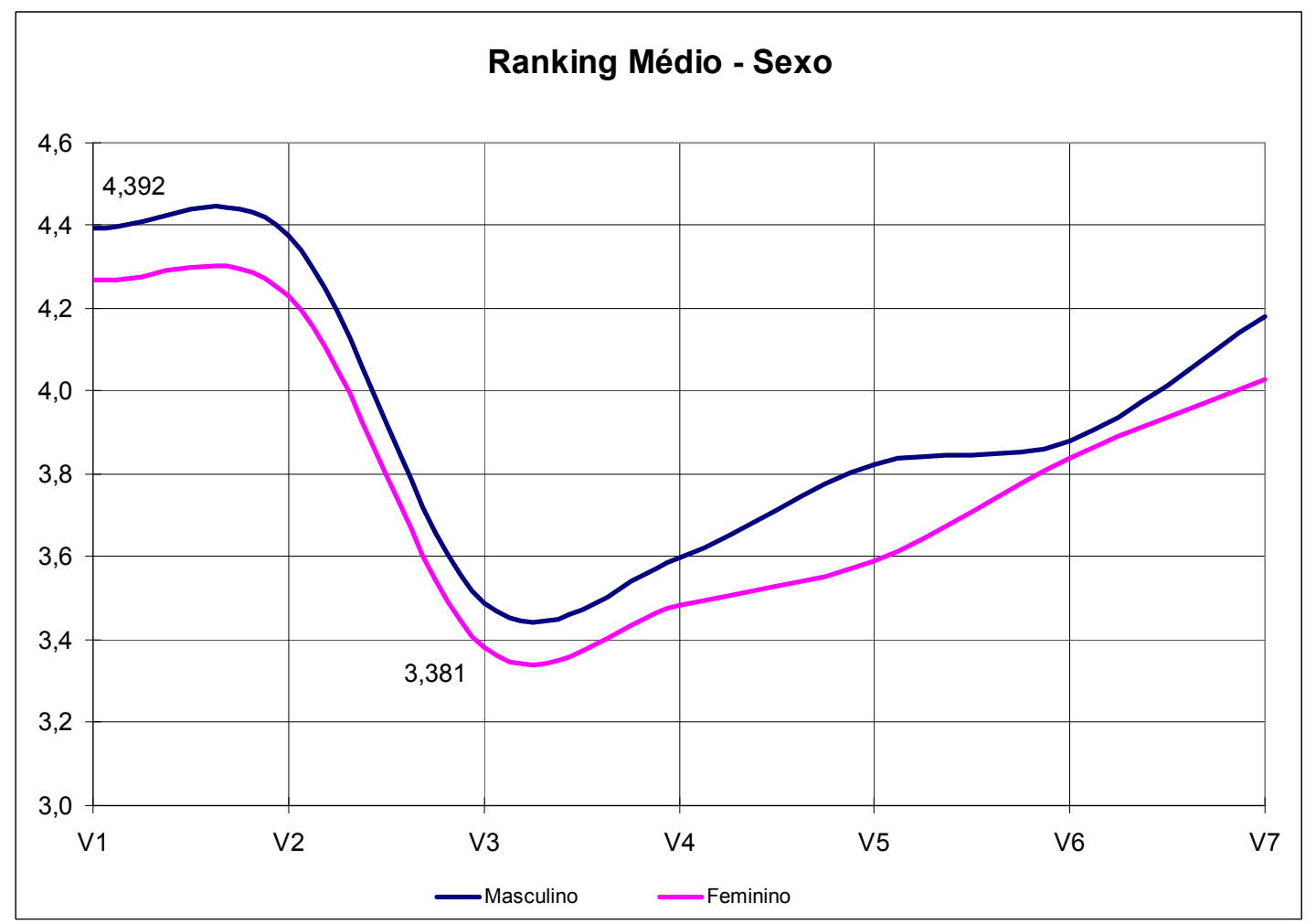

Figura 4.10 - Ranking Médio estratificado por sexo.

A figura 4.10 mostra que os dados obtidos pela estratificação por sexo dos pesquisados, mostra claramente que a opinião feminina é mais crítica com relação a todas as assertivas, uma vez que a curva representativa da opinião feminina permanece o tempo todo abaixo da curva que aponta os valores médios da opinião masculina. Os valores de máximo e mínimo seguem o padrão do ranking médio, com 4,392 pontos na assertiva $\mathrm{V} 1$ e 3,381 pontos na assertiva V3 e também seguindo o padrão do valor mínimo estar acima do limiar de avaliação "Indiferente", com seu corte na linha de três pontos. 


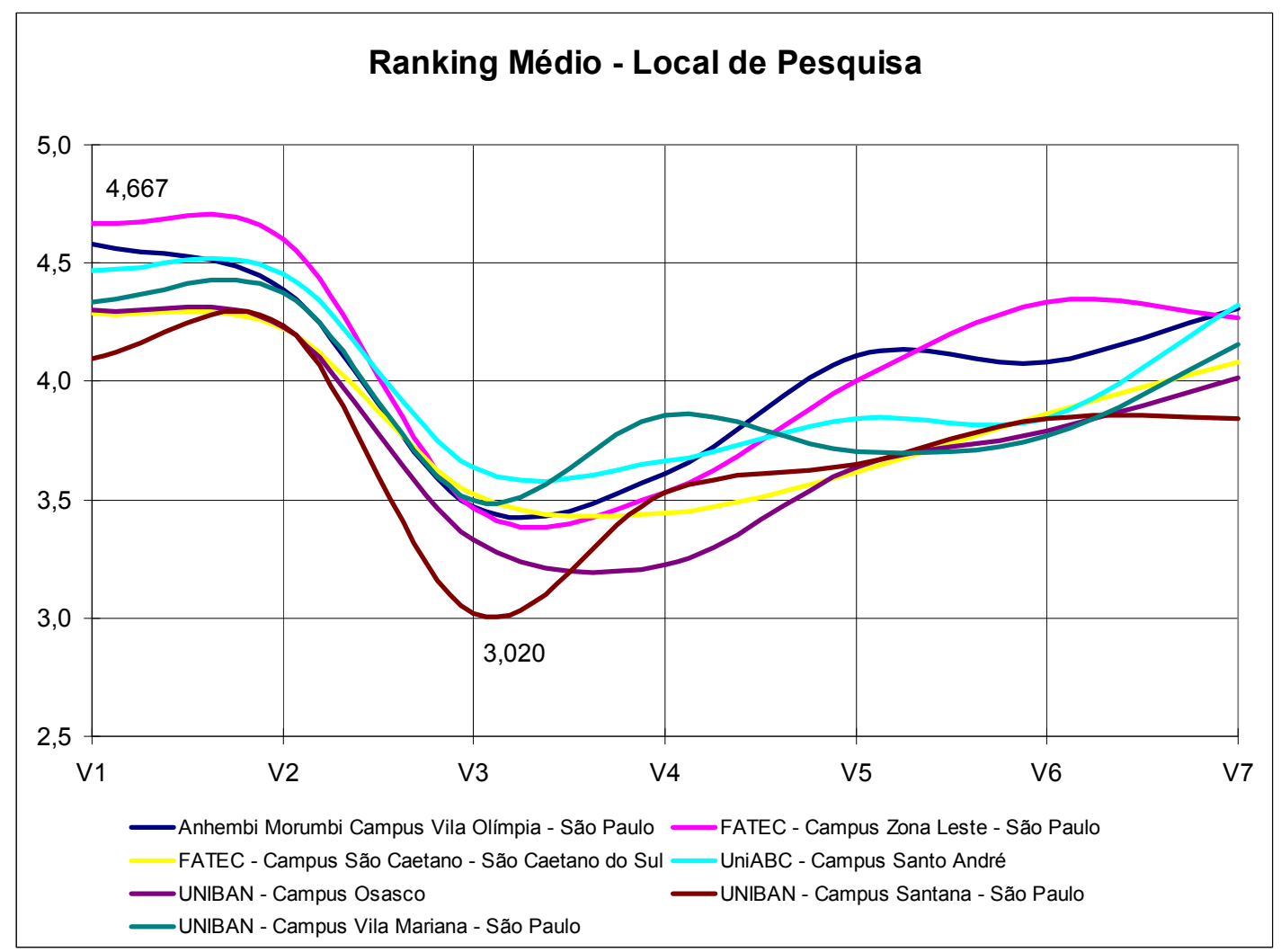

Figura 4.11 - Ranking Médio estratificado por local de pesquisa.

A estratificação por local de pesquisa, na figura 4.11, (Universidade Anhembi Morumbi Campus Vila Olímpia, FATEC Zona Leste e São Caetano, UniABC Campus Santo André e Uniban Campus Santana, Vila Mariana e Osasco) mostra que a opinião em cada um dos locais é muito semelhante, bastando observar o padrão das curvas de valores médios de cada um dos locais para cada uma das assertivas e verificar que existe uma similaridade no comportamento. Ainda assim o valor máximo, de 4,667 pontos, alcançado na FATEC Zona Leste, na assertiva V1, é superior ao valor médio geral desta assertiva com 4,344 pontos. Ainda em consonância com o padrão observado no ranking médio a assertiva V3 é a com menor pontuação neste estrato, com 3,020 pontos, especificamente na Uniban, Campus Santana. Da mesma forma que a observada no ranking médio, apesar de ser a menor pontuação, ainda está acima do limiar de três pontos. 


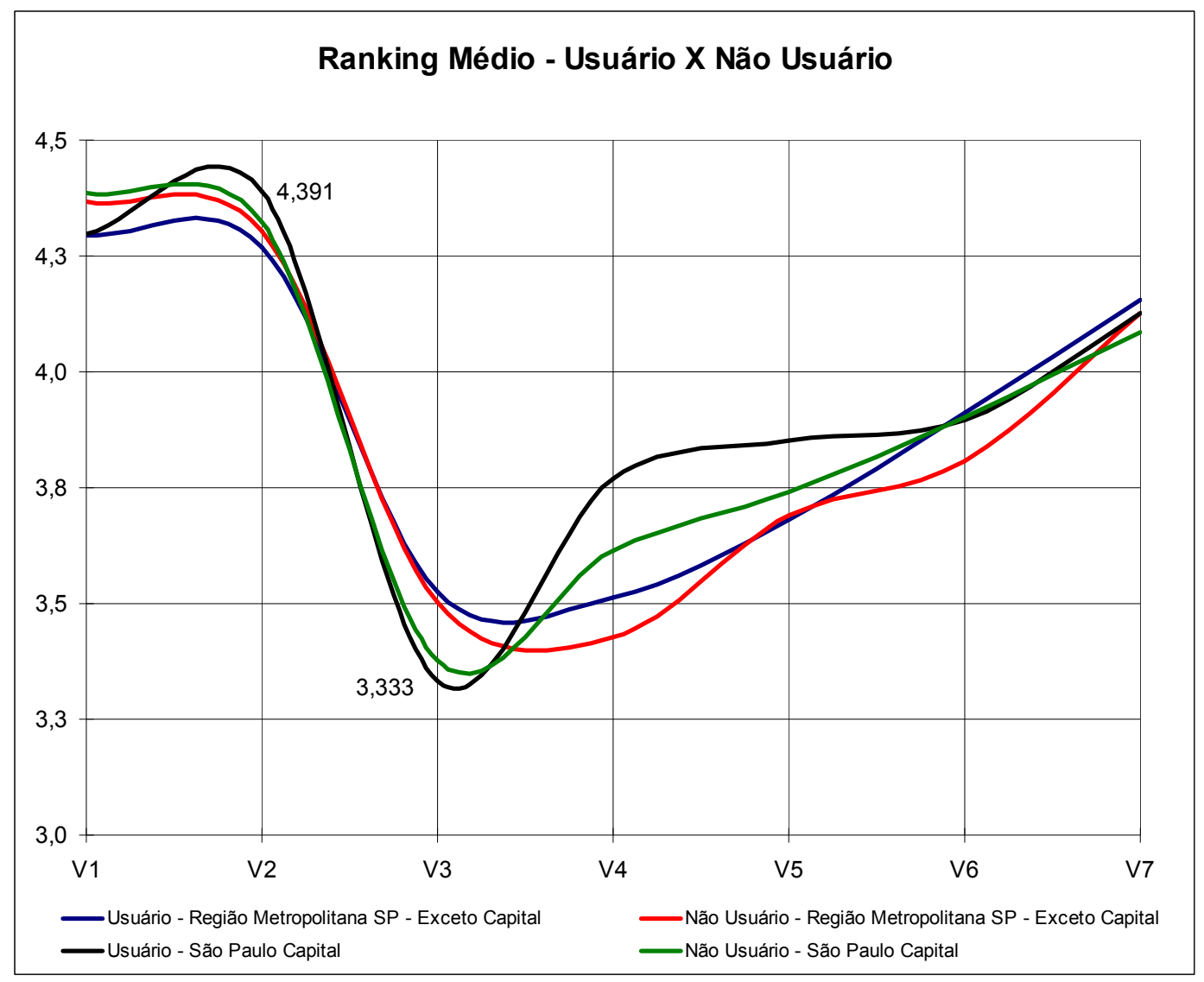

Figura 4.12 - Ranking Médio por tipo de utilização.

A caracterização de "usuário" utilizada neste trabalho considera que a freqüência de utilização do sistema seja igual ou superior a três vezes por semana. Assim, foram observados 4 tipos de utilizadores, dois usuários e dois não usuários (Usuário Região Metropolitana e Capital e Não Usuário Região Metropolitana e Capital). Estabelecido este conceito a avaliação do gráfico 4.12 mostra que, diferente do ranking médio geral, a maior pontuação é indicada na assertiva V2 - Aumento da qualidade de vida devido a diminuição da poluição do ar, sonora, visual e dano ecológico, com 4,391 pontos, valor ligeiramente superior ao encontrado no ranking médio geral de 4,319 pontos. O menor valor continua sendo na assertiva $V 3$, com 3,333 pontos. Uma observação significativa nesta análise é que os valores de máximo e mínimo ocorrem no mesmo estrato, Usuário, morador em São Paulo, Capital. 


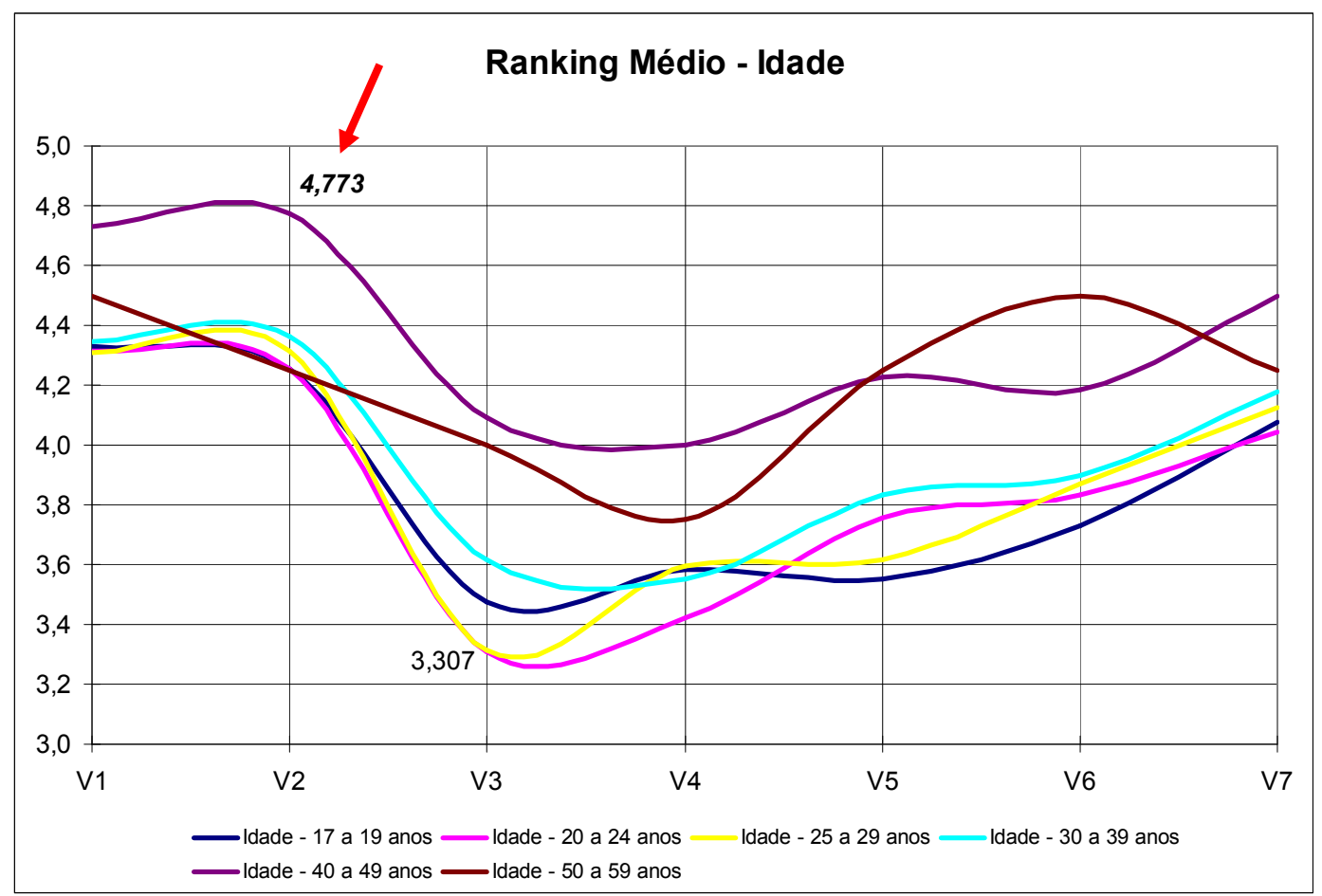

Figura 4.13 - Ranking Médio estratificado por Idade.

O ranking médio estratificado por idade (figura 4.13) tem as seguintes classes: idade de 17 a 19 anos, de 20 a 24 anos, de 25 a 29 anos, de 30 a 39 anos, de 40 a 49 anos e de 50 a 59 anos. Existe uma distribuição uniforme entre as curvas, não existindo um padrão estreito de comportamento. É neste estrato que encontra-se o maior valor de ranking médio, com 4,773 pontos na assertiva V2. Este valor é pertencente a classe de idade de 40 a 49 anos. No outro extremo tem-se o menor valor do estrato, porém não o menor de todos os estratos, repetindo-se na assertiva V3 com 3,307 pontos para a classe de idade de 25 a 29 anos, porém mantendo a sua posição acima do limiar de 3 pontos. 


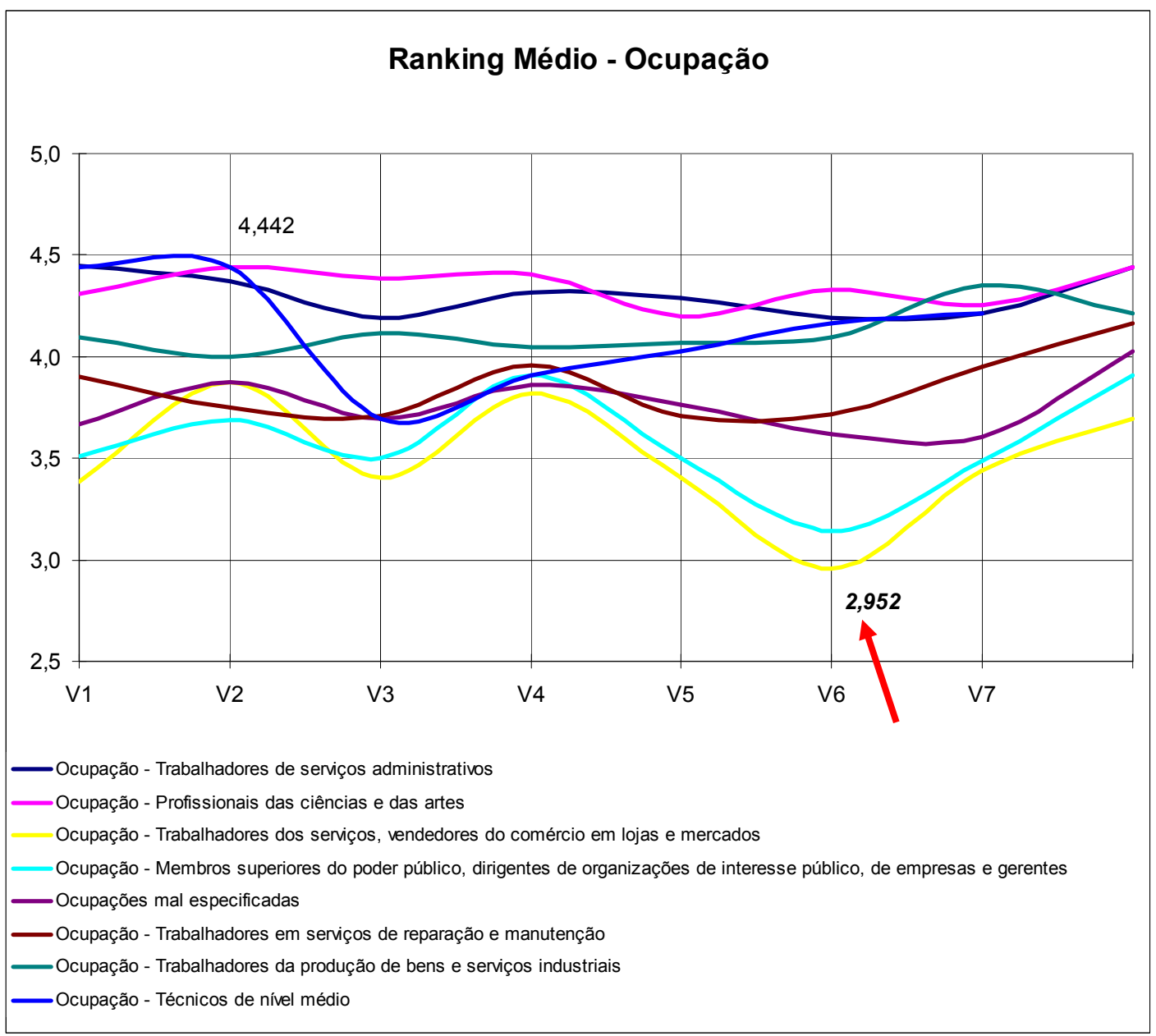

Figura 4.14 - Ranking Médio estratificado por Ocupação.

O gráfico do ranking médio por ocupação (figura 4.14) é o que apresenta o menor valor de ranking médio calculado, com 2,952 pontos na assertiva V6 Uso das fontes de petróleo de maneira inteligente, pela classe Trabalhadores de Serviços, Vendedores do Comércio em Lojas e Mercadorias. Observe-se que este valor, apesar de ser o menor em todos os estratos, inclusive ultrapassando o limiar de 3 pontos, aponta para uma assertiva que até agora permanecia dentro de uma regularidade e não havia sido citada como valor máximo ou mínimo em qualquer uma das análises. Novamente o valor máximo é encontrada na assertiva V2, 4,442 pontos, para a classe Profissionais das Ciências e Artes. O ranking médio desta classe em especial parece ter 0 comportamento mais homogêneo de todas as classes avaliadas pelo método do ranking médio. 


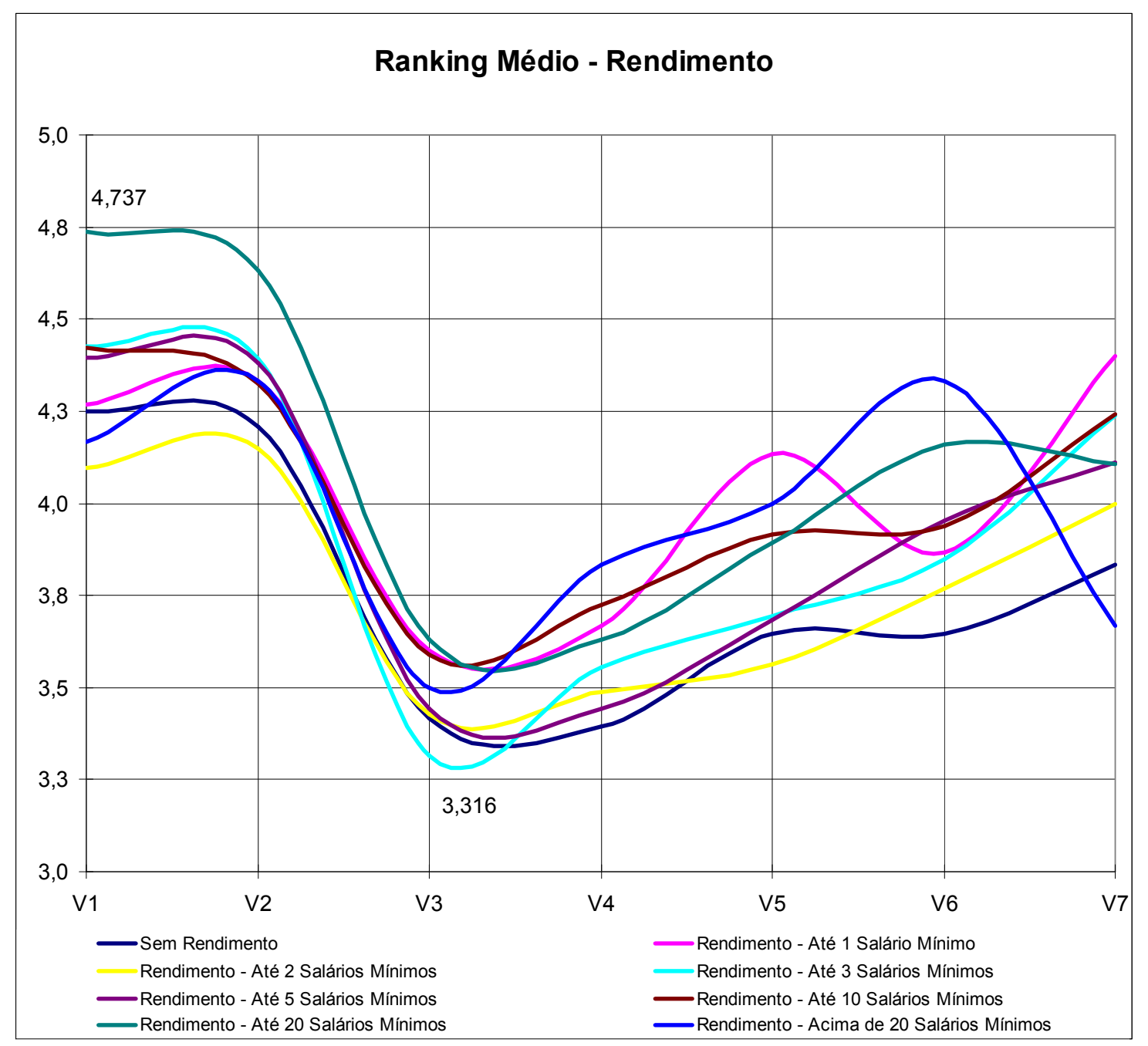

Figura 4.15 - Ranking Médio estratificado por Rendimento.

No gráfico do ranking médio por rendimento (figura 4.15) o menor valor volta a ser apontado na assertiva V3, acima do limiar de 3 pontos, com 3,316 pontos para a classe de rendimento de até 3 salários mínimos. 0 maior ranking médio deste estrato fica localizado na classe de rendimento de até 20 salários mínimos, com 4,737 pontos, na assertiva V1. O comportamento observado nos valores calculados do ranking médio para este estrato parecem ser semelhantes, com algumas pequenas variações para cada uma das classes, notadamente nas assertivas V5, V6 e V7. 


\subsection{Tratamento de Dados Especialistas}

\subsubsection{Introdução}

A aplicação do método MAH foi destinada aos especialistas no assunto, com um total de trinta e quatro matrizes preenchidas pelos especialistas dos seguintes setores: Metrô SP, CPTM, Associação dos Engenheiros e Arquitetos Metroviários de São Paulo - AEAMESP e Acadêmicos da EESC e Escola Politécnica. Estes especialistas dividem-se conforme mostrado na Figura 4.16.

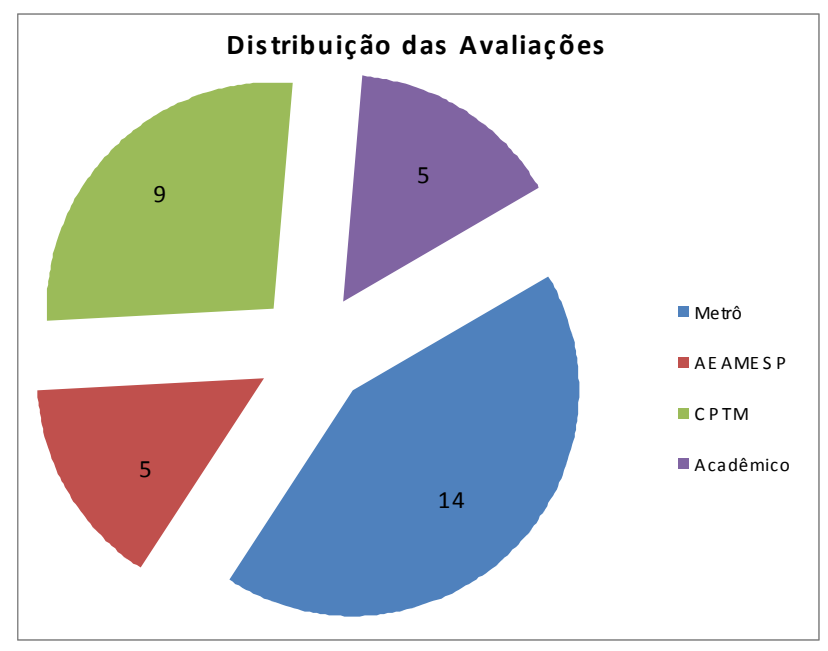

Figura 4.16 - Distribuição das Avaliações entre os especialistas.

A realização desta pesquisa foi iniciada com um contato prévio com cada um dos especialistas para explicar o objetivo da pesquisa e também para explicar a forma de preenchimento da matriz na planilha eletrônica. Após este contato inicial a planilha com a matriz para preenchimento foi enviada para 0 correio eletrônico do especialista ou, quando possível, entregue diretamente ao especialista em meio magnético. Após o preenchimento, a devolução da planilha foi por meio de correio eletrônico. Por tratar-se de uma avaliação que envolveu sete assertivas (V1 a V7) a aplicação de uma planilha eletrônica simples foi possível.

As assertivas estudadas são as mesmas que a população avaliou com uso da Escala de Likert: 
- V1 - Diminuição do trânsito devido ao uso do Transporte sobre Trilhos;

- V2 - Aumento da qualidade de vida devido a diminuição da poluição do ar, sonora, visual e dano ecológico;

- V3 - Economia do dinheiro público devido a baixos investimentos em construção e manutenção de vias públicas;

- V4 - Acesso aos serviços públicos com maior eficiência (hospitais, repartições públicas, etc);

- V5 - Melhora a economia da cidade e dos centros regionais;

- V6 - Uso das fontes de petróleo com eficiência devido ao menor consumo em função do uso do transporte público;

- V7 - Redução no custo dos acidentes de trânsito e danos provocados por eles.

O preenchimento da matriz é simples e a própria planilha possui um indicador para mostrar ao especialista quais os fatores alcançados com a avaliação conduzida e qual a consistência alcançada com a avaliação indicando a necessidade, ou não, de reavaliação da comparação executada, conforme mostrado nas Figuras 4.17 e 4.18.

O preenchimento é realizado somente nas células que não estão destacadas. A planilha faz o preenchimento dos valores nas células que são pareadas. Por exemplo, se na avaliação da coluna a) e linha b) foi preenchido com o valor 2 a coluna b) com a linha a) será automaticamente preenchido com o valor $1 / 2$. A diagonal da planilha também não é preenchida pois a diagonal possui a avaliação do critério por ele mesmo e não poderia ser diferente da unidade. 


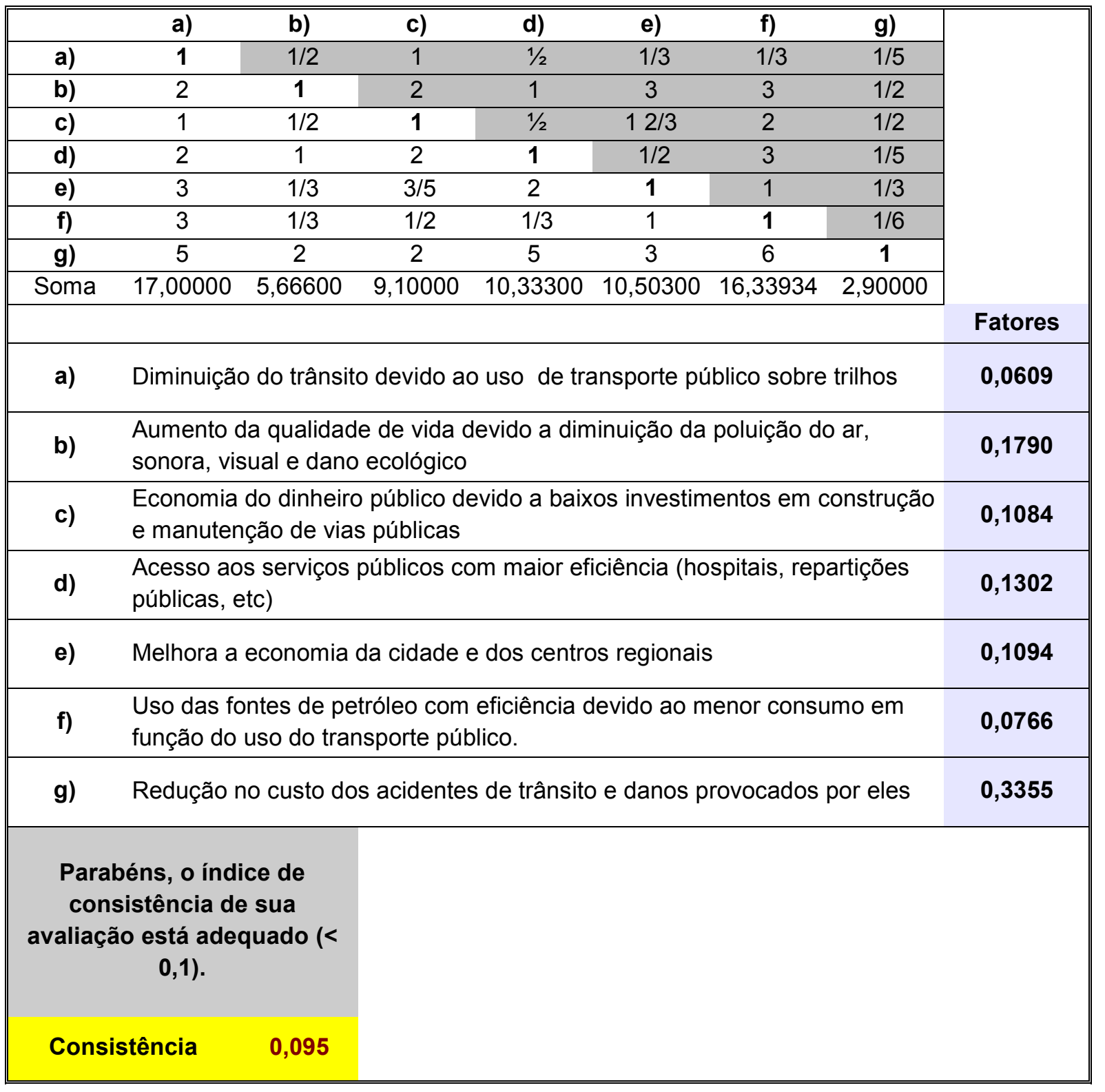

Figura 4.17 - Matriz de Comparação Par a Par com Consistência Adequada

\begin{tabular}{|cccccccc|}
\hline & a) & b) & c) & d) & e) & f) & g) \\
\hline a) & $\mathbf{1}$ & $1 / 2$ & $1 / 3$ & $1 / 2$ & $1 / 3$ & $1 / 3$ & $1 / 5$ \\
\hline b) & 2 & $\mathbf{1}$ & $1 / 2$ & $1 / 3$ & 3 & 3 & $1 / 2$ \\
\hline c) & 3 & 2 & $\mathbf{1}$ & $1 / 3$ & $11 / 2$ & 2 & $1 / 2$ \\
\hline d) & 2 & 3 & 3 & $\mathbf{1}$ & $1 / 2$ & 3 & $1 / 8$ \\
\hline e) & 3 & $1 / 3$ & $2 / 3$ & 2 & $\mathbf{1}$ & $1 / 2$ & $1 / 3$ \\
\hline f) & 3 & $1 / 3$ & $1 / 2$ & $1 / 3$ & 2 & $\mathbf{1}$ & $1 / 8$ \\
\hline g) & 5 & 2 & 2 & 8 & 3 & 8 & $\mathbf{1}$ \\
\hline Soma & 19,00000 & 9,16600 & 8,00000 & 12,49967 & 11,33634 & 17,83934 & 2,78333 \\
\hline
\end{tabular}

a) Diminuição do trânsito devido ao uso de transporte público sobre trilhos

Fatores 


\begin{tabular}{|c|c|c|}
\hline b) & $\begin{array}{l}\text { Aumento da qualidade de vida devido a diminuição da poluição do ar, sonora, } \\
\text { visual e dano ecológico }\end{array}$ & 0,1309 \\
\hline c) & $\begin{array}{l}\text { Economia do dinheiro público devido a baixos investimentos em construção e } \\
\text { manutenção de vias públicas }\end{array}$ & 0,1360 \\
\hline d) & $\begin{array}{l}\text { Acesso aos serviços públicos com maior eficiência (hospitais, repartições } \\
\text { públicas, etc) }\end{array}$ & 0,1636 \\
\hline e) & Melhora a economia da cidade e dos centros regionais & 0,0962 \\
\hline f) & $\begin{array}{l}\text { Uso das fontes de petróleo com eficiência devido ao menor consumo em função } \\
\text { do uso do transporte público. }\end{array}$ & 0,0801 \\
\hline g) & Redução no custo dos acidentes de trânsito e danos provocados por eles & 0,3491 \\
\hline \multicolumn{3}{|c|}{$\begin{array}{c}\text { Atenção, índice de } \\
\text { consistência acima do valor } \\
\text { mínimo }(>0,1) \text {, refaça a } \\
\text { avaliação. }\end{array}$} \\
\hline \multicolumn{3}{|c|}{ Consistência $\quad 0,210$} \\
\hline
\end{tabular}

Figura 4.18 - Matriz de Comparação Par a Par com Consistência Inadequada.

\subsubsection{Resultados da Pesquisa}

Os resultados das avaliações realizadas pelos especialistas são apresentados nas Tabelas 4.2 a 4.6. A Tabela 4.7 mostra uma comparação das médias das avaliações estratificadas por ramo e a Tabela 4.8 indica a classificação das médias das assertivas. 
Tabela 4.2 - Fatores da Avaliação Par a Par dos Especialistas

\begin{tabular}{|c|c|c|c|c|c|c|c|c|}
\hline Especialista & Ramo & $\mathrm{V} 1$ & $\mathrm{~V} 2$ & V3 & $\begin{array}{c}\text { Variáveis } \\
\text { V4 } \\
\end{array}$ & V5 & V6 & V7 \\
\hline A1 & Acadêmico & 0,08991 & 0,21625 & 0,05620 & 0,09184 & 0,10415 & 0,13012 & 0,31154 \\
\hline $\mathrm{A} 2$ & Acadêmico & 0,05325 & 0,25637 & 0,07380 & 0,16777 & 0,10244 & 0,08415 & 0,26221 \\
\hline A3 & Acadêmico & 0,19597 & 0,20802 & 0,05270 & 0,13349 & 0,07051 & 0,14736 & 0,19196 \\
\hline A4 & Acadêmico & 0,23076 & 0,08157 & 0,05675 & 0,21671 & 0,27097 & 0,03611 & 0,10713 \\
\hline A5 & Acadêmico & 0,09120 & 0,06405 & 0,32880 & 0,14897 & 0,10664 & 0,15652 & 0,10381 \\
\hline E1 & AEAMESP & 0,06202 & 0,18380 & 0,07144 & 0,17513 & 0,13335 & 0,11560 & 0,25866 \\
\hline E2 & AEAMESP & 0,06825 & 0,19820 & 0,06019 & 0,16663 & 0,10213 & 0,11104 & 0,29357 \\
\hline E3 & AEAMESP & 0,26927 & 0,12952 & 0,14322 & 0,07215 & 0,12435 & 0,10440 & 0,15710 \\
\hline E4 & AEAMESP & 0,04411 & 0,13092 & 0,13598 & 0,16356 & 0,09622 & 0,08011 & 0,34911 \\
\hline E5 & AEAMESP & 0,08209 & 0,19299 & 0,05131 & 0,25642 & 0,10678 & 0,09389 & 0,21652 \\
\hline C1 & СРТМ & 0,14512 & 0,19885 & 0,01735 & 0,29334 & 0,11239 & 0,08059 & 0,15235 \\
\hline $\mathrm{C} 2$ & СРТМ & 0,05030 & 0,25135 & 0,10141 & 0,13299 & 0,08935 & 0,11149 & 0,26311 \\
\hline C3 & СРТМ & 0,04040 & 0,19564 & 0,08518 & 0,20713 & 0,10599 & 0,08303 & 0,28264 \\
\hline $\mathrm{C} 4$ & СРТМ & 0,04500 & 0,16408 & 0,05932 & 0,17305 & 0,12227 & 0,10187 & 0,33441 \\
\hline C5 & СРТМ & 0,09085 & 0,26431 & 0,05726 & 0,12856 & 0,15815 & 0,06838 & 0,23249 \\
\hline C6 & СРТМ & 0,05141 & 0,23759 & 0,06109 & 0,13923 & 0,19458 & 0,08380 & 0,23230 \\
\hline $\mathrm{C} 7$ & СРТМ & 0,03674 & 0,13966 & 0,09544 & 0,13057 & 0,14861 & 0,13055 & 0,31843 \\
\hline C8 & СРТМ & 0,17368 & 0,11051 & 0,06246 & 0,32483 & 0,10480 & 0,18497 & 0,03876 \\
\hline C9 & СРТМ & 0,36834 & 0,19414 & 0,08729 & 0,16464 & 0,07126 & 0,07232 & 0,04201 \\
\hline M1 & Metrô & 0,28668 & 0,11058 & 0,05264 & 0,30676 & 0,07316 & 0,09211 & 0,07807 \\
\hline M2 & Metrô & 0,14496 & 0,22769 & 0,02435 & 0,11508 & 0,04097 & 0,06181 & 0,38515 \\
\hline M3 & Metrô & 0,02870 & 0,39373 & 0,08571 & 0,29831 & 0,08742 & 0,07266 & 0,03346 \\
\hline M4 & Metrô & 0,08093 & 0,36440 & 0,05578 & 0,31663 & 0,06140 & 0,03938 & 0,08149 \\
\hline M5 & Metrô & 0,06181 & 0,05769 & 0,08516 & 0,12113 & 0,11634 & 0,23001 & 0,32787 \\
\hline M6 & Metrô & 0,13438 & 0,37604 & 0,03572 & 0,04306 & 0,03954 & 0,09685 & 0,27441 \\
\hline M7 & Metrô & 0,05063 & 0,27965 & 0,08310 & 0,17006 & 0,10637 & 0,06059 & 0,24960 \\
\hline
\end{tabular}


Tabela 4.2 - (Continuação) Fatores da Avaliação Par a Par dos Especialistas

\begin{tabular}{|c|c|c|c|c|c|c|c|c|}
\hline \multirow{2}{*}{ Especialista } & \multirow{2}{*}{ Ramo } & \multicolumn{7}{|c|}{ Variáveis } \\
\hline & & V1 & V2 & V3 & V4 & V5 & V6 & V7 \\
\hline M8 & Metrô & 0,09773 & 0,19833 & 0,06929 & 0,15180 & 0,15309 & 0,08780 & 0,24196 \\
\hline M9 & Metrô & 0,05168 & 0,23774 & 0,07016 & 0,14749 & 0,12466 & 0,13315 & 0,23512 \\
\hline M10 & Metrô & 0,06452 & 0,29958 & 0,06378 & 0,13937 & 0,10776 & 0,11273 & 0,21226 \\
\hline M11 & Metrô & 0,05178 & 0,28280 & 0,07678 & 0,11742 & 0,14663 & 0,10617 & 0,21842 \\
\hline M12 & Metrô & 0,02361 & 0,05264 & 0,27791 & 0,16772 & 0,10971 & 0,10621 & 0,26219 \\
\hline M13 & Metrô & 0,34629 & 0,20448 & 0,06576 & 0,15092 & 0,06769 & 0,05214 & 0,11272 \\
\hline M14 & Metrô & 0,06200 & 0,08685 & 0,11850 & 0,16394 & 0,12681 & 0,15867 & 0,28324 \\
\hline \multicolumn{2}{|c|}{ Média } & 0,11134 & 0,19970 & 0,08551 & 0,17263 & 0,11171 & 0,10262 & 0,21649 \\
\hline \multicolumn{2}{|c|}{ Desvio Padrão } & 0,09274 & 0,08855 & 0,06258 & 0,06989 & 0,04369 & 0,04103 & 0,09638 \\
\hline
\end{tabular}

Tabela 4.3 - Opinião dos Especialistas - Acadêmica

\begin{tabular}{|c|c|c|c|c|c|c|c|c|}
\hline \multirow[b]{2}{*}{ Especialista } & \multirow[b]{2}{*}{ Ramo } & \multicolumn{7}{|c|}{ Variáveis } \\
\hline & & $\mathrm{V} 1$ & $\mathrm{~V} 2$ & V3 & V4 & V5 & V6 & V7 \\
\hline $\mathrm{A} 1$ & Acadêmico & 0,08991 & 0,21625 & 0,05620 & 0,09184 & 0,10415 & 0,13012 & 0,31154 \\
\hline $\mathrm{A} 2$ & Acadêmico & 0,05325 & 0,25637 & 0,07380 & 0,16777 & 0,10244 & 0,08415 & 0,26221 \\
\hline A3 & Acadêmico & 0,19597 & 0,20802 & 0,05270 & 0,13349 & 0,07051 & 0,14736 & 0,19196 \\
\hline A4 & Acadêmico & 0,23076 & 0,08157 & 0,05675 & 0,21671 & 0,27097 & 0,03611 & 0,10713 \\
\hline A5 & Acadêmico & 0,09120 & 0,06405 & 0,32880 & 0,14897 & 0,10664 & 0,15652 & 0,10381 \\
\hline \multicolumn{2}{|c|}{ Média } & 0,13222 & 0,16525 & 0,11365 & 0,15176 & 0,13094 & 0,11085 & 0,19533 \\
\hline \multicolumn{2}{|c|}{ Desvio Padrão } & 0,07662 & 0,08657 & 0,12055 & 0,04584 & 0,07966 & 0,05022 & 0,09239 \\
\hline
\end{tabular}


Tabela 4.4 - Opinião dos Especialistas - Associação dos Engenheiros e Arquitetos

\begin{tabular}{|c|c|c|c|c|c|c|c|c|}
\hline \multirow{2}{*}{ Especialista } & \multirow{2}{*}{ Ramo } & \multicolumn{7}{|c|}{ Variáveis } \\
\hline & & V1 & $\mathrm{V} 2$ & V3 & V4 & V5 & V6 & V7 \\
\hline E1 & AEAMESP & 0,06202 & 0,18380 & 0,07144 & 0,17513 & 0,13335 & 0,11560 & 0,25866 \\
\hline E2 & AEAMESP & 0,06825 & 0,19820 & 0,06019 & 0,16663 & 0,10213 & 0,11104 & 0,29357 \\
\hline E3 & AEAMESP & 0,26927 & 0,12952 & 0,14322 & 0,07215 & 0,12435 & 0,10440 & 0,15710 \\
\hline E4 & AEAMESP & 0,06092 & 0,17897 & 0,10841 & 0,13015 & 0,10944 & 0,07661 & 0,33549 \\
\hline E5 & AEAMESP & 0,08209 & 0,19299 & 0,05131 & 0,25642 & 0,10678 & 0,09389 & 0,21652 \\
\hline \multicolumn{2}{|c|}{ Média } & 0,10851 & 0,17670 & 0,08691 & 0,16010 & 0,11521 & 0,10031 & 0,25227 \\
\hline \multicolumn{2}{|c|}{ Desvio Padrão } & 0,09026 & 0,02743 & 0,03825 & 0,06742 & 0,01311 & 0,01556 & 0,06893 \\
\hline
\end{tabular}

Tabela 4.5 - Opinião dos Especialistas - CPTM

\begin{tabular}{|c|c|c|c|c|c|c|c|c|}
\hline Especialista & Ramo & V1 & V2 & V3 & $\begin{array}{c}\text { Variáveis } \\
\text { V4 }\end{array}$ & V5 & V6 & V7 \\
\hline $\mathrm{C} 1$ & CPTM & 0,14512 & 0,19885 & 0,01735 & 0,29334 & 0,11239 & 0,08059 & 0,15235 \\
\hline $\mathrm{C} 2$ & СРТМ & 0,05030 & 0,25135 & 0,10141 & 0,13299 & 0,08935 & 0,11149 & 0,26311 \\
\hline C3 & CPTM & 0,04040 & 0,19564 & 0,08518 & 0,20713 & 0,10599 & 0,08303 & 0,28264 \\
\hline $\mathrm{C} 4$ & CPTM & 0,04500 & 0,16408 & 0,05932 & 0,17305 & 0,12227 & 0,10187 & 0,33441 \\
\hline C5 & CPTM & 0,09085 & 0,26431 & 0,05726 & 0,12856 & 0,15815 & 0,06838 & 0,23249 \\
\hline C6 & CPTM & 0,05141 & 0,23759 & 0,06109 & 0,13923 & 0,19458 & 0,08380 & 0,23230 \\
\hline $\mathrm{C7}$ & СРТМ & 0,03674 & 0,13966 & 0,09544 & 0,13057 & 0,14861 & 0,13055 & 0,31843 \\
\hline $\mathrm{C} 8$ & CPTM & 0,17368 & 0,11051 & 0,06246 & 0,32483 & 0,10480 & 0,18497 & 0,03876 \\
\hline C9 & СРTM & 0,36834 & 0,19414 & 0,08729 & 0,16464 & 0,07126 & 0,07232 & 0,04201 \\
\hline \multirow{2}{*}{\multicolumn{2}{|c|}{$\begin{array}{l}\text { Média } \\
\text { Desvio Padrão }\end{array}$}} & 0,11132 & 0,19513 & 0,06964 & 0,18826 & 0,12305 & 0,10189 & 0,21072 \\
\hline & & 0,10829 & 0,05119 & 0,02585 & 0,07348 & 0,03801 & 0,03700 & 0,11023 \\
\hline
\end{tabular}


Tabela 4.6 - Opinião dos Especialistas - Metrô

\begin{tabular}{|c|c|c|c|c|c|c|c|c|}
\hline \multirow{2}{*}{ Especialista } & \multirow{2}{*}{ Ramo } & \multicolumn{7}{|c|}{ Variáveis } \\
\hline & & V1 & $\mathrm{V} 2$ & V3 & V4 & V5 & V6 & V7 \\
\hline M1 & Metrô & 0,28668 & 0,11058 & 0,05264 & 0,30676 & 0,07316 & 0,09211 & 0,07807 \\
\hline M2 & Metrô & 0,14496 & 0,22769 & 0,02435 & 0,11508 & 0,04097 & 0,06181 & 0,38515 \\
\hline M3 & Metrô & 0,02870 & 0,39373 & 0,08571 & 0,29831 & 0,08742 & 0,07266 & 0,03346 \\
\hline M4 & Metrô & 0,08093 & 0,36440 & 0,05578 & 0,31663 & 0,06140 & 0,03938 & 0,08149 \\
\hline M5 & Metrô & 0,06181 & 0,05769 & 0,08516 & 0,12113 & 0,11634 & 0,23001 & 0,32787 \\
\hline M6 & Metrô & 0,13438 & 0,37604 & 0,03572 & 0,04306 & 0,03954 & 0,09685 & 0,27441 \\
\hline M7 & Metrô & 0,05063 & 0,27965 & 0,08310 & 0,17006 & 0,10637 & 0,06059 & 0,24960 \\
\hline M8 & Metrô & 0,09773 & 0,19833 & 0,06929 & 0,15180 & 0,15309 & 0,08780 & 0,24196 \\
\hline M9 & Metrô & 0,05168 & 0,23774 & 0,07016 & 0,14749 & 0,12466 & 0,13315 & 0,23512 \\
\hline M10 & Metrô & 0,06452 & 0,29958 & 0,06378 & 0,13937 & 0,10776 & 0,11273 & 0,21226 \\
\hline M11 & Metrô & 0,05178 & 0,28280 & 0,07678 & 0,11742 & 0,14663 & 0,10617 & 0,21842 \\
\hline M12 & Metrô & 0,02361 & 0,05264 & 0,27791 & 0,16772 & 0,10971 & 0,10621 & 0,26219 \\
\hline M13 & Metrô & 0,34629 & 0,20448 & 0,06576 & 0,15092 & 0,06769 & 0,05214 & 0,11272 \\
\hline M14 & Metrô & 0,06200 & 0,08685 & 0,11850 & 0,16394 & 0,12681 & 0,15867 & 0,28324 \\
\hline \multicolumn{2}{|c|}{ Média } & 0,10612 & 0,22658 & 0,08319 & 0,17212 & 0,09725 & 0,10073 & 0,21400 \\
\hline \multicolumn{2}{|c|}{ Desvio Padrão } & 0,09637 & 0,11561 & 0,06055 & 0,07994 & 0,03640 & 0,04932 & 0,10169 \\
\hline
\end{tabular}

Tabela 4.7 - Comparação das Médias das variáveis

\begin{tabular}{|c|c|c|c|c|c|c|c|}
\hline & V1 & V2 & V3 & V4 & V5 & V6 & V7 \\
\hline Média Geral & 0,11185 & 0,20115 & 0,08467 & 0,17161 & 0,11211 & 0,10252 & 0,21607 \\
\hline Acadêmicos & 0,13222 & 0,16525 & 0,11365 & 0,15176 & 0,13094 & 0,11085 & 0,19533 \\
\hline AEAMESP & 0,10851 & 0,17670 & 0,08691 & 0,16010 & 0,11521 & 0,10031 & 0,25227 \\
\hline СРТМ & 0,11132 & 0,19513 & 0,06964 & 0,18826 & 0,12305 & 0,10189 & 0,21072 \\
\hline Metrô & 0,10612 & 0,22658 & 0,08319 & 0,17212 & 0,09725 & 0,10073 & 0,21400 \\
\hline
\end{tabular}


Tabela 4.8 - Classificação das Variáveis com base na média

\begin{tabular}{cccccc}
\hline \hline Classificação & Média Geral & Acadêmicos & AEAMESP & CPTM & Metrô \\
\hline \hline $1^{\circ}$ & V7 & V7 & V7 & V7 & V2 \\
$2^{\circ}$ & V2 & V2 & V2 & V2 & V7 \\
$3^{\circ}$ & V4 & V4 & V4 & V4 & V4 \\
$4^{\circ}$ & V5 & V1 & V5 & V5 & V1 \\
$5^{\circ}$ & V1 & V5 & V1 & V1 & V6 \\
$6^{\circ}$ & V6 & V3 & V6 & V6 & V5 \\
$7^{\circ}$ & V3 & V6 & V3 & V3 & V3 \\
\hline \hline
\end{tabular}

A tabela 4.8 apresenta a classificação das assertivas médias. Enquanto em primeiro lugar temos a V7 para acadêmicos, AEAMESP e CPTM, seguindo a mesma tendência apresentada na Média Geral, os especialistas do Metrô classificam a V2 como a mais importante. No segundo lugar de importância esta situação inverte-se, somente os especialistas do Metrô consideram V7 como a mais importante, enquanto os demais apontam V2 como a segunda mais importante, novamente seguindo a classificação obtida na Média Geral. No terceiro lugar é unânime a assertiva V4. Deste ponto em diante começam a acontecer diferenças nas médias, variando qual posição cada uma ocupa em função do ramo. É interessante observar que a classificação obtida pela CPTM é idêntica a classificação obtida com os especialistas da AEAMESP, que, por sua vez, são idênticas a classificação da Média Geral. O ponto mais destoante da análise encontra-se na assertiva V5 que na Média Geral e também na AEAMESP e CPTM ocupa a $4^{\text {a }}$ posição, respectivamente com os valores [0,11211:0,11521:0,12305] ocupa, na classificação obtida com os especialistas do Metrô a $6^{\text {a }}$ posição, com 0,09725 pontos. 


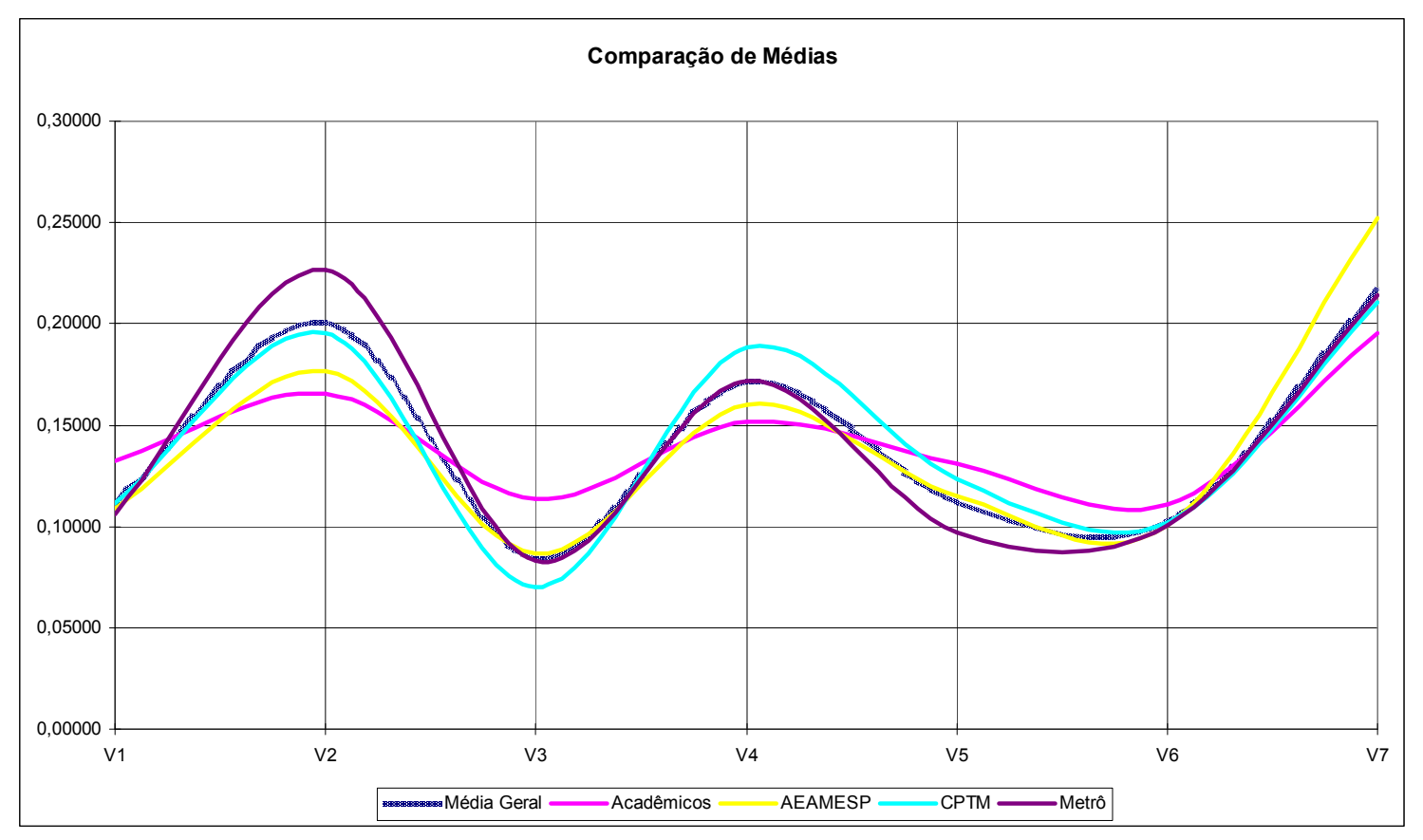

Figura 4.19 - Gráfico de Comparação das Médias

A análise do gráfico da figura 4.19 mostra que as médias dos fatores acompanham a mesma tendência, denotando coerência na avaliação. Porém, utilizando-se a técnica ANOVA para comparação das médias o valor de Fcalculado foi maior que Ftabelado e, desta forma, a hipótese nula (as médias são iguais) é rejeitada, demonstrando que as opiniões dos especialistas são divergentes.

O método aqui utilizado para identificar a classificação das assertivas por ordem de importância mostrou-se adequado e particularmente simples de ser aplicado. Os resultados, quando analisados separadamente por aquilo que neste trabalho convencionou-se como ramo, mostram que a opinião dos especialistas é muito parecida, porém a comparação de médias não paponta para o mesmo caminho. Destaca-se o fato que esta pesquisa foi aplicada individualmente e não houve conhecimento dos resultados gerais ou parciais por parte dos pesquisados. Estas características parecem mostrar que as respostas e os dados analisados são consistentes. 


\section{Capítulo 5 - Conclusões}

\subsection{Da Proposta do Trabalho}

A proposta deste trabalho foi obter conhecimento com a aplicação de solução de problemas de cunho prático da engenharia de transportes. Os problemas estudados foram orientados pelas seguintes perguntas:

a. A sociedade é perceptiva quanto aos benefícios que um sistema de transporte público urbano sobre trilhos pode trazer às comunidades ?

b. Qual é a opinião dos especialistas sobre os benefícios advindos com a implantação de um sistema de transporte público urbano sobre trilhos?

c. A percepção da sociedade e dos especialistas do setor de transportes, com relação a estes benefícios, é alinhada, ou seja, existe igualdade de opiniões?

Os resultados obtidos com a aplicação das técnicas apresentadas neste trabalho mostram que a sociedade tem uma boa percepção dos benefícios advindos com a implantação de um sistema de transporte público sobre trilhos, a opinião dos especialistas tem divergências com reação a opinião da sociedade, e que o alinhamento das percepções entre sociedade e especialistas não é completo. 


\subsection{Percepção da Sociedade}

Os resultados mostrados no Capítulo 4 indicam que a porção compreendida pelas assertivas com resposta "Concordo Totalmente" e "Concordo" sempre representam mais de $50 \%$ da área sob a curva de distribuição normal, enquanto a porção compreendida pelas respostas "Discordo" e "Discordo Totalmente" alcançam o máximo, no valor médio, de 10,52\%, mostrados na Tabela 5.1 .

Tabela 5.1 - Resumo da Opinião da Sociedade - Likert

\begin{tabular}{cccccccccc}
\hline \hline \multirow{2}{*}{ Opiniões } & \multicolumn{7}{c}{ Variáveis } & \multicolumn{2}{c}{ Média } \\
& V1 & V2 & V3 & V4 & V5 & V6 & V7 & \\
\hline \hline CT & $50,81 \%$ & $50,35 \%$ & $18,48 \%$ & $21,02 \%$ & $21,94 \%$ & $24,25 \%$ & $39,03 \%$ & $32,27 \%$ & \\
C & $38,57 \%$ & $36,49 \%$ & $34,41 \%$ & $35,57 \%$ & $40,88 \%$ & $47,11 \%$ & $41,11 \%$ & $39,16 \%$ & \\
I & $6,24 \%$ & $9,01 \%$ & $25,64 \%$ & $24,02 \%$ & $27,02 \%$ & $20,79 \%$ & $13,63 \%$ & $18,05 \%$ & $18,05 \%$ \\
D & $3,00 \%$ & $3,00 \%$ & $16,17 \%$ & $16,40 \%$ & $8,78 \%$ & $6,47 \%$ & $5,54 \%$ & $8,48 \%$ & \\
DT & $1,39 \%$ & $1,15 \%$ & $5,31 \%$ & $3,00 \%$ & $1,39 \%$ & $1,39 \%$ & $0,69 \%$ & $2,05 \%$ & \\
Soma CT + C & $89,38 \%$ & $86,84 \%$ & $52,89 \%$ & $56,58 \%$ & $62,82 \%$ & $71,36 \%$ & $80,14 \%$ & & \\
Soma D + DT & $4,39 \%$ & $4,16 \%$ & $21,48 \%$ & $19,40 \%$ & $10,16 \%$ & $7,85 \%$ & $6,24 \%$ & & \\
\hline \hline
\end{tabular}

Estes resultados, por si só, são excelentes indicadores da percepção da sociedade e poderiam responder a questão (a) de maneira positiva, ou seja, a sociedade possui uma percepção razoável dos benefícios que são alcançados com a implantação de um sistema de transporte público urbano sobre trilhos, e, mais ainda, a discordância da população sobre os benefícios é baixa.

Uma avaliação item a item mostra que a variável V3 (economia do dinheiro público devido a baixos investimentos em construção e manutenção de vias públicas) é a que apresenta os mais baixos valores de aceitação, com a somatória de "Concordo" e "Concordo Totalmente" representando 52,89\% e a somatória de "Discordo" e "Discordo Totalmente" com 21,48\%. 
No outro extremo desta avaliação temos a variável V1 (diminuição do trânsito devido ao uso do transporte público), com 89,38\% de aceitação, quando somados os conceitos de "Concordo" e "Concordo Totalmente" e apenas 4,39\% de discordância, no resultado da soma de "Discordo" e "Discordo Totalmente".

O ranking médio, mostrado na Tabela 5.2, repete este resultado mostrando que o menor ranking médio é de 3,446 pontos, atribuído, novamente, à variável V3 (economia do dinheiro público devido a baixos investimentos em construção e manutenção de vias públicas), enquanto o maior ranking médio é obtido na variável V1 (diminuição do trânsito devido ao uso do transporte público), com 4,344 pontos. De fato, a distância entre os dois valores não chega a um ponto e considerando a escala adotada variando de um a cinco, a diferença entre a pontuação máxima e mínima, de 0,898 pontos, representa uma diferença de aproximadamente $18 \%$ entre o maior e menor valor.

Tabela 5.2 - Ranking Médio das Opiniões Emitidas Pela Sociedade

\begin{tabular}{cccccccc}
\hline \hline \multirow{2}{*}{ Opiniões } & V1 & V2 & V3 & V4 & V5 & V6 & V7 \\
\hline \hline CT & 220 & 218 & 80 & 91 & 95 & 105 & 169 \\
C & 167 & 158 & 149 & 154 & 177 & 204 & 178 \\
I & 27 & 39 & 111 & 104 & 117 & 90 & 59 \\
D & 13 & 13 & 70 & 71 & 38 & 28 & 24 \\
DT & 6 & 5 & 23 & 13 & 6 & 6 & 3 \\
Ranking Médio & 4,344 & 4,319 & 3,446 & 3,552 & 3,732 & 3,864 & 4,122 \\
\hline \hline
\end{tabular}

A análise das curvas do ranking médio estratificado pelas variáveis sócio-econômicas mostra que o padrão das curvas é muito semelhante ao padrão da curva do ranking médio geral, indicando um comportamento esperado das respostas, sugerindo que a pesquisa exploratória foi bem sucedida no seu intento de medir a percepção da sociedade com relação aos benefícios que um sistema de transporte público urbano sobre trilhos pode 
oferecer.

Considerando as premissas apresentadas e a avaliação dos indicadores apresentados ao longo deste trabalho é possível, então, responder a pergunta (a) com uma razoável margem de certeza, de que a população em geral tem uma boa percepção dos benefícios alcançados com a implantação de um sistema de transporte público urbano sobre trilhos.

\subsection{Percepção dos Especialistas}

O capítulo 4 deste trabalho, baseando-se no Método de Análise Hierárquica - MAH, faz a análise dos resultados obtidos frente à pesquisa realizada junto aos especialistas.

Para medir a percepção dos especialistas utilizou-se outro instrumento, diferente do utilizado junto a população, por dois motivos:

a. Intenção de testar outro instrumento para realização da pesquisa, e;

b. A utilização do MAH junto à população seria trabalhosa, dada a relativa complexidade deste método.

Com a utilização do MAH a percepção dos especialistas pôde ser avaliada em termos de ranqueamento das assertivas V1 a V7. Este ranqueamento indicou que, na opinião dos especialistas, a assertiva V7 (redução no custo dos acidentes de trânsito e danos provocados por eles) é a mais importante, com uma pontuação de 0,214, em uma escala que varia de zero a um, enquanto a assertiva menos importante é a V3 (economia do dinheiro público devido a baixos investimentos em construção e manutenção de vias públicas), com 0,063 pontos. 
Os ranqueamentos discordantes nesta análise são dois:

a. Os especialistas do Metrô SP consideram V2 a assertiva mais importante, com 0,227 pontos, contudo a opinião da assertiva menos importante é igual ao resultado geral, considerando V3 a menos importante, e;

b. Os acadêmicos consideram V6 a assertiva com menor importância, com 0,103 pontos. Por outro lado a assertiva de maior importância, V7, é alinhada com os demais, à exceção dos especialistas do Metrô SP.

A avaliação do gráfico com as variações das pontuações atribuídas a cada uma das variáveis mostra que a avaliação dos Acadêmicos é a que apresenta a menor variação entre os fatores, enquanto a avaliação dos especialistas do Metrô SP é a que apresenta a maior variabilidade, contudo as variações entre a maior e menor pontuação não ultrapassam 0,061 pontos, 0 que em uma escala de zero a um representa um valor em torno de $6 \%$, respondendo, desta forma, a pergunta (b).

\subsection{Comparação das Percepções}

A comparação das percepções entre a sociedade e os especialistas, apesar de serem medidas em diferentes escalas, foi a maneira adotada para responder a pergunta (c), colocada no início deste capítulo. Esta comparação é apresentada na figura 5.1 e na tabela 5.3.

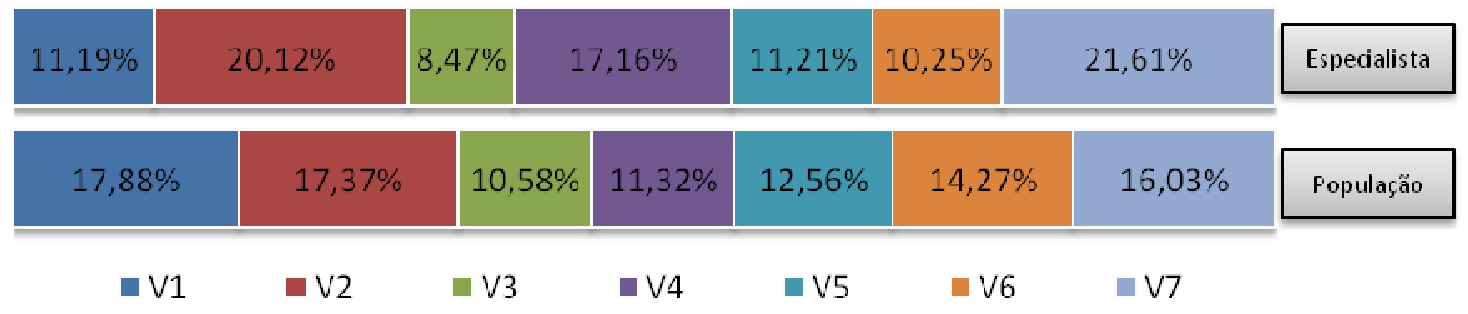

Figra 5.1 - Comparação dos escores entre Especilaitas e População 
Tabela 5.3 - Ranqueamento e Comparação da Opinião da População e Especialistas.

\begin{tabular}{ccccc}
\hline \hline \multirow{2}{*}{ Variáveis } & \multicolumn{2}{c}{ Sociedade } & \multicolumn{3}{c}{ Especialistas } \\
& Classificação & $\%$ & \multicolumn{3}{c}{ Classificação } & $\%$ \\
\hline \hline V1 & $1^{\circ}$ & $17,88 \%$ & $5^{\circ}$ & $11,19 \%$ \\
V2 & $2^{\circ}$ & $17,37 \%$ & $2^{\circ}$ & $20,12 \%$ \\
V3 & $7^{\circ}$ & $10,58 \%$ & $7^{\circ}$ & $8,47 \%$ \\
V4 & $6^{\circ}$ & $11,32 \%$ & $3^{\circ}$ & $17,16 \%$ \\
V5 & $5^{\circ}$ & $12,56 \%$ & $4^{\circ}$ & $11,21 \%$ \\
V6 & $4^{\circ}$ & $14,27 \%$ & $6^{\circ}$ & $10,25 \%$ \\
V7 & $3^{\circ}$ & $16,03 \%$ & $1^{\circ}$ & $21,61 \%$ \\
\hline \hline
\end{tabular}

Como mostrado no ranqueamento geral dos benefícios sob a ótica da sociedade o benefício V1 é considerado o de maior importância.

No ranqueamento geral dos especialistas o benefício V7 é considerado o mais importante, no conjunto de benefícios apresentados neste trabalho.

É ponto comum entre os dois grupos, sociedade e especialistas, a segunda posição do ranqueamento (V2). A variável V3 é considerada o benefício menos importante, dentre os apresentados, tanto para a sociedade como para os especialistas.

A comparação das percepções, entre sociedade e especialistas, mostrou que estas não são alinhadas, respondendo a pergunta (c). Para a verificação deste quesito foi calculado o $\tau$ de Kendal, e o resultado alcançado é de 0,24, indicando uma correlação fraca entre as variáveis. Neste contexto é importante observar que a opinião dos especialistas é revestida de embasamento técnico que em geral aponta para a solução ótima, enquanto a sociedade utiliza conceitos nem sempre tangíveis para expressar a sua opinião. 
Por outro lado, existe o governo que é um agente no sistema de transportes, devendo atender as necessidades da sociedade com a implantação de sistemas de transporte público urbano com base em informações técnicas, para que a maior demanda possível seja atendida, com qualidade e economia. Contudo, não é incomum que a decisão pela implantação de um sistema de transportes público urbano siga uma lógica baseada em anseios populares, ou mesmo de pequenos grupos, em detrimento da fundamentação técnica, incorrendo em situações de investimento em sistemas que não proverão o retorno necessário para o sucesso do empreendimento. Tal situação talvez possa ser explicada pela possibilidade deste tipo de decisão auxiliar na obtenção de posições, por intermédio da manifestação da sociedade, ou destes grupos, nos poderes legislativo e executivo do governo.

\subsection{Sugestões para Trabalhos Futuros}

Este trabalho, com seu caráter exploratório, demonstra que a percepção da sociedade sobre os benefícios alcançados com a implantação de um sistema de transporte público urbano sobre trilhos é razoavelmente apurada, de maneira que a condução de uma pesquisa com uma amostra que seja estatisticamente válida é viável.

Sugere-se, também, a elaboração de um novo conjunto de benefícios, com base na opinião da sociedade, com a implantação de sistemas de transporte sobre trilhos.

Alternativa para trabalhos futuros é a aplicação do questionário com a escala de Likert para dois grupos distintos, um de especialistas e outro de 
usuários do sistema de transporte sobre trilhos, para medir a percepção de cada um dos grupos utilizando uma escala única. 


\section{Referências}

BANCO MUNDIAL. Cidades em Movimento: Estratégia de Transporte Urbano do Banco Mundial. Tradução Eduardo de Farias Lima. São Paulo: Sumatra Editorial, 2003.

BRAND, C.; PRESTON, J. Which Technology for Urban Public Transport? A Review of a System Performance, Costs and Impacts. Proceedings of Institution of Civil Engineers Transport 156, Issue TR4, Paper 13215. Oxford, UK, 2003. $10 \mathrm{p}$.

CERVERO, R. Land Market Impacts of Urban Rail Transit and Joint Development: An Empirical Study of Rail Transit in Washington, D.C. and Atlanta. Working Paper UCTC No. 135. Sixth World Conference on Transport Research, Lyon, France, 1992.

CERVERO, R.; SANDOVAL, O.; LANDIS, J. Transportion as a Stimulus of Welfare-to-Work. Journal of Planning Education and Research No. 22. Associaton of Collegiate Schools of Planning, 2002. 14 p.

CHEN, H. ; RUFOLO, A. ; DUECKER, K.J. Measuring the Impact of Light Rail Systems on Single Family Home Values: A Hedonic Approach with GIS Application. Discussion Paper 97-3, Center for Urban Studies, College of Urban and Public Affairs, Portland State University, Oregon, USA, 1997.

CIA DO METROPOLITANO DE SÃO PAULO - METRÔ. Balanço Social. Publicação Interna, São Paulo, 2004.

COSTA, J.M.S.P. Contribuição à Comparação de Meios para o Transporte Urbano. Escola de Engenharia de São Carlos, Universidade de São Paulo, São Carlos, 2001.

DARONCHO, C. Contribuição à Análise de Qualidade de Viagens e suas Relações com a Distribuição de Defeitos em Segmentos de Rodovias. Escola 
de Engenharia de São Carlos, Universidade de São Paulo, São Carlos, 2001.

DIAZ, R.B. Impact of Rail Transit in Property Values. APTA Rapid Transit Conference Proceedings Papers. Business and Community Development, Track 3 - Partnering, pp 1-8, Clean, VA, 1999.

DORN, J.L. Rail-Volution Conference. Disponível em:

http://www.fta.dot.gov/2636 12406 ENG Printable.htm Acesso em 23 jun. 2006.

ECMT. Sustainable Policies Transports. Paris: OECD Publications, 2000.

ECO, U. Como se Faz uma Tese. Rio de Janeiro: Perspectiva, 1977.

FARIA, C.A. Percepção do Usuário com Relação às Características do Nível de Serviço do Transporte Coletivo Urbano por Ônibus. 1985. 152 p. Dissertação (Mestrado) - Escola de Engenharia de São Carlos, Universidade de São Paulo, São Carlos, 1985.

FELEX, J.B. O usuário: um instrumento de avaliação. São Carlos. 203p. Tese (Doutorado) - Escola de Engenharia de São Carlos, Universidade de São Paulo, 1983.

FELZ, H. Revitaliser les Centres Villes par les Transports Publics. In: $48^{\mathrm{TH}}$ Congres International - UITP. Commission Internationale de la Circulation et de L'Amenagement Urbain, Budapest, 1989.

FERRAZ, A.C.P. ; TORRES, I.G.E. Transporte Público Urbano. $2^{\text {a }}$ ed. São Carlos: Rima Editora, 2004.

FTA. Joint Identification Clients Needs. Disponível em:

http://www.fta.dot.gov/5805 2207 ENG Printable.htm Acesso em 23 jun. 2006.

GATZLAFF, D.H. ; SMITH, M.T. The Impact of the Miami Metrorail on the Value of Residences near Station Locations. Land Economics, February, 69, 1, pp. 54-66, 1993.

GLEAVER, S.D. What Light Rail Can Do For The Cities. A Review of the Evidence. Passenger Transport Executive Group. Londres, 2005. 
GOODWIL, J.A. Public Transportation Synthesis Series III. Relationships Between Business and Public Transportation. National Center of Transit Research, Center of Urban Transportation Research, University of South Florida, 2004.

GUILFORD, J.P. Fundamental Statistics in Psychology and Education. $2^{\mathrm{a}}$ ed. Toronto: McGraw Hill Book Company, Inc., 1950.

HIDALGO, D.; YEPES, T. Are Bus Rapid Transit Systems Effective in Poverty Reduction? Experience of Bogotá's TransMilenio and Lessons For Other Cities. TRB Annual Meeting, 2005.

HAIR, J. F., ANDERSON, R. E., TATHAM, R. L., BLACK, W. C. Multivariate data analysis. $5^{\mathrm{a}}$ ed. New Jersey: Prentice Hall, 1998.

IBGE. Tabela de Resultados Disponível em:

http://www.ibge.gov.br/home/estatistica/economia/cadastroempresa/2003/tabel a1.pdf Acesso em 22 abr. 2006.

JUTULSTAD, $\mathrm{H}$. Calculating the Benefits of Public Transport to the Community. AS Oslo Sporveier, Norway. Disponível em: http://www.sporveier.no Acesso em: 17 nov. 2005.

KAWAMOTO, E. Análise de Sistemas de Transporte. Escola de Engenharia de São Carlos, Departamento de Transportes. $2^{\mathrm{a}}$ ed. São Carlos, 2002.

LEVINE,D.M., STEPHAN, D., KREHBIEL, T.C., BERENSON, M.L. Estatística Teoria e Aplicações.LTC Livros Técnicos e Cíentificos Editora. $3^{a}$ ed. Rio de Janeiro, 2004.

LEWIS, D.; WILLIANS, F.L. Policy and Planning as Public Choice: Mass Transit in the USA. Burlington, VT, Ashgate, 1999.

LIKERT, R. (1932). A technique for the measurement of attitudes. Archives of Psychology, n. 140.

LISBOA, M. V. Contribuição para tomada de decisão na classificação e seleção de alternativas de traçado para rodovias em trechos urbanizados / São Paulo, 2002. 194p. Dissertação (Mestrado) - Escola Politécnica da Universidade de São Paulo. Departamento de Engenharia de Transportes. 
LITMAN, T. Land Use Impact Costs of Transportation. World Transport Policy \& Practice, Vol. 1, No. 4, pp. 9-16, 1995.

LITMAN, T. Evaluating Public Transit Benefits and Costs. Best Practices Guidebook. Victoria Transport Policy Institute, 88 p., Victoria, BC, Canada, 2004.

LITMAN, T. Evaluating Rail Transit Criticism. Victoria Transport Policy Institute, 44 p., Victoria, BC, Canada, 2005(a).

LITMAN, T. Rail Transit in America. A Comprehensive Evaluation of Benefits. Victoria Transport Policy Institute, 50 p., Victoria, BC, Canada, 2005(b).

MASTAGLIO, M. All Aboard! Commuter Rail: A growing Alternative for Metro Areas. Overview of Transportation Topics. National Association of Realtors. Disponível em: http://www.realtor.org/SG3.nsf/transection.pdf Acesso em: 16 jan. 2006

MELO, R.A.. Avaliadores, Notas e Qualidade de Pavimentos. 1998. 136 p. Dissertação (Mestrado) - Escola de Engenharia de São Carlos, Universidade de São Paulo, São Carlos, 1998.

OLIVEIRA, L.H. Exemplo de cáclulo de Ranking Médio para Likert. Notas de Aula. Metodologia Científica e Técnicas de Pesquisa em Administração. Mestrado em Adm. e Desenvolvimento Organizacional. PPGA CNEC/FACECA: Varginha, 2005.

O'MAHOY, M. Environmental and Social Transport Costs: a case Study of Ireland. TRB 2005 Annual Meeting, 2004.

PADULA, F.R.G. Qualidade de pavimentos e auditoria. São Carlos. 73p. Dissertação (Mestrado) - Escola de Engenharia de São Carlos, Universidade de São Paulo, 1999.

PEZERICO, L.A.M. Sistemas de Avaliação de Desempenho no Transporte Urbano: Uma Abordagem para o Setor Metroferroviário. 2004. 116 p. Dissertação (Mestrado Profissionalizante) - Escola de Engenharia, Universidade Federal do Rio Grande do Sul, Porto Alegre, 2004. 
RATTON NETO, H.X.; CURY, M.V.Q.; CASTELLO BRANCO, J.E. Sistema Metroferroviário Brasileiro - Problemas e Soluções. Programa de Engenharia de Transportes da COPPE/UFRJ. $1^{\text {a }}$ Ed. Rio de Janeiro, 2006.

REVILLION, A.S.P. A Utilização de Pesquisas Exploratórias na Área de Marketing. RIMAR - Revista Interdisciplinar de Marketing, v.2, n.2., Porto Alegre, 2003.

RIBEIRO NETO, A.A.A. Contribuição à Avaliação do Transporte Urbano por Ônibus. 2001. 98 p. Dissertação (Mestrado) - Escola de Engenharia de São Carlos, Universidade de São Paulo, São Carlos, 2001.

RICHARDSON, R.J. Pesquisa Social. Métodos e Técnicas. $3^{a}$ ed. São Paulo: Editora Atlas, 2007.

RIDLEY, T.M.; FAWKNER, J. Benefit Sharing: the Funding of Urban Transport through Contributions from External Beneficiaries. In: $47^{\mathrm{TH}}$ International Congress - UITP. International Metropolitan Railways Committee, Lausanne, 1987.

RODRIGUES, M. O. Avaliação da Qualidade do Transporte Coletivo da Cidade de São Carlos. Escola de Engenharia de São Carlos, Universidade de São Paulo, São Carlos, 2006.

SAATY, T.L. Método de Análise Hierárquica. Tradução e Revisão Técnica de Wainer da Silveira e Silva, $1^{a}$ ed. São Paulo: Makron Books do Brasil Editora, 1991.

SALOMON,V.P.; MONTEVECHI, J.A.B.; PAMPLONA, E.O. Justificativas para aplicação do método de análise hierárquica. 19 ENEGEP. Rio de Janeiro, 1999.

SILVA, A.N. R.; WAYT, R.. Notas de aula do curso de modelos de avaliação multicritério. Convênio da Escola de Engenharia de São Carlos, Universidade de São Paulo com a Universidade de Melbourne, Austrália. São Carlos, 2004.

SCHAPIRO, R.J.; HASSET, K.A.; ARNOLD, F.S. Conserving Energy and Preserving the Environment: The Role of Public Transportation. APTA American Public Transportation Association, 2002. 
Benefits. Journal of the Transportation Research Board, record n. 1785, Paper n. 02-4136, p. 18-24, Washington, 2002.

SHIFTAN, Y. ; BEN-AKIVA, M. ; JONG, G. ; HAKKERT, S. ; SIMMONDS, D. Evaluation of Externalities in Transport Projects. STELLA FG4 Workshop. EJTIR, 2, nº 3 / 4, pp. 285-304, 2003.

SCHRANK, D.; LOMAX, T. The 2005 Urban Mobility Report. Texas Transportation Institute. The Texas A\&M University System, 2005.

SIERPINSKA, A., KILPATRICK, J., BALACHEFF, N. What is research in mathematics education and what are their results. Journal for Research in Mathematics Education , 24(3), 1993.

STRAND, J. ; VAGNES, M. The Relationship Between Property Values and Railroad Proximity: a Study Based on Hedonic Prices and Real State Brokers' Appraisals. Kluwer Academic Publishers. Transportation 28, pp. 137-156, 2001.

TYSON, W.J. Non-user Benefits of Public Transport. UITP Magazine n. 05/99, p. 40-45, 1999.

TYSON, W.J. Who Profits from Public Transport? Non-User Benefits: the Hidden Treasures for the Community. $49^{\mathrm{TH}}$ International Congress - UITP. International Commission for Transport Economics, Stockholm, 1991.

VARGAS, D. A Construção de uma Escala de Atitudes Frente ao Álcool, ao Alcoolismo e ao Alcoolista: um Estudo Psicométrico. 2005. 244 p. Tese (Doutorado) - Escola de Enfermagem de Ribeirão Preto, Universidade de São Paulo, Ribeirão Preto, 2005.

VIVIER, J. Comparison of the External Costs of Public Transport and Cars in Urban Areas: The Case of the Greater Paris Region. UITP Magazine n. 05/99, p. 36-38, 1999.

WEYRICH, P.M.; LIND, W.S. Twelve Anti-Transit Myths. A conservative Critiques. Free Congress Research an Education Foundation. Washington, 2001.

WEYRICH, P.M.; LIND, W.S. How Transit Benefit s People How Do Not Ride It: A Conservative Inquiry. Free Congress Research an Education Foundation. Washington, 2003. 


\section{Apêndice A - Formulário de}

\section{Pesquisa junto a Sociedade}

Questionário de Pesquisa - Benefícios do Transporte Público Sobre Trilh
\begin{tabular}{|l|l|}
\hline Local $R E C I F E$ & Data \\
\hline 1) Sexo & Feminino () \\
\hline
\end{tabular}

\begin{tabular}{|l|l|l|l|}
\hline \multicolumn{4}{|c|}{ Quantas vezes por semana utiliza transporte sobre trilhos (Metro, CPTM) } \\
\hline Nǎ Usa & & 4 Vezes por semana & \\
\hline 1 Vez por Semana & & 5 Vezes por semana & \\
\hline 2 Vezes por semana & & Fim de semana & \\
\hline 3 Vezes por semana & & Todos os dias & \\
\hline
\end{tabular}

\begin{tabular}{|l|l|}
\hline \multicolumn{2}{|c|}{ 3) Idade } \\
\hline 17 a 19 anos & \\
\hline 20 a 24 anos & \\
\hline 25 a 29 anos & \\
\hline 30 a 39 anos & \\
\hline 40 a 49 anos & \\
\hline 50 a 59 anos & \\
\hline Acima de 60 anos & \\
\hline
\end{tabular}

\begin{tabular}{|l|l|}
\hline \multicolumn{2}{|c|}{ 4) Rendimento } \\
\hline Sem rendimento & \\
\hline Ate RS 415,00 & \\
\hline RS 415,00 a RS 830,00 & \\
\hline RS 830,00 a RS $1.245,00$ & \\
\hline RS $1.245,00$ a RS $2.075,00$ & \\
\hline RS $2.075,00$ a RS $4.150,00$ & \\
\hline RS $4.150,00$ a RS $8.300,00$ & \\
\hline Acima de RS $8.300,00$ & \\
\hline
\end{tabular}

\section{5) Ocupação}

Membros das forças armadas, policiais e bombeiros militares

Membros seperiores do pode pthilico, dirlgentes de crganila

Ocupą̧tes mal especificadas

Profissionais das ciências e das artes

Trahalhadores dos serviços, vendedones do comércio em lojas e mercados

Trahalhadores de serviços administrativos

Trahalhadores em serviços de reparaçäo e manutençăo

Trahalhadores da produçțo de bens e serviços industriais

Técnicos de nível médio

6) Opinar sobre os beneficios do Transporte Sobre Trilhos para a comunidade:

\begin{tabular}{|c|c|c|c|c|c|}
\hline $\begin{array}{l}\text { Diminuiç̦̃o do trânsito devido ao uso do } \\
\text { Transporte sobre Trilhos. } \\
\end{array}$ & $\mathrm{CT}$ & C & I & D & DT \\
\hline $\begin{array}{l}\text { Aumento da qualidade de vida devido a } \\
\text { diminuiçăo da poluiçto do ar, sonora, visual e } \\
\text { dano ecológico. }\end{array}$ & $\mathrm{CT}$ & C & I & D & DT \\
\hline $\begin{array}{l}\text { Economia do dinheiro público devido a baixos } \\
\text { investimentos em construçto e manutençto de } \\
\text { vias públicas. }\end{array}$ & $\mathrm{CT}$ & C & I & D & DT \\
\hline $\begin{array}{l}\text { Aces50 a0s serviç05 públic05 com maior eficiéncia } \\
\text { hospitais, repartiçles públicas, etc). }\end{array}$ & $\mathrm{CT}$ & C & I & D & DT \\
\hline $\begin{array}{l}\text { Melhora a economia da cidade e dos centros } \\
\text { regionais. }\end{array}$ & $\mathrm{CT}$ & C & I & D & DT \\
\hline $\begin{array}{l}\text { Uso das fontes de petróleo com eficiéncia devido } \\
\text { o menor consumo em funç̧o do uso do } \\
\text { transporte público. }\end{array}$ & $\mathrm{CT}$ & C & I & D & DT \\
\hline $\begin{array}{l}\text { Reduçăo no custo dos acidentes de tránsito e } \\
\text { danos provocados por eles. }\end{array}$ & $\mathrm{CT}$ & C & I & D & DT \\
\hline
\end{tabular}




\section{Apêndice B - Modelo da Planilha Enviada aos Especialistas}

\begin{tabular}{|c|c|c|c|c|c|c|c|c|c|c|}
\hline & a) & b) & c) & d) & e) & f) & g) & & \multirow{8}{*}{\multicolumn{2}{|c|}{ \#DIV/0! }} \\
\hline a) & 1 & \#DIV/O! & \#DIV/O! & \#DIV/O! & \#DIV/O! & \#DIV/O! & \#DIV/O! & & & \\
\hline b) & & 1 & \#DIV/O! & \#DIV/0! & \#DIV/0! & \#DIV/O! & \#DIV/O! & & & \\
\hline c) & & & 1 & \#DIV/O! & \#DIV/O! & \#DIV/O! & \#DIV/O! & & & \\
\hline d) & & & & 1 & \#DIV/O! & \#DIV/O! & \#DIV/O! & & & \\
\hline e) & & & & & 1 & \#DIV/O! & \#DIV/O! & & & \\
\hline f) & & & & & & 1 & \#DIV/O! & & & \\
\hline \multirow{3}{*}{$\begin{array}{l}\text { g) } \\
\text { Soma }\end{array}$} & & & & & & & 1 & & & \\
\hline & 1,00000 & \#DIV/0! & \#DIV/0! & \#DIV/0! & \#DIV/O! & \#DIV/0! & \#DIV/0! & & Consistência & \#DIV/0! \\
\hline & & & & & & & & Fatores & \\
\hline a) & \multicolumn{7}{|c|}{ Diminuição do trânsito devido ao uso do Transporte Público sobre Trilhos } & \#DIV/0! & \multirow{2}{*}{\multicolumn{2}{|c|}{$\begin{array}{l}\text { \#DIV/0! } \\
\text { \#DIV/0! }\end{array}$}} \\
\hline b) & \multicolumn{7}{|c|}{$\begin{array}{l}\text { Aumento da qualidade de vida devido a diminuição da poluição do ar, } \\
\text { sonora, visual e dano ecológico }\end{array}$} & \#DIV/0! & & \\
\hline c) & \multicolumn{7}{|c|}{$\begin{array}{l}\text { Economia do dinheiro público devido a baixos investimentos em construção } \\
\text { e manutenção de vias públicas }\end{array}$} & \#DIV/0! & \multicolumn{2}{|l|}{ \#DIV/0! } \\
\hline d) & \multicolumn{7}{|c|}{$\begin{array}{l}\text { Acesso aos serviços públicos com maior eficiência (hospitais, repartições } \\
\text { públicas, etc) }\end{array}$} & \#DIV/0! & \multicolumn{2}{|l|}{ \#DIV/0! } \\
\hline e) & \multicolumn{7}{|c|}{ Melhora a economia da cidade e dos centros regionais } & \#DIV/0! & \multicolumn{2}{|l|}{ \#DIV/0! } \\
\hline f) & \multicolumn{7}{|c|}{$\begin{array}{l}\text { Uso das fontes de petróleo com eficiência devido ao menor consumo em } \\
\text { função do uso do transporte público. }\end{array}$} & \#DIV/0! & \multicolumn{2}{|l|}{ \#DIV/0! } \\
\hline g) & \multicolumn{7}{|c|}{ Redução no custo dos acidentes de trânsito e danos provocados por eles } & \#DIV/0! & \multicolumn{2}{|l|}{ \#DIV/0! } \\
\hline
\end{tabular}




\section{Apêndice C-Resultados da Pesquisa Junto a Sociedade}

\begin{tabular}{|c|c|c|c|c|c|c|c|c|c|c|c|c|c|c|c|}
\hline $\mathbf{N}^{\circ}$ Ordem & Local & Região & Usuário SN & Sexo & Rendimento & Usuário & Idade & Ocupação & V1 & V2 & V3 & V4 & V5 & V6 & v7 \\
\hline 1 & Uniban SAN & $\mathrm{SP}$ & $\mathrm{N}$ & $f$ & 3 & $\mathrm{~F}$ & 2 & 6 & $\mathrm{C}$ & $\mathrm{C}$ & DT & $\mathrm{D}$ & 1 & $\mathrm{C}$ & $\mathrm{C}$ \\
\hline 2 & Uniban SAN & SP & $\mathrm{N}$ & $\mathrm{m}$ & 4 & $\mathrm{~N}$ & 2 & 6 & CT & $\mathrm{CT}$ & I & $C$ & I & C & CT \\
\hline 3 & Uniban SAN & SP & $\mathrm{N}$ & $\mathrm{m}$ & 3 & $\mathrm{~N}$ & 3 & 8 & $\mathrm{CT}$ & $\mathrm{C}$ & I & I & I & C & C \\
\hline 4 & Uniban SAN & SP & $S$ & $f$ & 2 & 7 & 3 & 6 & $\mathrm{D}$ & I & DT & C & C & I & I \\
\hline 5 & Uniban SAN & SP & $S$ & $\mathrm{~m}$ & 5 & 5 & 3 & 6 & $\mathrm{CT}$ & CT & I & $\mathrm{CT}$ & CT & C & C \\
\hline 6 & Uniban SAN & SP & $S$ & $f$ & 4 & 5 & 3 & 6 & I & $\mathrm{D}$ & DT & C & $\mathrm{D}$ & I & $\mathrm{D}$ \\
\hline 7 & Uniban SAN & SP & $S$ & $\mathrm{~m}$ & 3 & 5 & 3 & 6 & $\mathrm{CT}$ & $\mathrm{CT}$ & I & C & $C$ & $\mathrm{CT}$ & CT \\
\hline 8 & Uniban SAN & SP & $\mathrm{N}$ & $\mathrm{m}$ & 5 & $\mathrm{~N}$ & 3 & 8 & $\mathrm{CT}$ & $\mathrm{CT}$ & $\mathrm{CT}$ & $\mathrm{CT}$ & $\mathrm{CT}$ & $\mathrm{CT}$ & $\mathrm{CT}$ \\
\hline 9 & Uniban SAN & SP & $S$ & $f$ & 3 & 5 & 3 & 6 & $C$ & C & I & C & $\mathrm{D}$ & I & C \\
\hline 10 & Uniban SAN & SP & $\mathrm{N}$ & $f$ & 6 & $\mathrm{~N}$ & 5 & 6 & C & CT & $\mathrm{CT}$ & I & $C$ & C & I \\
\hline 11 & Uniban SAN & SP & $S$ & $f$ & 5 & 5 & 5 & 6 & $\mathrm{CT}$ & CT & $\mathrm{CT}$ & C & CT & $\mathrm{CT}$ & CT \\
\hline 12 & Uniban SAN & SP & $\mathrm{N}$ & $\mathrm{m}$ & 2 & $\mathrm{~N}$ & 2 & 6 & $\mathrm{CT}$ & CT & CT & C & CT & C & CT \\
\hline 13 & Uniban SAN & SP & $\mathrm{N}$ & $\mathrm{m}$ & 3 & $\mathrm{~N}$ & 2 & 6 & $\mathrm{C}$ & $\mathrm{C}$ & I & I & $C$ & I & 1 \\
\hline 14 & Uniban SAN & SP & $\mathrm{N}$ & $\mathrm{m}$ & 3 & $\mathrm{~N}$ & 3 & 6 & C & CT & $\mathrm{CT}$ & $\mathrm{CT}$ & $C$ & C & C \\
\hline 15 & Uniban SAN & SP & $\mathrm{N}$ & $\mathrm{m}$ & 4 & $\mathrm{~N}$ & 4 & 7 & C & CT & I & I & I & C & $D$ \\
\hline 16 & Uniban SAN & SP & $S$ & $\mathrm{~m}$ & 3 & 7 & 2 & 6 & C & CT & DT & I & C & C & C \\
\hline 17 & Uniban SAN & SP & $\mathrm{N}$ & $f$ & 5 & 1 & 3 & 6 & C & $\mathrm{C}$ & DT & C & C & C & C \\
\hline 18 & Uniban SAN & SP & $\mathrm{N}$ & $f$ & 4 & $\mathrm{~N}$ & 3 & 6 & C & C & DT & $D$ & $\mathrm{D}$ & C & $D$ \\
\hline 19 & Uniban SAN & SP & $\mathrm{N}$ & $f$ & 4 & $\mathrm{~N}$ & 2 & 6 & $\mathrm{CT}$ & CT & I & C & I & C & C \\
\hline 20 & Uniban SAN & SP & $S$ & $\mathrm{~m}$ & 3 & 5 & 3 & 6 & CT & CT & DT & C & C & CT & C \\
\hline 21 & Uniban SAN & SP & $\mathrm{N}$ & $f$ & 2 & $\mathrm{~N}$ & 2 & 6 & DT & $D$ & DT & I & $D$ & I & DT \\
\hline 22 & Uniban SAN & SP & $\mathrm{N}$ & $f$ & 5 & $\mathrm{~N}$ & 4 & 3 & C & I & DT & I & I & 1 & 1 \\
\hline
\end{tabular}




\begin{tabular}{|c|c|c|c|c|c|c|c|c|c|c|c|c|c|c|c|}
\hline $\mathrm{N}^{\circ}$ Ordem & Local & Região & Usuário SN & Sexo & Rendimento & Usuário & Idade & Ocupação & V1 & V2 & V3 & V4 & V5 & V6 & V7 \\
\hline 23 & Uniban SAN & SP & $\mathrm{N}$ & $f$ & 5 & $\mathrm{~N}$ & 3 & 6 & C & C & $C$ & $\mathrm{D}$ & $\mathrm{D}$ & C & C \\
\hline 24 & Uniban SAN & SP & $S$ & $f$ & 5 & 3 & 3 & 6 & C & C & I & $\mathrm{CT}$ & $\mathrm{CT}$ & C & C \\
\hline 25 & Uniban SAN & SP & $\mathrm{N}$ & $\mathrm{m}$ & 6 & $\mathrm{~N}$ & 5 & 6 & C & C & $D$ & I & $\mathrm{D}$ & C & C \\
\hline 26 & Uniban SAN & SP & $\mathrm{N}$ & $\mathrm{m}$ & 5 & $\mathrm{~N}$ & 3 & 8 & C & C & C & C & $\mathrm{D}$ & $\mathrm{D}$ & I \\
\hline 27 & Uniban SAN & SP & $S$ & $\mathrm{~m}$ & 6 & 3 & 5 & 2 & $\mathrm{CT}$ & C & C & $\mathrm{CT}$ & $\mathrm{CT}$ & $\mathrm{CT}$ & $\mathrm{CT}$ \\
\hline 28 & Uniban SAN & SP & $S$ & $\mathrm{~m}$ & 0 & 3 & 5 & 6 & $\mathrm{CT}$ & $\mathrm{CT}$ & C & C & $\mathrm{CT}$ & C & C \\
\hline 29 & Uniban SAN & SP & $S$ & $f$ & 3 & 3 & 3 & 6 & $\mathrm{D}$ & C & I & C & I & $\mathrm{D}$ & 1 \\
\hline 30 & Uniban SAN & SP & $S$ & $\mathrm{~m}$ & 5 & 5 & 4 & 6 & $\mathrm{CT}$ & $\mathrm{CT}$ & $\mathrm{D}$ & I & I & I & C \\
\hline 31 & Uniban SAN & SP & $\mathrm{N}$ & $\mathrm{m}$ & 5 & 1 & 4 & 2 & C & $\mathrm{CT}$ & $\mathrm{CT}$ & C & $\mathrm{CT}$ & $\mathrm{D}$ & $D$ \\
\hline 32 & Uniban SAN & SP & $\mathrm{N}$ & $\mathrm{m}$ & 6 & $\mathrm{~N}$ & 5 & 1 & $\mathrm{CT}$ & $\mathrm{CT}$ & $\mathrm{CT}$ & $\mathrm{CT}$ & $\mathrm{CT}$ & CT & CT \\
\hline 33 & Uniban SAN & SP & $\mathrm{N}$ & $f$ & 5 & $F$ & 4 & 8 & $\mathrm{CT}$ & $\mathrm{CT}$ & I & C & $\mathrm{CT}$ & $\mathrm{CT}$ & $\mathrm{CT}$ \\
\hline 34 & Uniban SAN & SP & $\mathrm{N}$ & $\mathrm{m}$ & 4 & 1 & 4 & 6 & I & I & $D$ & $D$ & I & C & C \\
\hline 35 & Uniban SAN & SP & $S$ & $f$ & 2 & 5 & 3 & 8 & C & $D$ & DT & C & $\mathrm{D}$ & 1 & 1 \\
\hline 36 & Uniban SAN & SP & $\mathrm{N}$ & $f$ & 7 & $\mathrm{~N}$ & 5 & 2 & C & C & $D$ & $D$ & C & C & C \\
\hline 37 & Uniban SAN & SP & $S$ & $f$ & 5 & 5 & 4 & 6 & C & C & C & C & C & C & C \\
\hline 38 & Uniban SAN & SP & $\mathrm{N}$ & $\mathrm{m}$ & 5 & $\mathrm{~N}$ & 5 & 8 & $\mathrm{CT}$ & $\mathrm{CT}$ & C & C & C & $\mathrm{D}$ & C \\
\hline 39 & Uniban SAN & SP & $\mathrm{N}$ & $\mathrm{m}$ & 5 & $\mathrm{~N}$ & 4 & 8 & $\mathrm{CT}$ & C & C & C & $\mathrm{CT}$ & C & $\mathrm{CT}$ \\
\hline 40 & Uniban SAN & SP & $S$ & $f$ & 5 & 7 & 4 & 6 & $\mathrm{CT}$ & $\mathrm{CT}$ & $\mathrm{CT}$ & C & C & C & $\mathrm{CT}$ \\
\hline 41 & Uniban SAN & SP & $\mathrm{N}$ & $\mathrm{m}$ & 6 & $\mathrm{~N}$ & 6 & 2 & C & C & C & C & C & C & C \\
\hline 42 & Uniban SAN & SP & $S$ & $\mathrm{~m}$ & 5 & 5 & 3 & 6 & DT & $D$ & I & $D$ & C & C & C \\
\hline 43 & Uniban SAN & SP & $S$ & $\mathrm{~m}$ & 3 & 5 & 2 & 5 & C & C & $D$ & C & I & CT & C \\
\hline 44 & Uniban SAN & SP & $S$ & $\mathrm{~m}$ & 4 & 5 & 3 & 6 & $\mathrm{CT}$ & $\mathrm{CT}$ & C & DT & $D$ & C & C \\
\hline 45 & Uniban SAN & SP & $S$ & $f$ & 4 & 3 & 2 & 8 & DT & $\mathrm{CT}$ & I & $D$ & C & C & $\mathrm{CT}$ \\
\hline 46 & Uniban SAN & SP & $\mathrm{N}$ & $\mathrm{m}$ & 3 & $\mathrm{~N}$ & 2 & 5 & $\mathrm{D}$ & C & I & $D$ & C & $\mathrm{D}$ & $\mathrm{CT}$ \\
\hline 47 & Uniban SAN & SP & $S$ & $f$ & 4 & 5 & 4 & 6 & $\mathrm{CT}$ & $\mathrm{CT}$ & $\mathrm{CT}$ & $\mathrm{CT}$ & $\mathrm{CT}$ & C & $\mathrm{CT}$ \\
\hline 48 & Uniban SAN & SP & $S$ & $f$ & 3 & 5 & 3 & 5 & $\mathrm{CT}$ & $\mathrm{CT}$ & C & $\mathrm{D}$ & C & $\mathrm{CT}$ & $\mathrm{CT}$ \\
\hline 49 & Uniban SAN & SP & $\mathrm{N}$ & $f$ & 3 & 2 & 1 & 6 & C & I & $\mathrm{D}$ & I & $\mathrm{D}$ & C & $\mathrm{D}$ \\
\hline 50 & Uniban SAN & SP & $\mathrm{N}$ & $\mathrm{m}$ & 4 & $\mathrm{~N}$ & 3 & 6 & $\mathrm{CT}$ & $\mathrm{CT}$ & I & $C$ & $\mathrm{CT}$ & $\mathrm{CT}$ & 1 \\
\hline
\end{tabular}




\begin{tabular}{|c|c|c|c|c|c|c|c|c|c|c|c|c|c|c|c|}
\hline $\mathbf{N}^{\circ}$ Ordem & Local & Região & Usuário SN & Sexo & Rendimento & Usuário & Idade & Ocupação & V1 & V2 & V3 & V4 & V5 & V6 & V7 \\
\hline 51 & Uniban SAN & $\mathrm{SP}$ & $\mathrm{N}$ & $\mathrm{m}$ & 2 & $\mathrm{~N}$ & 2 & 6 & $\mathrm{CT}$ & C & $D$ & C & I & C & 1 \\
\hline 52 & Uniban VMN & SP & $S$ & $f$ & 3 & 5 & 3 & 6 & $\mathrm{CT}$ & $\mathrm{CT}$ & I & C & I & C & CT \\
\hline 53 & Uniban VMN & SP & $\mathrm{N}$ & $\mathrm{m}$ & 3 & $\mathrm{~N}$ & 2 & 6 & $\mathrm{C}$ & 1 & I & $\mathrm{C}$ & $C$ & I & 1 \\
\hline 54 & Uniban VMN & SP & $\mathrm{N}$ & $f$ & 4 & $\mathrm{~N}$ & 4 & 6 & $\mathrm{CT}$ & CT & $\mathrm{D}$ & C & C & $\mathrm{C}$ & C \\
\hline 55 & Uniban VMN & SP & $S$ & $\mathrm{~m}$ & 3 & 3 & 2 & 5 & $\mathrm{CT}$ & $\mathrm{CT}$ & $D$ & $\mathrm{D}$ & CT & $\mathrm{CT}$ & CT \\
\hline 56 & Uniban VMN & SP & $\mathrm{N}$ & $f$ & 5 & 1 & 2 & 6 & C & C & $D$ & I & C & C & $\mathrm{C}$ \\
\hline 57 & Uniban VMN & SP & $\mathrm{N}$ & $f$ & 3 & 2 & 1 & 3 & $\mathrm{D}$ & DT & DT & I & $D$ & I & I \\
\hline 58 & Uniban VMN & SP & $\mathrm{N}$ & $f$ & 3 & 2 & 2 & 2 & C & I & I & I & I & I & $\mathrm{C}$ \\
\hline 59 & Uniban VMN & SP & $\mathrm{N}$ & $f$ & 2 & 2 & 1 & 6 & CT & $\mathrm{CT}$ & C & C & I & I & CT \\
\hline 60 & Uniban VMN & SP & $\mathrm{N}$ & $\mathrm{m}$ & 3 & $\mathrm{~N}$ & 2 & 5 & $\mathrm{C}$ & $\mathrm{CT}$ & I & C & C & C & CT \\
\hline 61 & Uniban VMN & SP & $S$ & $\mathrm{~m}$ & 2 & 5 & 3 & 6 & C & I & I & C & C & I & I \\
\hline 62 & Uniban VMN & SP & $\mathrm{N}$ & $\mathrm{m}$ & 4 & $\mathrm{~N}$ & 2 & 5 & $\mathrm{CT}$ & $\mathrm{C}$ & I & C & C & 1 & CT \\
\hline 63 & Uniban VMN & SP & $S$ & $\mathrm{~m}$ & 2 & 7 & 2 & 3 & C & C & $D$ & C & 1 & I & I \\
\hline 64 & Uniban VMN & SP & $S$ & $\mathrm{~m}$ & 2 & 5 & 2 & 6 & $\mathrm{CT}$ & $\mathrm{CT}$ & I & $C$ & C & 1 & $\mathrm{C}$ \\
\hline 65 & Uniban VMN & SP & $S$ & $f$ & 2 & 7 & 1 & 6 & $\mathrm{C}$ & C & 1 & $\mathrm{C}$ & C & $\mathrm{C}$ & $\mathrm{C}$ \\
\hline 66 & Uniban VMN & SP & $S$ & $f$ & 5 & 4 & 3 & 6 & C & C & C & C & C & C & C \\
\hline 67 & Uniban VMN & SP & $S$ & $f$ & 3 & 5 & 2 & 6 & $\mathrm{CT}$ & C & C & I & C & C & C \\
\hline 68 & Uniban VMN & SP & $S$ & $f$ & 3 & 5 & 2 & 6 & C & C & I & $\mathrm{C}$ & C & C & C \\
\hline 69 & Uniban VMN & SP & $\mathrm{N}$ & $f$ & 2 & 1 & 2 & 3 & C & C & CT & C & I & C & C \\
\hline 70 & Uniban VMN & SP & $S$ & $\mathrm{~m}$ & 3 & 7 & 3 & 6 & C & C & C & $\mathrm{CT}$ & C & C & CT \\
\hline 71 & Uniban VMN & SP & $S$ & $f$ & 3 & 7 & 3 & 6 & $\mathrm{CT}$ & $\mathrm{CT}$ & $\mathrm{C}$ & $\mathrm{CT}$ & CT & C & CT \\
\hline 72 & Uniban VMN & SP & $\mathrm{N}$ & $f$ & 3 & 2 & 1 & 6 & $\mathrm{CT}$ & $\mathrm{CT}$ & $\mathrm{C}$ & C & I & $\mathrm{CT}$ & CT \\
\hline 73 & Uniban VMN & SP & $S$ & $f$ & 4 & 7 & 3 & 6 & $\mathrm{CT}$ & $\mathrm{CT}$ & C & $\mathrm{CT}$ & I & C & CT \\
\hline 74 & Uniban VMN & SP & $\mathrm{N}$ & $f$ & 4 & 1 & 3 & 6 & $\mathrm{CT}$ & C & CT & $\mathrm{CT}$ & CT & $\mathrm{CT}$ & CT \\
\hline 75 & Uniban VMN & SP & $\mathrm{N}$ & $\mathrm{m}$ & 2 & 1 & 1 & 5 & $\mathrm{CT}$ & $\mathrm{CT}$ & $\mathrm{C}$ & C & C & C & CT \\
\hline 76 & Uniban VMN & SP & $S$ & $f$ & 2 & 7 & 3 & 3 & C & $\mathrm{CT}$ & C & C & I & $\mathrm{C}$ & CT \\
\hline 77 & Uniban VMN & SP & $S$ & $\mathrm{~m}$ & 1 & 7 & 1 & 5 & $\mathrm{CT}$ & $\mathrm{CT}$ & C & I & C & I & $\mathrm{CT}$ \\
\hline 78 & Uniban VMN & SP & $\mathrm{N}$ & $\mathrm{m}$ & 5 & 1 & 4 & 6 & $\mathrm{CT}$ & $\mathrm{CT}$ & CT & 1 & $\mathrm{CT}$ & $\mathrm{CT}$ & $\mathrm{CT}$ \\
\hline
\end{tabular}




\begin{tabular}{|c|c|c|c|c|c|c|c|c|c|c|c|c|c|c|c|}
\hline $\mathbf{N}^{\circ}$ Ordem & Local & Região & Usuário SN & Sexo & Rendimento & Usuário & Idade & Ocupação & V1 & V2 & V3 & V4 & V5 & V6 & V7 \\
\hline 79 & Uniban VMN & $\mathrm{SP}$ & $S$ & $f$ & 2 & 7 & 2 & 3 & $\mathrm{CT}$ & $\mathrm{CT}$ & $\mathrm{CT}$ & $\mathrm{CT}$ & $\mathrm{CT}$ & $\mathrm{CT}$ & CT \\
\hline 80 & Uniban VMN & SP & $S$ & $\mathrm{~m}$ & 1 & 5 & 1 & 3 & $\mathrm{C}$ & $\mathrm{CT}$ & C & C & CT & $\mathrm{C}$ & $\mathrm{C}$ \\
\hline 81 & Uniban VMN & SP & $S$ & $f$ & 3 & 7 & 2 & 6 & $\mathrm{CT}$ & $\mathrm{CT}$ & 1 & C & I & $\mathrm{C}$ & $\mathrm{C}$ \\
\hline 82 & Uniban VMN & SP & $\mathrm{N}$ & $\mathrm{m}$ & 1 & $\mathrm{~N}$ & 2 & 5 & $\mathrm{C}$ & $C$ & $\mathrm{D}$ & C & C & $\mathrm{C}$ & CT \\
\hline 83 & Uniban VMN & SP & $S$ & $\mathrm{~m}$ & 0 & 7 & 1 & 5 & $\mathrm{CT}$ & $\mathrm{CT}$ & 1 & C & C & 1 & $\mathrm{C}$ \\
\hline 84 & Uniban VMN & SP & $\mathrm{N}$ & $\mathrm{m}$ & 0 & $\mathrm{~N}$ & 2 & 3 & $\mathrm{C}$ & C & I & I & $\mathrm{C}$ & $\mathrm{C}$ & $\mathrm{C}$ \\
\hline 85 & Uniban VMN & SP & $\mathrm{N}$ & $f$ & 0 & $\mathrm{~F}$ & 1 & 3 & $\mathrm{CT}$ & C & 1 & CT & C & 1 & CT \\
\hline 86 & Uniban VMN & SP & $S$ & $\mathrm{~m}$ & 2 & 3 & 4 & 6 & $\mathrm{CT}$ & C & $\mathrm{C}$ & C & $\mathrm{C}$ & $\mathrm{C}$ & $\mathrm{C}$ \\
\hline 87 & Uniban VMN & SP & $S$ & $f$ & 3 & 5 & 3 & 6 & CT & $\mathrm{CT}$ & C & $\mathrm{D}$ & $\mathrm{D}$ & $\mathrm{D}$ & $\mathrm{D}$ \\
\hline 88 & Uniban VMN & SP & $\mathrm{N}$ & $f$ & 3 & $\mathrm{~N}$ & 3 & 5 & $\mathrm{C}$ & $\mathrm{CT}$ & C & C & I & C & CT \\
\hline 89 & Uniban VMN & SP & $\mathrm{N}$ & $\mathrm{m}$ & 4 & $\mathrm{~N}$ & 4 & 5 & I & I & $C$ & I & I & I & CT \\
\hline 90 & Uniban VMN & SP & $\mathrm{N}$ & $f$ & 3 & $\mathrm{~N}$ & 3 & 6 & CT & $\mathrm{CT}$ & I & CT & I & 1 & CT \\
\hline 91 & Uniban VMN & SP & $\mathrm{N}$ & $f$ & 3 & $\mathrm{~N}$ & 2 & 6 & $\mathrm{C}$ & $C$ & $C$ & C & $\mathrm{C}$ & C & $\mathrm{C}$ \\
\hline 92 & Uniban VMN & SP & $S$ & $f$ & 5 & 5 & 4 & 6 & CT & $\mathrm{CT}$ & $C$ & CT & I & C & $\mathrm{C}$ \\
\hline 93 & Uniban VMN & SP & $S$ & $f$ & 0 & 5 & 2 & 3 & 1 & C & 1 & $\mathrm{C}$ & 1 & 1 & $\mathrm{C}$ \\
\hline 94 & Uniban VMN & SP & $\mathrm{N}$ & $\mathrm{m}$ & 3 & $\mathrm{~N}$ & 4 & 5 & C & C & $\mathrm{C}$ & $\mathrm{D}$ & I & I & C \\
\hline 95 & Uniban VMN & SP & $\mathrm{N}$ & $\mathrm{m}$ & 0 & 1 & 3 & 3 & C & I & 1 & I & $\mathrm{C}$ & $D$ & C \\
\hline 96 & Uniban VMN & SP & $\mathrm{N}$ & $f$ & 0 & $\mathrm{~N}$ & 2 & 3 & C & CT & C & I & C & $\mathrm{C}$ & $\mathrm{C}$ \\
\hline 97 & Uniban VMN & SP & $S$ & $\mathrm{~m}$ & 2 & 5 & 2 & 5 & $\mathrm{D}$ & $C$ & DT & DT & $D$ & $D$ & I \\
\hline 98 & Uniban VMN & SP & $S$ & $f$ & 2 & 7 & 3 & 5 & I & C & I & I & I & $\mathrm{C}$ & C \\
\hline 99 & Uniban VMN & SP & $S$ & $\mathrm{~m}$ & 2 & 7 & 1 & 6 & $\mathrm{CT}$ & C & I & I & $D$ & $\mathrm{C}$ & I \\
\hline 100 & Uniban VMN & SP & $\mathrm{N}$ & $f$ & 2 & 1 & 2 & 3 & $\mathrm{C}$ & $\mathrm{CT}$ & I & $\mathrm{C}$ & $\mathrm{C}$ & $\mathrm{C}$ & C \\
\hline 101 & Uniban VMN & SP & $S$ & $\mathrm{~m}$ & 2 & 5 & 2 & 5 & $\mathrm{C}$ & C & $\mathrm{C}$ & C & $\mathrm{C}$ & $\mathrm{C}$ & C \\
\hline 102 & Uniban VMN & SP & $S$ & $\mathrm{~m}$ & 2 & 5 & 4 & 5 & $D$ & C & DT & $\mathrm{CT}$ & I & $\mathrm{C}$ & $\mathrm{D}$ \\
\hline 103 & Uniban VMN & SP & $S$ & $f$ & 2 & 7 & 3 & 6 & $\mathrm{C}$ & $\mathrm{CT}$ & C & $\mathrm{C}$ & I & $\mathrm{C}$ & I \\
\hline 104 & Uniban VMN & SP & $S$ & $\mathrm{~m}$ & 3 & 7 & 3 & 6 & $\mathrm{CT}$ & $\mathrm{CT}$ & C & $\mathrm{C}$ & I & 1 & CT \\
\hline 105 & Uniban VMN & SP & $S$ & $\mathrm{~m}$ & 3 & 7 & 3 & 8 & $\mathrm{C}$ & $\mathrm{D}$ & I & I & I & 1 & I \\
\hline 106 & Uniban VMN & SP & $\mathrm{N}$ & $\mathrm{m}$ & 3 & $\mathrm{~N}$ & 2 & 6 & $\mathrm{CT}$ & $\mathrm{CT}$ & $\mathrm{C}$ & CT & $\mathrm{C}$ & CT & CT \\
\hline
\end{tabular}




\begin{tabular}{|c|c|c|c|c|c|c|c|c|c|c|c|c|c|c|c|}
\hline $\mathbf{N}^{\circ}$ Ordem & Local & Região & Usuário SN & Sexo & Rendimento & Usuário & Idade & Ocupação & V1 & V2 & V3 & V4 & V5 & V6 & V7 \\
\hline 107 & Uniban VMN & SP & $S$ & $f$ & 2 & 7 & 2 & 6 & $\mathrm{CT}$ & $\mathrm{CT}$ & $C$ & 1 & $\mathrm{I}$ & 1 & $C$ \\
\hline 108 & Uniban VMN & SP & $\mathrm{N}$ & $f$ & 2 & $\mathrm{~N}$ & 4 & 5 & $\mathrm{C}$ & I & $\mathrm{C}$ & $\mathrm{C}$ & $C$ & $\mathrm{C}$ & $\mathrm{D}$ \\
\hline 109 & Uniban VMN & SP & $S$ & $f$ & 3 & 5 & 2 & 5 & $\mathrm{C}$ & $\mathrm{CT}$ & 1 & $\mathrm{C}$ & 1 & I & $D$ \\
\hline 110 & Uniban VMN & SP & $S$ & $\mathrm{~m}$ & 3 & 5 & 2 & 5 & $\mathrm{CT}$ & $\mathrm{CT}$ & I & $\mathrm{C}$ & $C$ & $\mathrm{C}$ & $\mathrm{C}$ \\
\hline 111 & Uniban VMN & SP & $S$ & $\mathrm{~m}$ & 3 & 7 & 3 & 6 & $\mathrm{D}$ & C & I & $\mathrm{C}$ & $C$ & $\mathrm{C}$ & $\mathrm{C}$ \\
\hline 112 & Uniban VMN & SP & $S$ & $f$ & 3 & 7 & 1 & 5 & $\mathrm{CT}$ & $\mathrm{CT}$ & $\mathrm{CT}$ & $\mathrm{CT}$ & $\mathrm{CT}$ & $\mathrm{CT}$ & CT \\
\hline 113 & Uniban VMN & SP & $S$ & $\mathrm{~m}$ & 3 & 7 & 2 & 5 & I & C & C & C & $C$ & I & 1 \\
\hline 114 & Uniban VMN & SP & S & $\mathrm{m}$ & 3 & 5 & 2 & 5 & $\mathrm{CT}$ & $\mathrm{CT}$ & $\mathrm{CT}$ & $\mathrm{CT}$ & $C$ & $\mathrm{CT}$ & CT \\
\hline 115 & Uniban VMN & SP & $\mathrm{N}$ & $f$ & 3 & 2 & 3 & 6 & $\mathrm{C}$ & $\mathrm{CT}$ & I & 1 & I & $\mathrm{C}$ & CT \\
\hline 116 & Uniban VMN & SP & $S$ & $f$ & 3 & 7 & 2 & 5 & $\mathrm{C}$ & I & C & 1 & $C$ & I & C \\
\hline 117 & Uniban VMN & SP & $\mathrm{N}$ & $\mathrm{m}$ & 4 & $\mathrm{~N}$ & 3 & 6 & $\mathrm{CT}$ & $\mathrm{CT}$ & C & $\mathrm{CT}$ & $\mathrm{CT}$ & C & C \\
\hline 118 & Uniban VMN & SP & $\mathrm{S}$ & f & 4 & 5 & 4 & 6 & $\mathrm{CT}$ & $\mathrm{CT}$ & $\mathrm{CT}$ & $\mathrm{CT}$ & $\mathrm{CT}$ & $\mathrm{CT}$ & CT \\
\hline 119 & Uniban VMN & SP & $\mathrm{N}$ & $\underline{f}$ & 4 & $\mathrm{~N}$ & 2 & 6 & C & $\mathrm{CT}$ & C & $\mathrm{D}$ & D & I & C \\
\hline 120 & Uniban VMN & SP & $\mathrm{N}$ & $\mathrm{m}$ & 4 & $\mathrm{~N}$ & 2 & 6 & $\mathrm{CT}$ & C & 1 & C & 1 & I & 1 \\
\hline 121 & Uniban VMN & SP & $\mathrm{N}$ & $f$ & 4 & $\mathrm{~N}$ & 3 & 6 & $\mathrm{CT}$ & $\mathrm{CT}$ & I & $\mathrm{C}$ & $C$ & $\mathrm{CT}$ & CT \\
\hline 122 & Uniban VMN & SP & $S$ & $\mathrm{~m}$ & 4 & 3 & 3 & 5 & $\mathrm{C}$ & $\mathrm{CT}$ & I & C & $C$ & $\mathrm{C}$ & C \\
\hline 123 & Uniban VMN & SP & $\mathrm{N}$ & $\mathrm{m}$ & 6 & 1 & 4 & 4 & $\mathrm{CT}$ & C & C & C & I & $\mathrm{C}$ & I \\
\hline 124 & Uniban VMN & SP & $\mathrm{N}$ & $f$ & 5 & 1 & 4 & 3 & $\mathrm{CT}$ & $\mathrm{C}$ & I & C & $\mathrm{C}$ & C & $\mathrm{CT}$ \\
\hline 125 & Uniban VMN & SP & $\mathrm{N}$ & $\mathrm{m}$ & 5 & $\mathrm{~N}$ & 3 & 7 & $\mathrm{CT}$ & $\mathrm{CT}$ & 1 & C & $\mathrm{CT}$ & $\mathrm{C}$ & C \\
\hline 126 & Uniban VMN & SP & $\mathrm{N}$ & $f$ & 5 & 1 & 5 & 5 & $\mathrm{CT}$ & $\mathrm{CT}$ & $\mathrm{CT}$ & $\mathrm{CT}$ & $\mathrm{CT}$ & CT & CT \\
\hline 127 & Uniban VMN & SP & $\mathrm{N}$ & $\mathrm{m}$ & 5 & 1 & 4 & 2 & $\mathrm{C}$ & $\mathrm{CT}$ & $\mathrm{CT}$ & C & $\mathrm{CT}$ & CT & CT \\
\hline 128 & Uniban VMN & SP & S & $\mathrm{m}$ & 5 & 5 & 5 & 5 & $\mathrm{CT}$ & $\mathrm{CT}$ & $\mathrm{C}$ & $\mathrm{CT}$ & $C$ & I & CT \\
\hline 129 & Uniban VMN & SP & $S$ & $f$ & 5 & 7 & 6 & 2 & $\mathrm{C}$ & $\mathrm{C}$ & C & $\mathrm{C}$ & $C$ & $\mathrm{C}$ & C \\
\hline 130 & Uniban - OS & RMSP & $\mathrm{N}$ & $f$ & 4 & $\mathrm{~N}$ & 3 & 6 & $\mathrm{C}$ & I & I & 1 & I & I & I \\
\hline 131 & Uniban - OS & RMSP & $\mathrm{N}$ & $\mathrm{m}$ & 3 & $\mathrm{~N}$ & 4 & 9 & C & C & C & $\mathrm{D}$ & $C$ & C & $\mathrm{C}$ \\
\hline 132 & Uniban - OS & RMSP & $\mathrm{S}$ & $\mathrm{m}$ & 3 & 5 & 2 & 7 & C & C & I & $D$ & $\mathrm{D}$ & $\mathrm{C}$ & $\mathrm{CT}$ \\
\hline 133 & Uniban - OS & RMSP & $\mathrm{N}$ & $\mathrm{m}$ & 5 & $\mathrm{~N}$ & 3 & 3 & $\mathrm{CT}$ & $\mathrm{CT}$ & $\mathrm{CT}$ & CT & $\mathrm{CT}$ & CT & $\mathrm{CT}$ \\
\hline 134 & Uniban - OS & RMSP & $\mathrm{S}$ & $f$ & 4 & 5 & 3 & 2 & C & $\mathrm{C}$ & $\mathrm{D}$ & $\mathrm{D}$ & $\mathrm{D}$ & I & $\mathrm{C}$ \\
\hline
\end{tabular}




\begin{tabular}{|c|c|c|c|c|c|c|c|c|c|c|c|c|c|c|c|}
\hline $\mathrm{N}^{\circ}$ Ordem & Local & Região & Usuário SN & Sexo & Rendimento & Usuário & Idade & Ocupação & V1 & V2 & V3 & V4 & V5 & V6 & V7 \\
\hline 135 & Uniban - OS & RMSP & $\mathrm{N}$ & $f$ & 3 & $\mathrm{~N}$ & 4 & 5 & $\mathrm{C}$ & $C$ & DT & DT & $C$ & I & $C$ \\
\hline 136 & Uniban - OS & RMSP & $\mathrm{N}$ & $f$ & 1 & $\mathrm{~N}$ & 3 & 5 & $\mathrm{C}$ & $\mathrm{C}$ & I & C & $C$ & $\mathrm{C}$ & C \\
\hline 137 & Uniban - OS & RMSP & $\mathrm{N}$ & $f$ & 2 & $\mathrm{~N}$ & 5 & 5 & C & $\mathrm{CT}$ & $\mathrm{CT}$ & $\mathrm{CT}$ & $\mathrm{CT}$ & I & CT \\
\hline 138 & Uniban - OS & RMSP & $\mathrm{N}$ & $f$ & 4 & 1 & 3 & 6 & C & $D$ & $D$ & $D$ & $C$ & $D$ & $D$ \\
\hline 139 & Uniban - OS & RMSP & $\mathrm{N}$ & $\mathrm{m}$ & 3 & $\mathrm{~N}$ & 3 & 6 & $\mathrm{CT}$ & $C$ & $D$ & $\mathrm{C}$ & $C$ & $\mathrm{C}$ & $\mathrm{C}$ \\
\hline 140 & Uniban - OS & RMSP & $\mathrm{N}$ & $f$ & 0 & $\mathrm{~N}$ & 3 & 3 & C & $\mathrm{C}$ & C & $\mathrm{D}$ & $\mathrm{D}$ & I & $\mathrm{C}$ \\
\hline 141 & Uniban - OS & RMSP & $\mathrm{N}$ & $f$ & 2 & $\mathrm{~N}$ & 2 & 5 & C & $\mathrm{C}$ & C & $\mathrm{D}$ & $\mathrm{D}$ & $\mathrm{C}$ & C \\
\hline 142 & Uniban - OS & RMSP & $\mathrm{N}$ & $f$ & 5 & $\mathrm{~N}$ & 4 & 6 & $\mathrm{CT}$ & $\mathrm{C}$ & $\mathrm{C}$ & 1 & I & I & $\mathrm{C}$ \\
\hline 143 & Uniban - OS & RMSP & $\mathrm{N}$ & $f$ & 3 & $\mathrm{~N}$ & 4 & 6 & $\mathrm{CT}$ & $\mathrm{CT}$ & C & 1 & $C$ & $\mathrm{C}$ & C \\
\hline 144 & Uniban - OS & RMSP & $\mathrm{N}$ & $f$ & 4 & $\mathrm{~N}$ & 3 & 6 & $\mathrm{C}$ & I & $D$ & 1 & $C$ & $\mathrm{C}$ & C \\
\hline 145 & Uniban - OS & RMSP & $\mathrm{N}$ & $f$ & 5 & $\mathrm{~N}$ & 5 & 6 & $\mathrm{CT}$ & $\mathrm{CT}$ & $\mathrm{C}$ & C & $C$ & $\mathrm{CT}$ & $\mathrm{C}$ \\
\hline 146 & Uniban - OS & RMSP & $\mathrm{N}$ & $f$ & 1 & 1 & 1 & 3 & C & I & 1 & I & C & I & C \\
\hline 147 & Uniban - OS & RMSP & $S$ & $f$ & 2 & 5 & 1 & 5 & $\mathrm{D}$ & $D$ & $D$ & $\mathrm{D}$ & $\mathrm{D}$ & $\mathrm{C}$ & C \\
\hline 148 & Uniban - OS & RMSP & $\mathrm{N}$ & $\mathrm{m}$ & 1 & $\mathrm{~N}$ & 1 & 3 & $\mathrm{C}$ & $\mathrm{CT}$ & C & I & I & $\mathrm{C}$ & $\mathrm{C}$ \\
\hline 149 & Uniban - OS & RMSP & $\mathrm{N}$ & $\mathrm{m}$ & 4 & $\mathrm{~N}$ & 3 & 8 & C & $\mathrm{C}$ & $\mathrm{C}$ & I & I & I & C \\
\hline 150 & Uniban - OS & RMSP & $\mathrm{N}$ & $f$ & 0 & $\mathrm{~N}$ & 2 & 5 & $\mathrm{C}$ & C & C & $\mathrm{C}$ & $\mathrm{C}$ & $\mathrm{C}$ & C \\
\hline 151 & Uniban - OS & RMSP & $\mathrm{N}$ & $\mathrm{m}$ & 3 & $\mathrm{~N}$ & 2 & 7 & CT & $\mathrm{CT}$ & C & CT & $\mathrm{CT}$ & CT & CT \\
\hline 152 & Uniban - OS & RMSP & $S$ & $f$ & 2 & 5 & 4 & 6 & C & $\mathrm{CT}$ & $\mathrm{CT}$ & I & I & I & CT \\
\hline 153 & Uniban - OS & RMSP & $\mathrm{N}$ & $\mathrm{m}$ & 3 & $\mathrm{~N}$ & 3 & 6 & C & $\mathrm{CT}$ & 1 & C & $C$ & I & CT \\
\hline 154 & Uniban - OS & RMSP & $S$ & $f$ & 3 & 5 & 3 & 2 & $\mathrm{C}$ & $\mathrm{CT}$ & C & $\mathrm{CT}$ & $\mathrm{CT}$ & CT & CT \\
\hline 155 & Uniban - OS & RMSP & $\mathrm{N}$ & $\mathrm{m}$ & 4 & $\mathrm{~N}$ & 4 & 6 & $\mathrm{CT}$ & C & C & I & I & $\mathrm{C}$ & C \\
\hline 156 & Uniban - OS & RMSP & $\mathrm{N}$ & $f$ & 2 & $\mathrm{~N}$ & 2 & 6 & $\mathrm{CT}$ & $\mathrm{CT}$ & I & $\mathrm{D}$ & I & $\mathrm{C}$ & CT \\
\hline 157 & Uniban - OS & RMSP & $\mathrm{N}$ & $\mathrm{m}$ & 5 & $\mathrm{~N}$ & 4 & 3 & $\mathrm{CT}$ & $\mathrm{CT}$ & I & $\mathrm{D}$ & $\mathrm{CT}$ & $\mathrm{C}$ & 1 \\
\hline 158 & Uniban - OS & RMSP & $\mathrm{N}$ & $\mathrm{m}$ & 5 & $\mathrm{~N}$ & 2 & 6 & $\mathrm{CT}$ & I & I & $\mathrm{CT}$ & $\mathrm{CT}$ & $\mathrm{CT}$ & $\mathrm{C}$ \\
\hline 159 & Uniban - OS & RMSP & $\mathrm{N}$ & $\mathrm{m}$ & 1 & 2 & 2 & 3 & $\mathrm{CT}$ & $\mathrm{CT}$ & 1 & $\mathrm{D}$ & $\mathrm{CT}$ & C & $\mathrm{CT}$ \\
\hline 160 & Uniban - OS & RMSP & $\mathrm{N}$ & $f$ & 2 & $\mathrm{~N}$ & 2 & 6 & C & $\mathrm{CT}$ & C & 1 & 1 & $\mathrm{C}$ & C \\
\hline 161 & Uniban - OS & RMSP & $\mathrm{S}$ & f & 3 & 7 & 2 & 6 & $\mathrm{CT}$ & $\mathrm{C}$ & D & CT & C & CT & C \\
\hline 162 & Uniban - OS & RMSP & $\mathrm{S}$ & $\mathrm{m}$ & 3 & 5 & 4 & 6 & $\mathrm{CT}$ & $\mathrm{CT}$ & CT & I & C & $\mathrm{C}$ & $\mathrm{C}$ \\
\hline
\end{tabular}




\begin{tabular}{|c|c|c|c|c|c|c|c|c|c|c|c|c|c|c|c|}
\hline $\mathbf{N}^{\circ}$ Ordem & Local & Região & Usuário SN & Sexo & Rendimento & Usuário & Idade & Ocupação & V1 & V2 & V3 & V4 & V5 & V6 & V7 \\
\hline 163 & Uniban - OS & RMSP & $\mathrm{N}$ & $\mathrm{m}$ & 2 & $\mathrm{~N}$ & 3 & 7 & C & $\mathrm{CT}$ & DT & C & C & C & C \\
\hline 164 & Uniban - OS & RMSP & $\mathrm{N}$ & $\mathrm{m}$ & 5 & $\mathrm{~N}$ & 4 & 2 & I & C & C & C & I & C & I \\
\hline 165 & Uniban - OS & RMSP & $\mathrm{N}$ & $\mathrm{m}$ & 5 & $\mathrm{~N}$ & 3 & 6 & C & $\mathrm{CT}$ & I & C & C & C & $\mathrm{CT}$ \\
\hline 166 & Uniban - OS & RMSP & $\mathrm{N}$ & $\mathrm{m}$ & 3 & 2 & 3 & 8 & C & C & C & I & I & C & C \\
\hline 167 & Uniban - OS & RMSP & $\mathrm{N}$ & $\mathrm{m}$ & 4 & $\mathrm{~N}$ & 4 & 6 & $\mathrm{CT}$ & $\mathrm{CT}$ & $\mathrm{CT}$ & $\mathrm{CT}$ & $\mathrm{CT}$ & $\mathrm{CT}$ & $\mathrm{CT}$ \\
\hline 168 & Uniban - OS & RMSP & $\mathrm{N}$ & $\mathrm{m}$ & 2 & $\mathrm{~N}$ & 2 & 1 & C & $\mathrm{CT}$ & C & C & I & $\mathrm{D}$ & C \\
\hline 169 & Uniban - OS & RMSP & $\mathrm{N}$ & $f$ & 2 & 1 & 2 & 8 & $\mathrm{D}$ & I & $D$ & I & I & I & $D$ \\
\hline 170 & Uniban - OS & RMSP & $\mathrm{N}$ & $\mathrm{m}$ & 3 & $\mathrm{~N}$ & 4 & 8 & $\mathrm{CT}$ & C & I & C & C & $\mathrm{CT}$ & $\mathrm{CT}$ \\
\hline 171 & Uniban - OS & RMSP & $\mathrm{N}$ & $\mathrm{m}$ & 3 & $\mathrm{~N}$ & 2 & 6 & $\mathrm{CT}$ & C & I & I & C & 1 & 1 \\
\hline 172 & Uniban - OS & RMSP & $\mathrm{N}$ & $\mathrm{m}$ & 4 & $\mathrm{~F}$ & 4 & 6 & $\mathrm{CT}$ & C & I & I & I & C & C \\
\hline 173 & Uniban - OS & RMSP & $\mathrm{N}$ & $\mathrm{m}$ & 5 & $\mathrm{~N}$ & 3 & 2 & $\mathrm{CT}$ & C & $D$ & $\mathrm{D}$ & $\mathrm{D}$ & 1 & $\mathrm{D}$ \\
\hline 174 & Uniban - OS & RMSP & $\mathrm{N}$ & $\mathrm{m}$ & 3 & $\mathrm{~N}$ & 2 & 8 & C & C & I & C & C & 1 & C \\
\hline 175 & Uniban - OS & RMSP & $\mathrm{N}$ & $\mathrm{m}$ & 5 & $\mathrm{~N}$ & 4 & 6 & $\mathrm{CT}$ & CT & C & I & I & CT & $\mathrm{CT}$ \\
\hline 176 & Uniban - OS & RMSP & $S$ & $f$ & 2 & 7 & 2 & 5 & C & C & $\mathrm{D}$ & I & $\mathrm{D}$ & $\mathrm{D}$ & 1 \\
\hline 177 & Uniban - OS & RMSP & $S$ & $\mathrm{~m}$ & 3 & 5 & 2 & 6 & I & DT & I & $D$ & $D$ & $\mathrm{D}$ & $D$ \\
\hline 178 & Uniban - OS & RMSP & $\mathrm{N}$ & $\mathrm{m}$ & 3 & $\mathrm{~N}$ & 1 & 5 & $\mathrm{CT}$ & $\mathrm{CT}$ & $\mathrm{CT}$ & I & I & $\mathrm{D}$ & $\mathrm{CT}$ \\
\hline 179 & Uniban - OS & RMSP & $\mathrm{N}$ & $\mathrm{m}$ & 2 & $\mathrm{~N}$ & 2 & 8 & $\mathrm{CT}$ & C & C & C & C & C & $\mathrm{CT}$ \\
\hline 180 & Uniban - OS & RMSP & $\mathrm{N}$ & $\mathrm{m}$ & 2 & $\mathrm{~N}$ & 2 & 8 & I & C & C & $\mathrm{D}$ & C & C & $\mathrm{D}$ \\
\hline 181 & Uniban - OS & RMSP & $S$ & $\mathrm{~m}$ & 2 & 7 & 3 & 5 & C & C & $D$ & C & C & C & $\mathrm{D}$ \\
\hline 182 & Uniban - OS & RMSP & $S$ & $\mathrm{~m}$ & 6 & 5 & 5 & 8 & $\mathrm{CT}$ & $\mathrm{CT}$ & CT & $D$ & $\mathrm{CT}$ & CT & $\mathrm{CT}$ \\
\hline 183 & Uniban - OS & RMSP & $S$ & $\mathrm{~m}$ & 2 & 5 & 2 & 6 & C & $\mathrm{CT}$ & I & $D$ & $\mathrm{D}$ & C & $\mathrm{CT}$ \\
\hline 184 & Uniban - OS & RMSP & $S$ & $f$ & 0 & 7 & 2 & 8 & $\mathrm{CT}$ & C & C & $D$ & $\mathrm{CT}$ & C & $\mathrm{CT}$ \\
\hline 185 & Uniban - OS & RMSP & $\mathrm{N}$ & $\mathrm{m}$ & 2 & $\mathrm{~N}$ & 2 & 8 & C & $\mathrm{CT}$ & $\mathrm{CT}$ & $D$ & C & C & $\mathrm{CT}$ \\
\hline 186 & Uniban - OS & RMSP & $\mathrm{N}$ & $\mathrm{m}$ & 0 & $\mathrm{~N}$ & 3 & 6 & I & I & I & I & I & 1 & 1 \\
\hline 187 & Uniban - OS & RMSP & $S$ & $\mathrm{~m}$ & 6 & 5 & 5 & 8 & $\mathrm{CT}$ & $\mathrm{CT}$ & I & $\mathrm{CT}$ & $\mathrm{CT}$ & $\mathrm{CT}$ & $\mathrm{CT}$ \\
\hline 188 & Uniban - OS & RMSP & $S$ & $f$ & 3 & 7 & 4 & 6 & $\mathrm{CT}$ & $\mathrm{CT}$ & $\mathrm{D}$ & $\mathrm{CT}$ & 1 & C & $\mathrm{D}$ \\
\hline 189 & Uniban - OS & RMSP & $\mathrm{N}$ & $\mathrm{m}$ & 0 & $\mathrm{~N}$ & 3 & 6 & $\mathrm{CT}$ & C & $\mathrm{D}$ & C & C & CT & C \\
\hline 190 & Uniban - OS & RMSP & $\mathrm{N}$ & $\mathrm{m}$ & 2 & $\mathrm{~N}$ & 2 & 6 & C & C & $\mathrm{C}$ & $\mathrm{D}$ & I & C & C \\
\hline
\end{tabular}




\begin{tabular}{|c|c|c|c|c|c|c|c|c|c|c|c|c|c|c|c|}
\hline $\mathrm{N}^{\circ}$ Ordem & Local & Região & Usuário SN & Sexo & Rendimento & Usuário & Idade & Ocupação & V1 & V2 & V3 & V4 & V5 & V6 & V7 \\
\hline 191 & Uniban - OS & RMSP & $\mathrm{N}$ & $\mathrm{m}$ & 2 & 1 & 4 & 6 & C & C & $C$ & DT & 1 & C & C \\
\hline 192 & Uniban - OS & RMSP & $\mathrm{N}$ & $\mathrm{m}$ & 2 & $\mathrm{~N}$ & 2 & 9 & $\mathrm{CT}$ & $\mathrm{CT}$ & I & C & $\mathrm{C}$ & C & $\mathrm{CT}$ \\
\hline 193 & Uniban - OS & RMSP & $\mathrm{N}$ & $\mathrm{m}$ & 0 & $\mathrm{~N}$ & 1 & 3 & C & $\mathrm{CT}$ & C & $\mathrm{CT}$ & $\mathrm{C}$ & I & C \\
\hline 194 & Uniban - OS & RMSP & $\mathrm{N}$ & $\mathrm{m}$ & 5 & 1 & 2 & 8 & $\mathrm{CT}$ & CT & C & $\mathrm{CT}$ & CT & C & C \\
\hline 195 & Uniban - OS & RMSP & $\mathrm{N}$ & $\mathrm{m}$ & 3 & $\mathrm{~N}$ & 3 & 6 & C & C & DT & I & CT & C & C \\
\hline 196 & Anhembi - VO & SP & $S$ & $\mathrm{~m}$ & 5 & 5 & 4 & 9 & C & $\mathrm{CT}$ & $\mathrm{D}$ & $\mathrm{CT}$ & CT & C & $\mathrm{CT}$ \\
\hline 197 & Anhembi - VO & SP & $\mathrm{N}$ & $\mathrm{m}$ & 4 & $\mathrm{~N}$ & 2 & 5 & $\mathrm{CT}$ & $\mathrm{CT}$ & C & $\mathrm{CT}$ & CT & CT & $\mathrm{CT}$ \\
\hline 198 & Anhembi - VO & SP & $\mathrm{S}$ & $\mathrm{m}$ & 3 & 7 & 2 & 3 & $\mathrm{CT}$ & $\mathrm{CT}$ & C & $\mathrm{CT}$ & CT & $\mathrm{CT}$ & $\mathrm{CT}$ \\
\hline 199 & Anhembi - VO & SP & $\mathrm{N}$ & $\mathrm{m}$ & 0 & $\mathrm{~N}$ & 3 & 6 & C & C & I & I & $\mathrm{C}$ & I & C \\
\hline 200 & Anhembi - VO & SP & $\mathrm{N}$ & $\mathrm{m}$ & 3 & $\mathrm{~N}$ & 3 & 6 & $\mathrm{CT}$ & C & $D$ & $D$ & $\mathrm{C}$ & $\mathrm{CT}$ & $\mathrm{CT}$ \\
\hline 201 & Anhembi - VO & SP & $\mathrm{N}$ & $\mathrm{m}$ & 5 & $\mathrm{~N}$ & 3 & 9 & C & C & $\mathrm{C}$ & C & C & C & C \\
\hline 202 & Anhembi - VO & SP & $\mathrm{N}$ & $\mathrm{m}$ & 4 & $\mathrm{~N}$ & 3 & 9 & $\mathrm{CT}$ & CT & $C$ & C & CT & $\mathrm{CT}$ & CT \\
\hline 203 & Anhembi - VO & SP & $\mathrm{N}$ & $f$ & 5 & $\mathrm{~N}$ & 4 & 6 & $\mathrm{CT}$ & CT & CT & $\mathrm{CT}$ & CT & CT & $\mathrm{CT}$ \\
\hline 204 & Anhembi - VO & SP & $\mathrm{N}$ & $\mathrm{m}$ & 6 & $\mathrm{~N}$ & 4 & 4 & $\mathrm{CT}$ & CT & $\mathrm{CT}$ & I & I & C & I \\
\hline 205 & Anhembi - VO & SP & $S$ & $f$ & 5 & 5 & 2 & 6 & C & I & CT & I & CT & C & $\mathrm{CT}$ \\
\hline 206 & Anhembi - VO & SP & $S$ & $\mathrm{~m}$ & 5 & 5 & 3 & 6 & $\mathrm{CT}$ & $\mathrm{CT}$ & C & I & CT & CT & CT \\
\hline 207 & Anhembi - VO & SP & $\mathrm{N}$ & $f$ & 6 & 1 & 3 & 6 & $\mathrm{CT}$ & CT & DT & DT & I & C & C \\
\hline 208 & Anhembi - VO & SP & $\mathrm{N}$ & $\mathrm{m}$ & 5 & $\mathrm{~N}$ & 3 & 8 & $\mathrm{CT}$ & CT & C & C & I & C & $\mathrm{CT}$ \\
\hline 209 & Anhembi - VO & SP & $\mathrm{N}$ & $\mathrm{m}$ & 5 & $\mathrm{~N}$ & 3 & 9 & $\mathrm{CT}$ & C & C & $\mathrm{D}$ & $\mathrm{C}$ & CT & $\mathrm{CT}$ \\
\hline 210 & Anhembi - VO & SP & $S$ & $f$ & 5 & 5 & 2 & 9 & $\mathrm{CT}$ & C & C & I & C & CT & C \\
\hline 211 & Anhembi - VO & SP & $\mathrm{N}$ & $\mathrm{m}$ & 5 & $\mathrm{~N}$ & 3 & 9 & C & C & C & $\mathrm{CT}$ & I & C & $\mathrm{CT}$ \\
\hline 212 & Anhembi - VO & SP & $S$ & $f$ & 5 & 7 & 3 & 6 & $\mathrm{CT}$ & $\mathrm{CT}$ & I & $\mathrm{D}$ & CT & C & $\mathrm{CT}$ \\
\hline 213 & Anhembi - VO & SP & $S$ & $\mathrm{~m}$ & 5 & 7 & 5 & 4 & $\mathrm{CT}$ & CT & C & C & $\mathrm{C}$ & C & $\mathrm{CT}$ \\
\hline 214 & Anhembi - VO & SP & $\mathrm{N}$ & $\mathrm{m}$ & 5 & 1 & 3 & 6 & C & I & $D$ & $\mathrm{D}$ & $\mathrm{C}$ & C & I \\
\hline 215 & Anhembi - VO & SP & $\mathrm{N}$ & $f$ & 5 & $\mathrm{~N}$ & 2 & 3 & $\mathrm{CT}$ & C & I & C & I & $\mathrm{D}$ & I \\
\hline 216 & Anhembi - VO & SP & $\mathrm{N}$ & $f$ & 5 & $\mathrm{~N}$ & 2 & 3 & $\mathrm{CT}$ & CT & $\mathrm{C}$ & $\mathrm{CT}$ & CT & C & $\mathrm{CT}$ \\
\hline 217 & Anhembi - VO & SP & $\mathrm{N}$ & $f$ & 5 & $\mathrm{~N}$ & 3 & 3 & $\mathrm{CT}$ & CT & C & C & C & C & C \\
\hline 218 & Anhembi - VO & SP & $\mathrm{S}$ & $f$ & 5 & 5 & 3 & 3 & I & DT & DT & $\mathrm{D}$ & I & I & I \\
\hline
\end{tabular}




\begin{tabular}{|c|c|c|c|c|c|c|c|c|c|c|c|c|c|c|c|}
\hline $\mathrm{N}^{\circ}$ Ordem & Local & Região & Usuário SN & Sexo & Rendimento & Usuário & Idade & Ocupação & V1 & V2 & V3 & V4 & V5 & V6 & V7 \\
\hline 219 & Anhembi - VO & SP & $S$ & $\mathrm{~m}$ & 5 & 4 & 4 & 6 & $\mathrm{CT}$ & C & $C$ & $\mathrm{CT}$ & C & I & C \\
\hline 220 & Anhembi - VO & SP & $\mathrm{N}$ & $f$ & 5 & $\mathrm{~N}$ & 3 & 2 & $\mathrm{CT}$ & $\mathrm{CT}$ & $\mathrm{CT}$ & $\mathrm{CT}$ & $\mathrm{CT}$ & $\mathrm{CT}$ & $\mathrm{CT}$ \\
\hline 221 & Anhembi - VO & SP & $S$ & $f$ & 4 & 5 & 4 & 4 & C & C & C & $\mathrm{D}$ & C & C & $\mathrm{CT}$ \\
\hline 222 & Anhembi - VO & SP & $S$ & $\mathrm{~m}$ & 4 & 7 & 3 & 2 & $\mathrm{CT}$ & $\mathrm{CT}$ & CT & $\mathrm{CT}$ & $\mathrm{CT}$ & CT & $\mathrm{CT}$ \\
\hline 223 & Anhembi - VO & SP & $\mathrm{N}$ & $\mathrm{m}$ & 6 & 1 & 4 & 8 & $\mathrm{CT}$ & $\mathrm{CT}$ & $D$ & C & C & C & C \\
\hline 224 & Anhembi - VO & SP & $\mathrm{N}$ & $\mathrm{m}$ & 5 & $\mathrm{~N}$ & 4 & 6 & C & C & C & I & I & C & C \\
\hline 225 & Anhembi - VO & SP & $S$ & $\mathrm{~m}$ & 4 & 3 & 2 & 3 & $\mathrm{CT}$ & C & I & C & C & C & C \\
\hline 226 & Anhembi - VO & SP & $\mathrm{N}$ & $\mathrm{m}$ & 5 & $\mathrm{~N}$ & 4 & 3 & $\mathrm{D}$ & $\mathrm{D}$ & $\mathrm{D}$ & $\mathrm{D}$ & $\mathrm{D}$ & $\mathrm{D}$ & $\mathrm{D}$ \\
\hline 227 & Anhembi - VO & SP & $S$ & $f$ & 5 & 5 & 3 & 4 & $\mathrm{CT}$ & $\mathrm{CT}$ & C & C & C & C & C \\
\hline 228 & Anhembi - VO & SP & $S$ & $\mathrm{~m}$ & 5 & 5 & 4 & 3 & $\mathrm{CT}$ & $\mathrm{CT}$ & DT & C & $\mathrm{CT}$ & I & I \\
\hline 229 & Anhembi - VO & SP & $\mathrm{N}$ & $f$ & 4 & $\mathrm{~N}$ & 3 & 9 & I & $\mathrm{CT}$ & I & C & C & I & C \\
\hline 230 & Anhembi - VO & SP & $\mathrm{N}$ & $f$ & 4 & $\mathrm{~F}$ & 2 & 2 & $\mathrm{CT}$ & $\mathrm{CT}$ & C & C & $\mathrm{CT}$ & $\mathrm{CT}$ & C \\
\hline 231 & Anhembi - VO & SP & $\mathrm{N}$ & $f$ & 7 & $\mathrm{~N}$ & 6 & 2 & $\mathrm{CT}$ & $\mathrm{CT}$ & C & C & C & CT & $\mathrm{CT}$ \\
\hline 232 & FATEC ZL & SP & $S$ & $\mathrm{~m}$ & 1 & 3 & 4 & 9 & $\mathrm{CT}$ & $\mathrm{CT}$ & $C$ & CT & $\mathrm{CT}$ & $\mathrm{CT}$ & CT \\
\hline 233 & FATEC ZL & SP & $\mathrm{N}$ & $\mathrm{m}$ & 6 & 1 & 6 & 6 & $\mathrm{CT}$ & C & $C$ & I & $\mathrm{CT}$ & CT & C \\
\hline 234 & FATEC ZL & SP & $S$ & $\mathrm{~m}$ & 5 & 5 & 2 & 6 & $\mathrm{CT}$ & $\mathrm{CT}$ & C & $\mathrm{CT}$ & C & CT & CT \\
\hline 235 & FATEC ZL & SP & $\mathrm{N}$ & $\mathrm{m}$ & 3 & $\mathrm{~N}$ & 4 & 3 & $\mathrm{CT}$ & $\mathrm{CT}$ & C & C & C & C & $\mathrm{CT}$ \\
\hline 236 & FATEC ZL & SP & $S$ & $\mathrm{~m}$ & 3 & 7 & 2 & 3 & C & C & DT & $D$ & I & C & I \\
\hline 237 & FATEC ZL & SP & $\mathrm{N}$ & $f$ & 3 & $F$ & 2 & 6 & $\mathrm{CT}$ & $\mathrm{CT}$ & $\mathrm{CT}$ & C & C & CT & 1 \\
\hline 238 & FATEC ZL & SP & $S$ & $\mathrm{~m}$ & 3 & 3 & 3 & 6 & $\mathrm{CT}$ & $\mathrm{CT}$ & $\mathrm{CT}$ & $\mathrm{CT}$ & $\mathrm{CT}$ & $\mathrm{CT}$ & $\mathrm{CT}$ \\
\hline 239 & FATEC ZL & SP & $S$ & $\mathrm{~m}$ & 2 & 4 & 2 & 6 & $\mathrm{CT}$ & C & $D$ & C & C & C & C \\
\hline 240 & FATEC ZL & SP & $S$ & $\mathrm{~m}$ & 5 & 5 & 4 & 5 & $\mathrm{CT}$ & $\mathrm{CT}$ & I & $D$ & CT & C & C \\
\hline 241 & FATEC ZL & SP & $S$ & $f$ & 2 & 5 & 3 & 6 & I & C & C & I & I & I & I \\
\hline 242 & FATEC ZL & SP & $\mathrm{N}$ & $\mathrm{m}$ & 5 & $\mathrm{~N}$ & 5 & 6 & $\mathrm{CT}$ & $\mathrm{CT}$ & $\mathrm{CT}$ & $\mathrm{CT}$ & $\mathrm{CT}$ & $\mathrm{CT}$ & $\mathrm{CT}$ \\
\hline 243 & FATEC ZL & SP & $\mathrm{N}$ & $f$ & 6 & $\mathrm{~N}$ & 3 & 3 & $\mathrm{CT}$ & C & $D$ & I & I & C & C \\
\hline 244 & FATEC ZL & SP & $\mathrm{N}$ & $f$ & 2 & 2 & 2 & 6 & C & C & $\mathrm{D}$ & $D$ & I & I & C \\
\hline 245 & FATEC ZL & SP & $S$ & $f$ & 1 & 7 & 2 & 3 & C & $\mathrm{CT}$ & I & I & C & CT & CT \\
\hline 246 & FATEC ZL & SP & $S$ & $f$ & 3 & 7 & 2 & 3 & $\mathrm{CT}$ & $\mathrm{CT}$ & $C$ & I & I & C & CT \\
\hline
\end{tabular}




\begin{tabular}{|c|c|c|c|c|c|c|c|c|c|c|c|c|c|c|c|}
\hline $\mathbf{N}^{\circ}$ Ordem & Local & Região & Usuário SN & Sexo & Rendimento & Usuário & Idade & Ocupação & V1 & V2 & V3 & V4 & V5 & V6 & V7 \\
\hline 247 & UniABC & RMSP & $S$ & $f$ & 3 & 5 & 4 & 6 & $\mathrm{CT}$ & $\mathrm{CT}$ & CT & 1 & I & $\mathrm{C}$ & $C$ \\
\hline 248 & UniABC & RMSP & $\mathrm{N}$ & $f$ & 2 & $\mathrm{~N}$ & 2 & 3 & $\mathrm{C}$ & $\mathrm{C}$ & $\mathrm{C}$ & I & $\mathrm{CT}$ & $\mathrm{C}$ & C \\
\hline 249 & UniABC & RMSP & $\mathrm{N}$ & $\mathrm{m}$ & 5 & $\mathrm{~N}$ & 4 & 9 & $\mathrm{CT}$ & $\mathrm{CT}$ & C & $\mathrm{CT}$ & $\mathrm{CT}$ & CT & CT \\
\hline 250 & UniABC & RMSP & $\mathrm{N}$ & $\mathrm{m}$ & 5 & $\mathrm{~N}$ & 4 & 6 & $\mathrm{CT}$ & $\mathrm{CT}$ & $D$ & I & $C$ & $\mathrm{C}$ & CT \\
\hline 251 & UniABC & RMSP & $S$ & $\mathrm{~m}$ & 3 & 5 & 4 & 6 & $\mathrm{CT}$ & $\mathrm{CT}$ & $\mathrm{CT}$ & $\mathrm{CT}$ & $\mathrm{CT}$ & $\mathrm{CT}$ & CT \\
\hline 252 & UniABC & RMSP & $\mathrm{N}$ & $f$ & 0 & $\mathrm{~N}$ & 2 & 6 & C & $\mathrm{C}$ & C & $\mathrm{C}$ & $C$ & $\mathrm{C}$ & $\mathrm{C}$ \\
\hline 253 & UniABC & RMSP & $\mathrm{N}$ & $f$ & 3 & $\mathrm{~N}$ & 4 & 8 & C & $C$ & C & I & $C$ & $\mathrm{C}$ & CT \\
\hline 254 & UniABC & RMSP & $\mathrm{N}$ & $\mathrm{m}$ & 4 & $\mathrm{~N}$ & 3 & 9 & $\mathrm{CT}$ & $\mathrm{CT}$ & $\mathrm{CT}$ & $\mathrm{CT}$ & $\mathrm{CT}$ & $\mathrm{CT}$ & CT \\
\hline 255 & UniABC & RMSP & $\mathrm{N}$ & $\mathrm{m}$ & 3 & $\mathrm{~N}$ & 4 & 9 & $\mathrm{CT}$ & $\mathrm{CT}$ & C & $\mathrm{CT}$ & $C$ & $\mathrm{CT}$ & CT \\
\hline 256 & UniABC & RMSP & $S$ & $f$ & 4 & 5 & 4 & 6 & I & C & $D$ & DT & I & $\mathrm{C}$ & 1 \\
\hline 257 & UniABC & RMSP & $\mathrm{N}$ & $\mathrm{m}$ & 3 & $\mathrm{~N}$ & 3 & 5 & $\mathrm{CT}$ & $\mathrm{CT}$ & $D$ & $D$ & $C$ & C & CT \\
\hline 258 & UniABC & RMSP & $\mathrm{N}$ & $\mathrm{m}$ & 3 & $\mathrm{~N}$ & 3 & 6 & $\mathrm{CT}$ & $\mathrm{CT}$ & $\mathrm{CT}$ & C & $C$ & $\mathrm{CT}$ & CT \\
\hline 259 & UniABC & RMSP & $\mathrm{N}$ & $\mathrm{m}$ & 2 & $\mathrm{~N}$ & 4 & 6 & C & C & C & CT & $C$ & C & C \\
\hline 260 & UniABC & RMSP & $S$ & f & 3 & 5 & 2 & 6 & C & C & D & C & I & I & 1 \\
\hline 261 & UniABC & RMSP & $\mathrm{N}$ & $\mathrm{m}$ & 3 & $\mathrm{~N}$ & 3 & 6 & $\mathrm{CT}$ & $\mathrm{CT}$ & $\mathrm{CT}$ & $\mathrm{CT}$ & $\mathrm{CT}$ & $\mathrm{CT}$ & CT \\
\hline 262 & UniABC & RMSP & $\mathrm{N}$ & $f$ & 3 & $\mathrm{~N}$ & 4 & 8 & $\mathrm{CT}$ & $\mathrm{CT}$ & $\mathrm{CT}$ & $\mathrm{CT}$ & $\mathrm{CT}$ & $\mathrm{CT}$ & CT \\
\hline 263 & UniABC & RMSP & $S$ & $f$ & 3 & 5 & 3 & 6 & $\mathrm{C}$ & $\mathrm{CT}$ & C & C & $\mathrm{C}$ & $\mathrm{C}$ & CT \\
\hline 264 & UniABC & RMSP & $\mathrm{N}$ & $f$ & 2 & $\mathrm{~N}$ & 2 & 6 & $\mathrm{CT}$ & C & I & 1 & $\mathrm{CT}$ & $\mathrm{CT}$ & CT \\
\hline 265 & UniABC & RMSP & $\mathrm{N}$ & $\mathrm{m}$ & 4 & $\mathrm{~N}$ & 2 & 6 & $\mathrm{CT}$ & I & C & 1 & I & C & CT \\
\hline 266 & UniABC & RMSP & $S$ & $\mathrm{~m}$ & 3 & 5 & 3 & 8 & C & C & 1 & C & C & I & CT \\
\hline 267 & UniABC & RMSP & $\mathrm{N}$ & $\mathrm{m}$ & 4 & $\mathrm{~N}$ & 2 & 6 & $\mathrm{CT}$ & $\mathrm{CT}$ & I & $D$ & C & $\mathrm{C}$ & C \\
\hline 268 & UniABC & RMSP & $\mathrm{N}$ & $f$ & 4 & 1 & 4 & 6 & C & $\mathrm{C}$ & $\mathrm{C}$ & $D$ & I & $\mathrm{C}$ & $\mathrm{C}$ \\
\hline 269 & UniABC & RMSP & $\mathrm{N}$ & $\mathrm{m}$ & 4 & $\mathrm{~N}$ & 3 & 6 & $\mathrm{CT}$ & $\mathrm{CT}$ & C & C & I & $\mathrm{C}$ & C \\
\hline 270 & UniABC & RMSP & $\mathrm{N}$ & $\mathrm{m}$ & 3 & $\mathrm{~N}$ & 4 & 6 & $\mathrm{CT}$ & $\mathrm{CT}$ & I & C & $\mathrm{CT}$ & DT & CT \\
\hline 271 & UniABC & RMSP & $\mathrm{N}$ & $\mathrm{m}$ & 7 & 1 & 2 & 9 & $\mathrm{CT}$ & $\mathrm{CT}$ & $\mathrm{D}$ & $\mathrm{CT}$ & $\mathrm{C}$ & $\mathrm{CT}$ & DT \\
\hline 272 & UniABC & RMSP & $S$ & $\mathrm{~m}$ & 3 & 5 & 3 & 8 & $\mathrm{CT}$ & C & I & DT & DT & DT & CT \\
\hline 273 & UniABC & RMSP & $S$ & $\mathrm{~m}$ & 4 & 7 & 2 & 6 & $\mathrm{CT}$ & $\mathrm{CT}$ & D & C & $C$ & $\mathrm{D}$ & CT \\
\hline 274 & UniABC & RMSP & $\mathrm{N}$ & $\mathrm{m}$ & 2 & $\mathrm{~N}$ & 1 & 6 & $\mathrm{CT}$ & $\mathrm{C}$ & $\mathrm{D}$ & DT & I & DT & CT \\
\hline
\end{tabular}




\begin{tabular}{|c|c|c|c|c|c|c|c|c|c|c|c|c|c|c|c|}
\hline $\mathbf{N}^{\circ}$ Ordem & Local & Região & Usuário SN & Sexo & Rendimento & Usuário & Idade & Ocupação & V1 & V2 & V3 & V4 & V5 & V6 & V7 \\
\hline 275 & UniABC & RMSP & $S$ & $f$ & 2 & 5 & 1 & 3 & $\mathrm{CT}$ & CT & $\mathrm{CT}$ & $\mathrm{CT}$ & CT & $\mathrm{CT}$ & $\mathrm{CT}$ \\
\hline 276 & UniABC & RMSP & $S$ & $\mathrm{~m}$ & 3 & 5 & 2 & 6 & $\mathrm{CT}$ & I & $\mathrm{C}$ & I & C & $\mathrm{C}$ & C \\
\hline 277 & UniABC & RMSP & $\mathrm{N}$ & $\mathrm{m}$ & 5 & $\mathrm{~N}$ & 4 & 8 & C & I & $\mathrm{D}$ & C & 1 & $\mathrm{C}$ & CT \\
\hline 278 & UniABC & RMSP & $S$ & $\mathrm{~m}$ & 0 & 5 & 4 & 3 & C & C & C & C & C & $\mathrm{C}$ & C \\
\hline 279 & UniABC & RMSP & $S$ & $\mathrm{~m}$ & 3 & 5 & 4 & 8 & C & CT & $\mathrm{D}$ & I & 1 & $\mathrm{C}$ & CT \\
\hline 280 & UniABC & RMSP & $\mathrm{N}$ & $f$ & 3 & 1 & 4 & 6 & C & C & C & 1 & C & I & $\mathrm{C}$ \\
\hline 281 & UniABC & RMSP & $\mathrm{N}$ & $\mathrm{m}$ & 2 & $\mathrm{~N}$ & 2 & 5 & C & C & $D$ & 1 & I & I & C \\
\hline 282 & UniABC & RMSP & $S$ & $\mathrm{~m}$ & 3 & 7 & 3 & 6 & $\mathrm{CT}$ & CT & C & 1 & 1 & I & CT \\
\hline 283 & UniABC & RMSP & $\mathrm{N}$ & $\mathrm{m}$ & 2 & $\mathrm{~N}$ & 2 & 9 & $\mathrm{CT}$ & $\mathrm{CT}$ & $\mathrm{CT}$ & $\mathrm{CT}$ & CT & $\mathrm{CT}$ & CT \\
\hline 284 & UniABC & RMSP & $\mathrm{N}$ & $\mathrm{m}$ & 3 & $\mathrm{~N}$ & 3 & 3 & $\mathrm{CT}$ & $\mathrm{CT}$ & $\mathrm{CT}$ & $\mathrm{CT}$ & CT & $\mathrm{CT}$ & CT \\
\hline 285 & UniABC & RMSP & $S$ & $f$ & 3 & 7 & 4 & 8 & C & $\mathrm{CT}$ & $D$ & $\mathrm{CT}$ & C & $\mathrm{CT}$ & C \\
\hline 286 & UniABC & RMSP & $S$ & $\mathrm{~m}$ & 4 & 5 & 4 & 6 & C & C & C & $D$ & C & $D$ & C \\
\hline 287 & UniABC & RMSP & $\mathrm{N}$ & $f$ & 3 & 2 & 4 & 6 & $\mathrm{CT}$ & CT & I & C & 1 & 1 & CT \\
\hline 288 & UniABC & RMSP & $\mathrm{N}$ & $f$ & 2 & $\mathrm{~N}$ & 3 & 8 & $\mathrm{CT}$ & $\mathrm{CT}$ & $C$ & C & 1 & $\mathrm{CT}$ & CT \\
\hline 289 & UniABC & RMSP & $S$ & $f$ & 2 & 7 & 1 & 6 & $\mathrm{CT}$ & $\mathrm{CT}$ & $\mathrm{CT}$ & $\mathrm{CT}$ & CT & $\mathrm{CT}$ & CT \\
\hline 290 & UniABC & RMSP & $\mathrm{N}$ & $\mathrm{m}$ & 7 & $\mathrm{~N}$ & 3 & 3 & $D$ & C & C & I & C & C & I \\
\hline 291 & UniABC & RMSP & $\mathrm{N}$ & $f$ & 3 & $\mathrm{~N}$ & 2 & 6 & C & $\mathrm{CT}$ & D & $\mathrm{D}$ & C & $\mathrm{D}$ & CT \\
\hline 292 & UniABC & RMSP & $\mathrm{N}$ & $\mathrm{m}$ & 5 & $\mathrm{~N}$ & 4 & 5 & $\mathrm{C}$ & $\mathrm{CT}$ & I & I & $\mathrm{D}$ & $\mathrm{C}$ & C \\
\hline 293 & UniABC & RMSP & $S$ & $\mathrm{~m}$ & 2 & 5 & 1 & 3 & $\mathrm{D}$ & $D$ & C & $D$ & $\mathrm{D}$ & $\mathrm{D}$ & C \\
\hline 294 & UniABC & RMSP & $\mathrm{N}$ & $f$ & 2 & $\mathrm{~N}$ & 1 & 3 & C & C & C & $\mathrm{CT}$ & C & I & CT \\
\hline 295 & UniABC & RMSP & $\mathrm{N}$ & $\mathrm{m}$ & 5 & $\mathrm{~N}$ & 3 & 5 & $\mathrm{CT}$ & C & C & DT & DT & C & C \\
\hline 296 & UniABC & RMSP & $\mathrm{N}$ & $f$ & 0 & $\mathrm{~N}$ & 1 & 4 & $\mathrm{CT}$ & $\mathrm{CT}$ & $\mathrm{D}$ & $D$ & C & C & C \\
\hline 297 & UniABC & RMSP & $\mathrm{N}$ & $\mathrm{m}$ & 3 & $\mathrm{~N}$ & 2 & 7 & $\mathrm{CT}$ & $\mathrm{CT}$ & $\mathrm{D}$ & $D$ & C & C & C \\
\hline 298 & UniABC & RMSP & $\mathrm{N}$ & $\mathrm{m}$ & 6 & $\mathrm{~N}$ & 4 & 9 & $\mathrm{CT}$ & $\mathrm{CT}$ & $\mathrm{CT}$ & $\mathrm{CT}$ & CT & $\mathrm{CT}$ & $\mathrm{CT}$ \\
\hline 299 & UniABC & RMSP & $S$ & $f$ & 2 & 5 & 1 & 6 & $\mathrm{CT}$ & $\mathrm{CT}$ & $\mathrm{CT}$ & C & C & $\mathrm{CT}$ & $\mathrm{CT}$ \\
\hline 300 & UniABC & RMSP & $\mathrm{N}$ & $\mathrm{m}$ & 5 & $\mathrm{~N}$ & 4 & 8 & $\mathrm{D}$ & I & $\mathrm{D}$ & $D$ & $\mathrm{D}$ & $D$ & C \\
\hline 301 & UniABC & RMSP & $S$ & $\mathrm{~m}$ & 4 & 7 & 1 & 7 & $\mathrm{CT}$ & CT & $\mathrm{CT}$ & $\mathrm{CT}$ & CT & $\mathrm{CT}$ & CT \\
\hline 302 & UniABC & RMSP & $\mathrm{N}$ & $\mathrm{m}$ & 3 & $\mathrm{~N}$ & 1 & 5 & $\mathrm{CT}$ & $\mathrm{CT}$ & $\mathrm{CT}$ & $\mathrm{CT}$ & CT & $\mathrm{CT}$ & $\mathrm{CT}$ \\
\hline
\end{tabular}




\begin{tabular}{|c|c|c|c|c|c|c|c|c|c|c|c|c|c|c|c|}
\hline $\mathrm{N}^{\circ}$ Ordem & Local & Região & Usuário SN & Sexo & Rendimento & Usuário & Idade & Ocupação & V1 & V2 & V3 & V4 & V5 & V6 & V7 \\
\hline 303 & UniABC & RMSP & $\mathrm{N}$ & $f$ & 3 & $\mathrm{~N}$ & 2 & 5 & $\mathrm{CT}$ & $\mathrm{CT}$ & $\mathrm{CT}$ & $\mathrm{CT}$ & CT & $\mathrm{CT}$ & $\mathrm{CT}$ \\
\hline 304 & UniABC & RMSP & $\mathrm{N}$ & $\mathrm{m}$ & 2 & $\mathrm{~N}$ & 2 & 6 & $\mathrm{CT}$ & $\mathrm{CT}$ & CT & $\mathrm{CT}$ & CT & CT & $\mathrm{CT}$ \\
\hline 305 & UniABC & RMSP & $\mathrm{N}$ & $\mathrm{m}$ & 6 & $\mathrm{~N}$ & 5 & 6 & C & $\mathrm{CT}$ & C & $\mathrm{CT}$ & $\mathrm{C}$ & C & C \\
\hline 306 & UniABC & RMSP & $\mathrm{N}$ & $f$ & 2 & $\mathrm{~N}$ & 3 & 6 & $\mathrm{CT}$ & CT & CT & $\mathrm{CT}$ & CT & CT & $\mathrm{CT}$ \\
\hline 307 & UniABC & RMSP & $\mathrm{N}$ & $f$ & 0 & $\mathrm{~N}$ & 2 & 4 & $\mathrm{CT}$ & $\mathrm{CT}$ & $\mathrm{CT}$ & $\mathrm{CT}$ & CT & $\mathrm{CT}$ & $\mathrm{CT}$ \\
\hline 308 & UniABC & RMSP & $\mathrm{N}$ & $\mathrm{m}$ & 2 & 2 & 2 & 3 & $\mathrm{CT}$ & CT & C & C & C & C & C \\
\hline 309 & UniABC & RMSP & $\mathrm{N}$ & $\mathrm{m}$ & 0 & $\mathrm{~N}$ & 2 & 3 & $\mathrm{CT}$ & CT & C & C & C & $\mathrm{D}$ & C \\
\hline 310 & UniABC & RMSP & $\mathrm{N}$ & $\mathrm{m}$ & 6 & $\mathrm{~N}$ & 3 & 5 & $\mathrm{CT}$ & $\mathrm{CT}$ & C & C & $\mathrm{C}$ & DT & I \\
\hline 311 & UniABC & RMSP & $\mathrm{N}$ & $f$ & 0 & $\mathrm{~N}$ & 2 & 9 & I & C & $D$ & $D$ & $\mathrm{C}$ & I & $D$ \\
\hline 312 & UniABC & RMSP & $\mathrm{N}$ & $f$ & 0 & $\mathrm{~N}$ & 1 & 3 & C & C & I & I & I & C & C \\
\hline 313 & UniABC & RMSP & $S$ & $f$ & 3 & 7 & 3 & 3 & C & $\mathrm{CT}$ & $D$ & I & I & C & $\mathrm{CT}$ \\
\hline 314 & UniABC & RMSP & $S$ & $\mathrm{~m}$ & 2 & 5 & 2 & 8 & $\mathrm{CT}$ & C & C & C & C & $\mathrm{CT}$ & CT \\
\hline 315 & UniABC & RMSP & $\mathrm{N}$ & $f$ & 2 & $\mathrm{~N}$ & 2 & 3 & C & CT & $\mathrm{CT}$ & $\mathrm{CT}$ & C & C & C \\
\hline 316 & UniABC & RMSP & $\mathrm{N}$ & $f$ & 0 & $\mathrm{~N}$ & 2 & 3 & C & I & $C$ & CT & C & 1 & $\mathrm{D}$ \\
\hline 317 & UniABC & RMSP & $S$ & $f$ & 1 & 5 & 3 & 9 & C & I & $C$ & $\mathrm{CT}$ & I & I & $\mathrm{D}$ \\
\hline 318 & UniABC & RMSP & $\mathrm{N}$ & $f$ & 7 & $\mathrm{~N}$ & 4 & 9 & C & I & C & C & I & I & C \\
\hline 319 & UniABC & RMSP & $\mathrm{N}$ & $f$ & 0 & $\mathrm{~N}$ & 1 & 6 & C & C & $D$ & $D$ & $D$ & C & $D$ \\
\hline 320 & UniABC & RMSP & $\mathrm{N}$ & $f$ & 3 & $\mathrm{~N}$ & 3 & 3 & $\mathrm{CT}$ & CT & I & I & $\mathrm{C}$ & 1 & C \\
\hline 321 & UniABC & RMSP & $\mathrm{N}$ & $f$ & 2 & 1 & 1 & 3 & C & I & I & C & $\mathrm{C}$ & C & C \\
\hline 322 & SCS & RMSP & $S$ & $f$ & 0 & 7 & 1 & 3 & $\mathrm{CT}$ & C & I & $D$ & C & $\mathrm{CT}$ & C \\
\hline 323 & Scs & RMSP & $\mathrm{N}$ & $\mathrm{m}$ & 5 & $\mathrm{~N}$ & 4 & 9 & $\mathrm{CT}$ & $\mathrm{CT}$ & $\mathrm{CT}$ & C & C & 1 & C \\
\hline 324 & Scs & RMSP & $\mathrm{N}$ & $\mathrm{m}$ & 4 & $\mathrm{~N}$ & 4 & 6 & $\mathrm{CT}$ & $\mathrm{CT}$ & C & $\mathrm{CT}$ & CT & $\mathrm{CT}$ & $\mathrm{CT}$ \\
\hline 325 & Scs & RMSP & $\mathrm{N}$ & $\mathrm{m}$ & 4 & $\mathrm{~N}$ & 1 & 3 & $\mathrm{CT}$ & $\mathrm{CT}$ & $\mathrm{CT}$ & C & $\mathrm{C}$ & CT & CT \\
\hline 326 & scs & RMSP & $S$ & $\mathrm{~m}$ & 4 & 5 & 5 & 6 & C & C & $\mathrm{C}$ & $D$ & $\mathrm{C}$ & C & C \\
\hline 327 & scs & RMSP & $\mathrm{N}$ & $\mathrm{m}$ & 3 & $\mathrm{~N}$ & 1 & 3 & $\mathrm{CT}$ & C & $D$ & I & I & C & C \\
\hline 328 & Scs & RMSP & $\mathrm{N}$ & $\mathrm{m}$ & 5 & $\mathrm{~N}$ & 5 & 6 & $\mathrm{CT}$ & CT & $\mathrm{CT}$ & $\mathrm{CT}$ & $\mathrm{C}$ & $\mathrm{CT}$ & CT \\
\hline 329 & SCS & RMSP & $\mathrm{N}$ & $\mathrm{m}$ & 2 & $\mathrm{~N}$ & 2 & 6 & C & I & C & DT & I & C & I \\
\hline 330 & SCS & RMSP & $\mathrm{N}$ & $\mathrm{m}$ & 2 & $\mathrm{~N}$ & 1 & 4 & C & CT & $\mathrm{CT}$ & CT & $\mathrm{C}$ & I & C \\
\hline
\end{tabular}




\begin{tabular}{|c|c|c|c|c|c|c|c|c|c|c|c|c|c|c|c|}
\hline $\mathrm{N}^{\circ}$ Ordem & Local & Região & Usuário SN & Sexo & Rendimento & Usuário & Idade & Ocupação & V1 & V2 & V3 & V4 & V5 & V6 & V7 \\
\hline 331 & SCS & RMSP & $S$ & $f$ & 4 & 5 & 3 & 3 & $\mathrm{CT}$ & $\mathrm{CT}$ & $C$ & C & I & $\mathrm{CT}$ & $\mathrm{CT}$ \\
\hline 332 & SCs & RMSP & $\mathrm{N}$ & $\mathrm{m}$ & 2 & $\mathrm{~F}$ & 1 & 9 & $\mathrm{CT}$ & $\mathrm{CT}$ & C & $\mathrm{C}$ & CT & CT & C \\
\hline 333 & scs & RMSP & $\mathrm{N}$ & $f$ & 4 & $\mathrm{~N}$ & 1 & 4 & I & C & $D$ & I & $\mathrm{C}$ & $\mathrm{D}$ & $\mathrm{D}$ \\
\hline 334 & scs & RMSP & $\mathrm{N}$ & $\mathrm{m}$ & 4 & $\mathrm{~N}$ & 3 & 4 & I & C & I & I & I & C & C \\
\hline 335 & scs & RMSP & $\mathrm{S}$ & $\mathrm{m}$ & 5 & 7 & 4 & 2 & C & C & C & $\mathrm{CT}$ & $\mathrm{C}$ & C & C \\
\hline 336 & SCs & RMSP & $S$ & $\mathrm{~m}$ & 5 & 7 & 4 & 6 & $\mathrm{CT}$ & $\mathrm{CT}$ & $\mathrm{CT}$ & $\mathrm{CT}$ & CT & $\mathrm{CT}$ & $\mathrm{CT}$ \\
\hline 337 & SCS & RMSP & $S$ & $\mathrm{~m}$ & 4 & 3 & 3 & 7 & $\mathrm{CT}$ & $\mathrm{CT}$ & $D$ & $D$ & C & $\mathrm{CT}$ & $\mathrm{CT}$ \\
\hline 338 & SCs & RMSP & $S$ & $\mathrm{~m}$ & 2 & 5 & 1 & 4 & C & $D$ & $\mathrm{D}$ & C & C & $\mathrm{D}$ & I \\
\hline 339 & SCs & RMSP & $S$ & $\mathrm{~m}$ & 2 & 7 & 2 & 9 & C & I & I & C & $\mathrm{C}$ & C & C \\
\hline 340 & scs & RMSP & $S$ & $\mathrm{~m}$ & 2 & 5 & 2 & 7 & C & I & $\mathrm{CT}$ & C & C & CT & C \\
\hline 341 & scs & RMSP & $\mathrm{N}$ & $\mathrm{m}$ & 3 & $\mathrm{~N}$ & 2 & 7 & $\mathrm{CT}$ & $\mathrm{CT}$ & I & I & CT & $\mathrm{CT}$ & $\mathrm{CT}$ \\
\hline 342 & SCS & RMSP & $\mathrm{N}$ & $\mathrm{m}$ & 0 & $\mathrm{~N}$ & 2 & 4 & $\mathrm{CT}$ & $\mathrm{CT}$ & C & C & C & C & $\mathrm{CT}$ \\
\hline 343 & SCs & RMSP & $\mathrm{N}$ & $\mathrm{m}$ & 2 & 2 & 2 & 4 & C & C & C & $D$ & $\mathrm{D}$ & C & C \\
\hline 344 & scs & RMSP & $\mathrm{N}$ & $\mathrm{m}$ & 5 & 2 & 4 & 8 & $\mathrm{CT}$ & $\mathrm{CT}$ & C & C & I & $\mathrm{CT}$ & CT \\
\hline 345 & SCs & RMSP & $\mathrm{N}$ & $\mathrm{m}$ & 4 & $\mathrm{~N}$ & 2 & 7 & I & I & DT & DT & DT & DT & DT \\
\hline 346 & scs & RMSP & $\mathrm{N}$ & $\mathrm{m}$ & 1 & $\mathrm{~N}$ & 2 & 3 & I & $\mathrm{CT}$ & I & I & C & I & CT \\
\hline 347 & scs & RMSP & $S$ & $\mathrm{~m}$ & 2 & 7 & 4 & 8 & DT & $\mathrm{CT}$ & $\mathrm{CT}$ & C & CT & C & $\mathrm{CT}$ \\
\hline 348 & scs & RMSP & $S$ & $f$ & 0 & 3 & 2 & 3 & C & $\mathrm{CT}$ & C & I & C & C & C \\
\hline 349 & SCs & RMSP & $\mathrm{N}$ & $\mathrm{m}$ & 4 & $\mathrm{~N}$ & 1 & 8 & $\mathrm{CT}$ & $\mathrm{CT}$ & I & $D$ & I & C & C \\
\hline 350 & SCs & RMSP & $\mathrm{N}$ & $\mathrm{m}$ & 0 & $\mathrm{~N}$ & 1 & 3 & $\mathrm{CT}$ & $\mathrm{CT}$ & $\mathrm{CT}$ & C & C & C & C \\
\hline 351 & SCS & RMSP & $\mathrm{N}$ & $\mathrm{m}$ & 0 & $\mathrm{~F}$ & 1 & 3 & C & C & I & I & C & C & C \\
\hline 352 & SCS & RMSP & $\mathrm{N}$ & $f$ & 0 & $\mathrm{~N}$ & 1 & 6 & $\mathrm{CT}$ & $\mathrm{CT}$ & I & $D$ & I & C & C \\
\hline 353 & SCS & RMSP & $S$ & $\mathrm{~m}$ & 2 & 5 & 1 & 6 & C & C & C & I & $\mathrm{D}$ & C & C \\
\hline 354 & SCS & RMSP & $\mathrm{N}$ & $f$ & 3 & $\mathrm{~N}$ & 2 & 6 & C & $D$ & $D$ & $D$ & $\mathrm{D}$ & $\mathrm{D}$ & $D$ \\
\hline 355 & SCS & RMSP & $\mathrm{N}$ & $f$ & 3 & $\mathrm{~N}$ & 3 & 9 & $\mathrm{CT}$ & C & $\mathrm{D}$ & $D$ & $\mathrm{D}$ & C & $\mathrm{CT}$ \\
\hline 356 & SCS & RMSP & $S$ & $f$ & 4 & 3 & 5 & 6 & $\mathrm{CT}$ & $\mathrm{CT}$ & $\mathrm{CT}$ & $\mathrm{CT}$ & C & C & $\mathrm{CT}$ \\
\hline 357 & SCS & RMSP & $\mathrm{N}$ & $\mathrm{m}$ & 5 & $\mathrm{~N}$ & 3 & 7 & $\mathrm{CT}$ & $\mathrm{CT}$ & $\mathrm{CT}$ & $C$ & $\mathrm{C}$ & C & $\mathrm{CT}$ \\
\hline 358 & SCS & RMSP & $\mathrm{S}$ & $\mathrm{m}$ & 2 & 7 & 2 & 5 & $\mathrm{C}$ & C & $\mathrm{D}$ & I & $\mathrm{C}$ & C & D \\
\hline
\end{tabular}




\begin{tabular}{|c|c|c|c|c|c|c|c|c|c|c|c|c|c|c|c|}
\hline $\mathbf{N}^{\circ}$ Ordem & Local & Região & Usuário SN & Sexo & Rendimento & Usuário & Idade & Ocupação & V1 & V2 & V3 & V4 & V5 & V6 & V7 \\
\hline 359 & SCS & RMSP & $S$ & $\mathrm{~m}$ & 3 & 5 & 3 & 4 & $C$ & $\mathrm{C}$ & $\mathrm{C}$ & $\mathrm{C}$ & C & $\mathrm{D}$ & 1 \\
\hline 360 & SCS & RMSP & $S$ & $\mathrm{~m}$ & 2 & 5 & 1 & 5 & C & C & I & $\mathrm{CT}$ & C & C & $\mathrm{C}$ \\
\hline 361 & SCS & RMSP & $\mathrm{N}$ & $\mathrm{m}$ & 3 & 1 & 1 & 7 & I & I & I & I & I & I & 1 \\
\hline 362 & SCS & RMSP & $\mathrm{N}$ & $\mathrm{m}$ & 0 & $\mathrm{~N}$ & 1 & 9 & I & I & I & I & I & I & I \\
\hline 363 & SCS & RMSP & $S$ & $f$ & 3 & 5 & 2 & 3 & $\mathrm{C}$ & 1 & I & I & I & I & 1 \\
\hline 364 & SCS & RMSP & $\mathrm{N}$ & $\mathrm{m}$ & 1 & $\mathrm{~F}$ & 4 & 9 & $\mathrm{CT}$ & $\mathrm{CT}$ & CT & $\mathrm{C}$ & CT & $\mathrm{C}$ & CT \\
\hline 365 & SCS & RMSP & $S$ & $\mathrm{~m}$ & 1 & 5 & 2 & 5 & $\mathrm{CT}$ & $\mathrm{CT}$ & CT & $\mathrm{CT}$ & CT & $\mathrm{CT}$ & CT \\
\hline 366 & SCS & RMSP & $\mathrm{N}$ & $f$ & 5 & $\mathrm{~N}$ & 4 & 3 & $\mathrm{CT}$ & C & CT & $\mathrm{CT}$ & $\mathrm{CT}$ & $C$ & $\mathrm{C}$ \\
\hline 367 & SCS & RMSP & $\mathrm{N}$ & $\mathrm{m}$ & 3 & $\mathrm{~N}$ & 4 & 8 & I & I & I & I & 1 & I & 1 \\
\hline 368 & SCS & RMSP & $\mathrm{N}$ & $f$ & 0 & 2 & 1 & 3 & C & C & $\mathrm{C}$ & C & C & C & $\mathrm{C}$ \\
\hline 369 & Scs & RMSP & $\mathrm{N}$ & $\mathrm{m}$ & 3 & $\mathrm{~N}$ & 2 & 3 & $\mathrm{CT}$ & $\mathrm{CT}$ & CT & $C$ & C & $C$ & $\mathrm{C}$ \\
\hline 370 & Scs & RMSP & $S$ & $\mathrm{~m}$ & 5 & 5 & 1 & 3 & $C$ & C & I & I & 1 & 1 & $\mathrm{C}$ \\
\hline 371 & Scs & RMSP & $S$ & $f$ & 0 & 5 & 1 & 3 & $\mathrm{CT}$ & $\mathrm{CT}$ & CT & $C$ & C & $\mathrm{CT}$ & CT \\
\hline 372 & Scs & RMSP & $S$ & $\mathrm{~m}$ & 0 & 7 & 3 & 3 & C & $C$ & I & $\mathrm{D}$ & $\mathrm{CT}$ & C & I \\
\hline 373 & Scs & RMSP & $\mathrm{N}$ & $\mathrm{m}$ & 2 & $\mathrm{~N}$ & 2 & 3 & $\mathrm{CT}$ & $\mathrm{CT}$ & C & $\mathrm{D}$ & I & I & CT \\
\hline 374 & SCS & RMSP & $S$ & $f$ & 0 & 7 & 1 & 3 & C & $C$ & $\mathrm{D}$ & $\mathrm{D}$ & 1 & C & I \\
\hline 375 & SCS & RMSP & $S$ & $f$ & 1 & 5 & 1 & 6 & C & $\mathrm{D}$ & 1 & C & 1 & I & C \\
\hline 376 & Scs & RMSP & $\mathrm{N}$ & $\mathrm{m}$ & 2 & $\mathrm{~N}$ & 2 & 3 & $\mathrm{CT}$ & C & I & I & $\mathrm{CT}$ & 1 & CT \\
\hline 377 & SCS & RMSP & $\mathrm{N}$ & $f$ & 0 & 1 & 2 & 3 & C & $\mathrm{D}$ & 1 & $C$ & $C$ & $C$ & I \\
\hline 378 & SCS & RMSP & $\mathrm{N}$ & $\mathrm{m}$ & 0 & $\mathrm{~N}$ & 1 & 9 & C & $\mathrm{C}$ & $\mathrm{C}$ & C & C & C & C \\
\hline 379 & SCS & RMSP & $\mathrm{N}$ & $\mathrm{m}$ & 0 & $\mathrm{~N}$ & 1 & 9 & C & $\mathrm{C}$ & $\mathrm{C}$ & I & I & $\mathrm{C}$ & $\mathrm{C}$ \\
\hline 380 & SCS & RMSP & $\mathrm{N}$ & $\mathrm{m}$ & 4 & $\mathrm{~N}$ & 1 & 5 & C & C & $\mathrm{C}$ & $C$ & C & $C$ & C \\
\hline 381 & SCS & RMSP & $S$ & $f$ & 0 & 5 & 1 & 1 & C & C & I & C & $\mathrm{D}$ & I & I \\
\hline 382 & SCS & RMSP & $S$ & $\mathrm{~m}$ & 0 & 7 & 1 & 9 & C & $\mathrm{CT}$ & I & $\mathrm{CT}$ & $\mathrm{D}$ & I & I \\
\hline 383 & SCS & RMSP & $S$ & $\mathrm{~m}$ & 0 & 5 & 1 & 9 & $\mathrm{CT}$ & $\mathrm{CT}$ & $\mathrm{D}$ & I & I & I & I \\
\hline 384 & SCS & RMSP & $S$ & $\mathrm{~m}$ & 0 & 5 & 2 & 9 & I & C & C & C & C & C & C \\
\hline 385 & SCS & RMSP & $S$ & $\mathrm{~m}$ & 0 & 3 & 1 & 9 & C & C & C & $C$ & C & C & C \\
\hline 386 & SCS & RMSP & $\mathrm{N}$ & $\mathrm{m}$ & 2 & 1 & 2 & 3 & $\mathrm{CT}$ & $\mathrm{C}$ & $D$ & $\mathrm{C}$ & CT & $\mathrm{CT}$ & CT \\
\hline
\end{tabular}




\begin{tabular}{|c|c|c|c|c|c|c|c|c|c|c|c|c|c|c|c|}
\hline $\mathrm{N}^{\circ}$ Ordem & Local & Região & Usuário SN & Sexo & Rendimento & Usuário & Idade & Ocupação & V1 & V2 & V3 & V4 & V5 & V6 & V7 \\
\hline 387 & SCS & RMSP & $\mathrm{N}$ & $\mathrm{m}$ & 0 & 2 & 1 & 3 & $\mathrm{CT}$ & $C$ & I & 1 & 1 & I & 1 \\
\hline 388 & SCS & RMSP & $\mathrm{N}$ & $\mathrm{m}$ & 0 & $\mathrm{~N}$ & 1 & 3 & $\mathrm{CT}$ & $\mathrm{C}$ & $\mathrm{CT}$ & $C$ & 1 & I & CT \\
\hline 389 & SCS & RMSP & $\mathrm{N}$ & $\mathrm{m}$ & 2 & $\mathrm{~N}$ & 1 & 6 & $\mathrm{CT}$ & $\mathrm{CT}$ & I & I & 1 & C & CT \\
\hline 390 & SCS & RMSP & $\mathrm{N}$ & $f$ & 3 & $\mathrm{~N}$ & 3 & 5 & $\mathrm{CT}$ & $\mathrm{CT}$ & $\mathrm{C}$ & C & $D$ & $\mathrm{C}$ & $\mathrm{C}$ \\
\hline 391 & SCS & RMSP & $S$ & $f$ & 0 & 5 & 1 & 3 & $\mathrm{CT}$ & $\mathrm{CT}$ & I & I & 1 & $\mathrm{C}$ & CT \\
\hline 392 & SCS & RMSP & $\mathrm{N}$ & $f$ & 0 & $F$ & 1 & 3 & $\mathrm{C}$ & $\mathrm{CT}$ & $D$ & $D$ & 1 & I & $\mathrm{C}$ \\
\hline 393 & SCS & RMSP & $\mathrm{N}$ & $\mathrm{m}$ & 7 & $\mathrm{~N}$ & 4 & 9 & $\mathrm{CT}$ & $\mathrm{CT}$ & $\mathrm{CT}$ & CT & $\mathrm{CT}$ & CT & CT \\
\hline 394 & SCS & RMSP & $\mathrm{N}$ & $\mathrm{m}$ & 4 & $\mathrm{~N}$ & 2 & 8 & $\mathrm{CT}$ & $\mathrm{CT}$ & CT & CT & CT & CT & CT \\
\hline 395 & SCS & RMSP & $S$ & $\mathrm{~m}$ & 3 & 7 & 2 & 9 & CT & $\mathrm{CT}$ & $D$ & $C$ & CT & CT & CT \\
\hline 396 & SCS & RMSP & $\mathrm{N}$ & $\mathrm{m}$ & 3 & $\mathrm{~N}$ & 2 & 3 & I & I & I & I & I & I & I \\
\hline 397 & SCS & RMSP & $S$ & $\mathrm{~m}$ & 3 & 7 & 2 & 9 & $\mathrm{CT}$ & $\mathrm{CT}$ & $\mathrm{CT}$ & I & CT & CT & CT \\
\hline 398 & SCS & RMSP & $\mathrm{N}$ & $\mathrm{m}$ & 5 & $\mathrm{~N}$ & 4 & 7 & DT & DT & $D$ & DT & DT & DT & C \\
\hline 399 & SCS & RMSP & $S$ & $\mathrm{~m}$ & 3 & 5 & 2 & 7 & $\mathrm{CT}$ & $\mathrm{CT}$ & C & I & C & I & CT \\
\hline 400 & SCS & RMSP & $S$ & $\mathrm{~m}$ & 3 & 7 & 2 & 4 & $\mathrm{CT}$ & $\mathrm{CT}$ & $\mathrm{CT}$ & CT & CT & CT & CT \\
\hline 401 & SCS & RMSP & $\mathrm{N}$ & $\mathrm{m}$ & 0 & 1 & 1 & 3 & $\mathrm{CT}$ & $\mathrm{CT}$ & $\mathrm{CT}$ & CT & CT & СT & CT \\
\hline 402 & SCS & RMSP & $\mathrm{N}$ & $\mathrm{m}$ & 1 & $F$ & 2 & 7 & $\mathrm{C}$ & $C$ & $\mathrm{C}$ & I & C & $\mathrm{C}$ & C \\
\hline 403 & SCS & RMSP & $\mathrm{N}$ & $\mathrm{m}$ & 5 & $\mathrm{~N}$ & 5 & 8 & CT & $C$ & $D$ & I & 1 & I & I \\
\hline 404 & SCS & RMSP & $\mathrm{N}$ & $f$ & 0 & $\mathrm{~N}$ & 3 & 3 & I & I & I & $\mathrm{D}$ & $D$ & $D$ & I \\
\hline 405 & SCS & RMSP & $\mathrm{N}$ & $\mathrm{m}$ & 3 & $\mathrm{~N}$ & 2 & 7 & $\mathrm{CT}$ & $\mathrm{CT}$ & $D$ & CT & CT & CT & CT \\
\hline 406 & SCS & RMSP & $\mathrm{N}$ & $\mathrm{m}$ & 6 & $\mathrm{~N}$ & 5 & 9 & $\mathrm{CT}$ & $\mathrm{CT}$ & C & I & I & $\mathrm{C}$ & CT \\
\hline 407 & SCS & RMSP & $\mathrm{N}$ & $\mathrm{m}$ & 4 & $\mathrm{~N}$ & 3 & 6 & $\mathrm{CT}$ & C & I & $C$ & C & $\mathrm{C}$ & I \\
\hline 408 & SCS & RMSP & $\mathrm{N}$ & $\mathrm{m}$ & 2 & 1 & 1 & 6 & C & $\mathrm{CT}$ & $\mathrm{C}$ & $C$ & C & $\mathrm{C}$ & $\mathrm{C}$ \\
\hline 409 & SCS & RMSP & $\mathrm{N}$ & $\mathrm{m}$ & 6 & $\mathrm{~N}$ & 3 & 2 & $\mathrm{CT}$ & $\mathrm{CT}$ & C & CT & I & $\mathrm{C}$ & C \\
\hline 410 & SCS & RMSP & $S$ & $\mathrm{~m}$ & 4 & 5 & 3 & 9 & $\mathrm{CT}$ & $\mathrm{CT}$ & $\mathrm{CT}$ & CT & $\mathrm{CT}$ & CT & $\mathrm{CT}$ \\
\hline 411 & SCS & RMSP & $\mathrm{N}$ & $\mathrm{m}$ & 3 & $\mathrm{~N}$ & 2 & 9 & $\mathrm{C}$ & $C$ & I & $C$ & C & $\mathrm{C}$ & CT \\
\hline 412 & SCS & RMSP & $\mathrm{N}$ & $\mathrm{m}$ & 3 & $\mathrm{~N}$ & 1 & 9 & $\mathrm{CT}$ & $\mathrm{CT}$ & $C$ & $C$ & $C$ & C & $C$ \\
\hline 413 & SCS & RMSP & $\mathrm{N}$ & $\mathrm{m}$ & 5 & $\mathrm{~N}$ & 3 & 8 & DT & $C$ & $D$ & $C$ & 1 & СT & CT \\
\hline 414 & SCS & RMSP & $S$ & $\mathrm{~m}$ & 5 & 5 & 4 & 2 & I & I & I & I & I & I & I \\
\hline
\end{tabular}




\begin{tabular}{|c|c|c|c|c|c|c|c|c|c|c|c|c|c|c|c|}
\hline $\mathbf{N}^{\circ}$ Ordem & Local & Região & Usuário SN & Sexo & Rendimento & Usuário & Idade & Ocupação & V1 & V2 & V3 & V4 & V5 & V6 & V7 \\
\hline 415 & SCS & RMSP & $\mathrm{N}$ & $\mathrm{m}$ & 5 & $\mathrm{~N}$ & 4 & 6 & C & C & C & C & C & C & C \\
\hline 416 & SCS & RMSP & $\mathrm{N}$ & $f$ & 2 & $\mathrm{~N}$ & 2 & 5 & C & C & C & D & $C$ & D & C \\
\hline 417 & SCS & RMSP & $\mathrm{N}$ & $\mathrm{m}$ & 2 & $\mathrm{~N}$ & 2 & 9 & C & C & 1 & C & I & C & 1 \\
\hline 418 & Scs & RMSP & $\mathrm{N}$ & $f$ & 2 & 1 & 2 & 6 & $C$ & DT & DT & DT & DT & CT & $C$ \\
\hline 419 & scs & RMSP & $\mathrm{N}$ & $\mathrm{m}$ & 6 & $\mathrm{~N}$ & 4 & 9 & $C$ & $C$ & $\mathrm{D}$ & $\mathrm{D}$ & $C$ & $C$ & $C$ \\
\hline 420 & scs & RMSP & $\mathrm{N}$ & $\mathrm{m}$ & 4 & $\mathrm{~N}$ & 2 & 7 & 1 & C & $\mathrm{D}$ & $\mathrm{D}$ & $C$ & 1 & C \\
\hline 421 & scs & RMSP & $S$ & $\mathrm{~m}$ & 3 & 5 & 4 & 8 & $\mathrm{CT}$ & I & CT & $\mathrm{D}$ & 1 & CT & $C$ \\
\hline 422 & scs & RMSP & $\mathrm{N}$ & $\mathrm{m}$ & 4 & $\mathrm{~N}$ & 3 & 8 & CT & CT & CT & CT & $\mathrm{D}$ & CT & CT \\
\hline 423 & SCS & RMSP & $\mathrm{N}$ & $\mathrm{m}$ & 5 & $\mathrm{~N}$ & 4 & 9 & CT & CT & I & 1 & $C$ & C & CT \\
\hline 424 & scs & RMSP & $S$ & $\mathrm{~m}$ & 3 & 5 & 1 & 9 & C & C & C & C & $C$ & $C$ & C \\
\hline 425 & scs & RMSP & $\mathrm{N}$ & $\mathrm{m}$ & 5 & $\mathrm{~N}$ & 3 & 9 & $C$ & C & CT & C & $C$ & $C$ & C \\
\hline 426 & scs & RMSP & $N$ & $f$ & 5 & $\mathrm{~N}$ & 4 & 2 & $\mathrm{CT}$ & CT & C & 1 & $C$ & $C$ & CT \\
\hline 427 & scs & RMSP & $N$ & $\mathrm{~m}$ & 3 & $\mathrm{~N}$ & 2 & 7 & C & C & $\mathrm{D}$ & C & DT & $\mathrm{D}$ & C \\
\hline 428 & SCS & RMSP & $S$ & $\mathrm{~m}$ & 3 & 5 & 2 & 8 & CT & CT & D & 1 & I & CT & C \\
\hline 429 & scs & RMSP & $\mathrm{N}$ & $f$ & 4 & $\mathrm{~N}$ & 2 & 5 & $C$ & C & $C$ & I & I & $C$ & 1 \\
\hline 430 & scs & RMSP & $S$ & $\mathrm{~m}$ & 3 & 7 & 1 & 7 & $C$ & CT & DT & C & $C$ & I & $C$ \\
\hline 431 & scs & RMSP & $S$ & $f$ & 3 & 5 & 2 & 7 & $\mathrm{CT}$ & CT & CT & $\mathrm{D}$ & $C$ & $C$ & $C$ \\
\hline 432 & SCS & RMSP & $N$ & $\mathrm{~m}$ & 4 & $\mathrm{~N}$ & 4 & 6 & C & C & I & $\mathrm{D}$ & 1 & $C$ & $C$ \\
\hline 433 & SCS & RMSP & $S$ & $f$ & 3 & 7 & 1 & 4 & C & CT & CT & CT & CT & CT & CT \\
\hline
\end{tabular}




\section{Apêndice D - Resultados da Pesquisa Junto aos Especialistas}

\begin{tabular}{|c|c|c|c|c|c|c|c|}
\hline & & & & & & & \\
& a) & b) & c) & d) & e) & f) & g) \\
\hline a) & $\mathbf{1}$ & 1 & 3 & 3 & 3 & 1 & 1 \\
\hline b) & 1 & $\mathbf{1}$ & 3 & 1 & 3 & 1 & 3 \\
\hline c) & $1 / 3$ & $1 / 3$ & $\mathbf{1}$ & $1 / 3$ & 1 & $1 / 3$ & $1 / 5$ \\
\hline d) & $1 / 3$ & 1 & 3 & $\mathbf{1}$ & 3 & 1 & $1 / 3$ \\
\hline e) & $1 / 3$ & $1 / 3$ & 1 & $1 / 3$ & $\mathbf{1}$ & 1 & $1 / 3$ \\
\hline f) & 1 & 1 & 3 & 1 & 1 & $\mathbf{1}$ & 1 \\
\hline g) & 1 & $1 / 3$ & 5 & 3 & 3 & 1 & $\mathbf{1}$ \\
\hline Soma & 5,00000 & 5,00000 & 19,00000 & 9,66667 & 15,00000 & 6,33333 & 6,86667 \\
\hline
\end{tabular}

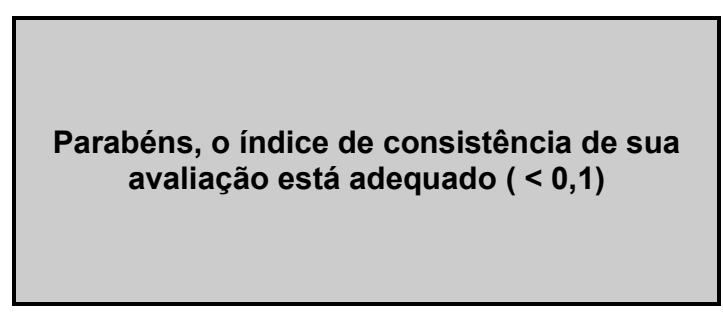

$$
\text { (1) }
$$

\begin{tabular}{|c|l|c|}
\cline { 3 - 3 } & \multicolumn{2}{l}{ Fatores } \\
\hline a) & Diminuição do trânsito devido ao uso de transporte público sobre trilhos & $\mathbf{0 , 1 9 6 0}$ \\
\hline b) & $\begin{array}{l}\text { Aumento da qualidade de vida devido a diminuição da poluição do ar, sonora, visual } \\
\text { e dano ecológico }\end{array}$ & $\mathbf{0 , 2 0 8 0}$ \\
\hline c) & $\begin{array}{l}\text { Economia do dinheiro público devido a baixos investimentos em construção e } \\
\text { manutenção de vias públicas }\end{array}$ & $\mathbf{0 , 0 5 2 7}$ \\
\hline d) & $\begin{array}{l}\text { Acesso aos serviços públicos com maior eficiência (hospitais, repartições públicas, } \\
\text { etc) }\end{array}$ & $\mathbf{0 , 1 3 3 5}$ \\
\hline e) & Melhora a economia da cidade e dos centros regionais & $\mathbf{0 , 0 7 0 5}$ \\
\hline f) & $\begin{array}{l}\text { Uso das fontes de petróleo com eficiência devido ao menor consumo em função do } \\
\text { uso do transporte público. }\end{array}$ & $\mathbf{0 , 1 4 7 4}$ \\
\hline g) & Redução no custo dos acidentes de trânsito e danos provocados por eles & $\mathbf{0 , 1 9 2 0}$ \\
\hline
\end{tabular}




\begin{tabular}{|c|c|c|c|c|c|c|c|}
\hline & a) & b) & c) & d) & e) & f) & g) \\
\hline a) & $\mathbf{1}$ & $1 / 4$ & $1 / 2$ & $1 / 2$ & $1 / 3$ & 1 & $1 / 6$ \\
\hline b) & 4 & $\mathbf{1}$ & $1 / 2$ & $1 / 4$ & $1 / 2$ & $1 / 2$ & $1 / 3$ \\
\hline $\mathbf{c )}$ & 2 & 2 & $\mathbf{1}$ & $1 / 3$ & 1 & 1 & $1 / 2$ \\
\hline $\mathbf{d})$ & 2 & 4 & 3 & $\mathbf{1}$ & 1 & $1 / 2$ & $1 / 3$ \\
\hline e) & 3 & 2 & 1 & 1 & $\mathbf{1}$ & $1 / 2$ & $1 / 2$ \\
\hline $\mathbf{f}$ & 1 & 2 & 1 & 2 & 2 & $\mathbf{1}$ & $1 / 2$ \\
\hline g) & 6 & 3 & 2 & 3 & 2 & 2 & $\mathbf{1}$ \\
\hline Soma & 19,00000 & 14,25000 & 9,00000 & 8,08333 & 7,83333 & 6,50000 & 3,33333 \\
\hline
\end{tabular}

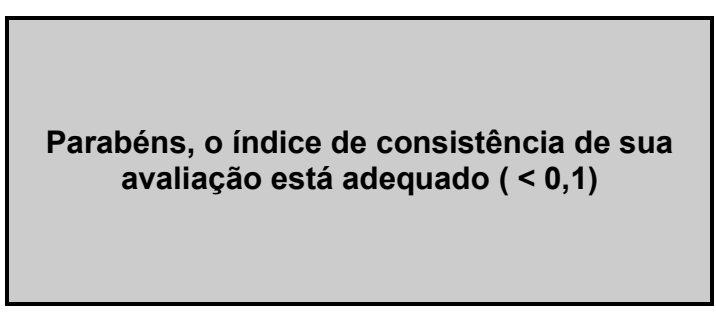

\begin{tabular}{|l|l|}
\hline Consistência & 0,098 \\
\hline
\end{tabular}

\begin{tabular}{|c|c|c|}
\hline & & Fatores \\
\hline a) & Diminuição do trânsito devido ao uso de transporte público sobre trilhos & 0,0620 \\
\hline b) & $\begin{array}{l}\text { Aumento da qualidade de vida devido a diminuição da poluição do ar, sonora, visual } \\
\text { e dano ecológico }\end{array}$ & 0,0868 \\
\hline c) & $\begin{array}{l}\text { Economia do dinheiro público devido a baixos investimentos em construção e } \\
\text { manutenção de vias públicas }\end{array}$ & 0,1185 \\
\hline d) & $\begin{array}{l}\text { Acesso aos serviços públicos com maior eficiência (hospitais, repartições públicas, } \\
\text { etc) }\end{array}$ & 0,1639 \\
\hline e) & Melhora a economia da cidade e dos centros regionais & 0,1268 \\
\hline f) & $\begin{array}{l}\text { Uso das fontes de petróleo com eficiência devido ao menor consumo em função do } \\
\text { uso do transporte público. }\end{array}$ & 0,1587 \\
\hline g) & Redução no custo dos acidentes de trânsito e danos provocados por eles & 0,2832 \\
\hline
\end{tabular}




\begin{tabular}{|c|c|c|c|c|c|c|c|}
\hline & a) & b) & c) & d) & e) & f) & g) \\
\hline a) & $\mathbf{1}$ & $1 / 2$ & 1 & $1 / 3$ & $1 / 2$ & 1 & 1 \\
\hline b) & 2 & $\mathbf{1}$ & 3 & 2 & 1 & 4 & $1 / 2$ \\
\hline c) & 1 & $1 / 3$ & $\mathbf{1}$ & $1 / 4$ & $1 / 2$ & 1 & $1 / 3$ \\
\hline d) & 3 & $1 / 2$ & 4 & $\mathbf{1}$ & $1 / 2$ & 2 & $1 / 3$ \\
\hline e) & 2 & 1 & 2 & 2 & $\mathbf{1}$ & 1 & $1 / 2$ \\
\hline f) & 1 & $1 / 4$ & 1 & $1 / 2$ & 1 & $\mathbf{1}$ & $1 / 2$ \\
\hline g) & 1 & 2 & 3 & 3 & 2 & 2 & $\mathbf{1}$ \\
\hline Soma & 11,00000 & 5,58333 & 15,00000 & 9,08333 & 6,50000 & 12,00000 & 4,16667 \\
\hline
\end{tabular}

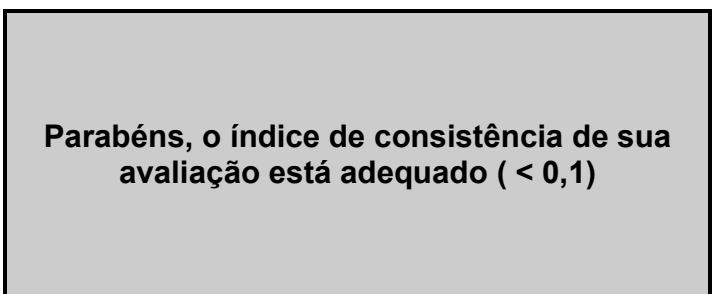

\begin{tabular}{|l|l|}
\hline Consistência & 0,083 \\
\hline
\end{tabular}

\begin{tabular}{|c|c|c|}
\hline & & Fatores \\
\hline a) & Diminuição do trânsito devido ao uso de transporte público sobre trilhos & 0,0977 \\
\hline b) & $\begin{array}{l}\text { Aumento da qualidade de vida devido a diminuição da poluição do ar, sonora, visual } \\
\text { e dano ecológico }\end{array}$ & 0,1983 \\
\hline c) & $\begin{array}{l}\text { Economia do dinheiro público devido a baixos investimentos em construção e } \\
\text { manutenção de vias públicas }\end{array}$ & 0,0693 \\
\hline d) & $\begin{array}{l}\text { Acesso aos serviços públicos com maior eficiência (hospitais, repartições públicas, } \\
\text { etc) }\end{array}$ & 0,1518 \\
\hline e) & Melhora a economia da cidade e dos centros regionais & 0,1531 \\
\hline f) & $\begin{array}{l}\text { Uso das fontes de petróleo com eficiência devido ao menor consumo em função do } \\
\text { uso do transporte público. }\end{array}$ & 0,0878 \\
\hline g) & Redução no custo dos acidentes de trânsito e danos provocados por eles & 0,2420 \\
\hline
\end{tabular}




\begin{tabular}{|c|c|c|c|c|c|c|c|}
\hline & a) & b) & c) & d) & e) & f) & g) \\
\hline a) & $\mathbf{1}$ & $1 / 5$ & $1 / 2$ & $1 / 3$ & $1 / 3$ & $1 / 3$ & $1 / 2$ \\
\hline b) & 5 & $\mathbf{1}$ & 3 & $1 / 2$ & 3 & 3 & 1 \\
\hline c) & 2 & $1 / 3$ & $\mathbf{1}$ & $1 / 2$ & $1 / 2$ & $1 / 2$ & $1 / 3$ \\
\hline d) & 3 & 2 & 2 & $\mathbf{1}$ & $1 / 2$ & 1 & $1 / 4$ \\
\hline e) & 3 & $1 / 3$ & 2 & 2 & $\mathbf{1}$ & $1 / 2$ & $1 / 2$ \\
\hline f) & 3 & $1 / 3$ & 2 & 1 & 2 & $\mathbf{1}$ & $1 / 2$ \\
\hline g) & 2 & 1 & 3 & 4 & 2 & 2 & $\mathbf{1}$ \\
\hline Soma & 19,00000 & 5,19000 & 13,53030 & 9,33333 & 9,36364 & 8,36364 & 4,08333 \\
\hline
\end{tabular}

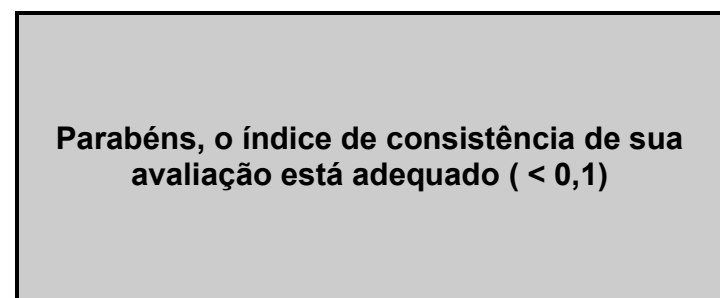

\begin{tabular}{|l|l|}
\hline Consistência & 0,099 \\
\hline
\end{tabular}

\begin{tabular}{|c|c|c|}
\hline & & Fatores \\
\hline a) & Diminuição do trânsito devido ao uso de transporte público sobre trilhos & 0,0517 \\
\hline b) & $\begin{array}{l}\text { Aumento da qualidade de vida devido a diminuição da poluição do ar, sonora, visual } \\
\text { e dano ecológico. }\end{array}$ & 0,2377 \\
\hline c) & $\begin{array}{l}\text { Economia do dinheiro público devido a baixos investimentos em construção e } \\
\text { manutenção de vias públicas }\end{array}$ & 0,0702 \\
\hline d) & $\begin{array}{l}\text { Acesso aos serviços públicos com maior eficiência (hospitais, repartições públicas, } \\
\text { etc.) }\end{array}$ & 0,1475 \\
\hline e) & Melhora a economia da cidade e dos centros regionais & 0,1247 \\
\hline f) & $\begin{array}{l}\text { Uso das fontes de petróleo com eficiência devido ao menor consumo em função do } \\
\text { uso do transporte público. }\end{array}$ & 0,1331 \\
\hline g) & Redução no custo dos acidentes de trânsito e danos provocados por eles & 0,2351 \\
\hline
\end{tabular}




\begin{tabular}{|c|c|c|c|c|c|c|c|}
\hline & a) & b) & c) & d) & e) & f) & g) \\
\hline a) & $\mathbf{1}$ & $2 / 5$ & $3 / 4$ & $1 / 4$ & $2 / 5$ & $2 / 7$ & $2 / 3$ \\
\hline b) & $21 / 2$ & $\mathbf{1}$ & 2 & 2 & 4 & $12 / 3$ & $1 / 2$ \\
\hline c) & $11 / 3$ & $1 / 2$ & $\mathbf{1}$ & $1 / 3$ & $1 / 2$ & $2 / 5$ & $1 / 5$ \\
\hline d) & 4 & $1 / 2$ & 3 & $\mathbf{1}$ & 1 & 3 & $1 / 2$ \\
\hline e) & $21 / 2$ & $1 / 4$ & 2 & 1 & $\mathbf{1}$ & 1 & $1 / 4$ \\
\hline f) & $31 / 2$ & $3 / 5$ & $21 / 2$ & $1 / 3$ & 1 & $\mathbf{1}$ & $1 / 4$ \\
\hline g) & $11 / 2$ & 2 & 5 & 2 & 4 & 4 & $\mathbf{1}$ \\
\hline Soma & 16,30000 & 5,25000 & 16,26923 & 6,91667 & 11,90000 & 11,35238 & 3,36667 \\
\hline
\end{tabular}

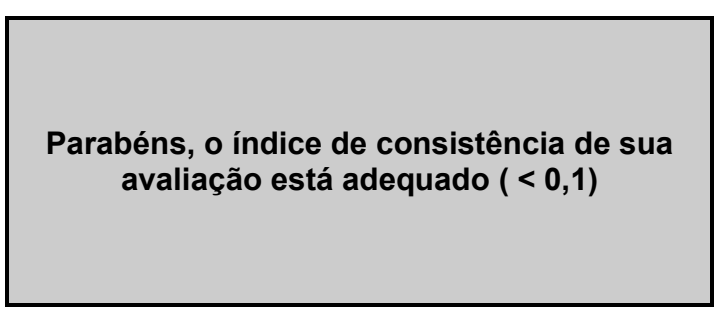

\begin{tabular}{|l|l|}
\hline Consistência & 0,095 \\
\hline
\end{tabular}

\begin{tabular}{|c|c|c|}
\hline & & Fatores \\
\hline a) & Diminuição do trânsito devido ao uso de transporte público sobre trilhos & 0,0683 \\
\hline b) & $\begin{array}{l}\text { Aumento da qualidade de vida devido a diminuição da poluição do ar, sonora, visual } \\
\text { e dano ecológico }\end{array}$ & 0,1982 \\
\hline c) & $\begin{array}{l}\text { Economia do dinheiro público devido a baixos investimentos em construção e } \\
\text { manutenção de vias públicas }\end{array}$ & 0,0602 \\
\hline d) & $\begin{array}{l}\text { Acesso aos serviços públicos com maior eficiência (hospitais, repartições públicas, } \\
\text { etc) }\end{array}$ & 0,1666 \\
\hline e) & Melhora a economia da cidade e dos centros regionais & 0,1021 \\
\hline f) & $\begin{array}{l}\text { Uso das fontes de petróleo com eficiência devido ao menor consumo em função do } \\
\text { uso do transporte público. }\end{array}$ & 0,1110 \\
\hline g) & Redução no custo dos acidentes de trânsito e danos provocados por eles & 0,2936 \\
\hline
\end{tabular}




\begin{tabular}{|c|c|c|c|c|c|c|c|}
\hline & a) & b) & c) & d) & e) & f) & g) \\
\hline a) & $\mathbf{1}$ & $1 / 3$ & 2 & $1 / 5$ & 1 & 1 & 2 \\
\hline b) & 3 & $\mathbf{1}$ & 9 & 1 & 9 & 7 & 8 \\
\hline c) & $1 / 2$ & $1 / 9$ & $\mathbf{1}$ & $1 / 5$ & 1 & 3 & $2 / 5$ \\
\hline d) & 5 & 1 & 5 & $\mathbf{1}$ & 5 & 7 & 6 \\
\hline e) & 1 & $1 / 9$ & 1 & $1 / 5$ & $\mathbf{1}$ & 3 & $1 / 3$ \\
\hline f) & 1 & $1 / 7$ & $1 / 3$ & $1 / 7$ & $1 / 3$ & $\mathbf{1}$ & $1 / 3$ \\
\hline g) & $1 / 2$ & $1 / 8$ & $21 / 2$ & $1 / 6$ & $24 / 5$ & $24 / 5$ & $\mathbf{1}$ \\
\hline Soma & 12,00000 & 2,82341 & 20,83333 & 2,90952 & 20,13333 & 24,80000 & 18,11429 \\
\hline
\end{tabular}

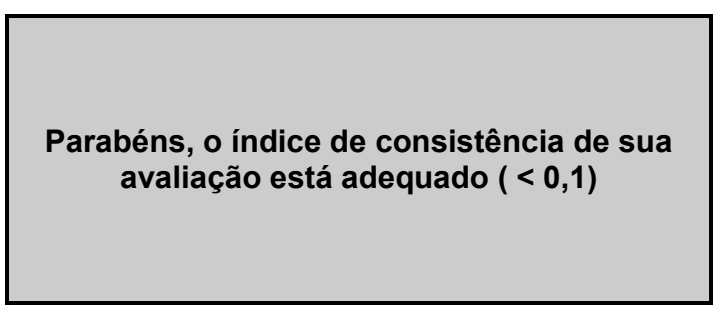

\begin{tabular}{|l|l|}
\hline Consistência & 0,097 \\
\hline
\end{tabular}

\begin{tabular}{|c|c|c|}
\hline & & Fatores \\
\hline a) & Diminuição do trânsito devido ao uso de transporte público sobre trilhos & 0,0809 \\
\hline b) & $\begin{array}{l}\text { Aumento da qualidade de vida devido a diminuição da poluição do ar, sonora, visual } \\
\text { e dano ecológico }\end{array}$ & 0,3644 \\
\hline c) & $\begin{array}{l}\text { Economia do dinheiro público devido a baixos investimentos em construção e } \\
\text { manutenção de vias públicas }\end{array}$ & 0,0558 \\
\hline d) & $\begin{array}{l}\text { Acesso aos serviços públicos com maior eficiência (hospitais, repartições públicas, } \\
\text { etc) }\end{array}$ & 0,3166 \\
\hline e) & Melhora a economia da cidade e dos centros regionais & 0,0614 \\
\hline f) & $\begin{array}{l}\text { Uso das fontes de petróleo com eficiência devido ao menor consumo em função do } \\
\text { uso do transporte público. }\end{array}$ & 0,0394 \\
\hline g) & Redução no custo dos acidentes de trânsito e danos provocados por eles & 0,0815 \\
\hline
\end{tabular}




\begin{tabular}{|c|c|c|c|c|c|c|c|}
\hline & a) & b) & c) & d) & e) & f) & g) \\
\hline a) & $\mathbf{1}$ & 5 & 3 & 1 & 3 & 6 & 3 \\
\hline b) & $1 / 5$ & $\mathbf{1}$ & 3 & $1 / 3$ & 1 & 1 & 3 \\
\hline c) & $1 / 3$ & $1 / 3$ & $\mathbf{1}$ & $1 / 5$ & 1 & $1 / 5$ & $1 / 2$ \\
\hline d) & 1 & 3 & 5 & $\mathbf{1}$ & 5 & 7 & 3 \\
\hline e) & $1 / 3$ & 1 & 1 & $1 / 5$ & $\mathbf{1}$ & 1 & 1 \\
\hline f) & $1 / 6$ & 1 & 5 & $1 / 7$ & 1 & $\mathbf{1}$ & 1 \\
\hline g) & $1 / 3$ & $1 / 3$ & 2 & $1 / 3$ & 1 & 1 & $\mathbf{1}$ \\
\hline Soma & 3,36667 & 11,66667 & 20,00000 & 3,20952 & 13,00000 & 17,20000 & 12,50000 \\
\hline
\end{tabular}

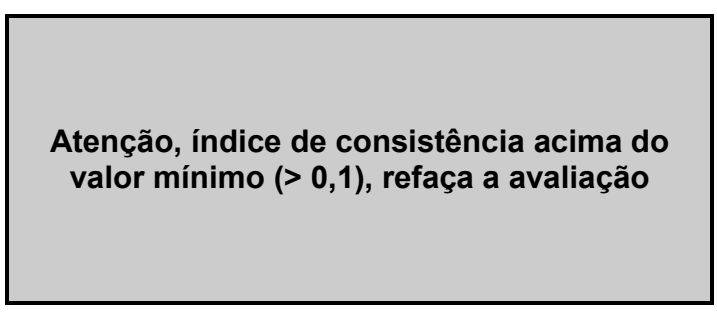

\begin{tabular}{|l|l|}
\hline Consistência & 0,101 \\
\hline
\end{tabular}

\begin{tabular}{|c|c|c|}
\hline & & Fatores \\
\hline a) & Diminuição do trânsito devido ao uso do Metrô & 0,2867 \\
\hline b) & $\begin{array}{l}\text { Aumento da qualidade de vida devido a diminuição da poluição do ar, sonora, visual } \\
\text { e dano ecológico }\end{array}$ & 0,1106 \\
\hline c) & $\begin{array}{l}\text { Economia do dinheiro público devido a baixos investimentos em construção e } \\
\text { manutenção de vias públicas }\end{array}$ & 0,0526 \\
\hline d) & $\begin{array}{l}\text { Acesso aos serviços públicos com maior eficiência (hospitais, repartições públicas, } \\
\text { etc) }\end{array}$ & 0,3068 \\
\hline e) & Melhora a economia da cidade e dos centros regionais & 0,0732 \\
\hline f) & $\begin{array}{l}\text { Uso das fontes de petróleo com eficiência devido ao menor consumo em função do } \\
\text { uso do transporte público. }\end{array}$ & 0,0921 \\
\hline g) & Redução no custo dos acidentes de trânsito e danos provocados por eles & 0,0781 \\
\hline
\end{tabular}




\begin{tabular}{|c|c|c|c|c|c|c|c|}
\hline & a) & b) & c) & d) & e) & f) & g) \\
\hline a) & $\mathbf{1}$ & $1 / 4$ & 1 & $1 / 2$ & 2 & 1 & $1 / 3$ \\
\hline b) & 4 & $\mathbf{1}$ & 4 & 2 & 2 & 3 & $1 / 3$ \\
\hline $\mathbf{c )}$ & 1 & $1 / 4$ & $\mathbf{1}$ & $1 / 2$ & $1 / 3$ & $1 / 2$ & $1 / 4$ \\
\hline $\mathbf{d})$ & 2 & $1 / 2$ & 2 & $\mathbf{1}$ & $1 / 2$ & $1 / 3$ & $1 / 3$ \\
\hline e) & $1 / 2$ & $1 / 2$ & 3 & 2 & $\mathbf{1}$ & $1 / 2$ & $1 / 3$ \\
\hline $\mathbf{f})$ & 1 & $1 / 3$ & 2 & 3 & 2 & $\mathbf{1}$ & $1 / 3$ \\
\hline g) & 3 & 3 & 4 & 3 & 3 & 3 & $\mathbf{1}$ \\
\hline Soma & 12,50000 & 5,83333 & 17,00000 & 12,00000 & 10,83333 & 9,33333 & 2,91667 \\
\hline
\end{tabular}

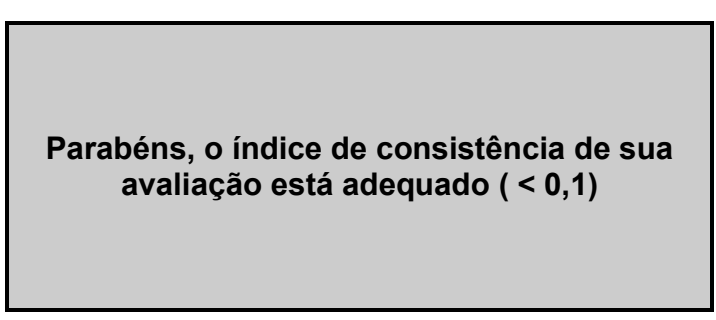

\begin{tabular}{|l|l|}
\hline Consistência & 0,088 \\
\hline
\end{tabular}

\begin{tabular}{|c|c|c|}
\hline & & Fatores \\
\hline a) & Diminuição do trânsito devido ao uso de transporte público sobre trilhos & 0,0899 \\
\hline b) & $\begin{array}{l}\text { Aumento da qualidade de vida devido a diminuição da poluição do ar, sonora, visual } \\
\text { e dano ecológico }\end{array}$ & 0,2162 \\
\hline c) & $\begin{array}{l}\text { Economia do dinheiro público devido a baixos investimentos em construção e } \\
\text { manutenção de vias públicas }\end{array}$ & 0,0562 \\
\hline d) & $\begin{array}{l}\text { Acesso aos serviços públicos com maior eficiência (hospitais, repartições públicas, } \\
\text { etc) }\end{array}$ & 0,0918 \\
\hline e) & Melhora a economia da cidade e dos centros regionais & 0,1041 \\
\hline f) & $\begin{array}{l}\text { Uso das fontes de petróleo com eficiência devido ao menor consumo em função do } \\
\text { uso do transporte público. }\end{array}$ & 0,1301 \\
\hline g) & Redução no custo dos acidentes de trânsito e danos provocados por eles & 0,3115 \\
\hline
\end{tabular}




\begin{tabular}{|c|c|c|c|c|c|c|c|}
\hline & a) & b) & c) & d) & e) & f) & g) \\
\hline a) & $\mathbf{1}$ & $1 / 5$ & $1 / 2$ & $1 / 4$ & $1 / 2$ & 1 & $2 / 5$ \\
\hline b) & 5 & $\mathbf{1}$ & 2 & $1 / 2$ & 2 & $21 / 2$ & $1 / 2$ \\
\hline c) & 2 & $1 / 2$ & $\mathbf{1}$ & $1 / 2$ & $1 / 2$ & $1 / 2$ & $1 / 5$ \\
\hline d) & 4 & 2 & 2 & $\mathbf{1}$ & $1 / 2$ & 2 & $1 / 2$ \\
\hline e) & 2 & $1 / 2$ & 2 & 2 & $\mathbf{1}$ & $1 / 2$ & $1 / 2$ \\
\hline f) & 1 & $2 / 5$ & 2 & $1 / 2$ & 2 & $\mathbf{1}$ & $1 / 2$ \\
\hline g) & $21 / 2$ & 2 & 5 & 2 & 2 & 2 & $\mathbf{1}$ \\
\hline Soma & 17,50000 & 6,60000 & 14,50000 & 6,75000 & 8,50000 & 9,50000 & 3,60000 \\
\hline
\end{tabular}

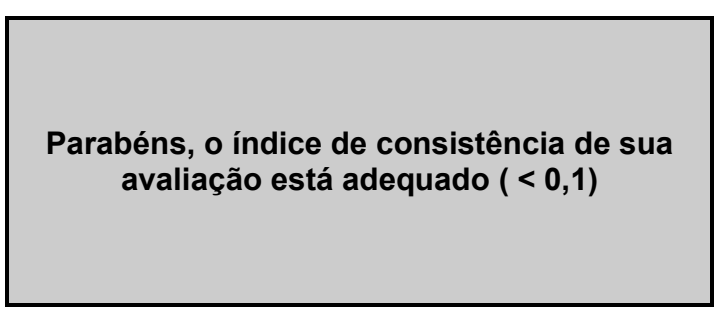

Consistência

0,086

\begin{tabular}{|c|c|c|}
\hline & & Fatores \\
\hline a) & Diminuição do trânsito devido ao uso de transporte público sobre trilhos & 0,0620 \\
\hline b) & $\begin{array}{l}\text { Aumento da qualidade de vida devido a diminuição da poluição do ar, sonora, visual } \\
\text { e dano ecológico }\end{array}$ & 0,1838 \\
\hline c) & $\begin{array}{l}\text { Economia do dinheiro público devido a baixos investimentos em construção e } \\
\text { manutenção de vias públicas }\end{array}$ & 0,0714 \\
\hline d) & $\begin{array}{l}\text { Acesso aos serviços públicos com maior eficiência (hospitais, repartições públicas, } \\
\text { etc) }\end{array}$ & 0,1751 \\
\hline e) & Melhora a economia da cidade e dos centros regionais & 0,1333 \\
\hline f) & $\begin{array}{l}\text { Uso das fontes de petróleo com eficiência devido ao menor consumo em função do } \\
\text { uso do transporte público. }\end{array}$ & 0,1156 \\
\hline g) & Redução no custo dos acidentes de trânsito e danos provocados por eles & 0,2587 \\
\hline
\end{tabular}




\begin{tabular}{|c|c|c|c|c|c|c|c|}
\hline & a) & b) & c) & d) & e) & f) & g) \\
\hline a) & $\mathbf{1}$ & $1 / 3$ & 5 & 3 & 3 & 3 & $1 / 3$ \\
\hline b) & 3 & $\mathbf{1}$ & 7 & 3 & 7 & 3 & $1 / 3$ \\
\hline c) & $1 / 5$ & $1 / 7$ & $\mathbf{1}$ & $1 / 7$ & $1 / 3$ & $1 / 3$ & $1 / 9$ \\
\hline d) & $1 / 3$ & $1 / 3$ & 7 & $\mathbf{1}$ & 3 & 3 & $1 / 3$ \\
\hline e) & $1 / 3$ & $1 / 7$ & 3 & $1 / 3$ & $\mathbf{1}$ & $1 / 3$ & $1 / 9$ \\
\hline f) & $1 / 3$ & $1 / 3$ & 3 & $1 / 3$ & 3 & $\mathbf{1}$ & $1 / 9$ \\
\hline g) & 3 & 3 & 9 & 3 & 9 & 9 & $\mathbf{1}$ \\
\hline Soma & 8,20000 & 5,28571 & 35,00000 & 10,80952 & 26,33333 & 19,66667 & 2,33333 \\
\hline
\end{tabular}

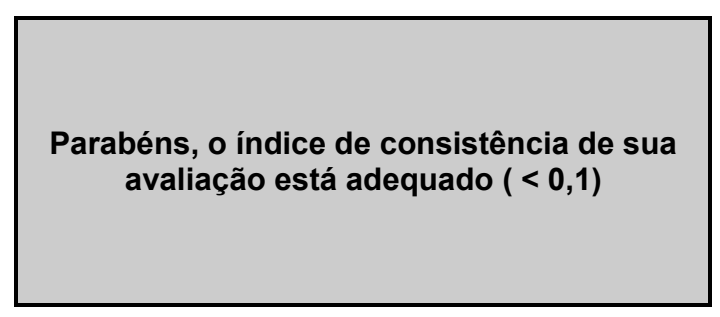

\begin{tabular}{|l|l|}
\hline Consistência & 0,086 \\
\hline
\end{tabular}

\begin{tabular}{|c|l|c|}
\cline { 3 - 3 } \multicolumn{2}{l|}{} & Fatores \\
\hline a) & Diminuição do trânsito devido ao uso do Metrô & $\mathbf{0 , 1 4 5 0}$ \\
\hline b) & $\begin{array}{l}\text { Aumento da qualidade de vida devido a diminuição da poluição do ar, sonora, } \\
\text { visual e dano ecológico }\end{array}$ & $\mathbf{0 , 2 2 7 7}$ \\
\hline c) & $\begin{array}{l}\text { Economia do dinheiro público devido a baixos investimentos em construção e } \\
\text { manutenção de vias públicas }\end{array}$ & $\mathbf{0 , 0 2 4 3}$ \\
\hline d) & $\begin{array}{l}\text { Acesso aos serviços públicos com maior eficiência (hospitais, repartições } \\
\text { públicas, etc) }\end{array}$ & $\mathbf{0 , 1 1 5 1}$ \\
\hline e) & Melhora a economia da cidade e dos centros regionais & $\mathbf{0 , 0 4 1 0}$ \\
\hline f) & $\begin{array}{l}\text { Uso das fontes de petróleo com eficiência devido ao menor consumo em função } \\
\text { do uso do transporte público. }\end{array}$ & $\mathbf{0 , 0 6 1 8}$ \\
\hline g) & Redução no custo dos acidentes de trânsito e danos provocados por eles & $\mathbf{0 , 3 8 5 2}$ \\
\hline
\end{tabular}




\begin{tabular}{|c|c|c|c|c|c|c|c|}
\hline & a) & b) & c) & d) & e) & f) & g) \\
\hline a) & $\mathbf{1}$ & 3 & 5 & 1 & 1 & 5 & 3 \\
\hline b) & 0,3 & $\mathbf{1}$ & 3 & $1 / 3$ & $1 / 5$ & 3 & $1 / 3$ \\
\hline c) & 0,2 & 0,3 & $\mathbf{1}$ & $1 / 3$ & $1 / 5$ & 3 & $1 / 3$ \\
\hline d) & 1,0 & 3,0 & 3,0 & $\mathbf{1}$ & 1 & 5 & 3 \\
\hline e) & 1,0 & 5,0 & 5,0 & 1,0 & $\mathbf{1}$ & 5 & 5 \\
\hline f) & 0,2 & 0,3 & 0,3 & 0,2 & 0,2 & $\mathbf{1}$ & $1 / 3$ \\
\hline g) & 0,3 & 3,0 & 3,0 & 0,3 & 0,2 & 3,0 & $\mathbf{1}$ \\
\hline Soma & 4,06667 & 15,66667 & 20,33333 & 4,20000 & 3,80000 & 25,00000 & 13,00000 \\
\hline
\end{tabular}

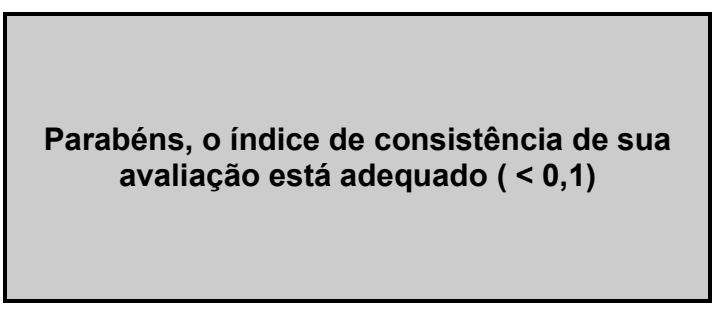

\begin{tabular}{|l|l|}
\hline Consistência & 0,076 \\
\hline
\end{tabular}

\begin{tabular}{|c|c|c|}
\hline & & Fatores \\
\hline a) & Diminuição do trânsito devido ao uso do Metrô & 0,2308 \\
\hline b) & $\begin{array}{l}\text { Aumento da qualidade de vida devido a diminuição da poluição do ar, } \\
\text { sonora, visual e dano ecológico }\end{array}$ & 0,0816 \\
\hline c) & $\begin{array}{l}\text { Economia do dinheiro público devido a baixos investimentos em construção } \\
\text { e manutenção de vias públicas }\end{array}$ & 0,0568 \\
\hline d) & $\begin{array}{l}\text { Acesso aos serviços públicos com maior eficiência (hospitais, repartições } \\
\text { públicas, etc) }\end{array}$ & 0,2167 \\
\hline e) & Melhora a economia da cidade e dos centros regionais & 0,2710 \\
\hline f) & $\begin{array}{l}\text { Uso das fontes de petróleo com eficiência devido ao menor consumo em } \\
\text { função do uso do transporte público. }\end{array}$ & 0,0361 \\
\hline g) & Redução no custo dos acidentes de trânsito e danos provocados por eles & 0,1071 \\
\hline
\end{tabular}




\begin{tabular}{|c|c|c|c|c|c|c|c|}
\hline & a) & b) & c) & d) & e) & f) & g) \\
\hline a) & $\mathbf{1}$ & $1 / 8$ & $11 / 9$ & $1 / 2$ & $2 / 7$ & $2 / 3$ & $1 / 5$ \\
\hline b) & 8 & $\mathbf{1}$ & 2 & $2 / 3$ & 2 & 8 & 2 \\
\hline c) & $8 / 9$ & $1 / 2$ & $\mathbf{1}$ & $1 / 3$ & 1 & 2 & $1 / 3$ \\
\hline d) & 2 & $11 / 2$ & 3 & $\mathbf{1}$ & 1 & 3 & $1 / 3$ \\
\hline e) & $31 / 2$ & $1 / 2$ & 1 & 1 & $\mathbf{1}$ & 1 & $1 / 3$ \\
\hline f) & $11 / 2$ & $1 / 8$ & $1 / 2$ & $1 / 3$ & 1 & $\mathbf{1}$ & $1 / 3$ \\
\hline g) & 5 & $1 / 2$ & 3 & 3 & 3 & 3 & $\mathbf{1}$ \\
\hline Soma & 21,90000 & 4,24900 & 11,61111 & 6,83333 & 9,28571 & 18,73118 & 4,53333 \\
\hline
\end{tabular}

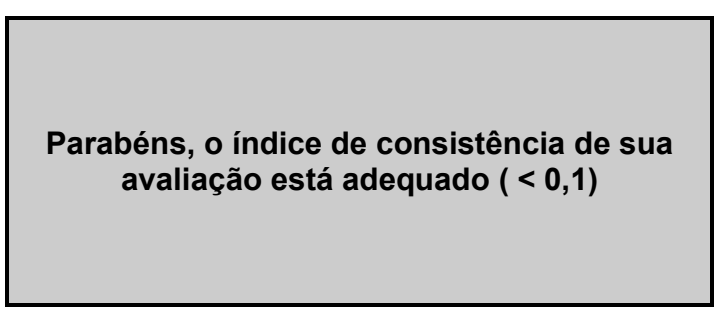

\begin{tabular}{|l|l|}
\hline Consistência & 0,086 \\
\hline
\end{tabular}

\begin{tabular}{|c|l|c|}
\cline { 3 - 3 } \multicolumn{2}{l|}{} & Fatores \\
\hline a) & Diminuição do trânsito devido ao uso de transporte público sobre trilhos & $\mathbf{0 , 0 5 0 6}$ \\
\hline b) & $\begin{array}{l}\text { Aumento da qualidade de vida devido a diminuição da poluição do ar, sonora, visual } \\
\text { e dano ecológico }\end{array}$ & $\mathbf{0 , 2 7 9 7}$ \\
\hline c) & $\begin{array}{l}\text { Economia do dinheiro público devido a baixos investimentos em construção e } \\
\text { manutenção de vias públicas }\end{array}$ & $\mathbf{0 , 0 8 3 1}$ \\
\hline d) & $\begin{array}{l}\text { Acesso aos serviços públicos com maior eficiência (hospitais, repartições públicas, } \\
\text { etc) }\end{array}$ & $\mathbf{0 , 1 7 0 1}$ \\
\hline e) & Melhora a economia da cidade e dos centros regionais & $\mathbf{0 , 1 0 6 4}$ \\
\hline f) & $\begin{array}{l}\text { Uso das fontes de petróleo com eficiência devido ao menor consumo em função do } \\
\text { uso do transporte público. }\end{array}$ & $\mathbf{0 , 0 6 0 6}$ \\
\hline g) & Redução no custo dos acidentes de trânsito e danos provocados por eles & $\mathbf{0 , 2 4 9 6}$ \\
\hline
\end{tabular}




\begin{tabular}{|c|c|c|c|c|c|c|c|}
\hline & a) & b) & c) & d) & e) & f) & g) \\
\hline a) & $\mathbf{1}$ & 1 & 5 & 5 & 8 & 6 & 2 \\
\hline b) & 1 & $\mathbf{1}$ & 2 & 1 & 3 & 5 & 2 \\
\hline c) & $1 / 5$ & $1 / 2$ & $\mathbf{1}$ & $1 / 2$ & $11 / 4$ & $2 / 3$ & $1 / 2$ \\
\hline d) & $1 / 5$ & 1 & 2 & $\mathbf{1}$ & $21 / 2$ & 3 & 2 \\
\hline e) & $1 / 8$ & $1 / 3$ & $4 / 5$ & $2 / 5$ & $\mathbf{1}$ & 3 & $1 / 2$ \\
\hline f) & $1 / 6$ & $1 / 5$ & $11 / 2$ & $1 / 3$ & $1 / 3$ & $\mathbf{1}$ & $1 / 2$ \\
\hline g) & $1 / 2$ & $1 / 2$ & 2 & $1 / 2$ & 2 & 2 & $\mathbf{1}$ \\
\hline Soma & 3,19167 & 4,53333 & 14,30000 & 8,73300 & 18,08300 & 20,67267 & 8,50000 \\
\hline
\end{tabular}

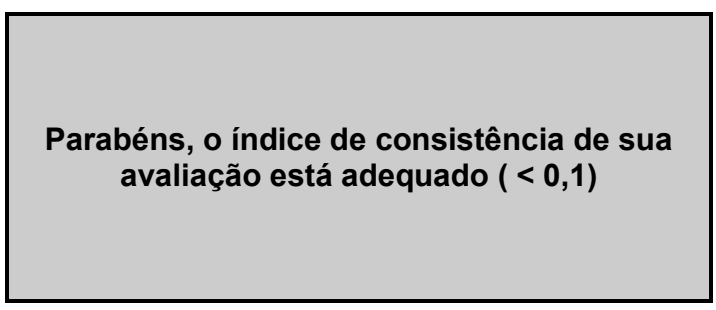

\begin{tabular}{|l|l|}
\hline Consistência & 0,070 \\
\hline
\end{tabular}

\begin{tabular}{|c|c|c|}
\hline & & Fatores \\
\hline a) & Diminuição do trânsito devido ao uso de transporte público sobre trilhos & 0,3463 \\
\hline b) & $\begin{array}{l}\text { Aumento da qualidade de vida devido a diminuição da poluição do ar, sonora, visual } \\
\text { e dano ecológico }\end{array}$ & 0,2045 \\
\hline c) & $\begin{array}{l}\text { Economia do dinheiro público devido a baixos investimentos em construção e } \\
\text { manutenção de vias públicas }\end{array}$ & 0,0658 \\
\hline d) & $\begin{array}{l}\text { Acesso aos serviços públicos com maior eficiência (hospitais, repartições públicas, } \\
\text { etc) }\end{array}$ & 0,1509 \\
\hline e) & Melhora a economia da cidade e dos centros regionais & 0,0677 \\
\hline f) & $\begin{array}{l}\text { Uso das fontes de petróleo com eficiência devido ao menor consumo em função do } \\
\text { uso do transporte público. }\end{array}$ & 0,0521 \\
\hline g) & Redução no custo dos acidentes de trânsito e danos provocados por eles & 0,1127 \\
\hline
\end{tabular}




\begin{tabular}{|c|c|c|c|c|c|c|c|}
\hline & a) & b) & c) & d) & e) & f) & g) \\
\hline a) & $\mathbf{1}$ & $1 / 5$ & 1 & $1 / 3$ & $1 / 3$ & $1 / 3$ & $1 / 3$ \\
\hline b) & 5 & $\mathbf{1}$ & 3 & 1 & 2 & 4 & 1 \\
\hline c) & 1 & $1 / 3$ & $\mathbf{1}$ & $1 / 3$ & $1 / 4$ & 1 & $1 / 3$ \\
\hline $\mathbf{d})$ & 3 & 1 & 3 & $\mathbf{1}$ & $1 / 3$ & 2 & $1 / 3$ \\
\hline e) & 3 & $1 / 2$ & 4 & 3 & $\mathbf{1}$ & 3 & $1 / 2$ \\
\hline $\mathbf{f}$ & 3 & $1 / 4$ & 1 & $1 / 2$ & $1 / 3$ & $\mathbf{1}$ & $1 / 2$ \\
\hline g) & 3 & 1 & 3 & 3 & 2 & 2 & $\mathbf{1}$ \\
\hline Soma & 19,00000 & 4,28333 & 16,00000 & 9,16667 & 6,24967 & 13,33634 & 4,00000 \\
\hline
\end{tabular}

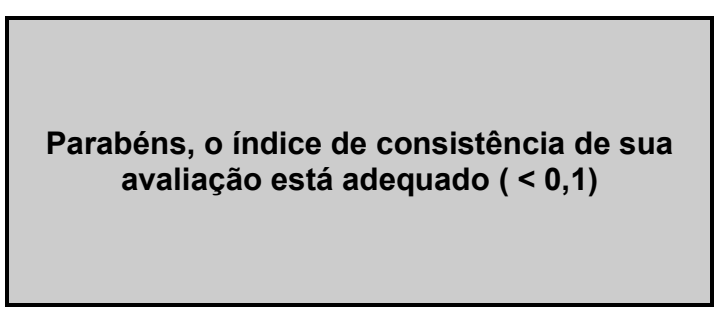

Consistência

0,065

\begin{tabular}{|c|c|c|}
\hline & & Fatores \\
\hline a) & Diminuição do trânsito devido ao uso de transporte público sobre trilhos & 0,0514 \\
\hline b) & $\begin{array}{l}\text { Aumento da qualidade de vida devido a diminuição da poluição do ar, sonora, visual } \\
\text { e dano ecológico }\end{array}$ & 0,2376 \\
\hline c) & $\begin{array}{l}\text { Economia do dinheiro público devido a baixos investimentos em construção e } \\
\text { manutenção de vias públicas }\end{array}$ & 0,0611 \\
\hline d) & $\begin{array}{l}\text { Acesso aos serviços públicos com maior eficiência (hospitais, repartições públicas, } \\
\text { etc) }\end{array}$ & 0,1392 \\
\hline e) & Melhora a economia da cidade e dos centros regionais & 0,1946 \\
\hline f) & $\begin{array}{l}\text { Uso das fontes de petróleo com eficiência devido ao menor consumo em função do } \\
\text { uso do transporte público. }\end{array}$ & 0,0838 \\
\hline g) & Redução no custo dos acidentes de trânsito e danos provocados por eles & 0,2323 \\
\hline
\end{tabular}




\begin{tabular}{|c|c|c|c|c|c|c|c|}
\hline & a) & b) & c) & d) & e) & f) & g) \\
\hline a) & $\mathbf{1}$ & 5 & 3 & $21 / 2$ & 8 & 3 & 5 \\
\hline b) & $1 / 5$ & $\mathbf{1}$ & 3 & 1 & 3 & 5 & 5 \\
\hline c) & $1 / 3$ & $1 / 3$ & $\mathbf{1}$ & $1 / 3$ & 2 & 1 & $21 / 2$ \\
\hline d) & $2 / 5$ & 1 & 3 & $\mathbf{1}$ & 2 & 3 & 3 \\
\hline e) & $1 / 8$ & $1 / 3$ & $1 / 2$ & $1 / 2$ & $\mathbf{1}$ & 2 & 2 \\
\hline f) & $1 / 3$ & $1 / 5$ & 1 & $1 / 3$ & $1 / 2$ & $\mathbf{1}$ & $21 / 2$ \\
\hline g) & $1 / 5$ & $1 / 5$ & $2 / 5$ & $1 / 3$ & $1 / 2$ & $2 / 5$ & $\mathbf{1}$ \\
\hline Soma & 2,59100 & 8,06667 & 11,90300 & 5,99967 & 17,00000 & 15,40300 & 21,00300 \\
\hline
\end{tabular}

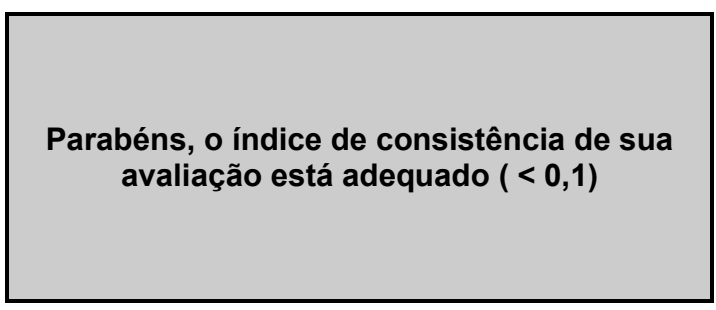

\begin{tabular}{|l|l|}
\hline Consistência & 0,095 \\
\hline
\end{tabular}

\begin{tabular}{|c|c|c|}
\hline & & Fatores \\
\hline a) & Diminuição do trânsito devido ao uso de transporte público sobre trilhos & 0,3683 \\
\hline b) & $\begin{array}{l}\text { Aumento da qualidade de vida devido a diminuição da poluição do ar, sonora, visual } \\
\text { e dano ecológico }\end{array}$ & 0,1941 \\
\hline c) & $\begin{array}{l}\text { Economia do dinheiro público devido a baixos investimentos em construção e } \\
\text { manutenção de vias públicas }\end{array}$ & 0,0873 \\
\hline d) & $\begin{array}{l}\text { Acesso aos serviços públicos com maior eficiência (hospitais, repartições públicas, } \\
\text { etc) }\end{array}$ & 0,1646 \\
\hline e) & Melhora a economia da cidade e dos centros regionais & 0,0713 \\
\hline f) & $\begin{array}{l}\text { Uso das fontes de petróleo com eficiência devido ao menor consumo em função do } \\
\text { uso do transporte público. }\end{array}$ & 0,0723 \\
\hline g) & Redução no custo dos acidentes de trânsito e danos provocados por eles & 0,0420 \\
\hline
\end{tabular}




\begin{tabular}{|c|c|c|c|c|c|c|c|}
\hline & a) & b) & c) & d) & e) & f) & g) \\
\hline a) & $\mathbf{1}$ & $1 / 7$ & $1 / 6$ & $1 / 2$ & $1 / 4$ & $1 / 2$ & $1 / 6$ \\
\hline b) & 7 & $\mathbf{1}$ & 3 & $1 / 2$ & 2 & 4 & $1 / 2$ \\
\hline c) & 6 & $1 / 3$ & $\mathbf{1}$ & $1 / 3$ & $1 / 2$ & $1 / 2$ & $1 / 3$ \\
\hline d) & 2 & 2 & 3 & $\mathbf{1}$ & 2 & 4 & $1 / 2$ \\
\hline e) & 4 & $1 / 2$ & 2 & $1 / 2$ & $\mathbf{1}$ & 1 & $1 / 3$ \\
\hline f) & 2 & $1 / 4$ & 2 & $1 / 4$ & 1 & $\mathbf{1}$ & $1 / 3$ \\
\hline g) & 6 & 2 & 3 & 2 & 3 & 3 & $\mathbf{1}$ \\
\hline Soma & 28,00000 & 6,22619 & 14,16667 & 5,08333 & 9,75000 & 14,00000 & 3,16667 \\
\hline
\end{tabular}

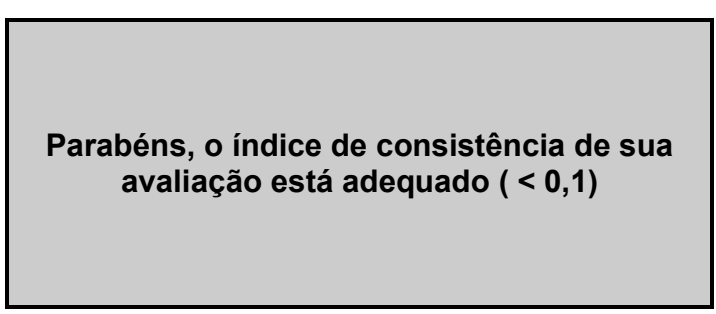

\begin{tabular}{|l|l|}
\hline Consistência & 0,088 \\
\hline
\end{tabular}

\begin{tabular}{|c|c|c|}
\hline & & Fatores \\
\hline a) & Diminuição do trânsito devido ao uso de transporte público sobre trilhos & 0,0404 \\
\hline b) & $\begin{array}{l}\text { Aumento da qualidade de vida devido a diminuição da poluição do ar, sonora, visual } \\
\text { e dano ecológico }\end{array}$ & 0,1956 \\
\hline c) & $\begin{array}{l}\text { Economia do dinheiro público devido a baixos investimentos em construção e } \\
\text { manutenção de vias públicas }\end{array}$ & 0,0852 \\
\hline d) & $\begin{array}{l}\text { Acesso aos serviços públicos com maior eficiência (hospitais, repartições públicas, } \\
\text { etc) }\end{array}$ & 0,2071 \\
\hline e) & Melhora a economia da cidade e dos centros regionais & 0,1060 \\
\hline f) & $\begin{array}{l}\text { Uso das fontes de petróleo com eficiência devido ao menor consumo em função do } \\
\text { uso do transporte público. }\end{array}$ & 0,0830 \\
\hline g) & Redução no custo dos acidentes de trânsito e danos provocados por eles & 0,2826 \\
\hline
\end{tabular}




\begin{tabular}{|c|c|c|c|c|c|c|c|}
\hline & a) & b) & c) & d) & e) & f) & g) \\
\hline a) & $\mathbf{1}$ & $1 / 3$ & 2 & $1 / 2$ & $1 / 4$ & $1 / 2$ & 1 \\
\hline b) & 3 & $\mathbf{1}$ & 4 & 2 & 3 & 5 & 1 \\
\hline c) & $1 / 2$ & $1 / 4$ & $\mathbf{1}$ & $1 / 3$ & $1 / 2$ & 1 & $1 / 3$ \\
\hline d) & 2 & $1 / 2$ & 3 & $\mathbf{1}$ & $1 / 2$ & 3 & $1 / 3$ \\
\hline e) & 4 & $1 / 3$ & 2 & 2 & $\mathbf{1}$ & 3 & $1 / 3$ \\
\hline $\mathbf{f )}$ & 2 & $1 / 5$ & 1 & $1 / 3$ & $1 / 3$ & $\mathbf{1}$ & $1 / 3$ \\
\hline g) & 1 & 1 & 3 & 3 & 3 & 3 & $\mathbf{1}$ \\
\hline Soma & 13,50000 & 3,61667 & 16,00000 & 9,16667 & 8,58300 & 16,50300 & 4,33333 \\
\hline
\end{tabular}

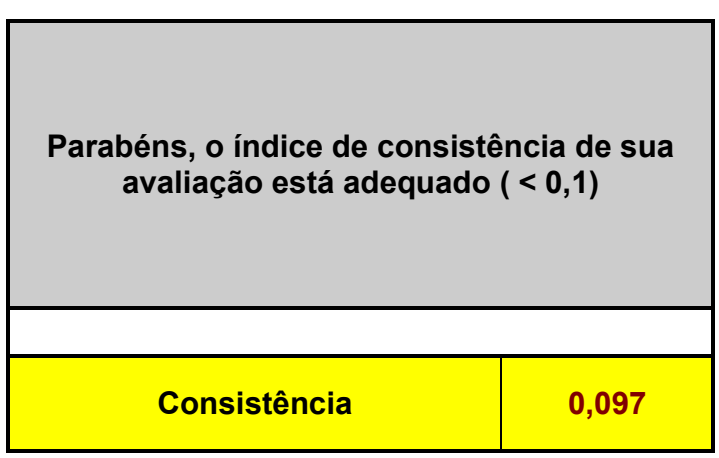

\begin{tabular}{|c|c|c|}
\hline & & Fatores \\
\hline a) & Diminuição do trânsito devido ao uso de transporte público sobre trilhos & 0,0909 \\
\hline b) & $\begin{array}{l}\text { Aumento da qualidade de vida devido a diminuição da poluição do ar, sonora, visual } \\
\text { e dano ecológico }\end{array}$ & 0,2643 \\
\hline c) & $\begin{array}{l}\text { Economia do dinheiro público devido a baixos investimentos em construção e } \\
\text { manutenção de vias públicas }\end{array}$ & 0,0573 \\
\hline d) & $\begin{array}{l}\text { Acesso aos serviços públicos com maior eficiência (hospitais, repartições públicas, } \\
\text { etc) }\end{array}$ & 0,1286 \\
\hline e) & Melhora a economia da cidade e dos centros regionais & 0,1581 \\
\hline f) & $\begin{array}{l}\text { Uso das fontes de petróleo com eficiência devido ao menor consumo em função do } \\
\text { uso do transporte público. }\end{array}$ & 0,0684 \\
\hline g) & Redução no custo dos acidentes de trânsito e danos provocados por eles & 0,2325 \\
\hline
\end{tabular}




\begin{tabular}{|c|c|c|c|c|c|c|c|}
\hline & a) & b) & c) & d) & e) & f) & g) \\
\hline a) & $\mathbf{1}$ & $1 / 5$ & $1 / 7$ & $1 / 7$ & $1 / 6$ & $1 / 4$ & $1 / 9$ \\
\hline b) & 5 & $\mathbf{1}$ & $1 / 5$ & $1 / 3$ & $1 / 5$ & $1 / 6$ & $1 / 5$ \\
\hline $\mathbf{c )}$ & 7 & 5 & $\mathbf{1}$ & 2 & 3 & 5 & 1 \\
\hline d) & 7 & 3 & $1 / 2$ & $\mathbf{1}$ & 3 & 2 & $1 / 2$ \\
\hline e) & 6 & 5 & $1 / 3$ & $1 / 3$ & $\mathbf{1}$ & 1 & $1 / 3$ \\
\hline f) & 4 & 6 & $1 / 5$ & $1 / 2$ & 1 & $\mathbf{1}$ & $1 / 3$ \\
\hline g) & 9 & 5 & 1 & 2 & 3 & 3 & $\mathbf{1}$ \\
\hline Soma & 39,00000 & 25,20000 & 3,37586 & 6,30919 & 11,37267 & 12,41667 & 3,47778 \\
\hline
\end{tabular}

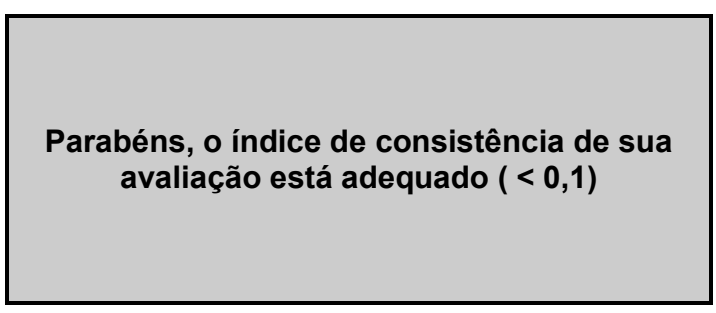

\begin{tabular}{|l|l|}
\hline Consistência & 0,091 \\
\hline
\end{tabular}

\begin{tabular}{|c|c|c|}
\hline & & Fatores \\
\hline a) & Diminuição do trânsito devido ao uso de transporte público sobre trilhos & 0,0236 \\
\hline b) & $\begin{array}{l}\text { Aumento da qualidade de vida devido a diminuição da poluição do ar, sonora, visual } \\
\text { e dano ecológico }\end{array}$ & 0,0526 \\
\hline c) & $\begin{array}{l}\text { Economia do dinheiro público devido a baixos investimentos em construção e } \\
\text { manutenção de vias públicas }\end{array}$ & 0,2779 \\
\hline d) & $\begin{array}{l}\text { Acesso aos serviços públicos com maior eficiência (hospitais, repartições públicas, } \\
\text { etc) }\end{array}$ & 0,1677 \\
\hline e) & Melhora a economia da cidade e dos centros regionais & 0,1097 \\
\hline f) & $\begin{array}{l}\text { Uso das fontes de petróleo com eficiência devido ao menor consumo em função do } \\
\text { uso do transporte público. }\end{array}$ & 0,1062 \\
\hline g) & Redução no custo dos acidentes de trânsito e danos provocados por eles & 0,2622 \\
\hline
\end{tabular}




\begin{tabular}{|c|c|c|c|c|c|c|c|}
\hline & a) & b) & c) & d) & e) & f) & g) \\
\hline a) & $\mathbf{1}$ & $1 / 2$ & 2 & $1 / 2$ & 1 & $1 / 2$ & $1 / 4$ \\
\hline b) & 2 & $\mathbf{1}$ & 2 & $1 / 2$ & 4 & 4 & $1 / 2$ \\
\hline $\mathbf{c )}$ & $1 / 2$ & $1 / 2$ & $\mathbf{1}$ & $1 / 4$ & $1 / 2$ & $1 / 2$ & $1 / 5$ \\
\hline d) & 2 & 2 & 4 & $\mathbf{1}$ & 1 & 3 & 3 \\
\hline e) & 1 & $1 / 4$ & 2 & 1 & $\mathbf{1}$ & 1 & $1 / 2$ \\
\hline $\mathbf{f})$ & 2 & $1 / 4$ & 2 & $1 / 3$ & 1 & $\mathbf{1}$ & $1 / 2$ \\
\hline g) & 4 & 2 & 5 & $1 / 3$ & 2 & 2 & $\mathbf{1}$ \\
\hline Soma & 12,50000 & 6,50000 & 18,00000 & 3,91633 & 10,50000 & 12,00000 & 5,95300 \\
\hline
\end{tabular}

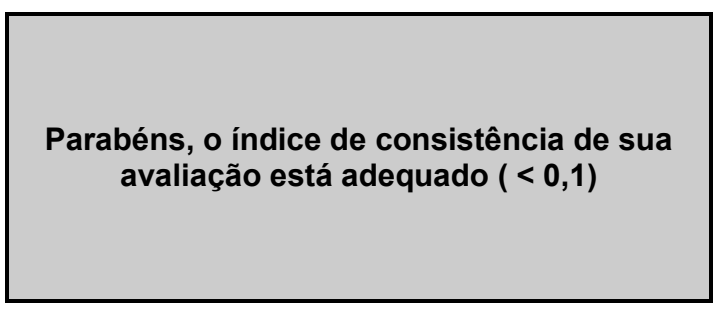

\begin{tabular}{|l|l|}
\hline Consistência & 0,094 \\
\hline
\end{tabular}

\begin{tabular}{|c|c|c|}
\hline & & Fatores \\
\hline a) & Diminuição do trânsito devido ao uso de transporte público sobre trilhos & 0,0821 \\
\hline b) & $\begin{array}{l}\text { Aumento da qualidade de vida devido a diminuição da poluição do ar, sonora, visual } \\
\text { e dano ecológico }\end{array}$ & 0,1930 \\
\hline c) & $\begin{array}{l}\text { Economia do dinheiro público devido a baixos investimentos em construção e } \\
\text { manutenção de vias públicas }\end{array}$ & 0,0513 \\
\hline d) & $\begin{array}{l}\text { Acesso aos serviços públicos com maior eficiência (hospitais, repartições públicas, } \\
\text { etc) }\end{array}$ & 0,2564 \\
\hline e) & Melhora a economia da cidade e dos centros regionais & 0,1068 \\
\hline f) & $\begin{array}{l}\text { Uso das fontes de petróleo com eficiência devido ao menor consumo em função do } \\
\text { uso do transporte público. }\end{array}$ & 0,0939 \\
\hline g) & Redução no custo dos acidentes de trânsito e danos provocados por eles & 0,2165 \\
\hline
\end{tabular}




\begin{tabular}{|c|c|c|c|c|c|c|c|}
\hline & a) & b) & c) & d) & e) & f) & g) \\
\hline a) & $\mathbf{1}$ & 2 & 3 & $1 / 2$ & 2 & $13 / 7$ & 3 \\
\hline b) & $1 / 2$ & $\mathbf{1}$ & 2 & $1 / 2$ & 2 & $1 / 3$ & $21 / 2$ \\
\hline c) & $1 / 3$ & $1 / 2$ & $\mathbf{1}$ & $1 / 6$ & 1 & $1 / 2$ & $12 / 3$ \\
\hline d) & 2 & 2 & 6 & $\mathbf{1}$ & 3 & 3 & 9 \\
\hline e) & $1 / 2$ & $1 / 2$ & 1 & $1 / 3$ & $\mathbf{1}$ & $1 / 5$ & 9 \\
\hline f) & $2 / 3$ & 3 & 2 & $1 / 3$ & 5 & $\mathbf{1}$ & 3 \\
\hline g) & $1 / 3$ & $2 / 5$ & $3 / 5$ & $1 / 9$ & $1 / 9$ & $1 / 3$ & $\mathbf{1}$ \\
\hline Soma & 5,36600 & 9,40000 & 15,60300 & 2,94300 & 14,11300 & 6,79490 & 29,35449 \\
\hline
\end{tabular}

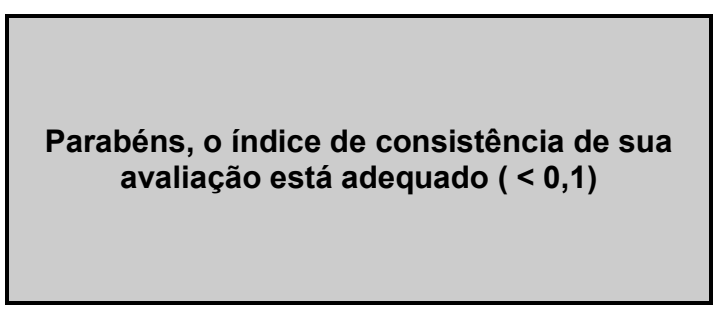

\begin{tabular}{|l|c|}
\hline Consistência & 0,098 \\
\hline
\end{tabular}

\begin{tabular}{|c|c|c|}
\hline & & Fatores \\
\hline a) & Diminuição do trânsito devido ao uso de transporte público sobre trilhos & 0,1737 \\
\hline b) & $\begin{array}{l}\text { Aumento da qualidade de vida devido a diminuição da poluição do ar, sonora, visual } \\
\text { e dano ecológico }\end{array}$ & 0,1105 \\
\hline c) & $\begin{array}{l}\text { Economia do dinheiro público devido a baixos investimentos em construção e } \\
\text { manutenção de vias públicas }\end{array}$ & 0,0625 \\
\hline d) & $\begin{array}{l}\text { Acesso aos serviços públicos com maior eficiência (hospitais, repartições públicas, } \\
\text { etc) }\end{array}$ & 0,3248 \\
\hline e) & Melhora a economia da cidade e dos centros regionais & 0,1048 \\
\hline f) & $\begin{array}{l}\text { Uso das fontes de petróleo com eficiência devido ao menor consumo em função do } \\
\text { uso do transporte público. }\end{array}$ & 0,1850 \\
\hline g) & Redução no custo dos acidentes de trânsito e danos provocados por eles & 0,0388 \\
\hline
\end{tabular}




\begin{tabular}{|c|c|c|c|c|c|c|c|}
\hline & a) & b) & c) & d) & e) & f) & g) \\
\hline a) & $\mathbf{1}$ & $1 / 9$ & $1 / 5$ & $1 / 7$ & $1 / 5$ & $1 / 3$ & 1 \\
\hline b) & 9 & $\mathbf{1}$ & 5 & 3 & 5 & 7 & 7 \\
\hline c) & 5 & $1 / 5$ & $\mathbf{1}$ & $1 / 7$ & 1 & 1 & 3 \\
\hline d) & 7 & $1 / 3$ & 7 & $\mathbf{1}$ & 5 & 7 & 7 \\
\hline e) & 5 & $1 / 5$ & 1 & $1 / 5$ & $\mathbf{1}$ & 1 & 3 \\
\hline f) & 3 & $1 / 7$ & 1 & $1 / 7$ & 1 & $\mathbf{1}$ & 3 \\
\hline g) & 1 & $1 / 7$ & $1 / 3$ & $1 / 7$ & $1 / 3$ & $1 / 3$ & $\mathbf{1}$ \\
\hline Soma & 31,00000 & 2,13016 & 15,53333 & 4,77143 & 13,53333 & 17,66667 & 25,00000 \\
\hline
\end{tabular}

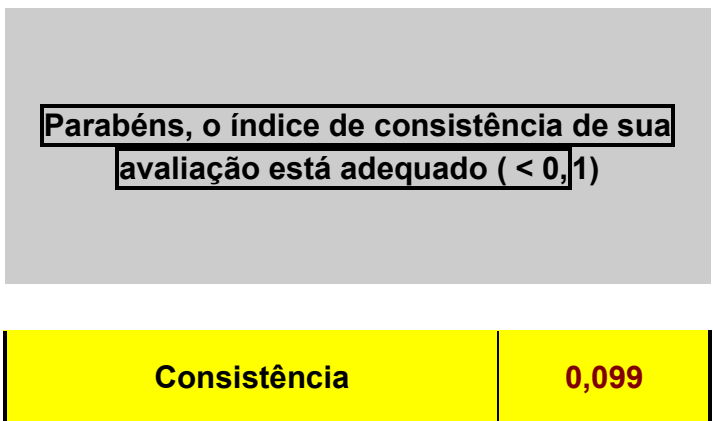

\begin{tabular}{|c|c|c|}
\hline & & Fatores \\
\hline a) & Diminuição do trânsito devido ao uso de transporte público sobre trilhos & 0,0287 \\
\hline b) & $\begin{array}{l}\text { Aumento da qualidade de vida devido a diminuição da poluição do ar, sonora, visual } \\
\text { e dano ecológico }\end{array}$ & 0,3937 \\
\hline c) & $\begin{array}{l}\text { Economia do dinheiro público devido a baixos investimentos em construção e } \\
\text { manutenção de vias públicas }\end{array}$ & 0,0857 \\
\hline d) & $\begin{array}{l}\text { Acesso aos serviços públicos com maior eficiência (hospitais, repartições públicas, } \\
\text { etc) }\end{array}$ & 0,2983 \\
\hline e) & Melhora a economia da cidade e dos centros regionais & 0,0874 \\
\hline f) & $\begin{array}{l}\text { Uso das fontes de petróleo com eficiência devido ao menor consumo em função do } \\
\text { uso do transporte público. }\end{array}$ & 0,0727 \\
\hline g) & Redução no custo dos acidentes de trânsito e danos provocados por eles & 0,0335 \\
\hline
\end{tabular}




\begin{tabular}{|c|c|c|c|c|c|c|c|}
\hline & a) & b) & c) & d) & e) & f) & g) \\
\hline a) & $\mathbf{1}$ & 1 & 1 & 1 & $1 / 3$ & $1 / 7$ & $1 / 7$ \\
\hline b) & 1 & $\mathbf{1}$ & 1 & $1 / 2$ & $1 / 2$ & $1 / 5$ & $1 / 6$ \\
\hline c) & 1 & 1 & $\mathbf{1}$ & 1 & 1 & $1 / 2$ & $1 / 5$ \\
\hline d) & 1 & 2 & 1 & $\mathbf{1}$ & 1 & 1 & $1 / 2$ \\
\hline e) & 3 & 2 & 1 & 1 & $\mathbf{1}$ & $1 / 3$ & $1 / 2$ \\
\hline $\mathbf{f}$ & 7 & 5 & 2 & 1 & 3 & $\mathbf{1}$ & $1 / 2$ \\
\hline g) & 7 & 6 & 5 & 2 & 2 & 2 & $\mathbf{1}$ \\
\hline Soma & 21,00000 & 18,00000 & 12,00000 & 7,50000 & 8,83333 & 5,17619 & 3,00952 \\
\hline
\end{tabular}

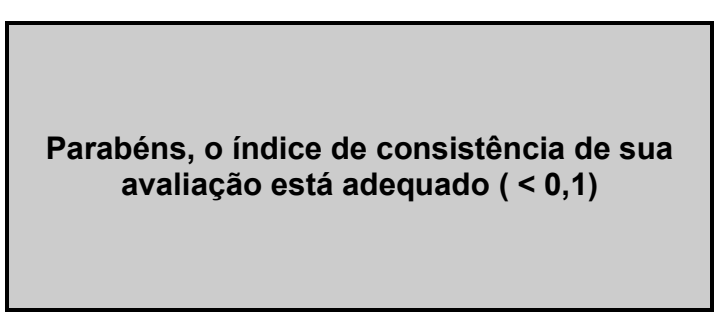

\begin{tabular}{|l|l|}
\hline Consistência & 0,060 \\
\hline
\end{tabular}

\begin{tabular}{|c|c|c|}
\hline & & Fatores \\
\hline a) & Diminuição do trânsito devido ao uso do Metrô & 0,0618 \\
\hline b) & $\begin{array}{l}\text { Aumento da qualidade de vida devido a diminuição da poluição do ar, sonora, visual } \\
\text { e dano ecológico }\end{array}$ & 0,0577 \\
\hline c) & $\begin{array}{l}\text { Economia do dinheiro público devido a baixos investimentos em construção e } \\
\text { manutenção de vias públicas }\end{array}$ & 0,0852 \\
\hline d) & $\begin{array}{l}\text { Acesso aos serviços públicos com maior eficiência (hospitais, repartições públicas, } \\
\text { etc) }\end{array}$ & 0,1211 \\
\hline e) & Melhora a economia da cidade e dos centros regionais & 0,1163 \\
\hline f) & $\begin{array}{l}\text { Uso das fontes de petróleo com eficiência devido ao menor consumo em função do } \\
\text { uso do transporte público. }\end{array}$ & 0,2300 \\
\hline g) & Redução no custo dos acidentes de trânsito e danos provocados por eles & 0,3279 \\
\hline
\end{tabular}




\begin{tabular}{|c|c|c|c|c|c|c|c|}
\hline & a) & b) & c) & d) & e) & f) & g) \\
\hline a) & $\mathbf{1}$ & $1 / 2$ & $1 / 3$ & $1 / 3$ & $1 / 2$ & $1 / 3$ & $1 / 9$ \\
\hline b) & 2 & $\mathbf{1}$ & 4 & 1 & 2 & 2 & $1 / 2$ \\
\hline c) & 3 & $1 / 4$ & $\mathbf{1}$ & $1 / 3$ & $1 / 2$ & $1 / 2$ & $1 / 7$ \\
\hline d) & 3 & 1 & 3 & $\mathbf{1}$ & $1 / 2$ & 3 & 1 \\
\hline e) & 2 & $1 / 2$ & 2 & 2 & $\mathbf{1}$ & $1 / 2$ & $1 / 3$ \\
\hline f) & 3 & $1 / 2$ & 2 & $1 / 3$ & 2 & $\mathbf{1}$ & $1 / 6$ \\
\hline g) & 9 & 2 & 7 & 1 & 3 & 6 & $\mathbf{1}$ \\
\hline Soma & 23,00000 & 5,75000 & 19,33333 & 5,99967 & 9,50000 & 13,33634 & 3,25397 \\
\hline
\end{tabular}

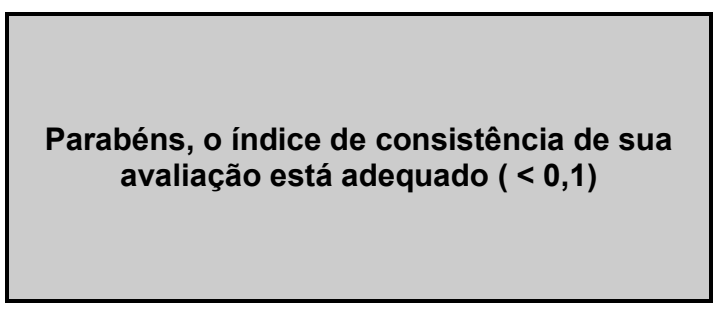

\begin{tabular}{|l|l|}
\hline Consistência & 0,097 \\
\hline
\end{tabular}

\begin{tabular}{|c|c|c|}
\hline & & Fatores \\
\hline a) & Diminuição do trânsito devido ao uso de transporte público sobre trilhos & 0,0450 \\
\hline b) & $\begin{array}{l}\text { Aumento da qualidade de vida devido a diminuição da poluição do ar, sonora, visual } \\
\text { e dano ecológico }\end{array}$ & 0,1641 \\
\hline c) & $\begin{array}{l}\text { Economia do dinheiro público devido a baixos investimentos em construção e } \\
\text { manutenção de vias públicas }\end{array}$ & 0,0593 \\
\hline d) & $\begin{array}{l}\text { Acesso aos serviços públicos com maior eficiência (hospitais, repartições públicas, } \\
\text { etc) }\end{array}$ & 0,1730 \\
\hline e) & Melhora a economia da cidade e dos centros regionais & 0,1223 \\
\hline f) & $\begin{array}{l}\text { Uso das fontes de petróleo com eficiência devido ao menor consumo em função do } \\
\text { uso do transporte público. }\end{array}$ & 0,1019 \\
\hline g) & Redução no custo dos acidentes de trânsito e danos provocados por eles & 0,3344 \\
\hline
\end{tabular}




\begin{tabular}{|c|c|c|c|c|c|c|c|}
\hline & a) & b) & c) & d) & e) & f) & g) \\
\hline a) & $\mathbf{1}$ & 2 & $1 / 4$ & $1 / 2$ & $1 / 2$ & $1 / 3$ & 2 \\
\hline b) & $1 / 2$ & $\mathbf{1}$ & $1 / 5$ & $1 / 2$ & 1 & $1 / 2$ & $1 / 2$ \\
\hline c) & 4 & 5 & $\mathbf{1}$ & 2 & 3 & 4 & 3 \\
\hline d) & 2 & 2 & $1 / 2$ & $\mathbf{1}$ & 2 & $1 / 2$ & 2 \\
\hline e) & 2 & 1 & $1 / 3$ & $1 / 2$ & $\mathbf{1}$ & $1 / 2$ & 2 \\
\hline f) & 3 & 2 & $1 / 4$ & 2 & 2 & $\mathbf{1}$ & $1 / 2$ \\
\hline g) & $1 / 2$ & 2 & $1 / 3$ & $1 / 2$ & $1 / 2$ & 2 & $\mathbf{1}$ \\
\hline Soma & 13,00000 & 15,00000 & 2,86600 & 7,00000 & 10,00300 & 8,83333 & 11,00300 \\
\hline
\end{tabular}

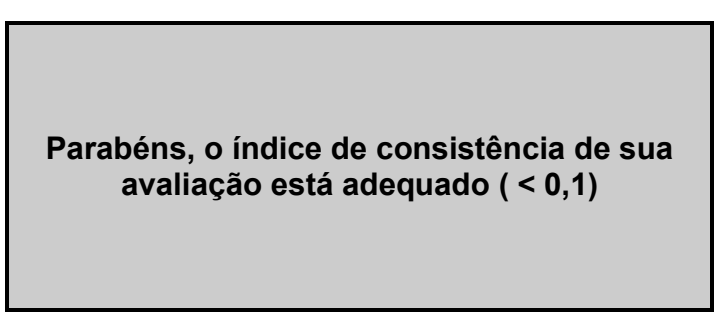

\begin{tabular}{|l|l|}
\hline Consistência & 0,091 \\
\hline
\end{tabular}

\begin{tabular}{|c|l|c|}
\cline { 3 - 3 } \multicolumn{2}{l|}{} & Fatores \\
\hline a) & Diminuição do trânsito devido ao uso de transporte público sobre trilhos & $\mathbf{0 , 0 9 1 2}$ \\
\hline b) & $\begin{array}{l}\text { Aumento da qualidade de vida devido a diminuição da poluição do ar, sonora, visual } \\
\text { e dano ecológico }\end{array}$ & $\mathbf{0 , 0 6 4 1}$ \\
\hline c) & $\begin{array}{l}\text { Economia do dinheiro público devido a baixos investimentos em construção e } \\
\text { manutenção de vias públicas }\end{array}$ & $\mathbf{0 , 3 2 8 8}$ \\
\hline d) & $\begin{array}{l}\text { Acesso aos serviços públicos com maior eficiência (hospitais, repartições públicas, } \\
\text { etc) }\end{array}$ & $\mathbf{0 , 1 4 9 0}$ \\
\hline e) & Melhora a economia da cidade e dos centros regionais & $\mathbf{0 , 1 0 6 6}$ \\
\hline f) & $\begin{array}{l}\text { Uso das fontes de petróleo com eficiência devido ao menor consumo em função do } \\
\text { uso do transporte público. }\end{array}$ & $\mathbf{0 , 1 5 6 5}$ \\
\hline g) & Redução no custo dos acidentes de trânsito e danos provocados por eles & $\mathbf{0 , 1 0 3 8}$ \\
\hline
\end{tabular}




\begin{tabular}{|c|c|c|c|c|c|c|c|}
\hline & a) & b) & c) & d) & e) & f) & g) \\
\hline a) & $\mathbf{1}$ & $1 / 5$ & 5 & 3 & 3 & 3 & $1 / 3$ \\
\hline b) & 5 & $\mathbf{1}$ & 9 & 5 & 7 & 3 & 3 \\
\hline c) & $1 / 5$ & $1 / 9$ & $\mathbf{1}$ & 1 & 1 & $1 / 3$ & $1 / 7$ \\
\hline d) & $1 / 3$ & $1 / 5$ & 1 & $\mathbf{1}$ & 1 & $1 / 3$ & $1 / 7$ \\
\hline e) & $1 / 3$ & $1 / 7$ & 1 & 1 & $\mathbf{1}$ & $1 / 3$ & $1 / 7$ \\
\hline f) & $1 / 3$ & $1 / 3$ & 3 & 3 & 3 & $\mathbf{1}$ & $1 / 5$ \\
\hline g) & 3 & $1 / 3$ & 7 & 7 & 7 & 5 & $\mathbf{1}$ \\
\hline Soma & 10,20000 & 2,32063 & 27,00000 & 21,00000 & 23,00000 & 13,00000 & 4,96190 \\
\hline
\end{tabular}

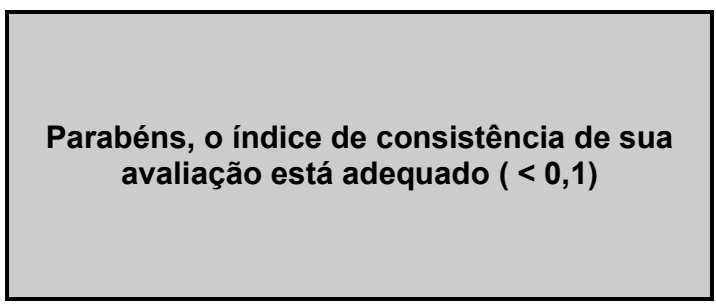

\begin{tabular}{|l|l|}
\hline Consistência & 0,081 \\
\hline
\end{tabular}

\begin{tabular}{|c|c|c|}
\hline & & Fatores \\
\hline a) & Diminuição do trânsito devido ao uso do Metrô & 0,1344 \\
\hline b) & $\begin{array}{l}\text { Aumento da qualidade de vida devido a diminuição da poluição do ar, sonora, visual } \\
\text { e dano ecológico }\end{array}$ & 0,3760 \\
\hline c) & $\begin{array}{l}\text { Economia do dinheiro público devido a baixos investimentos em construção e } \\
\text { manutenção de vias públicas }\end{array}$ & 0,0357 \\
\hline d) & $\begin{array}{l}\text { Acesso aos serviços públicos com maior eficiência (hospitais, repartições públicas, } \\
\text { etc) }\end{array}$ & 0,0431 \\
\hline e) & Melhora a economia da cidade e dos centros regionais & 0,0395 \\
\hline f) & $\begin{array}{l}\text { Uso das fontes de petróleo com eficiência devido ao menor consumo em função do } \\
\text { uso do transporte público. }\end{array}$ & 0,0969 \\
\hline g) & Redução no custo dos acidentes de trânsito e danos provocados por eles & 0,2744 \\
\hline
\end{tabular}




\begin{tabular}{|c|c|c|c|c|c|c|c|}
\hline & a) & b) & c) & d) & e) & f) & g) \\
\hline a) & $\mathbf{1}$ & $1 / 2$ & 1 & $1 / 2$ & $1 / 3$ & $1 / 3$ & $1 / 5$ \\
\hline b) & 2 & $\mathbf{1}$ & 2 & 1 & 3 & 3 & $1 / 2$ \\
\hline $\mathbf{c )}$ & 1 & $1 / 2$ & $\mathbf{1}$ & $1 / 2$ & $12 / 3$ & 2 & $1 / 2$ \\
\hline $\mathbf{d})$ & 2 & 1 & 2 & $\mathbf{1}$ & $1 / 2$ & 3 & $1 / 5$ \\
\hline e) & 3 & $1 / 3$ & $3 / 5$ & 2 & $\mathbf{1}$ & 1 & $1 / 3$ \\
\hline $\mathbf{f})$ & 3 & $1 / 3$ & $1 / 2$ & $1 / 3$ & 1 & $\mathbf{1}$ & $1 / 6$ \\
\hline g) & 5 & 2 & 2 & 5 & 3 & 6 & $\mathbf{1}$ \\
\hline Soma & 17,00000 & 5,66600 & 9,10000 & 10,33300 & 10,50300 & 16,33934 & 2,90000 \\
\hline
\end{tabular}

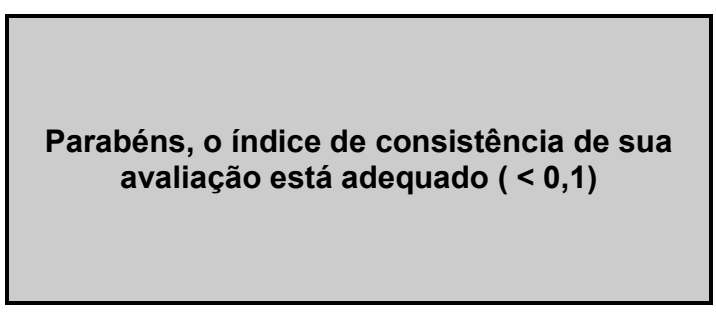

\begin{tabular}{|l|l|}
\hline Consistência & 0,095 \\
\hline
\end{tabular}

\begin{tabular}{|c|c|c|}
\hline & & Fatores \\
\hline a) & Diminuição do trânsito devido ao uso de transporte público sobre trilhos & 0,0609 \\
\hline b) & $\begin{array}{l}\text { Aumento da qualidade de vida devido a diminuição da poluição do ar, sonora, visual } \\
\text { e dano ecológico }\end{array}$ & 0,1790 \\
\hline c) & $\begin{array}{l}\text { Economia do dinheiro público devido a baixos investimentos em construção e } \\
\text { manutenção de vias públicas }\end{array}$ & 0,1084 \\
\hline d) & $\begin{array}{l}\text { Acesso aos serviços públicos com maior eficiência (hospitais, repartições públicas, } \\
\text { etc) }\end{array}$ & 0,1302 \\
\hline e) & Melhora a economia da cidade e dos centros regionais & 0,1094 \\
\hline f) & $\begin{array}{l}\text { Uso das fontes de petróleo com eficiência devido ao menor consumo em função do } \\
\text { uso do transporte público. }\end{array}$ & 0,0766 \\
\hline g) & Redução no custo dos acidentes de trânsito e danos provocados por eles & 0,3355 \\
\hline
\end{tabular}




\begin{tabular}{|c|c|c|c|c|c|c|c|}
\hline & a) & b) & c) & d) & e) & f) & g) \\
\hline a) & $\mathbf{1}$ & 3 & 2 & 2 & 1 & 3 & 4 \\
\hline b) & $1 / 3$ & $\mathbf{1}$ & $1 / 2$ & 3 & 1 & 2 & 1 \\
\hline c) & $1 / 2$ & 2 & $\mathbf{1}$ & 3 & $11 / 4$ & $3 / 4$ & $2 / 3$ \\
\hline d) & $1 / 2$ & $1 / 3$ & $1 / 3$ & $\mathbf{1}$ & $1 / 2$ & $1 / 2$ & 1 \\
\hline e) & 1 & 1 & $4 / 5$ & 2 & $\mathbf{1}$ & 1 & $1 / 3$ \\
\hline f) & $1 / 3$ & $1 / 2$ & $11 / 3$ & 2 & 1 & $\mathbf{1}$ & $1 / 2$ \\
\hline g) & $1 / 4$ & 1 & $14 / 9$ & 1 & 3 & 2 & $\mathbf{1}$ \\
\hline Soma & 3,91600 & 8,83600 & 7,38300 & 14,00601 & 8,75000 & 10,27223 & 8,52299 \\
\hline
\end{tabular}

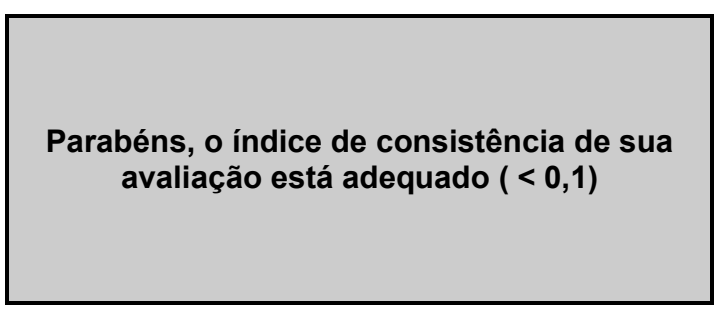

\begin{tabular}{|l|l|}
\hline Consistência & 0,097 \\
\hline
\end{tabular}

\begin{tabular}{|c|c|c|}
\hline & & Fatores \\
\hline a) & Diminuição do trânsito devido ao uso de transporte público sobre trilhos & 0,2693 \\
\hline b) & $\begin{array}{l}\text { Aumento da qualidade de vida devido a diminuição da poluição do ar, sonora, visual } \\
\text { e dano ecológico }\end{array}$ & 0,1295 \\
\hline c) & $\begin{array}{l}\text { Economia do dinheiro público devido a baixos investimentos em construção e } \\
\text { manutenção de vias públicas }\end{array}$ & 0,1432 \\
\hline d) & $\begin{array}{l}\text { Acesso aos serviços públicos com maior eficiência (hospitais, repartições públicas, } \\
\text { etc) }\end{array}$ & 0,0721 \\
\hline e) & Melhora a economia da cidade e dos centros regionais & 0,1243 \\
\hline f) & $\begin{array}{l}\text { Uso das fontes de petróleo com eficiência devido ao menor consumo em função do } \\
\text { uso do transporte público. }\end{array}$ & 0,1044 \\
\hline g) & Redução no custo dos acidentes de trânsito e danos provocados por eles & 0,1571 \\
\hline
\end{tabular}




\begin{tabular}{|c|c|c|c|c|c|c|c|}
\hline & a) & b) & c) & d) & e) & f) & g) \\
\hline a) & $\mathbf{1}$ & $1 / 2$ & $1 / 5$ & $1 / 6$ & $1 / 2$ & $1 / 2$ & $1 / 4$ \\
\hline b) & 2 & $\mathbf{1}$ & 3 & 3 & 5 & 3 & $1 / 2$ \\
\hline c) & 5 & $1 / 3$ & $\mathbf{1}$ & 1 & 1 & $1 / 3$ & $1 / 3$ \\
\hline d) & 6 & $1 / 3$ & 1 & $\mathbf{1}$ & $13 / 7$ & $11 / 4$ & $1 / 2$ \\
\hline e) & 2 & $1 / 5$ & 1 & $2 / 3$ & $\mathbf{1}$ & 1 & $1 / 2$ \\
\hline f) & 2 & $1 / 3$ & 3 & $4 / 5$ & 1 & $\mathbf{1}$ & $1 / 3$ \\
\hline g) & 4 & 2 & 3 & 2 & 2 & 3 & $\mathbf{1}$ \\
\hline Soma & 22,00000 & 4,69900 & 12,20300 & 8,66967 & 11,92857 & 10,08634 & 3,41667 \\
\hline
\end{tabular}

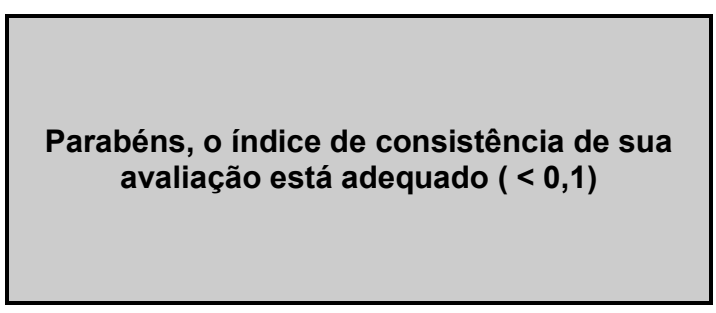

\begin{tabular}{|l|l|}
\hline Consistência & 0,097 \\
\hline
\end{tabular}

\begin{tabular}{|c|c|c|}
\hline & & Fatores \\
\hline a) & Diminuição do trânsito devido ao uso de transporte público sobre trilhos & 0,0503 \\
\hline b) & $\begin{array}{l}\text { Aumento da qualidade de vida devido a diminuição da poluição do ar, sonora, visual } \\
\text { e dano ecológico }\end{array}$ & 0,2513 \\
\hline c) & $\begin{array}{l}\text { Economia do dinheiro público devido a baixos investimentos em construção e } \\
\text { manutenção de vias públicas }\end{array}$ & 0,1014 \\
\hline d) & $\begin{array}{l}\text { Acesso aos serviços públicos com maior eficiência (hospitais, repartições públicas, } \\
\text { etc) }\end{array}$ & 0,1330 \\
\hline e) & Melhora a economia da cidade e dos centros regionais & 0,0894 \\
\hline f) & $\begin{array}{l}\text { Uso das fontes de petróleo com eficiência devido ao menor consumo em função do } \\
\text { uso do transporte público. }\end{array}$ & 0,1115 \\
\hline g) & Redução no custo dos acidentes de trânsito e danos provocados por eles & 0,2631 \\
\hline
\end{tabular}




\begin{tabular}{|c|c|c|c|c|c|c|c|}
\hline & a) & b) & c) & d) & e) & f) & g) \\
\hline a) & $\mathbf{1}$ & 1 & 9 & $1 / 3$ & 1 & 3 & 1 \\
\hline b) & 1 & $\mathbf{1}$ & 9 & 1 & 3 & 3 & 1 \\
\hline c) & $1 / 9$ & $1 / 9$ & $\mathbf{1}$ & $1 / 9$ & $1 / 9$ & $1 / 9$ & $1 / 9$ \\
\hline d) & 3 & 1 & 9 & $\mathbf{1}$ & 3 & 5 & 3 \\
\hline e) & 1 & $1 / 3$ & 9 & $1 / 3$ & $\mathbf{1}$ & 3 & $1 / 3$ \\
\hline f) & $1 / 3$ & $1 / 3$ & 9 & $1 / 5$ & $1 / 3$ & $\mathbf{1}$ & 1 \\
\hline g) & 1 & 1 & 9 & $1 / 3$ & 3 & 1 & $\mathbf{1}$ \\
\hline Soma & 7,44444 & 4,77778 & 55,00000 & 3,31111 & 11,44444 & 16,11111 & 7,44444 \\
\hline
\end{tabular}

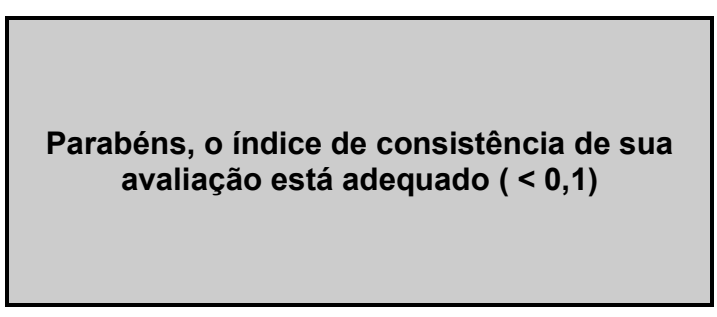

\begin{tabular}{|l|l|}
\hline Consistência & 0,085 \\
\hline
\end{tabular}

\begin{tabular}{|c|c|c|}
\hline & & Fatores \\
\hline a) & Diminuição do trânsito devido ao uso de transporte público sobre trilhos & 0,1451 \\
\hline b) & $\begin{array}{l}\text { Aumento da qualidade de vida devido a diminuição da poluição do ar, sonora, visual } \\
\text { e dano ecológico }\end{array}$ & 0,1989 \\
\hline c) & $\begin{array}{l}\text { Economia do dinheiro público devido a baixos investimentos em construção e } \\
\text { manutenção de vias públicas }\end{array}$ & 0,0174 \\
\hline d) & $\begin{array}{l}\text { Acesso aos serviços públicos com maior eficiência (hospitais, repartições públicas, } \\
\text { etc) }\end{array}$ & 0,2933 \\
\hline e) & Melhora a economia da cidade e dos centros regionais & 0,1124 \\
\hline f) & $\begin{array}{l}\text { Uso das fontes de petróleo com eficiência devido ao menor consumo em função do } \\
\text { uso do transporte público. }\end{array}$ & 0,0806 \\
\hline g) & Redução no custo dos acidentes de trânsito e danos provocados por eles & 0,1524 \\
\hline
\end{tabular}




\begin{tabular}{|c|c|c|c|c|c|c|c|}
\hline & a) & b) & c) & d) & e) & f) & g) \\
\hline a) & $\mathbf{1}$ & $1 / 4$ & $1 / 3$ & $1 / 3$ & $1 / 2$ & 1 & $1 / 6$ \\
\hline b) & 4 & $\mathbf{1}$ & 5 & 1 & 5 & 3 & 1 \\
\hline c) & 3 & $1 / 5$ & $\mathbf{1}$ & $1 / 2$ & $1 / 2$ & $1 / 2$ & $1 / 2$ \\
\hline d) & 3 & 1 & 2 & $\mathbf{1}$ & $1 / 2$ & $1 / 2$ & $1 / 3$ \\
\hline e) & 2 & $1 / 5$ & 2 & 2 & $\mathbf{1}$ & 2 & 1 \\
\hline f) & 1 & $1 / 3$ & 2 & 2 & $1 / 2$ & $\mathbf{1}$ & $1 / 2$ \\
\hline g) & 6 & 1 & 2 & 3 & 1 & 2 & $\mathbf{1}$ \\
\hline Soma & 20,00000 & 3,98300 & 14,33333 & 9,83333 & 9,00000 & 10,00300 & 4,50000 \\
\hline
\end{tabular}

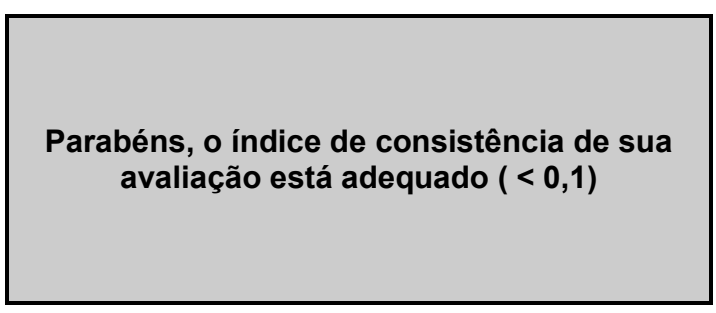

\begin{tabular}{|l|c|}
\hline Consistência & 0,099 \\
\hline
\end{tabular}

\begin{tabular}{|c|c|c|}
\hline & & Fatores \\
\hline a) & Diminuição do trânsito devido ao uso de transporte público sobre trilhos & 0,0518 \\
\hline b) & $\begin{array}{l}\text { Aumento da qualidade de vida devido a diminuição da poluição do ar, sonora, visual } \\
\text { e dano ecológico }\end{array}$ & 0,2828 \\
\hline c) & $\begin{array}{l}\text { Economia do dinheiro público devido a baixos investimentos em construção e } \\
\text { manutenção de vias públicas }\end{array}$ & 0,0768 \\
\hline d) & $\begin{array}{l}\text { Acesso aos serviços públicos com maior eficiência (hospitais, repartições públicas, } \\
\text { etc) }\end{array}$ & 0,1174 \\
\hline e) & Melhora a economia da cidade e dos centros regionais & 0,1466 \\
\hline f) & $\begin{array}{l}\text { Uso das fontes de petróleo com eficiência devido ao menor consumo em função do } \\
\text { uso do transporte público. }\end{array}$ & 0,1062 \\
\hline g) & Redução no custo dos acidentes de trânsito e danos provocados por eles & 0,2184 \\
\hline
\end{tabular}




\begin{tabular}{|c|c|c|c|c|c|c|c|}
\hline & a) & b) & c) & d) & e) & f) & g) \\
\hline a) & $\mathbf{1}$ & $1 / 5$ & 1 & $1 / 3$ & $1 / 3$ & $1 / 3$ & $1 / 3$ \\
\hline b) & 5 & $\mathbf{1}$ & 3 & 1 & 3 & 5 & 1 \\
\hline $\mathbf{c )}$ & 1 & $1 / 3$ & $\mathbf{1}$ & $1 / 3$ & 1 & 1 & $1 / 3$ \\
\hline $\mathbf{d})$ & 3 & 1 & 3 & $\mathbf{1}$ & 1 & 3 & $1 / 3$ \\
\hline e) & 3 & $1 / 3$ & 1 & 1 & $\mathbf{1}$ & 1 & $1 / 3$ \\
\hline $\mathbf{f}$ & 3 & $1 / 5$ & 1 & $1 / 3$ & 1 & $\mathbf{1}$ & $1 / 3$ \\
\hline g) & 3 & 1 & 3 & 3 & 3 & 3 & $\mathbf{1}$ \\
\hline Soma & 19,00000 & 4,06667 & 13,00000 & 7,00000 & 10,33333 & 14,33333 & 3,66667 \\
\hline
\end{tabular}

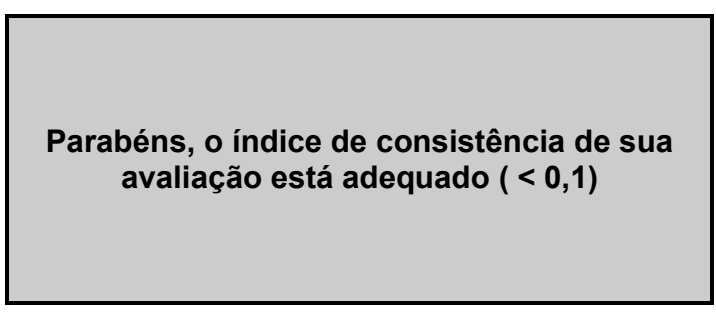

\begin{tabular}{|l|l|}
\hline Consistência & 0,052 \\
\hline
\end{tabular}

\begin{tabular}{|c|c|c|}
\hline & & Fatores \\
\hline a) & Diminuição do trânsito devido ao uso de transporte público sobre trilhos & 0,0533 \\
\hline b) & $\begin{array}{l}\text { Aumento da qualidade de vida devido a diminuição da poluição do ar, sonora, visual } \\
\text { e dano ecológico }\end{array}$ & 0,2564 \\
\hline c) & $\begin{array}{l}\text { Economia do dinheiro público devido a baixos investimentos em construção e } \\
\text { manutenção de vias públicas }\end{array}$ & 0,0738 \\
\hline d) & $\begin{array}{l}\text { Acesso aos serviços públicos com maior eficiência (hospitais, repartições públicas, } \\
\text { etc) }\end{array}$ & 0,1678 \\
\hline e) & Melhora a economia da cidade e dos centros regionais & 0,1024 \\
\hline f) & $\begin{array}{l}\text { Uso das fontes de petróleo com eficiência devido ao menor consumo em função do } \\
\text { uso do transporte público. }\end{array}$ & 0,0842 \\
\hline g) & Redução no custo dos acidentes de trânsito e danos provocados por eles & 0,2622 \\
\hline
\end{tabular}




\begin{tabular}{|c|c|c|c|c|c|c|c|}
\hline & a) & b) & c) & d) & e) & f) & g) \\
\hline a) & $\mathbf{1}$ & $1 / 5$ & 2 & $1 / 2$ & $1 / 3$ & $1 / 3$ & $1 / 3$ \\
\hline b) & 5 & $\mathbf{1}$ & 4 & 2 & 4 & 5 & 1 \\
\hline c) & $1 / 2$ & $1 / 4$ & $\mathbf{1}$ & $1 / 3$ & $2 / 3$ & 1 & $2 / 5$ \\
\hline $\mathbf{d})$ & 2 & $1 / 2$ & 3 & $\mathbf{1}$ & $2 / 3$ & 2 & $2 / 3$ \\
\hline e) & 3 & $1 / 4$ & $11 / 2$ & $11 / 2$ & $\mathbf{1}$ & $1 / 3$ & $2 / 5$ \\
\hline $\mathbf{f}$ & 3 & $1 / 5$ & 1 & $1 / 2$ & 3 & $\mathbf{1}$ & $2 / 5$ \\
\hline g) & 3 & 1 & $21 / 2$ & $11 / 2$ & $21 / 2$ & $21 / 2$ & $\mathbf{1}$ \\
\hline Soma & 17,50000 & 3,40000 & 15,00000 & 7,33333 & 12,16667 & 12,16667 & 4,20000 \\
\hline
\end{tabular}

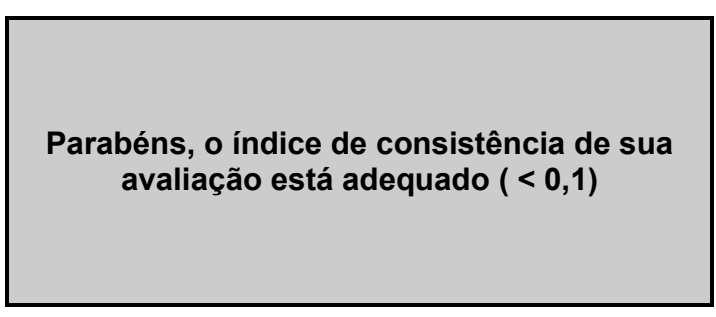

\begin{tabular}{|l|c|}
\hline Consistência & 0,088 \\
\hline
\end{tabular}

\begin{tabular}{|c|l|c|}
\cline { 3 - 3 } \multicolumn{2}{l|}{} & Fatores \\
\hline a) & Diminuição do trânsito devido ao uso de transporte público sobre trilhos & $\mathbf{0 , 0 6 4 5}$ \\
\hline b) & $\begin{array}{l}\text { Aumento da qualidade de vida devido a diminuição da poluição do ar, sonora, visual } \\
\text { e dano ecológico }\end{array}$ & $\mathbf{0 , 2 9 9 6}$ \\
\hline c) & $\begin{array}{l}\text { Economia do dinheiro público devido a baixos investimentos em construção e } \\
\text { manutenção de vias públicas }\end{array}$ & $\mathbf{0 , 0 6 3 8}$ \\
\hline d) & $\begin{array}{l}\text { Acesso aos serviços públicos com maior eficiência (hospitais, repartições públicas, } \\
\text { etc) }\end{array}$ & $\mathbf{0 , 1 3 9 4}$ \\
\hline e) & Melhora a economia da cidade e dos centros regionais & $\mathbf{0 , 1 0 7 8}$ \\
\hline f) & $\begin{array}{l}\text { Uso das fontes de petróleo com eficiência devido ao menor consumo em função do } \\
\text { uso do transporte público. }\end{array}$ & $\mathbf{0 , 1 1 2 7}$ \\
\hline g) & Redução no custo dos acidentes de trânsito e danos provocados por eles & $\mathbf{0 , 2 1 2 3}$ \\
\hline
\end{tabular}




\begin{tabular}{|c|c|c|c|c|c|c|c|}
\hline & a) & b) & c) & d) & e) & f) & g) \\
\hline a) & $\mathbf{1}$ & $1 / 5$ & $1 / 7$ & $1 / 4$ & $1 / 4$ & $1 / 2$ & $1 / 6$ \\
\hline b) & 5 & $\mathbf{1}$ & 1 & 1 & 1 & 2 & $1 / 4$ \\
\hline c) & 7 & 1 & $\mathbf{1}$ & $1 / 2$ & $1 / 3$ & $1 / 3$ & $1 / 4$ \\
\hline d) & 4 & 1 & 2 & $\mathbf{1}$ & 1 & 1 & $1 / 3$ \\
\hline e) & 4 & 1 & 3 & 1 & $\mathbf{1}$ & 1 & $1 / 2$ \\
\hline f) & 2 & $1 / 2$ & 3 & 1 & 1 & $\mathbf{1}$ & $1 / 2$ \\
\hline g) & 6 & 4 & 4 & 3 & 2 & 2 & $\mathbf{1}$ \\
\hline Soma & 29,00000 & 8,70000 & 14,14286 & 7,75000 & 6,58333 & 7,83333 & 3,00000 \\
\hline
\end{tabular}

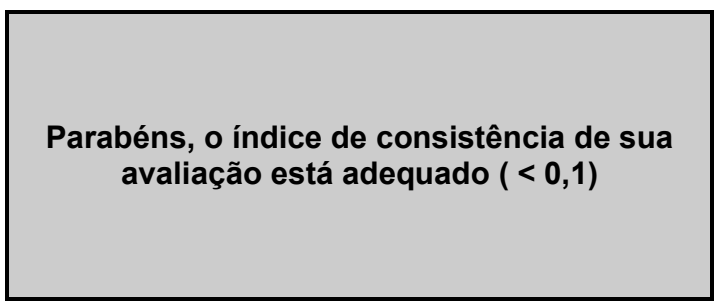

Consistência

\begin{tabular}{|c|c|c|}
\hline & & Fatores \\
\hline a) & Diminuição do trânsito devido ao uso de transporte público sobre trilhos & 0,0367 \\
\hline b) & $\begin{array}{l}\text { Aumento da qualidade de vida devido a diminuição da poluição do ar, sonora, visual } \\
\text { e dano ecológico }\end{array}$ & 0,1397 \\
\hline c) & $\begin{array}{l}\text { Economia do dinheiro público devido a baixos investimentos em construção e } \\
\text { manutenção de vias públicas }\end{array}$ & 0,0954 \\
\hline d) & $\begin{array}{l}\text { Acesso aos serviços públicos com maior eficiência (hospitais, repartições públicas, } \\
\text { etc) }\end{array}$ & 0,1306 \\
\hline e) & Melhora a economia da cidade e dos centros regionais & 0,1486 \\
\hline f) & $\begin{array}{l}\text { Uso das fontes de petróleo com eficiência devido ao menor consumo em função do } \\
\text { uso do transporte público. }\end{array}$ & 0,1305 \\
\hline g) & Redução no custo dos acidentes de trânsito e danos provocados por eles & 0,3184 \\
\hline
\end{tabular}

